\title{
MORE THAN WORDS: DECODING THE INFLUENCE OF USER-GENERATED IMAGES ON VISITING FRIENDS AND RELATIVES (VFR) TOURISM
}

\author{
By
}

MARLINI BAKRI

\begin{abstract}
A thesis
Submitted to the Victoria University of Wellington in fulfilment of the requirements for the degree of Doctor of Philosophy in Marketing
\end{abstract}

Victoria University of Wellington 


\begin{abstract}
Visual images are fundamental to the promotion of tourism destinations and convey critical aspects of destination image. As such, Destination Marketing Organisations (DMOs) have capitalised on the art of image making and disseminating place myths to capture the attention of consumers through mass media. However, the growing popularity of online networks has connected billions of active consumers, elevating word of mouth (WOM) into its electronic form, e-WOM, and causing a shift in the balance of power and knowledge - where DMOs are no longer solely responsible for the communication of a destination's image. Despite the growing number of studies surrounding e-WOM and user-generated content (UGC), few scholars have endeavoured to examine the capacity of user-generated images (UGI) as persuasive visual displays of WOM, and the role of their creators (consumers) as influencers able to spread marketing rhetoric; in particular aspects of destination image, through the visual mode.
\end{abstract}

Acknowledging the growing popularity of visual platforms and digital devices that allow consumers to articulate themselves creatively, this study introduces image-generated WOM (iWOM), and examines the value of UGI as visual manifestations of WOM, and its relevance to consumers, specifically sojourners (as skilled visual influencers), able to shape viewer perception and stimulate VFR (visiting friends and relatives) tourism - a form of tourism that is a product of existing social relationships. Underpinned by the theories of visual rhetoric and emotional contagion, and building on studies in destination image, WOM and VFR tourism, this iterative sequential mixed-methods research comprises expert interviews, quantitative analysis of dyadic/paired survey data and a rhetorical visual analysis.

Key theoretical contributions of this research include: moving the emphasis of WOM from textual/verbal to visual forms of communication; and establishing the position of UGI as persuasive artefacts that can be used to stimulate VFR tourism, where studies in VFR tourism have neglected research in areas pertaining to online communications. In addition, this study demonstrates the difference in the intervening role of tie strength and relationship type (friend/relative) in viewer consumption of images received. This study contributes to practice by establishing the importance of sojourners as critical online ambassadors able to connect destinations, specifically conurbations with constrained resources that tend to fall outside popular tourism centres, to global VFR markets. Further, the rich contextual findings garnered from the visual analysis provide insights into interactions between sojourners and the destination that have implications for city planners, tourism and hospitality marketers. 


\section{ACKNOWLEDGEMENTS}

This thesis is not the product of one, but of many - who have been sources of inspiration, support and knowledge.

First, I would like to express my sincere gratitude to my supervisors, Dr Jayne Krisjanous and Assoc Prof James E. Richard for being generous with their time, knowledge, patience, encouragement and guidance. Jayne and Jim, thank you for placing so much trust and belief in me - even on days I could not.

I have also been fortunate to work with Dr Janet Davey whose support and advice have been invaluable. My gratitude also goes out to Dr Stephan Gerschewski for his mentorship.

To Assoc Prof Val Hooper (Head of School) and Dr Micael-Lee Johnstone (PhD Director), thank you for the many kind words of encouragement, and enhancing the $\mathrm{PhD}$ experience. To the Research Committee, thank you for the opportunity and funding to conduct this research. To the many angels of level 11, thank you for the administrative support, free hugs, snacks and morning smiles that made my days brighter. Special thanks to Helen Hynes, for the little chats and the many opportunities to build my confidence in teaching.

I am also grateful to my $\mathrm{PhD}$ colleagues for the memories, I will forever cherish. To Lindsey, basic PhD life would have been totally harder without you. Himadree, Naghmeh, Sharmistha, Tega, Thu and Zhanna, thank you for nourishing me emotionally, mentally and literally (sideways). To Hamish, Martyn, Omar, Pablo, Rene and Umar I have learnt so much from each of you.

To all the participants who contributed to this thesis, thank you! Thank you for your time, knowledge, enthusiasm for this research and trusting me with your collection of memories. This thesis would not have been possible without you.

I would like to acknowledge the endless support and encouragement of my family. I am grateful to my family in Singapore for their forgiveness and understanding of my constant absence. To Johan, thank you for being patient with mummy and the countless cuddles. Last, to my wonderful husband Roy, thank you for always lifting my spirits, providing for our little family and being courageous enough to run away with me to a foreign land - only to endure the life of a $\mathrm{PhD}$ spouse.

To the many, this thesis is for all of you. 


\section{RELATED PUBLICATIONS}

Bakri, M., Krisjanous, J., Richard, J.E. (2020), “Decoding service brand image through usergenerated images", Journal of Services Marketing, 34(4), 429-442.

Bakri, M., Krisjanous, J., Richard, J. E. (2019) "You've got to see this! — Exploring persuasion strategies of sojourners through user-generated images," 25th Asia Pacific Tourism Association Annual Conference Proceedings, Danang, Vietnam: Asia Pacific Tourism Association (pp. 93-96)

Bakri, M. (2018). "Decoding user-generated images in VFR travel”. In I. Tussyadiah, L. Lalicic, E. Marine-Roig (Eds.), International Federation for Information Technology and Travel \& Tourism ENTER 2018 PhD Workshop, Jonkoping, Sweden: University of Surrey (pp. 82-86) 


\section{TABLE OF CONTENTS}

ABSTRACT ...........................................................................................................................................

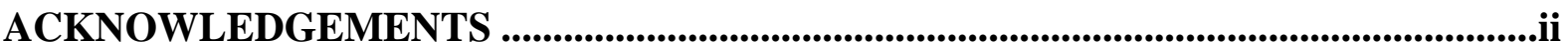

RELATED PUBLICATIONS......................................................................................... iii

TABLE OF CONTENTS ......................................................................................................iv

LIST OF TABLES ....................................................................................................................

LIST OF FIGURES ......................................................................................................................xii

LIST OF ABBREVIATIONS ................................................................................................... xiii

CHAPTER 1. Introduction .....................................................................................................................1

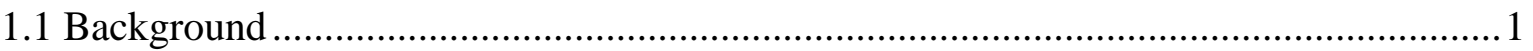

1.2 Motivations and opportunity ……………………………………………………....

1.2.1. Gap in understanding the value of UGI as articles of WOM...............................

1.2.2. Dearth of studies in VFR tourism that examine online interactions........................4

1.2.3. Overlooked role of sojourners as online destination ambassadors. ........................

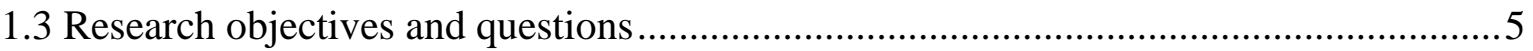

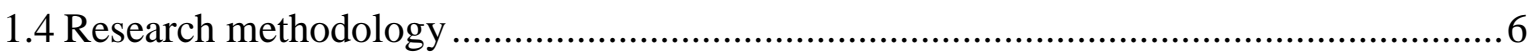

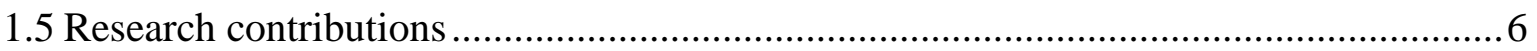

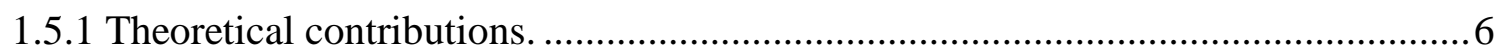

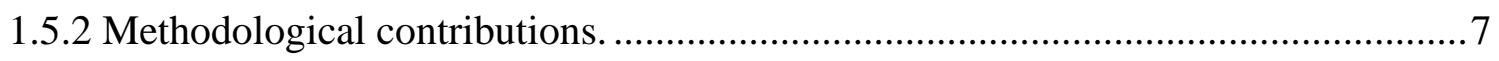

1.5.3 Managerial contributions and implications..................................................... 8

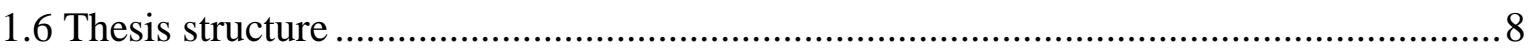

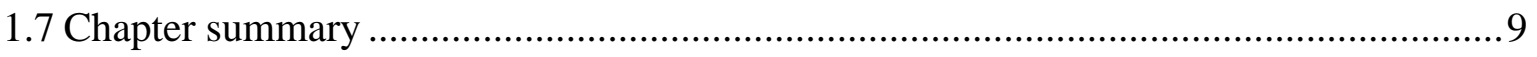

CHAPTER 2. Literature review ....................................................................................................10

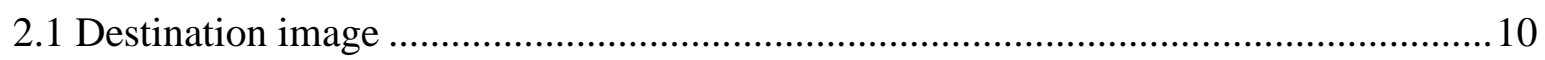




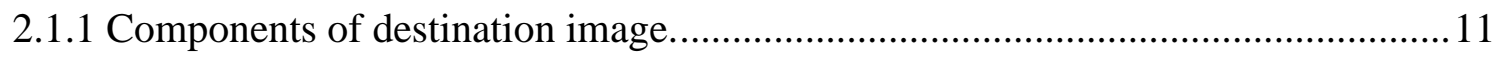

2.1.2 The role of visual images in conveying destination image ................................... 14

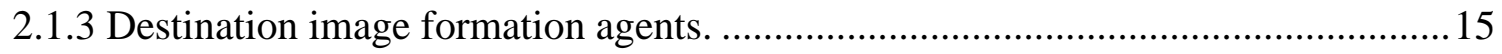

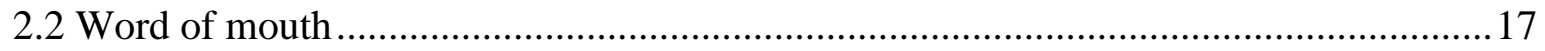

2.2.1 Word of mouth to electronic word of 'mouse' ...................................................... 18

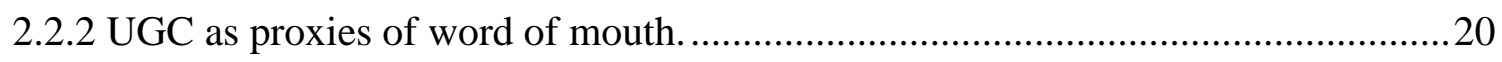

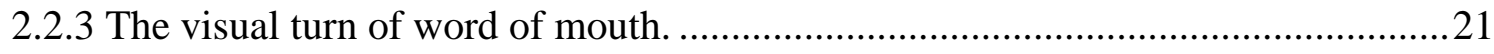

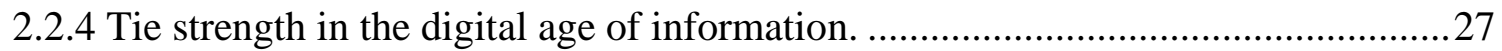

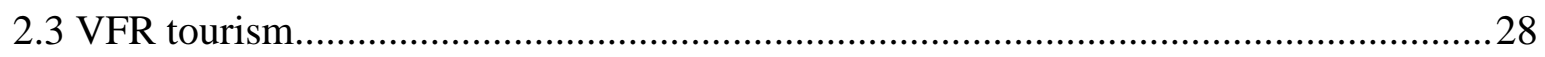

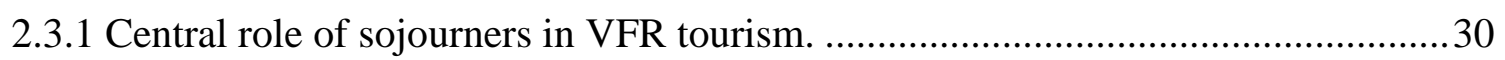

2.3.2 A representative overview of VFR tourism research........................................... 33

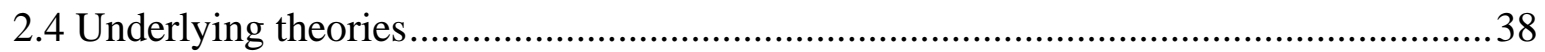

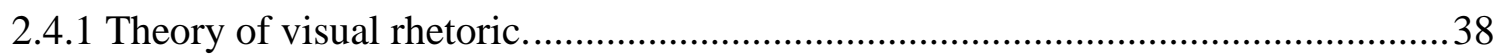

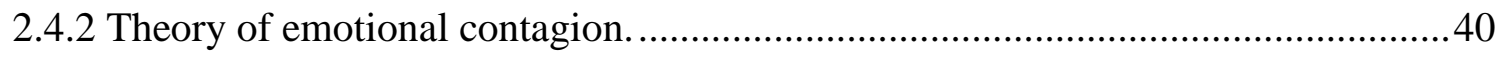

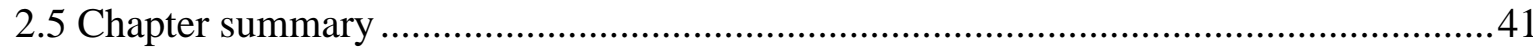

CHAPTER 3. Conceptual model and hypotheses.........................................................43

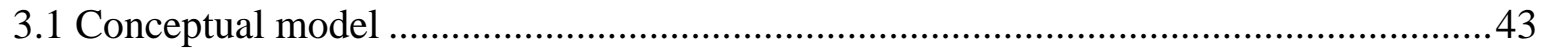

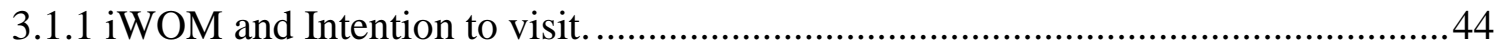

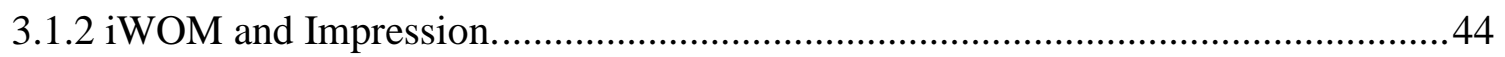

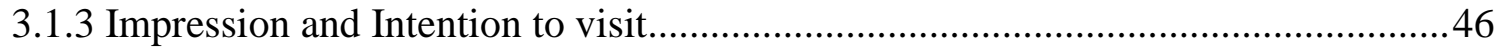

3.1.4 Mediation effect of viewer Impression. ............................................................ 46

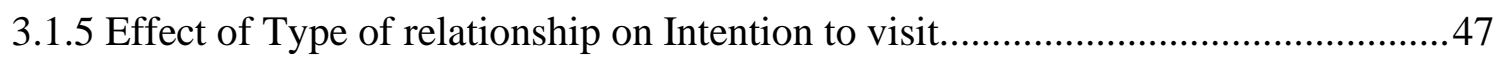

3.1.6 The moderating role of Tie strength ................................................................. 49

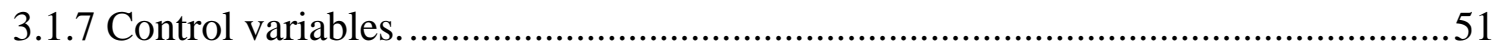

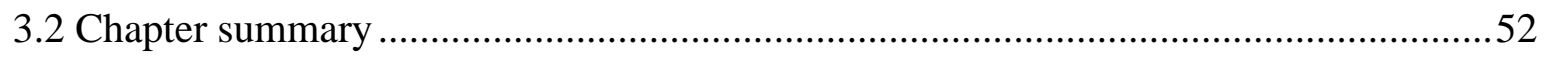

CHAPTER 4. Research methodology ...................................................................53

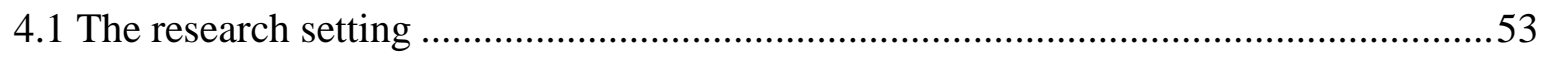

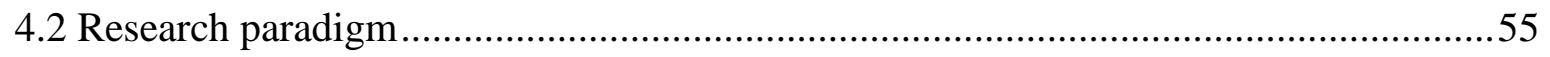

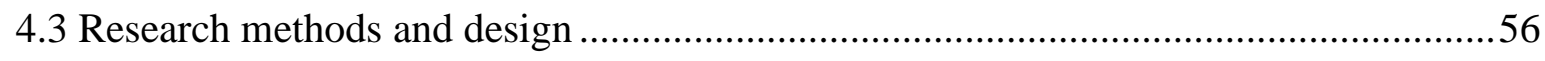




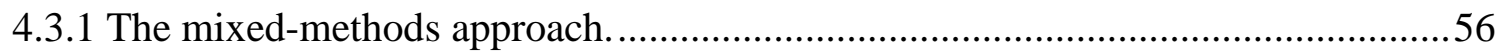

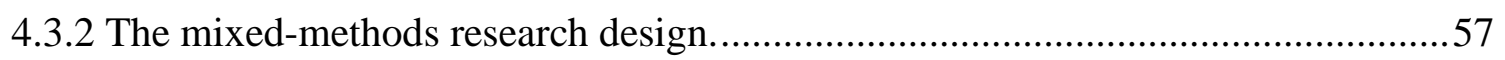

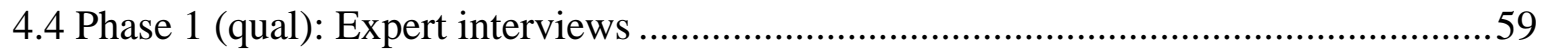

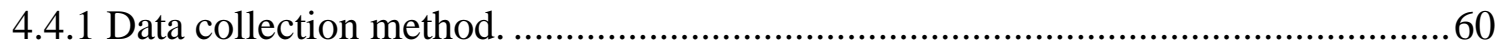

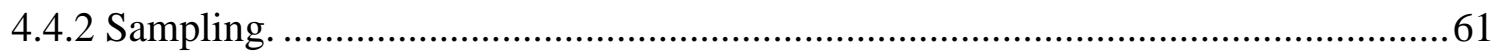

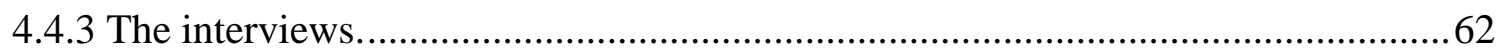

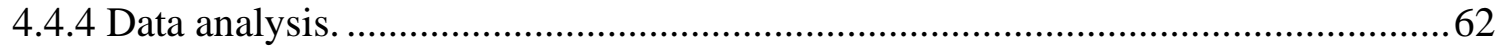

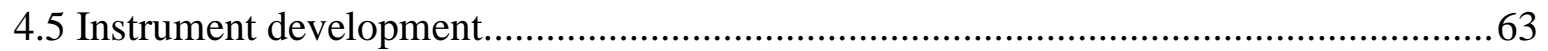

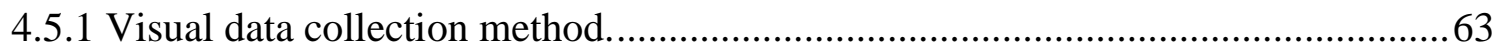

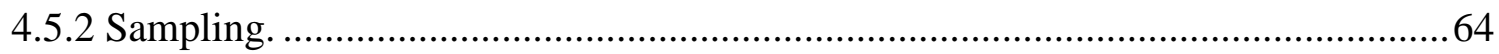

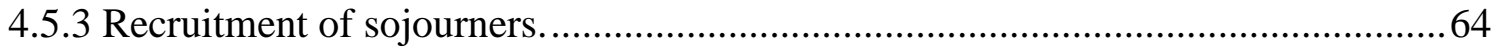

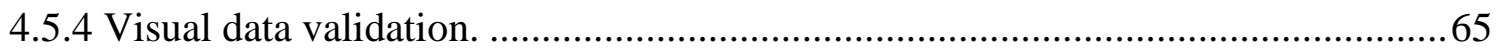

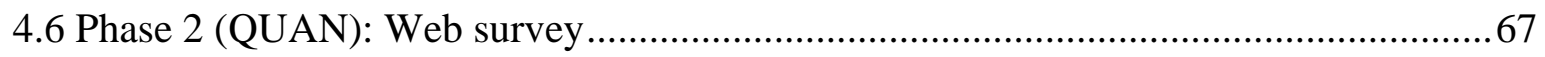

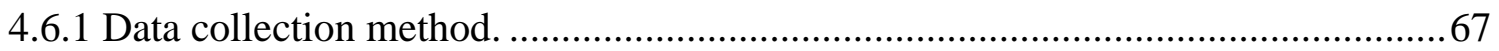

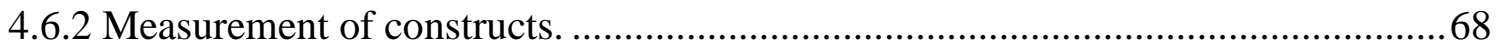

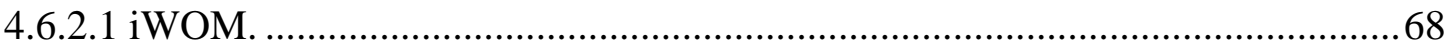

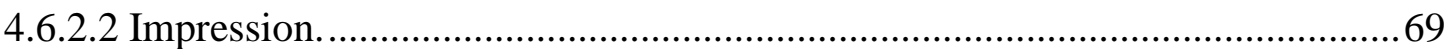

4.6.2.3 Type of relationship (friends vs. relatives) .................................................69

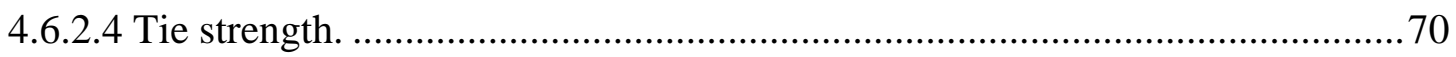

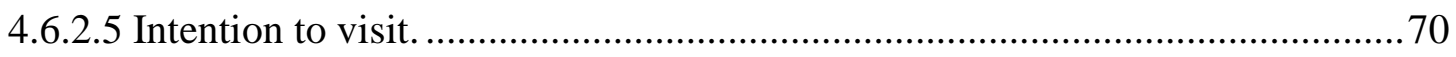

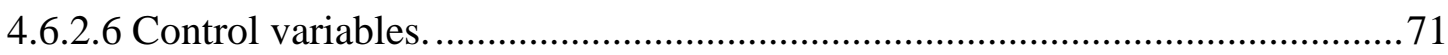

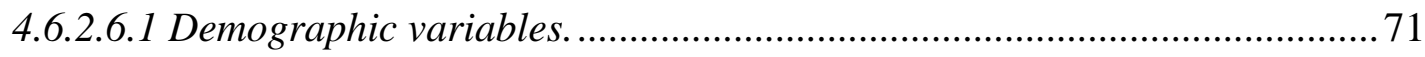

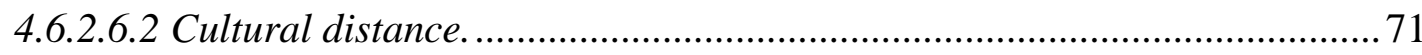

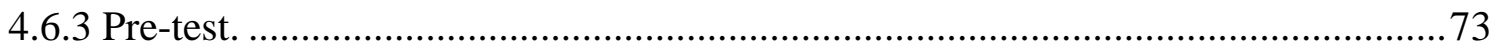

4.6.4 Sampling and survey implementation.............................................................. 73

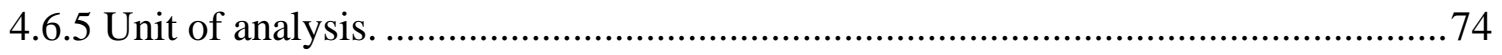

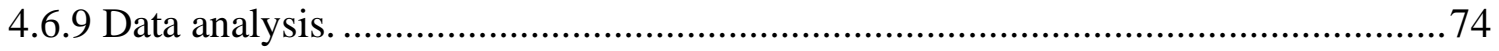

4.6.9.1 Structural equation modelling...................................................................... 74

4.6.9.2 Partial least squares-structural equation modelling (PLS-SEM) .................... 75 
4.7 Phase 3 (QUAL): Visual rhetorical analysis

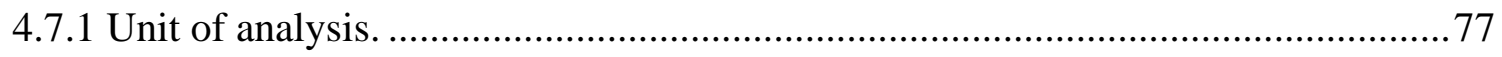

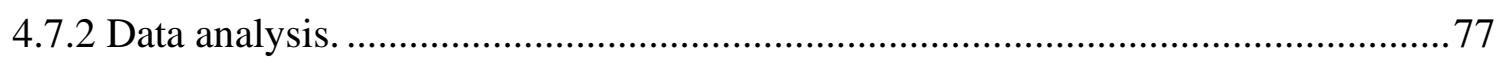

4.7.2.1 Identifying physical/manifest items....................................................... 79

4.7.2.2 Identifying and assessing how well the function is communicated.................79

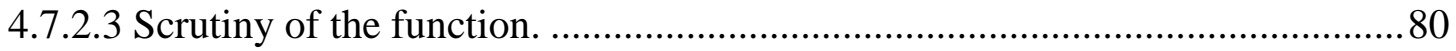

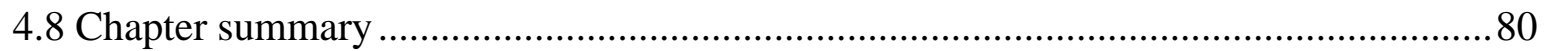

CHAPTER 5. Data analysis and results ........................................................................82

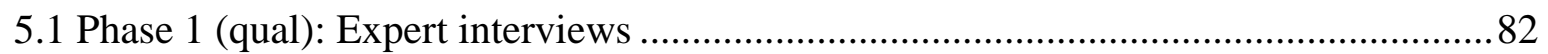

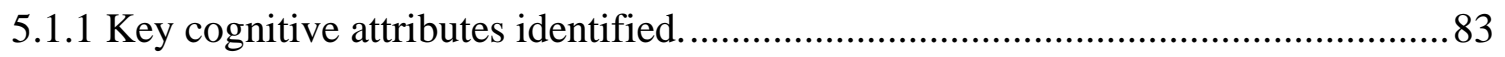

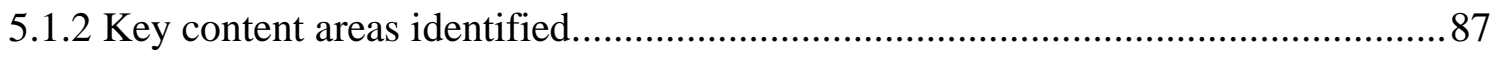

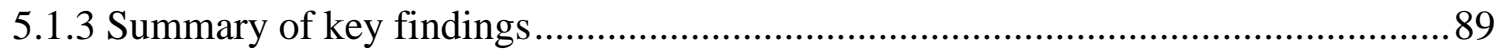

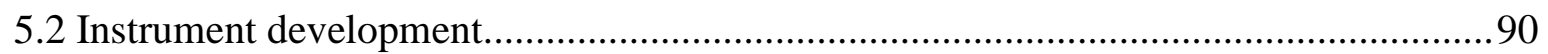

5.2.1 Demographic overview of participating sojourners......................................... 90

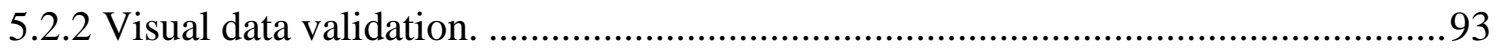

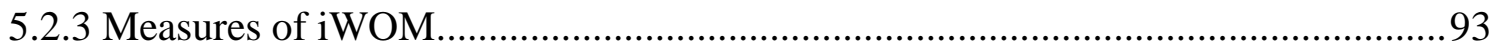

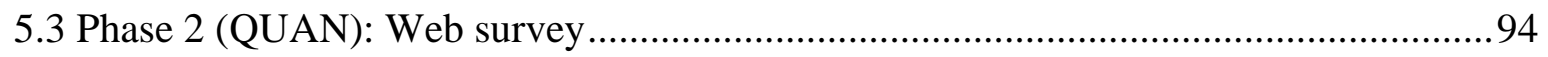

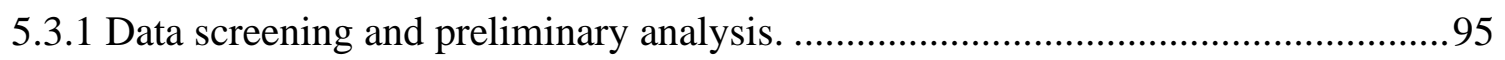

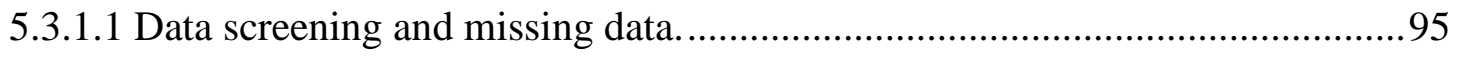

5.3.1.2 Demographic overview of participating overseas friends and relatives..........95

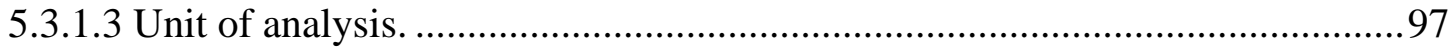

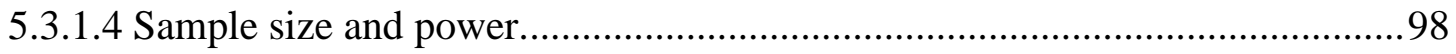

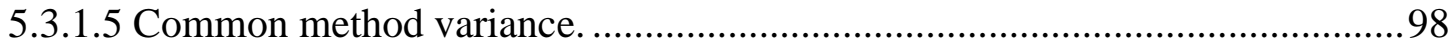

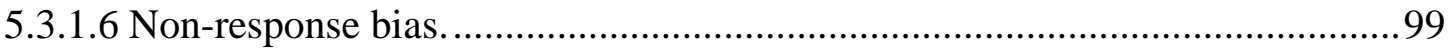

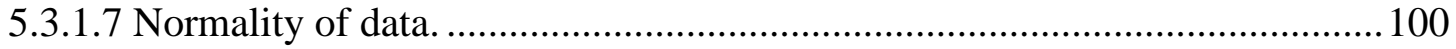

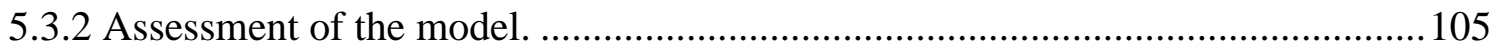

5.3.2.1 Assessment of the measurement model ...................................................... 106

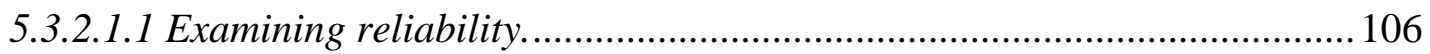


5.3.2.1.2 Examining convergent validity.

5.3.2.1.3 Examining discriminant validity

5.3.2.2 Assessment of the structural model.

5.3.2.2.1 Examining collinearity.

5.3.2.2.2 Predictive power and model fit.

5.2.2.2.3 Testing measurement invariance of composites (MICOM). 115

5.3.2.2.4 Hypotheses testing......

5.3.2.2.5 PLSpredict.

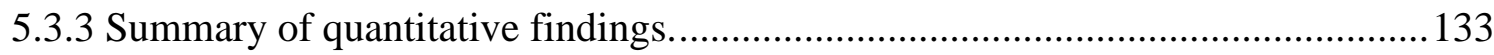

5.4 Phase 3 (QUAL): Visual rhetorical analysis.......................................................... 135

5.4.1 Identification of physical or manifest items..................................................... 135

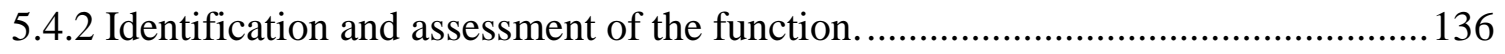

5.4.3 Scrutiny of the function and emergent meanings. ........................................... 143

5.4.4 Summary of findings from the visual analysis. ............................................... 145

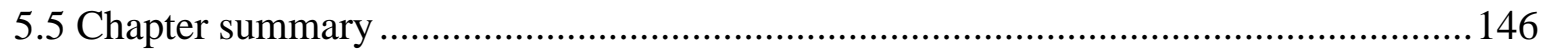

CHAPTER 6. Discussion and conclusion ...................................................................147

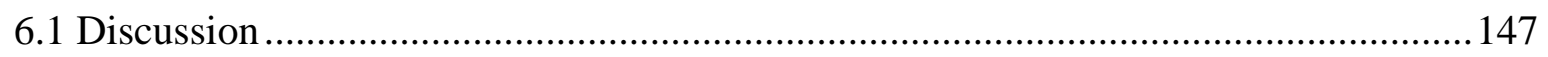

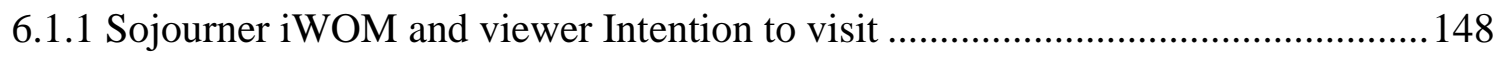

6.1.2 Sojourner iWOM and viewer Impression ...................................................... 148

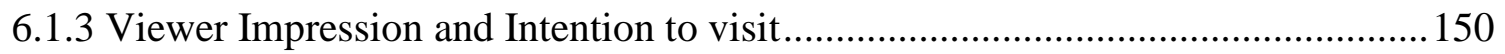

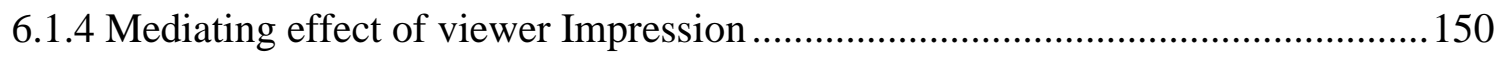

6.1.5 Differences between relationship type (friends vs. relatives) ............................. 151

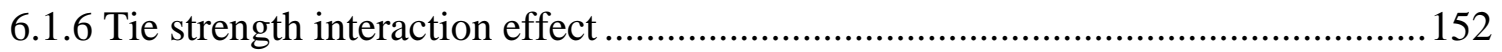

6.1.7 Effect of control variables age and cultural distance on intention to visit............. 154

6.1.8 Additional findings: differences in content type................................................ 155

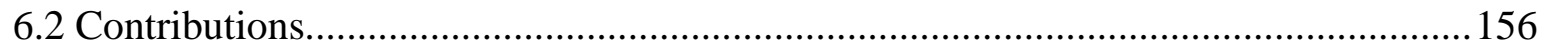

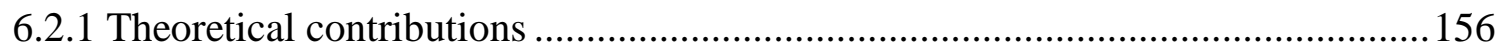

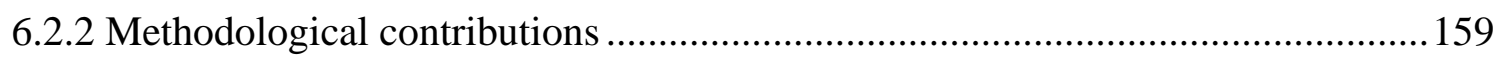




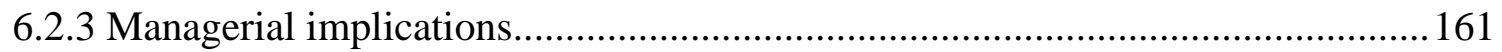

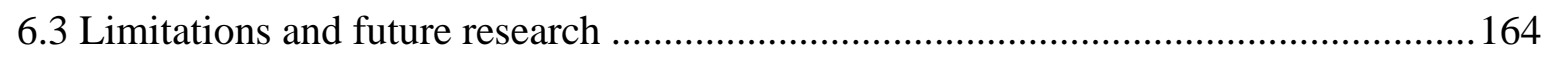

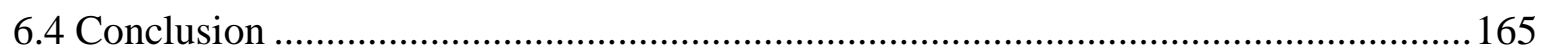

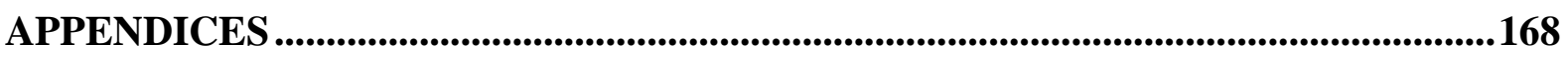

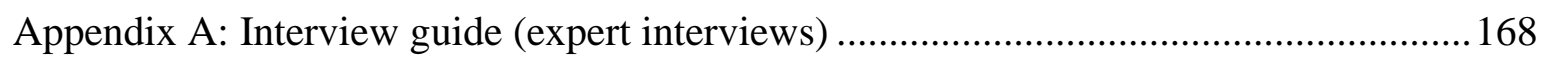

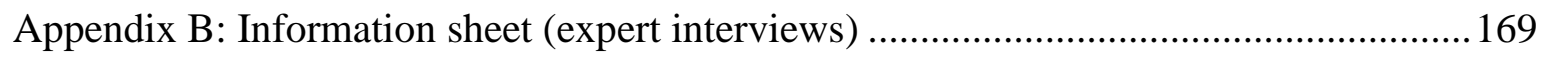

Appendix C: Qualtrics form visual data collection (sojourner) ................................... 170

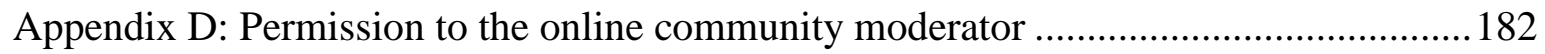

Appendix E: Recruitment advertisement (announcement of study) ................................ 183

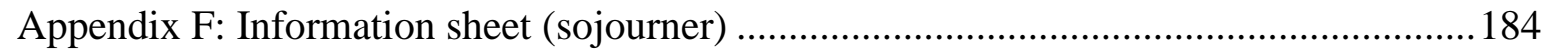

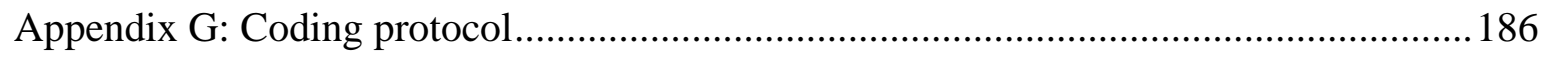

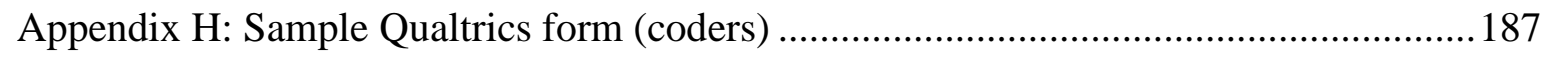

Appendix I: Sample Web survey (friends \& relatives).................................................... 195

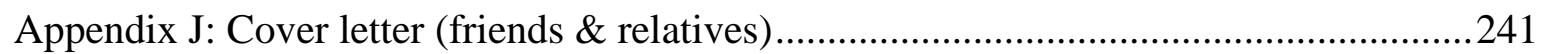

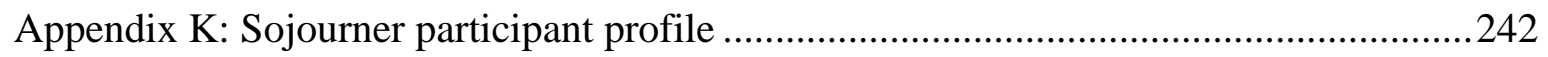

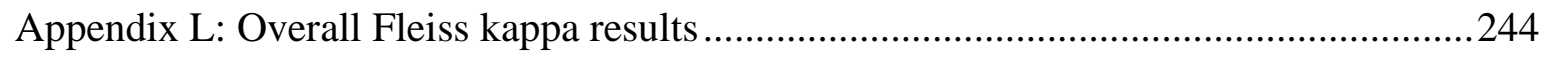

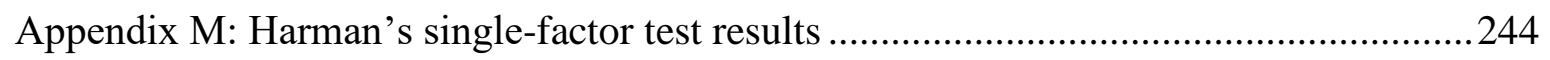

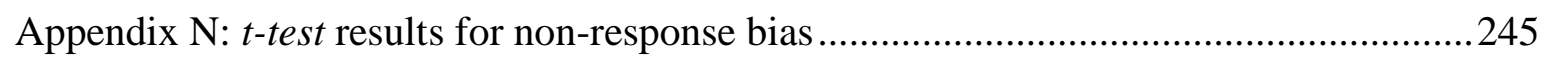

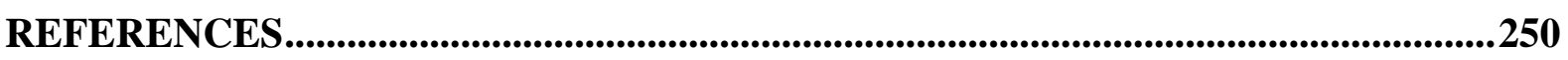




\section{LIST OF TABLES}

Table 2.1: Illustrative summary of UGC articles

Table 2.2: Leiper's (1995) five elements of the tourism system

Table 2.3: Illustrative summary of VFR tourism articles

Table 3.1: Summary of hypotheses proposed

Table 4.1: Overview of this study's iterative sequential mixed-methods design

Table 4.2 Items used to measure Intention to visit

Table 4.3: Clark and Pugh's (2001) cultural clusters and their 'cultural distance' from Britain

Table 4.4 An expanded application of Foss' (1994) rhetorical schema

Table 5.1: Summary of interview details

Table 5.2: Summary of interview findings (key cognitive attributes)

Table 5.3: Summary of interview findings (key content areas)

Table 5.4: Participating sojourner details

Table 5.5: Sojourner UGI sharing habits

Table 5.6: Web survey respondent profile (friends/relatives)

Table 5.7: Total number of observations

Table 5.8: Descriptive statistics

Table 5.9: Assessment of measurement model on loading, $\alpha, \mathrm{CR}$ and AVE

Table 5.10: Assessment of discriminant validity using HTMT criterion

Table 5.11: Collinearity assessment

Table 5.12: Explained variance and prediction relevance test

Table 5.13: Measurement invariance test using MICOM

Table 5.14: Direct effects

Table 5.15: Indirect effects

Table 5.16: Control variables

Table 5.17: PLS-MGA comparison test results (friends vs. relatives) 
Table 5.18: Multi-group comparison test results

Table 5.19: Interaction effects

Table 5.20: PLSpredict assessment

Table 5.21: Summary of hypotheses testing

Table 5.22. Summary results of content analyses 


\section{LIST OF FIGURES}

Figure 2.1: An application of Echtner and Ritchie's destination image framework

Figure 2.2: Destination image framework

Figure 2.3 Whole tourism model for VFR tourism

Figure 3.1: Conceptual model summary

Figure 4.1: Estimated migrant arrivals by visa type

Figure 4.2 The iterative sequential design

Figure 5.1: Overview of Phase 1 findings

Figure 5.2: Birthplace for people in Wellington Region, 2018 Census

Figure 5.3 PLS-SEM model evaluation

Figure 5.4: MICOM 3-step procedure

Figure 5.5: Simple slope plot of conditional interaction effect

Figure 5.6: Results of NVivo word-frequency analyses for predetermined categories

Figure 5.7: Examples of images submitted for Events

Figure 5.8: Examples of images submitted for Food and drinks/dining

Figure 5.9: Examples of images submitted for Urban city

Figure 5.10: Examples of images submitted for Nature/scenic landscape

Figure 5.11: Examples of images submitted for Your pick

Figure 5.12: Overview of denoted and connoted content identified 


\section{LIST OF ABBREVIATIONS}

CB SEM

CI

DMO

eWOM

HTMT

ICT

IP

iWOM

MICOM

OLS

PGI

PLS MGA

PLS-SEM

QUAL

QUAN

RDS

RQ

SEM

UGC

UGI

VAF

VF

VFR

VIF

VR

WCC

WOM

WRC

WREDA
Covariance-based structural equation modelling

Confidence interval

Destination marketing organisation

Electronic word of mouth

Heterotrait-monotrait

Information communication technology

Internet protocol

Image-generated word of mouth

Measurement invariance of composite models

Ordinary least squares

Participant-generated images

Partial-least squares multi-group analysis

Partial-least squares structural equation modelling

Qualitative

Quantitative

Respondent-driven sampling

Research question

Structural equation modelling

User-generated content

User-generated images

Variance accounted for

Visiting friend(s)

Visiting friends and relatives

Variance inflation factor

Visiting relative(s)

Wellington City Council

Word of mouth

Wellington Regional Council

Wellington Regional Economic Development Agency 


\section{CHAPTER 1. Introduction}

\subsection{Background}

In a society where commercial success is increasingly tied to the "artful creation of attractive merchandise, images, and brands", visual images in mass media are used by marketers as powerful tools to capture the attention of consumers (Weaver, 2009, p. 179). Described as "uniquely visual" (MacKay \& Fesenmaier, 1997, p. 540), tourism has capitalised on the practise of image making (Urry \& Larsen, 2011). According to the World Tourism Organization, an agency of the United Nations, tourism is a lucrative industry, where the total export value of international tourism alone is estimated at US\$1.7 trillion (International tourism highlights, 2019 edition, 2019). Additionally, tourism contributes significantly to the economic wellbeing of many countries. For example, the direct contribution of tourism to New Zealand is valued at NZ\$15.9 billion and is the country's largest export earner (Investment boost for New Zealand tourism, 2019).

The success of picturesque tourism is the product of calculated framing and communication of the destination image, where Destination Marketing Organisations (DMOs), agencies with a vested interest in the successful promotion of the destination, masterfully compose and spread place myths or stereotypical ideals through mainstream media, to arouse the desire for travel (Hopkins, 1998; Pike \& Page, 2014; Urry \& Larsen, 2011). Destination image is defined as a composite of attractions (tourism products) and attributes weaved together to form an overall impression, viewed as a depiction of reality (Beerli \& Martín, 2004b; MacKay \& Fesenmaier, 1997; Solonchak \& Pesina, 2015). However, the global prevalence of Internet connectivity, online platforms and mobile technology have led to the rise of usergenerated content (UGC). UGC is defined as the sharing of "opinions, thoughts, and perceptions toward brands, products, and firms through online reviews, blogs, Tweets, and Facebook posts" (Nam \& Kannan, 2014, p. 21). For tourism, UGC represents a form of word of mouth (WOM) that offers experiential and current travel information, free from market influence (Yoo \& Gretzel, 2011).

Recent studies illuminate the increasing consumer dependence on UGC in making travel decisions (Book, Tanford, Montgomery, \& Love, 2018; Munar \& Jacobsen, 2014; Tham, Croy, \& Mair, 2013), signalling the eroding influence DMOs have on consumers, who are turning away from traditional forms of media. The growing popularity and perceived potential benefits (and consequences) of UGC on tourism's multi-trillion-dollar industry have 
spurred numerous studies seeking to understand the implications and harness the benefits of UGC (e.g. Bosangit, Hibbert, \& McCabe, 2015; Marine-Roig \& Ferrer-Rosell, 2018; Tseng, $\mathrm{Wu}$, Morrison, Zhang, \& Chen, 2015). Despite the global popularity of online platforms with greater visual emphasis, the pivotal role user-generated images (UGI) play in shaping consumer decisions, and the recognised need to reconfigure traditional marketing practices (Dinhopl \& Gretzel, 2016), a majority of studies in marketing and tourism continue to focus on textual forms of UGC, found on open collaborative review sites and blogs ( $\mathrm{Lu}, \mathrm{Chen}, \&$ Law, 2018; Lu \& Stepchenkova, 2015). The attention on textual forms of UGC ignores the multi-modal nature of online content, resulting in only a small number of studies that examine the role of UGI as captured forms of WOM that relay attributes of destinations, and of consumers as creators and broadcasters of visual information (Lu et al., 2018; Ring, Tkaczynski, \& Dolnicar, 2016). Moreover, few studies critically assess how destination appeal is constructed, and how meanings of destinations (in a consumer-to-consumer context) are conveyed through the framing of UGI; even when market meanings are progressively derived from consumer-created content (Rossolatos, 2017; Schmallegger, Carson, \& Jacobsen, 2010). Specifically, tourism scholars overlook the experiences and interactions of the growing number of sojourners, who rely heavily on online platforms to communicate with overseas friends and relatives, where emergent studies in UGI place emphasis on tourist produced images (e.g., Nikjoo \& Bakhshi, 2019; Wang, Kirillova, \& Lehto, 2017).

The role of the sojourner is unique and fluid; shifting between that of tourist and resident; host and guest; as well as consumer and producer of tourism development and experiences (Choi \& Fu, 2018; Griffin, 2015; King \& Dwyer, 2015). Sojourners are characterised as individuals who have "long-term destination experience", such as international students and migrant workers, who are able to move backwards and forwards between countries, typically for a period of six months to five years (Choi \& Fu, 2018, p. 47). Markedly, given their multi-locality, sojourners are crucial links that bridge destinations to personal networks of overseas friends and relatives, making sojourners critical influencers in fuelling VFR (visiting friends and relatives) tourism (King \& Dwyer, 2015; Lee \& King, 2016). Broadly, VFR tourism refers to "tourism experiences that involve a prior relationship between a visitor and resident no matter the stated trip purpose, accommodation used, or activities engaged in" (Griffin, 2013b, p. 235).

VFR tourism is often linked to migration of people (Jackson 1990) and accounts for about a quarter of international travel (International tourism highlights, 2019 edition, 2019). VFR 
tourism is a significant tourism segment and contributes extensively to tourism economies. In particular, VFR tourism has been found to benefit densely inhabited conurbations (townships with urban centres) with modest tourist developments, and high migrant populations (McKercher, 1996; Provenzano \& Baggio, 2017) that typically fall outside popular tourism centres (Stepchenkova, Shichkova, Kim, Pennington-Gray, \& Rykhtik, 2015). Studies demonstrate the influence of sojourners, as residents, in attracting overseas friends and relatives as well as shaping the activity patterns of visits (Backer, 2010; Gitelson \& Kerstetter, 1994; Young, Corsun, \& Baloglu, 2007). Although VFR tourism is socially driven, there is a dearth of research linking VFR tourism to the burgeoning trend of technology mediated communication. Scholars stress that VFR tourism has "more to gain" from an understanding of the implications of online interactions, than other forms of tourism, given the growing use of information communication technology (ICT) and rising migration numbers (Backer \& King, 2015, p. 209). Moreover, despite VFR tourism's proven contribution to tourism economies, VFR is often neglected in tourism marketing campaigns and research (Yousuf \& Backer, 2015).

The impetus to investigate the role of UGI is heightened as destination attractiveness is linked to VFR tourism, and scholars elucidate the need for research that evaluates the hostdestination relationship (Backer, 2011; Tham, 2006). Moreover, given the rising scepticism of consumers towards social media influencers found on open platforms (Chatzigeorgiou, 2017; Holmes, 2019), concerns of misinformation (We are social, 2020), and the demonstrated preference of consumers in sharing and gaining travel insights from friends and relatives (Marine-Roig \& Ferrer-Rosell, 2018; Munar \& Jacobsen, 2014), the need to examine the position of sojourners, as online destination ambassadors, become critical (Uchinaka, Yoganathan, \& Osburg, 2019). This study builds on the argument for the growing need to examine "the influence of the influencer" in tourism, where the influence of different sources of information and degrees of tie strength are found to result in varying consumer behaviour and decision-making outcomes (Narangajavana Kaosiri, Callarisa Fiol, Moliner Tena, Rodríguez Artola, \& Sánchez García, 2019, p. 263). The following section details the motivations that drive this study. 


\subsection{Motivations and opportunity}

\subsubsection{Gap in understanding the value of UGI as articles of WOM.}

UGI are today part of common parlance in articulating personal experiences, and are influential sources of travel information that shape consumer perception and behaviour (Dinhopl \& Gretzel, 2016; Fox, Bacile, Nakhata, \& Weible, 2018). Scholars suggest that an examination of UGI allows for the discovery of rich contextual insights, able to inform and improve marketing, branding, communications as well as operational strategies of organisations - in particular services and tourism organisations, where services and tourism products contain high credence attributes (Bakri, Krisjanous, \& Richard, 2020). However, research linking UGI and WOM in marketing (King, Racherla, \& Bush, 2014; Lamberton \& Stephen, 2016), as well as tourism and hospitality remains limited (Lu \& Stepchenkova, 2015; Lu et al., 2018), providing fertile grounds for further research.

\subsubsection{Dearth of studies in VFR tourism that examine online interactions.}

The importance of VFR tourism scholarship, is demonstrated by the growing number of articles published in leading tourism journals such as: Annals of Tourism Research; Journal of Sustainable Tourism; Journal of Travel Research and Tourism Management (e.g. Backer, Leisch, \& Dolnicar, 2017; Lehto, Morrison, \& O’Leary, 2001; Marschall, 2017; Williams, 2013). However, scholars continue to overlook the pertinence of online communication and Information Communication Technology (ICT) in maintaining relationships across borders, and its influence in driving VFR tourism, resulting in calls for studies that examine the implications of online communications in VFR tourism (Backer \& King, 2015; Gafter \& Tchetchik, 2017). In addition, scholars cast light on the opportunity of gathering networked or dyadic data from VFR networks to enhance understanding of online interactions, as well as testing intervening variables, which could help marketers determine factors that influence decision making in VFR tourism (Choi \& Wu, 2018; Gafter \& Tchetchik, 2017).

\subsubsection{Overlooked role of sojourners as online destination ambassadors.}

Studies overlook the unique liquid position of sojourners, who shift between a variety of roles (i.e., tourists and residents; consumers and producers of tourism development and experiences). Given their extended stay in the host-destination sojourners are perceived to be destination experts, and are found to share positive information of the host destination (Humbracht, 2015). However, studies that explore the role of sojourners as online destination ambassadors remain scarce. According to Uchinaka et al. (2019) more studies are required to 
examine the role of the different types of residents as online destination ambassadors, where online platforms ease the challenges typically experienced by conurbations, such as: access to traditional tourist distribution channels and marketing resources (Pearce, Tan, \& Schott, 2004; Peirce \& Ritchie, 2007). To the best of the author's knowledge, there are no studies that examine the implications and construction of UGI produced by globally connected sojourners as persuasive communication articles that can be leveraged to market destinations to overseas VFR markets. Moreover, the relationship between the sojourner and friend or relative, allows for a deeper understanding of the role of tie strength in adding to the persuasive nature of images shared by sojourners.

\subsection{Research objectives and questions}

In view of the research gaps that provide motivation for this research, identified in Section 1.2 , the objectives of this thesis are to:

1. Better understand the value of UGI, in particular sojourner-produced images, in spreading persuasive image-generated WOM (iWOM), able to shape viewer perception, and stimulate VFR tourism.

2. Investigate the underlying role of tie strength, relationship type and impression as mechanisms that affect the link between iWOM and intention to visit.

3. Explore the role of sojourners as key online destination ambassadors, able to frame and shape destination perceptions in overseas VFR markets, through the visual mode.

This study draws from the theory of visual rhetoric, a theory that proposes the value of visual objects as narratives composed to persuade their audience (Blair, 2004; Foss, 2005), as well as emotional contagion theory, which demonstrates the influence of interpersonal bonds in decision making (Howard \& Gengler, 2001; Nemeroff \& Rozin, 1994). Further, it builds on established research in destination image, WOM and VFR tourism. This study seeks to meet the objectives of this thesis by answering the corresponding research questions (RQs).

RQ 1: How effective are sojourners as visual communicators, and of their images pushed to overseas friends and relatives as persuasive forms of word of mouth?

RQ 2: Given the centrality of relationships in VFR tourism, what roles do tie strength and relationship type play in shaping the perception of the iWOM receiver (friend/relative) towards the host destination?

RQ 3: What is the nature of iWOM shared by sojourners to their overseas networks? 
RQ 4: How are destination attributes framed, and what functions or meanings do the iWOM shared by sojourners convey?

\subsection{Research methodology}

This thesis employs an iterative sequential mixed-methods design (qual $\rightarrow$ QUAN $\rightarrow$ QUAL), rooted in a postpositivist perspective. In Phase 1, semi-structured expert interviews were conducted with the marketing managers of three organisations in charge of marketing Wellington to both internal and external audiences. The purpose of this phase was to gather relevant context that informed content areas in the gathering of visual stimuli (for use in subsequent phases), and measures for the survey instrument.

In Phase 2, dyadic Web surveys embedded with submitted sojourner-produced images were administered, and quantitative data were analysed through partial-least squares structural equation modelling (PLS-SEM). The purpose of Phase 2 was to examine the impact of sojourner-pushed iWOM on the intention of friends and relatives to visit the host-destination. Phase 2 further allowed for an understanding of the role of UGI as iWOM that fuel VFR tourism, where similar to WOM, iWOM is viewed to be equally capable of shaping tourism consumer impressions and decision making. Moreover, given the centrality of relationships in VFR tourism, Phase 2 provided an opportunity to understand the intervening roles of tie strength and relationship type in the evaluation of iWOM. Phase 2, which takes a quantitative approach, provided greater generalisability and validity to the study.

In Phase 3, a visual rhetorical analysis was conducted to triangulate and elaborate the findings of Phase 2. Given the richness of visual data, Phase 3 played a critical role in providing a more robust and nuanced understanding of the nature of sojourner constructed images shared as articles of WOM.

\subsection{Research contributions}

\subsubsection{Theoretical contributions.}

First, this study is seminal in the area of imagery and WOM, introducing and testing the concept of iWOM (Bakri et al., 2020; Lu \& Stepchenkova, 2015). In this study, images of sojourners are identified as rhetorical devices, capable of influencing viewer impression and intention. Consequently, this thesis furthers the application of visual rhetorical theory, which traditionally has been applied to examine firm-created content. This thesis, therefore, contributes an understanding of different strategies used by tourism consumers, specifically 
sojourners, in composing images for their audience or network of overseas friends and relatives.

Second, this thesis recognises the critical role of sojourners in attracting VFR tourists to the host destination. Adopting a multi-dimensional and integrative perspective, this research takes into account the interaction of the sojourner with the host destination and their overseas network through ICT. Importantly, this study advances the understanding of the increasingly important role of ICT in VFR tourism, where it allows sojourners to share destination experiences visually. This study further develops VFR tourism by investigating the value of sojourner-produced images as visual forms of WOM that articulate aspects of destination image. Moreover, it highlights the extent to which sojourners are active and adept visual communicators/online ambassadors, able to influence through their visual compositions. Consequently, it moves the focus of examining outcomes of VFR tourism to understanding the potential of iWOM as antecedents of VFR tourism.

Last, the prevailing relationship between the sojourner and his/her overseas network provides an opportunity to gather dyadic data. Dyadic data allows a deeper understanding of the role of tie strength in contributing to the persuasive nature of iWOM shared by sojourners, where prior tourism research focussed on open collaborative networks and review sites (Lu \& Stepchenkova, 2015). This study further contributes to the literature by establishing the differences of the complex decision-making process of the different groups (friends/relatives) receiving the information.

\subsubsection{Methodological contributions.}

This study provides a framework to critically assess the nature of UGI, where a component of this iterative-sequential mixed-methods study includes a visual rhetorical analysis - a method largely overlooked by tourism researchers (Park \& Kim, 2018). In addition, this study not only addresses the lack of tourism research that adopts a mixed-methods approach (KhooLattimore, Mura, \& Yung, 2019), but contributes by expanding the application of mixedmethods to include a visual analysis. Notably, this multi-dimensional study contributes methodologically by providing guidance for collecting dyadic/paired data. Scholars highlight the lack of primary and dyadic data, and the merits of such data in understanding online communication in VFR tourism (Gafter \& Tchetchik, 2017; Griffin, 2013a). 


\subsubsection{Managerial contributions and implications.}

First, this thesis provides marketers, specifically in conurbations, with empirical evidence to support the importance, and effectiveness of targeting and engaging sojourners in the marketing of destinations. This thesis demonstrates the ability of sojourners to construct persuasive images that shape destination image perceptions and intentions of the VFR tourism market.

Second the visual analysis demonstrates how sojourners articulate their destination experiences and leverage their duality as tourists/residents and being home/away, in the composition of their images, signalling their ability to create content relevant to their audience as well as ease cultural differences that are often found to affect destination choice. This further solidifies the position of sojourners as influential communicators, suitable for supporting post disaster tourism marketing strategies.

Third the findings of the quantitative phase of this study are valuable to marketers as they highlight the differences in how online information is received by friends and relatives. These findings could help marketers design suitable strategies to target friends and relatives, through sojourners.

Fourth, the insights gained through the visual rhetorical analysis provide a critical understanding of valued destination experiences that can help marketers audit and improve marketing communications strategies, as well as manage internal marketing to sojourners. Last, this study also provides insights for city councils/planners into the interactions of sojourners with the host destination, which contributes to a better understanding of the acculturation of sojourners.

\subsection{Thesis structure}

This thesis is organised in six chapters. Chapter 1 provides the background, motivation and intended contributions of this thesis. Chapter 2 reviews the literature on destination image, WOM and VFR tourism - highlighting gaps within the current literature. Chapter 3 discusses the development of the research framework that seeks to fill the identified gaps and presents the hypotheses. Chapter 4 outlines the research methodology and techniques used for analysing data garnered through this mixed-methods study. Chapter 5 presents the results of the various phases of the study. Chapter 6 provides an overarching discussion of the various phases of the study, the theoretical, methodological and practical contributions of this study, as well as limitations of this study and avenues for future research. 


\subsection{Chapter summary}

This chapter provides a background that underlies the study, an introductory overview of the motivations and opportunities (research gaps) found in the literature, as well as the theoretical, methodological and practical contributions of this study. Further, this chapter highlights the position of this thesis, where the objectives of this thesis are to: 1) better understand the value of sojourner-generated UGI as persuasive forms of visual WOM, able to stimulate VFR tourism, 2) to investigate the underlying role of tie strength, relationship type and impression as mechanisms that affect the link between iWOM and intention to visit and 3) explore the role of sojourners as online destination ambassadors, able to frame and shape destination perceptions in overseas VFR markets, through the visual mode. The next chapter provides a review of past and current literature, where the aim is to make evident research gaps in the literature that this thesis fills. 


\section{CHAPTER 2. Literature review}

This chapter reviews research from literature on destination image, WOM and VFR tourism. This chapter summarises relevant research findings and identifies research gaps in the literature that serve as building blocks for this thesis, and the development of the conceptual framework.

\subsection{Destination image}

Boulding (1956, p. 6), in his seminal work describes image as "subjective knowledge" that one "believe(s) to be true", and that the image primarily governs behaviour. In the 1970s, scholars introduced and examined the concept of destination image in tourism studies (Crompton, 1979; Gunn, 1988; Hunt, 1975), and the subject continues to be of interest (Afshardoost \& Eshaghi, 2020; Zhang, Fu, Cai, \& Lu, 2014). The attention on destination image is tied to its role as a critical brand element in the marketing of destinations (Blain, Levy, \& Ritchie, 2005), capable of influencing tourism consumers' pre/post-purchase behaviours and evaluations, such as on-site experience, satisfaction, loyalty, intention to visit/revisit and recommendations (Chen \& Tsai, 2007; Lee, Lee, \& Lee, 2014).

Several definitions of destination image have been developed (Echtner \& Ritchie, 2003; Gallarza, Saura, \& García, 2002; Lai \& Li, 2016; San Martín \& Rodriguez del Bosque, 2008). Aligned with Boulding (1956), definitions put forth by tourism scholars tend to describe destination image as "a compilation of beliefs and impressions based on information processing ... that result in a mental representation of the attributes and benefits sought of a destination" (Zhang et al., 2014, p. 215). Key characteristics of destination image are; reliance on perceptions rather than reality (Gartner, 1994; Hunt, 1975), ability to be developed prior to visits (Echtner \& Ritchie, 2003; Gunn, 1988), and capacity to influence the travel decision-making process, which at times are "not entirely rational and economically motivated" (Stepchenkova \& Mills, 2010, p. 576).

DMOs invest heavily in influencing destination image, where destination image is a critical differentiating factor for destinations, amid an increasingly competitive and globalised tourism market (Avraham \& Ketter, 2017; Pike \& Ryan, 2004). The goals of DMOs are to position, communicate and manage a favourable destination image in the minds of tourism consumers (Gartner, 1994; Pike \& Ryan, 2004; Stepchenkova \& Mills, 2010). To achieve the DMO's desired goals and outcomes an understanding of how destination image is constructed 
is required. The following section discusses the components of destination image, which draws links to studies of product and brand image.

\subsubsection{Components of destination image.}

Identified as an individual's mental belief or knowledge about a brand or destination, image is considered an attitudinal construct (Baloglu \& McCleary, 1999; Gardner \& Levy, 1955; Hunt, 1975; Keller, 1993; Padgett \& Allen, 1997). Brand image studies depict brand image as a process of layered succession that begins with 1) evaluating attributes, 2) identifying benefits, and ends with 3) the formation of attitudes towards a product or brand (Bakri et al., 2020; Keller, 1993). Attributes are defined as descriptive features of the product identified, and can be product (i.e., physical composition of the product and service features) or nonproduct related (i.e., product appearance, user imagery and usage imagery); benefits are the value that consumers attach to attributes of a product or service (i.e., functional, experiential and symbolic benefits); and attitudes are the overall evaluations of brands or products that drive consumer behaviour (Keller, 1993; 2003).

Similarly, in the marketing of destinations, attributes and characteristics of destinations acquired through a variety of communication/stimuli such as advertising, books and conversations with others, are compiled, benefits identified, and values assigned by tourism consumers towards the construction of destination image (Baloglu \& McCleary, 1999b; Gunn, 1988). Hunt (1975), in his study distributed to 4,000 households in the United States, demonstrates how attributes or characteristics of a destination, and the values assigned by tourism consumers, inform their mental image of a destination, which subsequently influences travel intentions.

Echtner and Ritchie (1993) suggest that destination image comprises attribute-based and holistic components, where each of the components contain functional (more tangible) and psychological (more abstract) attributes. The authors add that the image of destinations, can "range from those based on 'common' functional and psychological traits to those based on more ... unique features, events feelings or auras" (p. 3). Hence, in their conceptual framework of destination image, Echtner \& Ritchie (1993) proposed three continuums: 1) attribute-holistic; 2) functional-psychological; and 3) common-unique. The attribute-holistic continuum builds on research in psychology and consumer behaviour. The authors suggest that similar to products, destinations are evaluated based on perceptions of individual descriptive product-related features or attributes, as well as more holistic attributes, or 
imagery of physical characteristics and general feelings or atmosphere, as depicted in Figure 2.1 (Echtner \& Ritchie, 1993; MacInnis \& Price, 1987). The functional-

psychological continuum on the other hand, is explained by Echtner and Ritchie (1993) as characteristics that on one end, are functional or directly observable and on the other end of the continuum, are more abstract and difficult to observe and measure. The authors further describe the common-unique continuum to comprise features that are perceived to be unique to the destination, or common functional features such as transportation or accommodation facilities.

Building on attributes found in Echtner and Ritchie's (1993) destination image framework, tourism scholars adopt approaches consistent with attitudinal and consumer behavioural research, where the cognitive and affective components are taken into account (Fishbein \& Ajzen, 1975; Zajonc \& Markus, 1982). The cognitive component is defined as beliefs or knowledge an individual has of the characteristics or attributes of a destination (Baloglu \& McCleary, 1999; Beerli \& Martin, 2004a; Mak, 2017; Pike \& Ryan, 2004). In earlier studies of destination image, only the cognitive component was considered (Echtner \& Ritchie, 1993; San Martín \& Rodriguez del Bosque, 2008). However, increasingly, destination image studies include the affective component to the destination image framework (Baloglu \& McCleary, 1999; Beerlin \& Martin, 2004a; San Martín \& Rodriguez del Bosque, 2008). The affective component refers to the emotional response of individuals to the destination (Baloglu \& Brinberg, 1997; Beerli \& Martin, 2004a). In addition, a joint cognitive-affective approach has been adopted to capture destination image (Zhang et al., 2014). 
As presented in Figure 2.2, the combination of the affective and cognitive component, produce an overall or compound image or attitude that results in the positive or negative evaluation of a destination similar to attitudinal studies (Baloglu, 1997; Baloglu \& McCleary, 1999; Beerli \& Martín, 2004b; Bigné Alcañiz, Sánchez García, \& Sanz Blas, 2009; Mak, 2017; Stylidis, Belhassen, \& Shani, 2017). Figure 2.2 provides an illustration of the destination image framework drawn from destination image literature, listing examples of cognitive and affective attributes found in destination image studies (e.g., Baloglu \& Brinberg, 1997; Crompton, 1979; Echtner \& Ritchie, 2003; Hosany, Ekinci, \& Uysal, 2006; Kim \& Stepchenkova, 2015; Martínez \& Alvarez, 2010; Molinillo, Liébana-Cabanillas, Anaya-Sánchez, \& Buhalis, 2018).

\begin{tabular}{|c|c|c|}
\hline \multicolumn{2}{|l|}{ Cognitive attributes } & \\
\hline $\begin{array}{l}\text { Accessibility } \\
\text { Accommodation facilities } \\
\text { Architecture/buildings } \\
\text { Attractiveness } \\
\text { Beaches } \\
\text { Cities } \\
\text { Cleanliness } \\
\text { Climate/temperature } \\
\text { Costs/price levels } \\
\text { Crowdedness } \\
\text { Degree of urbanisation } \\
\text { Different cuisine/food and drink } \\
\text { Different customs and culture } \\
\text { Economic development/affluence } \\
\text { Extent of commercialisation } \\
\text { Facilities for information and tours } \\
\text { Fairs, exhibits, festivals } \\
\text { Fame/reputation } \\
\text { Familiar vs. exotic } \\
\text { Family or adult oriented }\end{array}$ & $\begin{array}{l}\text { Historic sites/museums } \\
\text { Hospitality/friendliness } \\
\text { Local infrastructure/transportation } \\
\text { Modernity level } \\
\text { National parks/wilderness activities } \\
\text { Nightlife and entertainment } \\
\text { Opportunity for adventure } \\
\text { Opportunity to increase knowledge } \\
\text { Personal safety } \\
\text { Political stability } \\
\text { Quality of service } \\
\text { Scenery/natural attractions } \\
\text { Shopping facilities } \\
\text { Sports facilities/activities } \\
\text { Tourist sites/activities } \\
\text { Trendy } \\
\text { Uniqueness }\end{array}$ & $\begin{array}{l}\text { Overall } \\
\text { image }\end{array}$ \\
\hline \multicolumn{2}{|l|}{ Affective attributes } & \\
\hline $\begin{array}{l}\text { Arousal } \\
\text { Excitement }\end{array}$ & $\begin{array}{l}\text { Pleasantness } \\
\text { Relaxation }\end{array}$ & \\
\hline
\end{tabular}

Figure 2.2: Destination image framework (Source: developed for this research)

In summary, destination image is the perceptions held of the destination and its tourism offerings - whether tangible (functional) or intangible (psychological) — that influence behaviour. Markedly, these perceptions are acquired from exposure to a variety of external 
stimuli (San Martín \& Rodriguez del Bosque, 2008), such as film, television programmes (Hudson, Wang, \& Gil, 2011; Josiam et al., 2015; Mak, 2017), advertisements and marketing collateral (Hunter, 2012; Jenkins, 2003). High in credence attributes, marketers heavily rely on the visual mode to frame, capture and articulate aspects of tourism products and services (Urry \& Larsen, 2011; Zeithaml, Parasuraman, \& Berry, 1985), where "human beings have a built-in capacity to comprehend images and spatial relations, and ... form psychological associations with respect to these concepts" (Dichter, 1985, p. 77). The next section looks to appraise the value of visual content in forming destination image, and its significance to tourism studies.

\subsubsection{The role of visual images in conveying destination image.}

From postcards to brochures and film, visual images have been the subject of several tourism studies (Connell, 2012; Hunter, 2012; Markwick, 2001; Stepchenkova \& Mills, 2010). Similar to the spoken word, images help in presenting a destination, and are powerful cues that communicate values, concepts, characteristics, attributes and ideas that go towards building the image of a destination (Baloglu \& Brinberg, 1997; MacKay \& Fesenmaier, 1997). These characteristics of visual images are beneficial to tourism, where visual images have the ability to "shape and reshape destination perceptions" of tourists (Kim \& Stepchenkova, 2015, p. 29).

Visual images are considered more interesting, more powerful than words, and help with the elaboration of potential benefits (Dichter, 1985; Phillips, Olson, \& Baumgartner, 1995; Roggeveen, Grewal, Townsend, \& Krishnan, 2015). Moreover, visual images conjure greater imagery and visions of imagined consumption, where imagery as a consumed experience supports the link between the visual image and satisfaction (MacInnis \& Price, 1987; MacKay \& Fesenmaier, 1997; Roggeveen et al., 2015; Ye \& Tussyadiah, 2011). Consumers depend on visual presentations to evaluate the benefits of a brand or product, when making purchasing decisions (Mitchell, 1986; Townsend \& Kahn, 2013; Underwood \& Klein, 2002). For example, Vilnai-Yavetz and Tifferet (2009) demonstrate the value of online images in influencing consumer perception. The findings of their experiment indicate a positive link between the use of images on an academic webpage and perceived service quality. The images were also found to provide participants with information on the university; such as its activities and facilities, adding tangibility to the purchase experience of services products. Thus, highlighting the value of images in reducing the psychological risks involved in 
consuming products with high-credence attributes such as services and tourism products. Tourism consumers rely on visuals to make judgments, where the more familiar and developed the destination image is in the mind of the consumer, the less perceived uncertainty the individual would have towards the destination (Kim \& Stepchenkova, 2015; Tasci \& Kozak, 2006), and greater the desire to visit (Beerli \& Martin, 2004a).

In addition, visual representations such as those found in brochures, advertisements and film communicate "instantaneous escape, relief and a road to betterment through consumption and fantasy of other places" (Urry \& Larsen, 2011, p. 173). Concomitantly, visual representations act as promises that convey the possibility of gaining the sought-after experiences that comes with choosing the destination (Ye \& Tussyadiah, 2011). The favourable image manifested by visual images, therefore, forms the basis by which prospective tourists judge the destination's potential to bring about satisfaction, where "the lure to visit a particular region ... is more visionary than tangible" (Hunt, 1975, p. 1).

As perceived analogues of reality, DMOs have used visual images to build, strengthen, or change the image of a destination (Avraham \& Ketter, 2017; Urry \& Larsen, 2011), illuminating the relationship between visual images and destination image, as well as the pertinence of visual images in the marketing of destinations. Despite the shifting role of consumers (from consumers to producers of tourism experiences and visual information), research examining images produced by consumers of tourism experiences remains scarce (Lu \& Stepchenkova, 2015; Park \& Kim, 2018). The following section provides a discussion of the different information agents of destination image, and the levels of influence they exert in informing destination image perceptions, where scrutiny of the various image formation agents highlights the differences and utility of each in the marketing of destinations.

\subsubsection{Destination image formation agents.}

Scholars suggest that the image formation process is a continuum that involves a variety of image formation agents, where agents are "forces" that exert influence on the perception of tourism consumers at varying degrees (Beerli \& Martín, 2004a; Gartner, 1994, p. 197). Notably, information agents are categorised into three broad groups: autonomous, induced and organic, which provide DMOs with different degrees of reach and control (Gartner, 1994). 
Autonomous agents comprise news reports, documentaries, film and popular culture, where DMOs largely have no control over the content created and the image projected. Autonomous agents are deemed influential given their high credibility and reach (Gartner, 1994). For example, studies demonstrate how agents use movies and television programmes from popular culture to shape destination image perceptions and tourism behaviours (S. Hudson et al., 2011; Josiam et al., 2015; Tessitore, Pandelaere, \& Van Kerckhove, 2014).

Induced agents on the other hand, consist of traditional advertising and marketing outlets such as print advertisements, tour operators and endorsed spokespeople. Distinguishable characteristics of induced agents are the control and influence destination marketers have over the image portrayed. Similar to autonomous agents, induced agents provide significant penetration into tourism markets. However, induced agents are perceived to be costly yet less credible than other sources of destination image formation (Gartner, 1994).

Organic agents, such as friends and relatives provide low reach, but are deemed highly credible and influential agents of destination image formation (Gartner, 1994). Further, scholars suggest that organic agents influence behaviour throughout the recreation experience, where "... people actively create meaningful places through conversation and interaction with others ..." (Crompton, 1981; Stokowski, 2002, p. 372). For tourism destinations, organic agents, therefore, represent highly important sources of destination image formation (Beerli \& Martín, 2004a).

Markedly, advances in ICT promote the exchange and reach of information (in a variety of modalities) from organic sources (Buhalis \& Law, 2008). Thus, strengthening the position of organic agents in the destination image formation process, which inherently, signals the need to revisit the typology proposed by Gartner (1994), in particular, organic agents. A renewed understanding of the mechanics behind interpersonal interactions, specifically the word of mouth (WOM) exchange between friends and relatives, in a progressively digitally connected society, could enhance the marketing and management of destination image formation. Consequently, scholars suggest a need for such studies (Stepchenkova \& Mills, 2010). The following sections provide an overview of WOM studies, and chart the development of WOM from oral, face-to-face conversations to technologically mediated exchanges, known as electronic word of mouth (eWOM). 


\subsection{Word of mouth}

Described by Arndt (1967b, p. 188) as the "sleeping giant", word of mouth (WOM) is the “... oldest mechanism by which opinions on products and brands are developed, expressed and spread ...", and largely described as “... one of the most powerful media ..." (p. 189). The Decatur study conducted by Katz and Lazarsfeld in the 1950s, is an early example in marketing research that demonstrates the impact of personal influence on decision making (Katz \& Lazarsfeld, 2017). Inspired by Gabriel Tarde (Tarde, 1901/2018), a French sociologist, who studied the role of conversations in shaping public opinion, the Decatur study of 800 female residents in Decatur, Illinois, provided empirical evidence that demonstrates the power and influence of face-to-face communications in comparison to traditional forms of media (Arndt, 1967b; Katz \& Lazarsfeld, 2017). Thus, paving the way for other studies in person-to-person communication, more commonly referred to as WOM. Defined as an "... oral, person-to-person communication between a perceived noncommercial communicator and a receiver concerning a brand, product or service ..." (Arndt, 1967b, p. 190), WOM highlights the importance of everyday conversations in shaping consumer attitudes and guiding purchasing decisions (Kozinets, de Valck, Wojnicki, \& Wilner, 2010). WOM is also considered as a trustworthy form of information independent of market influence (Baloglu \& McCleary, 1999; Echtner \& Ritchie, 2003). The subjective information garnered from experience, and the opinion of others, shared through WOM, therefore, becomes instrumental in the consumer decision-making process (Arndt, 1967a; Crompton, 1981; Murray, 1991). Consumer reliance on WOM is identified as a risk-reducing strategy, where the experience and opinons of others are used to mitigate associated risks involved in consuming products (Mangold, 1987). The role of WOM has been found to be particularly critical in the consumer's decision-making process, especially for products that are high in credence attributes (e.g., heterogenous, ephemeral and intangible), such as services and tourism products (Confente, 2015; Gunn, 1988; Jalilvand \& Heidari, 2017; Murray, 1991).

Scholars further cast light on the implications of WOM on both demand and supply (e.g., Arndt, 1967; Gombeski, Fay, Niedzielski, \& Weaver, 1988; Jalilvand \& Samiei, 2012; Kozinets et al., 2010; Ye, Law, \& Gu, 2009). In a field experiment, Arndt (1967a) illuminates how positive WOM facilitates product adoption, where $54 \%$ of participants who received positive WOM purchased the product. Baloglu and McCleary (1999) demonstrate the 
significance of WOM, which outstripped advertisements in influencing destination image perceptions. Markedly, empirical WOM studies support the critical role played by consumers as persuasive orators who "shape what people know, feel and do" (Buttle, 1998, p. 241). For marketers, WOM is considered an inexpensive form of advertising (Stepchenkova et al., 2015), providing influential forms of destination information that have the capacity to alter destination image perceptions of consumers (Hanlan \& Kelly, 2005). The position of WOM as a key marketing platform is increasingly crucial given the proliferation of information communication technology (ICT), platforms that allow for immediate dissemination and access of information. The ubiquity of ICT has consequently led to the growing influence and popularity of online communities, influencers and bloggers (Buhalis \& Law, 2008; Kozinets et al., 2010; McQuarrie, Miller, \& Phillips, 2013; Volo, 2010), marking the shift in the role of consumers, from passive receivers to active consumers and producers of online information (Ritzer \& Jurgenson, 2010). The next section of this chapter describes the transformation of WOM from being informal face-to-face exchanges into eWOM (electronic WOM), rapid online exchanges mediated by technology. The following section also highlights the implications of eWOM for both organisations and consumers.

\subsubsection{Word of mouth to electronic word of 'mouse'.}

The ubiquity of online networking platforms and Internet connectivity have resulted in the evolution of WOM into its electronic form, eWOM, which transforms face-to-face interactions into rapid, mediated many-to-many exchanges that span borders, capable of influencing consumer perception and purchasing decisions (Stringam \& Gerdes, 2010; Ye et al., 2009). Litvin, Goldsmith and Pan (2008) define eWOM as:

...all informal communications directed at consumers through Internet-based technology related to the usage or characteristics of particular goods and services, or their sellers. This includes communication between producers and consumers as well as those between consumers themselves - both integral parts of the WOM flow, and both distinctly differentiated from communications through mass media... (p. 461).

Notably, the proliferation of digitally connected devices and Web 2.0 platforms such as blogs, Wikis, social networking sites, virtual communities and review sites have resulted in a more interactive and social Web (Hennig-Thurau, Gwinner, Walsh, \& Gremler, 2004; Munar \& Jacobsen, 2014) - a departure from Web 1.0, a passive one-to-many form of 
communication, usually controlled by organisations. The collaborative nature of Web 2.0 coupled with the pervasiveness of ICT has redefined the means by which consumers seek and share information. The easy access to eWOM, empowers consumers — by providing greater control over the type of information consumers attend to as well as disseminate (Daugherty \& Hoffman, 2014).

Markedly, advances in ICT are “. . . shrinking the gap between indirect and direct product experiences ..." (Roggeveen et al., 2015, p. 44), where over $80 \%$ of social media posts are found to relay information about the self or one's own immediate experiences (Naaman, Boase, \& Lai, 2010). Consequently, eWOM spread through Web 2.0 platforms becomes a key indicator of consumer satisfaction and "market signal(s) of reputation" (Amblee and Bui, 2011, p.93), found to even outweigh price in influencing consumer decisions and various aspects of travel planning and consumption (Book et al., 2018; Leung, Law, van Hoof, \& Buhalis, 2013). For organisations, digital platforms that proliferate the rapid exchange of eWOM reduces information asymmetries that were once in favour of marketing managers (Christodoulides, 2009). Thus, adding pressure on marketers to reassess traditional marketing practices, and adopt creative means in leveraging the reach, as well as perceived trustworthiness tied to online consumer networks (Dinhopl \& Gretzel, 2016; Mangold \& Faulds, 2009; Xiang \& Gretzel, 2010). Conversely, scholars argue that Web 2.0 empowers not only consumers but also marketers, where Web 2.0 is seen as an instrumental "vehicle for the sharing of information and opinions", bridging businesses to customers, and customer to customer" (Jalilvand, Esfahani, \& Samiei, 2011, p. 43).

Importantly, eWOM provides new venues and forms in which destination image can be communicated (Jalilvand \& Heidari, 2017). For example, eWOM affords greater visibility to rural and regional destinations (Mariani, Di Felice, \& Mura, 2016; Melo, Hernández-Maestro, \& Muñoz-Gallego, 2017). The findings of the study conducted by Melo et al. (2017) of lodging establishments located in rural France indicate a relationship between online presence on forums and business performance. Reports of smaller regions benefitting from social media have also surfaced. For example, Freudenberg, a small rural German town, has become a popular tourism spot, and is receiving tourists from as far away as Japan, because of their visibility on social networking site, Instagram, where more than 11,000 photographs are tagged to the town (Staudenmaier, 2019). Similarly, a sunflower farm in rural Australia has gained popularity with travellers from Japan, China and Brazil, as a result of an 
Instagram photo uploaded by the farm owner's son (Kinsella \& Border, 2019). The examples highlight the growing significance of eWOM in boosting tourism consumer awareness and visits.

Notably, the social Web strips the elusiveness of traditional WOM (Arndt, 1967b), where eWOM materialises as user-generated content (UGC) shared on platforms such as blogs, social media networks and review sites (Duverger, 2013), providing marketers a window into consumer-to-consumer conversations, and consumption behaviours that provide critical marketing intelligence for strategic destination marketing, and management (Bakri et al., 2020). The opportunities of UGC, and its role in facilitating consumer decision making, places urgency for research surrounding the UGC phenomenon in the marketing of destinations (Mariani et al., 2016).

\subsubsection{UGC as proxies of word of mouth.}

UGC is viewed as manifestations of an individual's attempt to "make sense of the world ... and communicate ideas and values" (Huang, 2017, p. 119) that disseminate multiple personal perspectives of destinations, which have the potential to enhance visibility of destination images, and influence consumer choice (A. Tham et al., 2013). UGC comes in multiple forms, such as hypertext, videos, audio and still images (Ghose \& Han, 2009).

As digital displays of consumer experience, UGC, a form of WOM, not only guides the purchasing decision of consumers largely seeking information, but also provides critical sources of market intelligence that can be harnessed to shape marketing strategies. Prior to the Internet, consumer conversations or WOM exchanges about brands, products and destinations were "almost exclusively private (and offline), and thus difficult to study without relying on questionably accurate self-report data" (Lamberton \& Stephen, 2016, p. 152). UGC, therefore, provides marketers an opportunity to observe consumer-to-consumer conversations and examine destination perceptions (Marine-Roig \& Anton Clavé, 2015). As a form of earned media, UGC represents valuable outcomes for tourism destinations, specifically given the networked reach of consumers (Ashley and Tuten, 2015) that permits marketers to target and reach globally dispersed niche markets (Mariani et al., 2016).

The rising popularity, implications as well as opportunities of UGC have led to a stream of studies in the past decade, connecting UGC to organisational reputation (Baka, 2016), tourist experience (Huang, 2017), pre-purchase evaluations (Noone \& McGuire, 2014) and 
predicting tourist preferences (Pantano, Priporas, \& Stylos, 2017). Scholars also identify the importance of engaging consumers in creating and sharing UGC (Liu, Schuckert, \& Law, 2016; Perez-Vega, Taheri, Farrington, \& O'Gorman, 2018), which subsequently provides the opportunity for the extraction of latent dimensions that allow marketers to identify salient features linked to consumer satisfaction and value (Ayeh, Au, \& Law, 2013; Guo, Barnes, \& Jia, 2017; Lu \& Stepchenkova, 2012). Notably, UGC highlights the ability and awareness of consumers as online content producers who employ a variety of stratagems to create and share persuasive content, which shape the perceptions and behaviours of their audience (Berger, 2014; Kozinets et al., 2010; Ludwig et al., 2013). For example, in a study of 83 consumer blog sites, Kozinets et al. (2010) found that bloggers (consumers) alter their messages “. .. in ways that are attuned to a range of different individual and communal factors ..." (p. 86), suggesting sensitivity and awareness in managing their audience through online discourse. Similarly, Kim and Tussyadiah (2013) demonstrate how tourism consumers adopt a variety of self-presentation strategies, when sharing content online, to garner social support from their online audience.

The growing importance of UGC as persuasive information, and of consumers as adept and influential content producers, have led to emergent research that adopts a more granular approach in examining the persuasive nature of content shared online, such as the use of consensus language (Lee \& Kronrod, 2020) and figurative language found in UGC (Kronrod \& Danziger, 2013). Although there is growing research interest in UGC as persuasive forms of WOM, the role of images in the form of user-generated images (UGI) as artefacts of WOM is overlooked (Bakri et al., 2020). In addition, recent marketing research advocates for greater understanding of the relationship between linguistics, consumer behaviour and the concept of image; where language spans both text and visuals (Carnevale, Luna, \& Lerman, 2017; Goransson \& Fagerholm, 2018). The neglect of UGI in research stands particularly true for tourism research, which "remains predominantly textocentric" as demonstrated in the following section of this chapter (Balomenou \& Garrod, 2019, p. 201).

\subsubsection{The visual turn of word of mouth.}

Advances in ICT provide consumers with the tools, and freedom to "... construct digital collages using symbols and signs to represent and express their self-concepts ..." (Schau and Gilly, 2003, p.386). Recent studies highlight the rapid rise of the digital visual culture, where words are substituted for visual images in online exchanges. Fox et al. (2018) found that 
millennials utilise visual platforms to communicate with peers, where content uploaded on Snapchat resembled everyday personal conversations. Blazevic et al. (2013) described how non-verbal expressions of consumption-related behaviours, such as posing with a favourite brand, are commonly found on social networking sites, and are becoming important forms of consumer-driven information.

Further, given the popularity of visual platforms, the digital space has become a venue for self-presentation, management and branding, where traces of consumption continue to act as cues (Belk, 2013; Fox et al., 2018; Noth, 1988; Sung, Kim, \& Choi, 2018). Images shared online are, therefore, used to articulate attributes that are perceived to relay the concept of "the good life", and advance the sharer's social standing (Marwick, 2015; Wang et al., 2017, p. 686). Physical goods, places and people shown in the background of these carefully composed visual images add to "the array of possessions" that consumers use to represent themselves to others (Belk, 2013, p. 492; Lim, 2016). Emergent studies in UGI identify selfprojection and self-branding as key drivers for sharing images online (Fox et al., 2018; Wang et al., 2017). UGI, therefore, become rich sources of data that enable researchers to examine how sojourners use their experiences, and surroundings to promote and influence destination perceptions, and motivate VFR tourism (Seaton \& Tagg, 1995; Young et al., 2007).

Despite the flexibility of the digital space in accepting content in a variety of modalities, a majority of UGC studies, in tourism and marketing, ignore the multimodal nature of UGC, focussing instead on textual forms of content as well as rating scales (King et al., 2014; Lamberton \& Stephen, 2016; Lu et al., 2018). Consequently, overlooking the rich multilayered meanings that UGI capture and convey about tourism experiences and consumer behaviours (Balomenou \& Garrod, 2019; Park \& Kim, 2018; Ying et al., 2018). Table 2.1 provides a summary of UGC studies and illustrates how tourism and hospitality literature is replete with studies that continue to focus on textual content and rating scales found on collaborative platforms, such as TripAdvisor and other review sites. 
Table 2.1: Illustrative summary of UGC articles

\begin{tabular}{|c|c|c|c|c|}
\hline Authors & Context & Text & Rating & Images \\
\hline $\begin{array}{l}\text { Berezina, Bilgihan, Cobanoglu and } \\
\text { Okumus (2016) }\end{array}$ & $\begin{array}{l}\text { TripAdvisor reviews were collected to examine the key areas that result in } \\
\text { satisfied and dissatisfied hotel customers. Adopted a text mining approach. }\end{array}$ & $\mathrm{X}$ & & \\
\hline Book et al. (2018) & $\begin{array}{l}\text { Investigates the impact of social influence in the form of written reviews } \\
\text { and price on consumer decisions as well as post-decision dissonance. An } \\
\text { experiment using manipulated traveller reviews of two resorts was } \\
\text { conducted on student subjects. }\end{array}$ & $X$ & & \\
\hline Dinçer and Alrawadieh (2017) & $\begin{array}{l}\text { Examines negative reviews shared on travel websites of luxury hotels in } \\
\text { Jordan, as well as the response time and content provided by hotel } \\
\text { management. Content analysis was conducted on data of luxury hotels in } \\
\text { Amman, found on TripAdvisor to gain strategic insights. }\end{array}$ & $X$ & & \\
\hline Duan, Yu, Cao and Levy (2016) & $\begin{array}{l}\text { Evaluates the viability of using sentiment analysis to measure hotel quality } \\
\text { performance through user reviews. }\end{array}$ & $\mathrm{X}$ & & \\
\hline Duverger (2013) & $\begin{array}{l}\text { Examines the effect of UGC on firm performance. Longitudinal study } \\
\text { using } 138 \text { hotel reviews, ratings and monthly market share. }\end{array}$ & $\mathrm{X}$ & $\mathrm{X}$ & \\
\hline Gao, Li, Liu and Fang (2018) & $\begin{array}{l}\text { Examines the influence of consumer characteristics, specifically power } \\
\text { distance on online hotel ratings found on TripAdvisor. }\end{array}$ & & $\mathrm{X}$ & \\
\hline Guo et al. (2017) & $\begin{array}{l}\text { Proposes the use of latent Dirichlet analysis as a method to extract latent } \\
\text { dimensions that underpin consumer satisfaction of hotels, from large } \\
\text { review data. }\end{array}$ & $\mathrm{X}$ & $\mathrm{X}$ & \\
\hline Hu and Trivedi (2020) & $\begin{array}{l}\text { Proposes the use of text mining of TripAdvisor reviews to identify valued } \\
\text { brand attributes and examine hotel performance, brand positioning and } \\
\text { competitive environment. }\end{array}$ & $\mathrm{X}$ & $\mathrm{X}$ & \\
\hline
\end{tabular}


Table 2.1: (continued)

\begin{tabular}{|c|c|c|c|c|}
\hline Authors & Context & Text & Rating & Images \\
\hline Huang (2017) & $\begin{array}{l}\text { Examines the differences in reviews provided by domestic and foreign } \\
\text { consumers of a restaurant in China. Data was acquired through online } \\
\text { review sites such as TripAdvisor, Virtualtourist and Dazhongdianping. } \\
\text { A textual semantic network analysis was conducted. }\end{array}$ & $\mathrm{X}$ & & \\
\hline Kim and Stepchenkova (2015) & $\begin{array}{l}\text { Evaluates the ability of consumers from the US and Korea in identifying } \\
\text { latent dimensions from UGI. Further it inspects the potential of UGI in } \\
\text { influencing viewer attitude and intentions. UGI were retrieved from online } \\
\text { open platforms: Flickr, and survey was administered via MTurk. }\end{array}$ & & & $X$ \\
\hline Lo and Yao (2019) & $\begin{array}{l}\text { Examines the relationship between expertise of reviewer, rating } \\
\text { consistency, review valance and perceived credibility of hotel reviews, } \\
\text { through an experiment conducted with a student sample. }\end{array}$ & $\mathrm{X}$ & $X$ & \\
\hline Lu and Stepchenkova (2012) & $\begin{array}{l}\text { Proposes a quantitative method of analysing text reviews found on } \\
\text { TripAdvisor to identify attributes that are central to the consumer } \\
\text { satisfaction when staying in ecolodges. }\end{array}$ & $X$ & & \\
\hline $\begin{array}{l}\text { Marine-Roig and Ferrer-Rosell } \\
\text { (2018) }\end{array}$ & $\begin{array}{l}\text { Proposes the use of compositional analysis as a method to uncover the } \\
\text { distinctions between supply-side projected and demand-side perceived } \\
\text { destination image. The analysis uses data derived from DMO produced } \\
\text { content, travel guides and travel reviews by tourists found on TripAdvisor. }\end{array}$ & $X$ & & \\
\hline Noone and McGuire (2014) & $\begin{array}{l}\text { Examines the relationship between UGC (found on online travel agent } \\
\text { sites) and price, and their impact on consumer pre-purchase value and } \\
\text { quality assessment of hotels. }\end{array}$ & $X$ & $X$ & \\
\hline Oliveira and Panyik (2015) & $\begin{array}{l}\text { Content analysis was used to analyse social media posts of travellers, to } \\
\text { examine the influence of UGC on destination brands. }\end{array}$ & $X$ & & \\
\hline
\end{tabular}


Table 2.1: (continued)

\begin{tabular}{|c|c|c|c|c|}
\hline Authors & Context & Text & Rating & Images \\
\hline Philander and Zhong (2016) & $\begin{array}{l}\text { Examines the usefulness of sentiment analysis using Twitter data for } \\
\text { hospitality and tourism research. Analysed Twitter content of hotels located } \\
\text { in Las Vegas. }\end{array}$ & $\mathrm{X}$ & & \\
\hline Prayag, Hall and Wood (2018) & $\begin{array}{l}\text { Investigates the relationship between the perceptions of bed and breakfast } \\
\text { providers towards UGC and their emotions in response to TripAdvisor } \\
\text { comments written by customers. Content analysis of TripAdvisor reviews } \\
\text { and surveys with providers. }\end{array}$ & $X$ & $X$ & \\
\hline $\begin{array}{l}\text { Rodrigues, Brochado and Troilo, } \\
(2020)\end{array}$ & $\begin{array}{l}\text { Uses review data gathered from Booking.com to identify attributes that } \\
\text { result in consumer satisfaction/dissatisfaction. Semantic analysis using } \\
\text { Leximancer. }\end{array}$ & $X$ & & \\
\hline $\begin{array}{l}\text { Torres, Singh and Robertson-Ring } \\
\text { (2015) }\end{array}$ & $\begin{array}{l}\text { Evaluates the impact of valance and volume of online TripAdvisor rating } \\
\text { and reviews on online hotel booking transactions, using multiple } \\
\text { regressions. }\end{array}$ & $X$ & $X$ & \\
\hline Tseng et al., (2015) & $\begin{array}{l}\text { Examines blogs of international tourists to China to understand the } \\
\text { articulated destination image of China through the perspective of bloggers. } \\
\text { Content analyses of blogs found on Travelblog.org and Travelpod.com } \\
\text { were conducted using Leximancer. }\end{array}$ & $X$ & & \\
\hline Wu, Pearce and Dong (2017) & $\begin{array}{l}\text { A content analysis of reviews of hotel guests in Shanghai was conducted to } \\
\text { examine attributes that contribute to positive customer experiences. Data } \\
\text { was retrieved from Agoda, a hotel booking and review website. }\end{array}$ & $X$ & $X$ & \\
\hline Zhou, Ye, Pearce and Wu (2014) & $\begin{array}{l}\text { Uses hotel reviews as a benchmarking tool for customer satisfaction. Data } \\
\text { gathered from hotel booking and review sites such as: Agoda, } \\
\text { TripAdvisor and Booking.com. }\end{array}$ & $X$ & $\mathrm{X}$ & \\
\hline
\end{tabular}


In addition, the findings of Table 2.1 align with other literature reviews in tourism and hospitality (e.g., Litvin, Goldsmith, \& Pan, 2018; Lu \& Stepchenkova, 2015; Lu et al., 2018). For example, Lu et al. (2018) highlight the abundance of studies conducted using review data, and the neglect of online UGI in tourism and hospitality research. The authors further stress that online photos shared could "provide a considerable amount of data for analysis" (p. 111).

Although much of the tourism and hospitality literature has focussed on textual content and rating scales, emergent studies have begun to examine dimensions of the UGI phenomenon such as: motives behind sharing UGI (Wang et al., 2017); differences between the composition of tourist-produced UGI and destination-produced visuals (Tussyadiah, 2010); the effects of tourist-produced UGI on destination image (Kim \& Stepchenkova, 2015); and the role of tourist-produced selfies as a new way of touristic looking and performance (Dinhopl \& Gretzel, 2016). However, the research surrounding UGI focusses on images produced by tourists. To the best of this author's knowledge there are no studies that examine the creation and sharing of UGI by residents - specifically, sojourners who blur traditional tourist/resident dichotomies, and act as key information agents for destinations. Information shared by sojourners is found to be "strongly perceived to be reliable, unique ... based on their real life and good quality" (Choi \& Wu, 2018, p. 285).

Moreover, the studies on UGI neglect to examine the intervening constructs and behavioural processes that result from the consumption of UGI, which akin to verbal and textual forms of WOM, is linked to consumer decision making. The existing relationship between sojourner and overseas network provides further value, given that a majority of studies as demonstrated in Table 2.1, is found to be retrieved from open online platforms, where the anonymity of eWOM results in "multiple layers of uncertainty for generalisability" (Lu \& Stepchenkova, 2015, p. 140). Growing consumer mistrust of paid online influencers and fake reviews (Chatzigeorgiou, 2017; Dellarocas, 2003) also suggest the continued significance of eWOM shared among consumers with existing interpersonal ties that bring the eWOM experience closer to traditional WOM (Munar \& Jacobsen, 2013). Thus, resulting in a growing need to examine the influence of interpersonal bonds and emotions on travel decision making (Narangajavana Kaosiri et al., 2019; Woosnam, Stylidis, \& Ivkov, 2020). 


\subsubsection{Tie strength in the digital age of information.}

Tie strength is the "intensity of social relations between consumers" and is recognised as a critical underlying dimension that facilitates WOM (Brown \& Reingen, 1987, p. 351). Research in consumer behaviour suggests the central position of tie strength, where stronger ties result in greater trust, as well as the seeking and sharing of advice or WOM (Mcpherson, Smith-lovin, \& Cook, 2001). Friends and family members are largely considered to share strong ties (Berger, 2014), and are primarily cited as influential sources of WOM (AlmeidaGarcía, Domígunez-Azcue, Mercadé-Melé, \& Pérez-Tapia, 2020; Hanlan \& Kelly, 2005; Marine-Roig \& Ferrer-Rosell, 2018).

Although studies in eWOM suggest the diminishing role of interpersonal elements integral to WOM (such as tie strength) (Brown, Broderick, \& Lee, 2007; Tham et al., 2013), as exemplified by the abundance of research using open collaborative networks, recent studies demonstrate contrasting results (Choi \& Wu, 2018; Hanlan \& Kelly, 2005; Meuter, McCabe, \& Curran, 2013; Munar \& Jacobsen, 2014; Nikjoo \& Bakhshi, 2019). For example, Munar and Jacobsen (2014) found that tourism consumers preferred to share eWOM to select friends or specific groups. In addition, Nikjoo and Bakhshi (2019) noted that many people preferred to keep their social media accounts private. In the same vein, Deng and Li (2018, p. 268) argue that content shared by relatives or friends is "more likely to be viewed and trusted compared to information posted by marketers".

Blazevic et al. (2013, p. 302) argues that strength of ties facilitate the sharing of online content, where individuals tend to "interact more often, exchange more information and trust each other's information more", signalling the continued importance of traditional WOM dimensions, and the significance of online interactions with friends and relatives. Moreover, a recent report published by Hootsuite, a leading social media management platform company, highlights the growing trend of small private groups, predicting the future of social media as being "less social" (Holmes, 2019).

The role of interpersonal communication among friends and relatives is particularly important in fuelling the lucrative VFR tourism market, where socially dispersed friends and relatives become important sources of destination information, and influencers of destination image (Backer, 2010; Kim \& Agrusa, 2008; Morrison, Hsieh, \& O’Leary, 1995; PenningtonGray, 2003). According to Griffin (2015), advances in ICT allow migrants, such as sojourners, to connect, maintain and nurture relationships with overseas friends and relatives 
with greater ease. He predicts that instead of replacing the need for face-to-face interaction, communication technology permits "ongoing stimulus for maintaining relationships", which could drive VFR tourism (p. 74). Notably, organic agents such as friends, acquaintances and relatives continue to be cited as the most important sources of destination information, and influencers of destination image (Hanlan \& Kelly, 2005; Marine-Roig \& Ferrer-Rosell, 2018). Nonetheless, clarity on the implications of eWOM content disseminated through sojourners, to overseas friends and relatives remain unclear, where difficulty in accessing primary sources of WOM is cited as a reason (Marine-Roig \& Ferrer-Rosell, 2018). In addition, there is a paucity of research that examines the relationship of tie strength and the content shared online, where content can be shared by a myriad of people - friends, relatives, acquaintances and strangers (Wang, Wang, \& Wang, 2018).

The next section of the thesis provides a review of VFR tourism literature, highlighting the merits of the VFR segment to tourism economies, the centrality of sojourners as potential online ambassadors, as well as the scarcity of studies that examine the implications of online interactions in VFR tourism.

\subsection{VFR tourism}

VFR tourism is identified as the oldest and most widespread form of travel, where the first known account of VFR tourism was documented in the $17^{\text {th }}$ century (Backer, 2012; Leiper, 2004). Although VFR tourism is a long-established concept, it remains marginalised, and struggles to position itself as a valuable tourism segment worthy of the attention of both academics and marketing practitioners (Backer, 2019; Morrison, Woods, Pearce, Moscardo, $\&$ Sung, 2000).

The undervalued position of VFR tourism is largely attributed to narrow descriptions that portray VFR tourism as being merely a form of obligatory travel that only occurs for the purpose of visiting friends and/or relatives. VFR tourists are viewed as tourists who do not “participate in tourism related activities” (Hu, Morrison, \& O’Leary, 2002, p. 29) nor occupy commercial forms of accommodation but instead, stay in the homes of friends or relatives (Backer, 2012). Consequently, DMOs dismiss VFR tourism, classifying VFR tourists as a tourism segment with limited economic value, perceived to "come naturally" and who are "not influenced by tourist promotions" (Morrison et al., 2000, p. 110). 
Jackson's (2003) seminal article, originally published in 1990, exposed the underestimated size, and merits of the VFR tourism segment. Notably, Jackson (2003) called for scrutiny of travel data acquired by tourism authorities that inform and shape national-level tourism strategies, demonstrating the inadequacies of such data. For example, he highlights the limitations of immigration arrival forms that are reliant on the "self-assessment" of tourists, arguing that classifications found in such forms are "by no means clear cut", particularly for VFR tourists who "could readily, and honestly, state that they were holidaymakers" (Jackson, 2003, p. 20). Thus, resulting in an underestimated representation of the VFR tourism segment, and its economic significance and contribution.

VFR tourism as a key tourism segment, has been shown to be resilient during economic downturns, able to weather issues of seasonality, and spread the economic benefits of tourism deeper into the local economy (Bischoff \& Koenig-Lewis, 2007; McKercher, 1996; Young et al., 2007). The spending by hosts add to the economic contribution and value of VFR tourism (McKercher, 1996; Young et al., 2007), where the effects of VFR tourism is particularly felt in densely inhabited conurbations with high migrant populations (Michèle Langlois, Theodore, \& Ineson, 1999; Provenzano \& Baggio, 2017; Seaton \& Palmer, 1997).

Additionally, studies reveal the multi-faceted nature of VFR tourism is driven by a variety of motives (Backer, 2008; Hu et al., 2002). VFR tourists are identified as "hybrid travellers", who "combine several trip purposes and make stops in one or more other destinations ... to maximise ... constrained time and funds to gain the greatest benefits" (Hu et al., 2002, p. 29). For example, Griffin and Nunkoo (2016) found that $14.5 \%$ of international visitors who spent a night in paid accommodation in Canada had also stayed with a friend or relative, as part of a multi-destination trip. Similarly, Dutt and Ninov (2017) revealed that visits by VFRs in Dubai were largely a component or a "part of a holiday" (p. 260). Backer (2008) on the other hand, points to the role of destination attractiveness as a motivating factor behind VFR tourism, to explain differences in the length of stay between VFRs in the Sunshine Coast and Albury-Wodonga, Australia. Moreover, multiple studies demonstrate that not all VFR tourists stay in the homes of friends and relatives (e.g., Backer, 2008, 2010; Braunlich and Nadkarni, 1995; Griffin and Nunkoo, 2016; Morrison et al., 1995).

In summary, the findings of the studies are contrary to early definitions of VFR tourism that depict VFR tourism as a form of tourism driven by obligation and for the sole purpose of visiting friends and/or relatives. Despite the discrepancies behind the conceptualisation of 
VFR tourism, the "social element" of VFR travel is argued to be a key characteristic that differentiates VFR tourism from other types of tourism segments (Munoz, Griffin, \& Humbracht, 2017, p. 481). Recognising the importance of relationships within VFR tourism, Griffin (2013, p. 235) offers a reconceptualisation of VFR tourism, as "tourism experiences that involve a prior personal relationship between a visitor and resident no matter the stated trip purpose, accommodation used, or activities engaged in".

Although the centrality of relationships in VFR tourism, and the linkages between VFR tourism and immigration have been highlighted, little is known of the role and implications of the use of online communications in the maintenance of relationships, and online exchanges between sojourners and their overseas network (Backer, 2010; Kim \& Agrusa, 2008; Liu \& Ryan, 2011; Morrison et al., 2000; Pennington-Gray, 2003). The following section outlines the central role of sojourners, within the VFR tourism system, particularly sojourners who straddle two or more destinations, and their potential as critical online ambassadors.

\subsubsection{Central role of sojourners in VFR tourism.}

Studies in VFR tourism explicate the relationship between migration and tourism (Dwyer, Seetaram, Forsyth, \& King, 2014; Jackson, 2003; Massidda \& Romano, 2015; Provenzano \& Baggio, 2017), casting light on the central role of migrants, such as sojourners, as "poles of tourist flows" (Williams \& Hall, 2000, p. 7). For example, Shanka and Taylor (2003) found that two to three family members of international students in an Australian university travelled to attend graduation ceremonies; while Lee and King (2016, p. 465) found that out of 551 international students surveyed in Taiwan, $89.4 \%$ of respondents "strongly encouraged" their friends to visit Taiwan. Figure 2.3, an expansion of Leiper's whole tourism system model (Backer, 2008), depicts the central position of sojourners in VFR tourism connecting VFR tourists to key elements of the tourism system. 


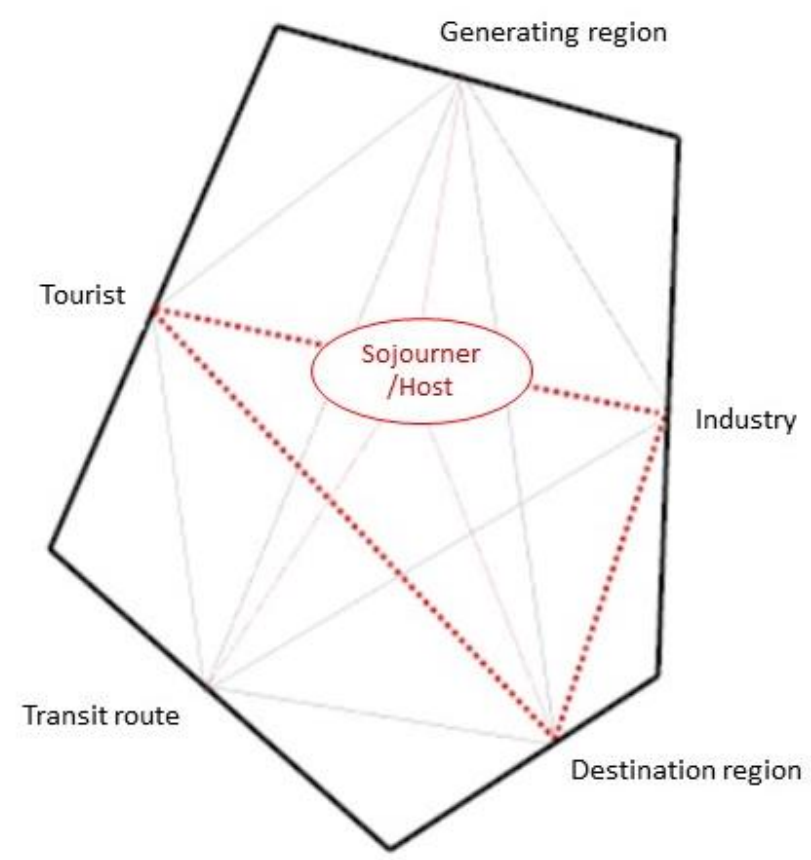

Figure 2.3: Whole tourism model for VFR tourism. (Adapted from Backer, 2008)

The tourism system was developed as an approach to study tourism in a "holistic and systematic way" (Leiper, 1995, p. 26). The five elements of the tourism system - generating region, industry, destination region, transit route and tourist — identified by Leiper (1995) form the boundaries of Figure 2.3, and are described in Table 2.2. Leiper (1995) suggests that any of the five elements can be used as a focal topic in the study of tourism. He explains that "studying tourists involves considering tourists in relation to the other four elements" within the tourism system - destination region, generating region, industry and transit route (Leiper, 1995, p. 26).

Table 2.2: Leiper's (1995) five elements of the tourism system

\begin{tabular}{ll}
\hline Element & Brief descriptions \\
\hline $\begin{array}{l}\text { Generating } \\
\text { region }\end{array}$ & $\begin{array}{l}\text { Places where trips begin, where people who will later be described } \\
\text { or counted as tourists start their journeys (p. 72). }\end{array}$ \\
Tourist & $\begin{array}{l}\text { Tourists are subsets of travellers and visitors (p. 6). } \\
\text { Industry }\end{array}$ \\
$\begin{array}{l}\text { Perceived as the supplier of everything consumed, used and } \\
\text { experienced by tourist (p. 112). }\end{array}$ \\
$\begin{array}{l}\text { Transit route } \\
\begin{array}{l}\text { An intermediate zone where the principal travel activity of tourism } \\
\text { occurs, distinct from visit activity in destinations (p. 81). }\end{array} \\
\text { region }\end{array}$ & $\begin{array}{l}\text { The feasible day-tripping range around tourist's accommodation, } \\
\text { encompassing the area that tourists visits on day trips (p. 87). }\end{array}$ \\
\hline
\end{tabular}


As potential hosts of VFR tourists, sojourners "are likely to influence, to varying degrees, the relationship of the VFR traveller with each other element in the whole tourism system" (Backer, 2008, p. 61). Specifically, the red dotted lines shown in Figure 2.3, illustrate the links between sojourners (as hosts), tourists, destination region and industry. In addition to presenting the significant relationship between sojourners and tourists - derived from the overseas networks of sojourners, Figure 2.3 highlights the link between sojourners and other facets of the tourism system; the destination region and industry, which influences sojourners' perception and representation of the destination.

Findings from an empirical study conducted by Choi and Wu (2018) indicate that sojourners are "motivated to talk about the destination region" (p. 286) and share online information. Moreover, migrants, such as sojourners, create "positive narratives to defend their mobility" as well as demonstrate their sense of pride for their current place of residence (Humbracht, 2015, p.646; Shani \& Uriely, 2012). In addition, sojourners exhibit characteristics of being on an extended form of tourism in their adoptive countries, actively seeking, "collecting, selecting, and disseminating" unique experiences during their sojourn (Choi and Wu, 2018, p. 286). Choi and Fu (2018, p. 51) further showcase sojourners' interaction with the host destination, where sojourners were found to express a desire for "unique and extensive" experiences. Consequently, the experiences acquired instil greater confidence within sojourners for exploring the host-destination.

Notably, unlike tourists the experience of sojourners is noted to be broader and deeper, given their involvement in, and exposure to, elements of the destination such as the natural environment, social relationships, workplace and history (Munoz et al., 2017; Stedman, Beckley, \& Ambard, 2004) - blurring the traditional tourist-resident dichotomy. Given their extended experience as residents in the host-destination, sojourners become destination experts, gatekeepers of destination information, who are able to shape destination perceptions, and trip activities of overseas friends and relatives (Gitelson \& Kerstetter, 1994; Liu \& Ryan, 2011; Young et al., 2007). Gitelson and Kerstetter (1994) demonstrate the significance of sojourners in the travel decision-making process of VFRs. The authors (p. 64) highlight that in many instances, residents, such as sojourners, were noted to play the "dominant or sole decision-making role" in areas such as deciding length of stay (29\%), and trip activities $(39 \%)$. 
Although studies elucidate the critical position and role of residents, in particular sojourners, in connecting destinations to extended global networks of VFRs, as well as their ability to shape destination perceptions and influence trip activities through their selective sharing of information, there is a paucity of research that examines the role of sojourners as online ambassadors and producers of online content that instigates VFR tourism.

\subsubsection{A representative overview of VFR tourism research.}

Having established the importance of VFR tourism to tourism economies and identifying the central role of sojourners within the tourism system, Table 2.3 provides a representative overview of studies surrounding VFR tourism. The literature review presented in Table 2.3 identifies the development of research focus, objectives and methods applied in VFR tourism. 
Table 2.3: Illustrative summary of VFR tourism articles

\begin{tabular}{|c|c|c|c|}
\hline Author/s & Method & Focus & Objective \\
\hline AlSaleh and Moufakkir (2019) & Qualitative & Visitor experience & $\begin{array}{l}\text { Examine the role of reversed culture shock through the experiences of } \\
\text { VFR tourists. }\end{array}$ \\
\hline Backer (2011) & Quantitative & $\begin{array}{l}\text { Visitor profile \& } \\
\text { characteristics }\end{array}$ & $\begin{array}{l}\text { Examine the relationship between VFR tourists' characteristics and length } \\
\text { of stay. }\end{array}$ \\
\hline Backer and King (2017) & Quantitative & $\begin{array}{l}\text { Visitor profile \& } \\
\text { characteristics }\end{array}$ & Examine the demographic of VFR tourists (i.e. education, age, income) \\
\hline Backer, Leisch and Dolnicar (2017) & Quantitative & VF vs VR & $\begin{array}{l}\text { Examine the differences between VFs and VRs in areas such as purpose } \\
\text { of visit, activities, demographics and expenditure. }\end{array}$ \\
\hline Bischoff and Koenig-Lewis (2007) & Quantitative & Role of resident & $\begin{array}{l}\text { Investigate the contribution of international students in attracting visits } \\
\text { from friends and relatives to the host destination. }\end{array}$ \\
\hline Capistrano and Weaver (2018) & Qualitative & $\begin{array}{l}\text { Resident-visitor } \\
\text { interaction }\end{array}$ & $\begin{array}{l}\text { Networked, multi-sited study that sought to understand the social } \\
\text { interactions, and emotional solidarity between host and friends. }\end{array}$ \\
\hline Choi and Fu (2018) & Qualitative & $\begin{array}{l}\text { Role of resident / } \\
\text { experience }\end{array}$ & Explores the characteristics of foreign sojourners' hosting experiences. \\
\hline Dutt and Ninov (2017) & Quantitative & $\begin{array}{l}\text { Resident } \\
\text { experience }\end{array}$ & $\begin{array}{l}\text { Examines the impact of VFR tourism on residents' (expatriates) learning } \\
\text { of host destination. }\end{array}$ \\
\hline Gitelson and Kerstetter (1994) & Quantitative & Role of resident & $\begin{array}{l}\text { Investigate the influence of residents on travel-related decisions of friends } \\
\text { and relatives (i.e. length of stay, activities). }\end{array}$ \\
\hline Griffin (2017) & Qualitative & $\begin{array}{l}\text { Resident } \\
\text { experience }\end{array}$ & $\begin{array}{l}\text { Investigates the impact of intra-regional hosting on cultural awareness, } \\
\text { and attachment of residents to the destination region. }\end{array}$ \\
\hline Janta and Christou (2019) & Qualitative & $\begin{array}{l}\text { Resident } \\
\text { experience }\end{array}$ & Examine the implications of hosting on female professional expats. \\
\hline $\begin{array}{l}\text { Lee, Morrison, You, Webb and Reid } \\
(2005)\end{array}$ & Quantitative & $\begin{array}{l}\text { Expenditure pattern } \\
\text { of visitors }\end{array}$ & $\begin{array}{l}\text { Examine expenditure patterns and economic contributions of French } \\
\text { VFRs visiting } 17 \text { countries. }\end{array}$ \\
\hline Lehto et al., (2001) & Quantitative & $\begin{array}{l}\text { Expenditure pattern } \\
\text { of visitors }\end{array}$ & $\begin{array}{l}\text { Examined different typology factors (sector, scope and accommodation) } \\
\text { and their impact on VFR spending. }\end{array}$ \\
\hline Liu and Ryan (2011) & Quantitative & Role of resident & Examine the role of Chinese international students as hosts. \\
\hline
\end{tabular}


Table 2.3: (continued)

\begin{tabular}{|c|c|c|c|}
\hline Author/s & Method & Focus & Objective \\
\hline Lockyer and Ryan (2007) & Quantitative & VF vs VR & $\begin{array}{l}\text { Investigate the differences between visiting friends and relatives (i.e. } \\
\text { patronage to destination attractions). }\end{array}$ \\
\hline McKercher (1996) & Quantitative & Role of resident & $\begin{array}{l}\text { Investigates residents' role in VFR tourism, and examines the viability of } \\
\text { interviewing residents to establish size and importance of VFR tourism. }\end{array}$ \\
\hline Morrison et al. (1995) & Quantitative & $\begin{array}{l}\text { Visitor profile \& } \\
\text { characteristics }\end{array}$ & Examine heterogeneity of domestic VFRs. \\
\hline $\begin{array}{l}\text { Moscardo, Pearce, Morrison, Green } \\
\text { and O’Leary (2000) }\end{array}$ & Quantitative & $\begin{array}{l}\text { Visitor profile \& } \\
\text { characteristics }\end{array}$ & $\begin{array}{l}\text { Explore the linkage between the different VFR tourist segments and } \\
\text { commercial tourism. }\end{array}$ \\
\hline Seaton and Palmer (1997) & Quantitative & $\begin{array}{l}\text { Expenditure pattern } \\
\text { of visitors }\end{array}$ & $\begin{array}{l}\text { Examine visitor spending against other tourist types, in areas such as } \\
\text { shopping, use of services and accommodation. }\end{array}$ \\
\hline Seaton and Tagg (1995) & Quantitative & $\begin{array}{l}\text { VF vs VR vs } \\
\text { VFVRs }\end{array}$ & Examine the distinctions among the different types of guests. \\
\hline Shani (2013) & Qualitative & Visitor experience & Explores the concept of being "home" and "away" among VFRs. \\
\hline Shani and Uriely (2012) & Qualitative & $\begin{array}{l}\text { Resident } \\
\text { experience }\end{array}$ & Examine the negative and positive aspects of hosting VFRs. \\
\hline Stepchenkova et al. (2015) & Quantitative & $\begin{array}{l}\text { Visitor profile \& } \\
\text { characteristics }\end{array}$ & $\begin{array}{l}\text { Examine the distinctions and segments of VFR visitors (i.e. place of } \\
\text { residence, distance travelled, accommodation type and VF or VR), } \\
\text { compares preplanning, during- and post-trip characteristics. }\end{array}$ \\
\hline Taheri, Jafari and O'Gorman (2014) & $\begin{array}{l}\text { Mixed } \\
\text { methods }\end{array}$ & $\begin{array}{l}\text { Resident-visitor } \\
\text { interaction }\end{array}$ & $\begin{array}{l}\text { Examine the performativity of resident-visitor interactions during meals, } \\
\text { develop a scale for ceremonious politeness. }\end{array}$ \\
\hline Young et al. (2007) & $\begin{array}{l}\text { Mixed } \\
\text { methods }\end{array}$ & Role of resident & $\begin{array}{l}\text { Segmenting of residents by their characteristics and involvement in VFR } \\
\text { tourism, particularly word-of-mouth behaviour. }\end{array}$ \\
\hline Yousuf and Backer (2017) & Qualitative & $\begin{array}{l}\text { Resident } \\
\text { experience }\end{array}$ & $\begin{array}{l}\text { Examine the differences in social interactions of residents hosting friends } \\
\text { vs. residents hosting relatives. }\end{array}$ \\
\hline $\begin{array}{l}\text { Zátori, Michalkó, Nagy, Kulcsár and } \\
\text { Balizs (2019) }\end{array}$ & $\begin{array}{l}\text { Mixed } \\
\text { methods }\end{array}$ & Visitor experience & Examine trip activities of domestic/short haul VFRs. \\
\hline
\end{tabular}


Studies in VFR tourism have largely focused on the volume and size of economic outcomes, and value of VFR tourism to provide concrete evidence of the significance of the VFR tourism segment (e.g., Backer, 2010, 2012; Braunlich and Nadkarni, 1995; Michèle Langlois et al., 1999). In addition, as illustrated in Table 2.3, studies in VFR tourism cast light on the homogeneity of the segment, examining the different typologies of VFRs (e.g., Backer, 2012; Moscardo et al., 2000; Pennington-Gray, 2003), and demographic characteristics of VFs and VRs, including trip and spending patterns (e.g., Backer et al., 2017; Lockyer and Ryan, 2007; Seaton and Tagg, 1995).

Similar to the extensive systematic reviews conducted by Griffin (2013b), as well as Yousuf and Backer (2015), Table 2.3 demonstrate the emphasis on quantitative methods in examining aspects of VFR tourism, where a majority of studies depended on secondary data. According to Backer and King (2017), unless scrutinised, secondary data derived from official sources "only provide basic information" that limit the ability to "understand the relationship between VFR and wider social phenomena" (p. 192). Increasingly, studies focus on social aspects of VFR tourism, such as the experience of VFRs and residents (AlSaleh \& Moufakkir, 2019; Choi \& Fu, 2018; Griffin, 2017; Shani, 2013; Shani \& Uriely, 2012), where qualitative interviews were employed to gain a deeper understanding of the social implications of VFR tourism. Griffin (2017) demonstrates the pertinence of hosting to sojourners well-being, acculturation and sense of identity. Hosting was also found to provide an opportunity for sojourners to explore the host destination.

Griffin (2017) illuminates the importance of co-created experiences gained from hosting, which are found to provide sojourners with a greater sense of attachment to the host destination, validating their decision to move. Similar to participants in Griffin's study, Choi and $\mathrm{Fu}$ (2018) found sojourners motivated in seeking unique experiences, where they actively communicated their knowledge to attract visitors. Conversely, Shani (2013, p. 11) examined the "convergence of 'home' and 'away' in the (VFR) tourist experience". Even though qualitative studies provide a more nuanced understanding surrounding the social phenomena of VFR tourism, Griffin (2013a) espouses the need for quantitative studies that utilise primary methods of data collection, to "cover the social aspects uncovered by qualitative studies", to further highlight the "missed opportunities for practitioners" (p. 798). Gafter and Tchetchik (2017) note the potential of examining intervening variables in investigating the use of ICT in VFR tourism, which is overlooked in existing literature. Seaton (2017), on the 
other hand, demonstrates the viability of using literary text as data to gain rich insights into VFR tourism, and urges scholars to explore non-standard forms of data. In addition, Table 2.3 casts light on the handful number of studies that adopt a mixed-methods approach, an approach used to provide keener insights into social, and behavioural phenomena in tourism and marketing (Azzopardi \& Nash, 2014; Davis, Golicic, \& Boerstler, 2011; Harrison \& Reilly, 2011; Molina-Azorín \& Font, 2015).

Notably, Table 2.3 emphasises the scarcity of studies that provide an integrated investigation of the interactions of residents with the host-destination as well as the residents' interactions with their overseas friends and relatives prior to the visit. In spite of the unique and fluid position of sojourners as tourists and residents as well as consumers, producers and information disseminators of tourism development and experiences (Choi \& Fu, 2018; Griffin, 2015; King \& Dwyer, 2015), research that theorises the outcomes of patterns in sojourners' communication of tourism information about the host-destination is sparse (Choi $\& \mathrm{Wu}, 2018)$.

Despite the increasing prevalence of creating and sharing content online in everyday social interactions, studies that examine online exchanges in VFR tourism are scarce (Backer \& King, 2015) - a stark contrast to the increasing research in wider tourism scholarship that examines online interactions of tourists and UGC to yield insights in shaping tourism strategies (e.g., Bosangit et al., 2015; Marine-Roig \& Ferrer-Rosell, 2018; Yang, Mao, \& Tang, 2018). In fact, the subject of online exchanges in VFR tourism is absent in both systematic content analyses of VFR tourism articles conducted by Griffin (2013a) and Yousuf and Backer (2015).

To the best of this author's knowledge, only two empirical studies in VFR tourism address the subject of ICT and online social interactions (e.g., Gafter \& Tchetchik, 2017; Tchetchik, 2015). A recent study conducted by Choi and Wu (2018), however, alludes to the importance of online interactions between sojourners and their network, where sojourners are found to be motivated to share information about the host destination and the positive outcomes tied to WOM shared by sojourners. However, none of the studies that examine ICT in VFR tourism, appear to evaluate the implications of online content (specifically sojourner-constructed images) on VFR tourism. This is despite the increasing trend of images replacing words in everyday conversations (Fox et al., 2018), the tangibility images provide experiences (Wang et al., 2017), and centrality of relationships within VFR tourism (Griffin, 2013b). 
Consequently, the implications of tie strength on online content shared by sojourners, and the role of UGI in VFR tourism are not well understood.

A limitation noted by authors studying online communications in VFR tourism is that data acquired in the studies were not dyadic or paired data (Choi \& Wu, 2018; Gafter \& Tchetchik, 2017). According to Choi and Wu (2018) connected/dyadic samples (between sojourner and overseas friend/relative) would enhance understanding of the impact of sojourners' online communications on the information recipient. Moreover, out of the 126 published works reviewed by Yousuf and Backer (2015), only five pieces of research (two journal articles, one conference proceeding and two book chapters) in VFR tourism were found to address the subject of marketing to VFRs. The scarcity in the number of studies, highlights an opportunity to examine the potential of marketing to VFRs through sojourners; specifically, the marketing of conurbations that tend to suffer tighter budgets, resources, control over stakeholders, limited commercial exposure and consumer awareness (Morgan, Pritchard, \& Pride, 2003; Peirce \& Ritchie, 2007; Pike \& Page, 2014).

VFR tourism is also a valuable target segment for crisis or disaster recovery marketing (Backer \& Ritchie, 2017). Sojourners, therefore, act as critical "international communicators" (Choi \& Fu, 2018, p. 49) that connect tourism and hospitality marketers to the profitable, yet difficult to reach international VFR segment (Chatzigeorgiou, 2017; Morrison et al., 2000; Lori Pennington-Gray, 2003).

\subsection{Underlying theories}

\subsubsection{Theory of visual rhetoric.}

The theory of visual rhetoric has roots in traditional rhetorical theory (Aristotle, 350BC/2004; Burke, 1969), which attends to strategies of verbal persuasion and interpersonal communication, such as WOM, that have a formative effect on the attitude of the information receiver (Burke, 1969; Buttle, 1998; Scott, 1994). Traditional rhetoric posits that the orator employs three forms of persuasions: ethos, pathos and logos. Ethos is identified as the personal appeal of the speaker, the way in which the speaker projects beliefs and credibility; pathos, the emotional appeal of the speech, and its ability to stir emotions; and logos, the examples and enthymeme used to support verbal discourse (Aristotle, 350BC/2004).

Scholars argue that similar to verbal content, visual images are a collection of symbols composed to perform communication, able to shape reputation, culture and the attitude of the 
receiver (Durgee, 2003; Olson, 2007). In particular, visual images are identified as enthymemes and articles of demonstration that force the audience to act in its own persuasion "by filling in that unexpressed premise" (Blair, 2004, p. 41). Defined as the way in which people "influence each other's thinking and behaviour through the strategic use of symbols" (Ehninger, 1972, p. 3), visual rhetoric gained momentum in the 1970s, where scholars called for an expanded view of the parameters of the study of rhetorical theory (Foss, 2005).

Building on the theory of visual rhetoric, research in consumer behaviour later established consumers' ability in 'reading' product attributes, and forming judgments through images (Scott \& Vargas, 2007). Similarly, research in tourism identifies the ability of consumers in inferring destination attributes from visual images, which have a formative effect on consumer perceptions (MacKay \& Fesenmaier, 1997). In extant advertising and marketing literature, visual rhetoric is used as a guiding theoretical lens and critical-analytical tool to examine the communicative dimensions of commercially produced images (Foss, 2005); where visual images comprise denoted and connoted content (Barthes, 1977).

Denoted content represents manifest objects found in images, while connoted content are latent messages concerned with "what the image signifies beyond mere appearances" (Kim \& Stepchenkova, 2015, p. 30). Specifically, studies that employ the theory of visual rhetoric primarily evaluate the taxonomy of commercially-produced images, in search for visual tropes and schemes that result in persuasion, and examine how these images are read or decoded (e.g., Campelo, Aitken, \& Gnoth, 2011; Scott \& Vargas, 2007). The theory of visual rhetoric, therefore, provides a useful lens in examining UGI of sojourners, where the paradigmatic and syntagmatic choices of denoted content found in sojourner-produced images become cues that trigger connoted meanings of destination image - a determining factor that influences visit intentions (Kim \& Stepchenkova, 2015).

A paradigmatic choice conveys meaning through differences between signs (manifest objects) included and excluded. Syntagmatic choices encompass the combination of paradigms used to form messages, where the conscious deliberation of the composition of the image parallels syntax of language or grammar used in verbal/textual communication (Mick, 1986). Thus, UGI marks the shifting role of consumers from passive receivers of information to empowered and discerning image makers, skilled in composing persuasive images that reinforce or rival firm-produced marketing rhetoric (Litvin et al., 2018). 
As a theoretical perspective, there is no "one received view" of how visual rhetoric should be studied (Bateman, 2014, p. 120; Foss, 2005). However, scholars stress the lack of, and need for, establishing testable constructs to explore the potential of visual images as rhetorical devices (Larsen, Luna, \& Peracchio, 2004; Phillips \& McQuarrie, 2004). Specifically, the need to link elements of the visual to "conceptual categories developed in social and cognitive psychology" (Phillips and McQuarrie, 2004, p.131), where the cognitive approach emphasises on the dynamic process of viewer's interaction with stimuli (Boeriis and Holsanova, 2012). However, not all visual objects are rhetoric; to qualify as visual rhetoric, "the image must be symbolic, involve human intervention, and be presented to an audience for the purpose of communicating" (Foss, 2005, p. 144).

As visual snapshots of destination experiences carefully framed and pushed to overseas networks of friends and relatives, UGI become captured forms of WOM that contribute significantly to destination image formation. In this study, visual rhetorical theory is adopted as the main underpinning theory to explain the position of sojourners as discerning visual communicators, and of the images as persuasive communicative artefacts; conceptualised in this study as image-generated word of mouth (iWOM). In this study, iWOM is viewed as visual articulations of destination experience and image that have the capacity to influence the overall impression of the receiver, and consequently visit intention.

\subsubsection{Theory of emotional contagion.}

The notion of emotions being transferable has long been discussed, resulting in the emergence of emotional contagion theory (Darwin, 1872; Hatfield, Cacioppo, \& Rapson, 1993). Hatfield, Bensman, Thornton and Rapson (2014) define emotional contagion as a multi-level phenomenon, where the "precipitating stimuli arise from one individual, act upon (i.e., be perceived and interpreted) by one or more other individuals, and yield corresponding/ complementary emotions" (p. 160). Markedly, the outcome of emotional contagion is an "attentional, emotional, and behavioural synchrony" among social entities (Hatfield et al., 2014, p. 160).

Studies that address emotional contagion theory attempt to explain how emotions are transmitted among people consciously or subconsciously in social interactions (HennigThurau, Groth, Paul, \& Gremier, 2006). Research in persuasive communication and marketing examine the influential role of emotional contagion on consumer attitude and decision making, where consumer behaviour is a "socially interactive experience" (Howard 
\& Gengler, 2001, p. 189). Hennig-Thurau et al. (2006) demonstrate how emotional displays of service employees have consequences on consumer attitude and behaviour. Nemeroff and Rozin (1994) provide insights into how emotions associated with a source can be transferred to a physical object, resulting in the evaluation of the object being desirable or undesirable.

Howard and Gengler (2001) highlight the role of emotional contagion in biasing consumer attitudes, where the results of the study demonstrate that when receivers had a positive connection with the source of the object, the emotions of the receiver of the object converges with the positive emotions of the source. Scholars further suggest that effects of emotional contagion can also be transmitted through direct sensory engagement, such as watching films and concert attendance (Coplan, 2006; Podoshen, 2013).

Central to emotional contagion theory is the relationship between the source of emotion and the receiver (Hatfield, Carpenter, \& Rapson, 2014). Specifically, pre-existing relationships and group memberships are identified to facilitate emotional contagion (Hess \& Fischer, 2013; Spoor \& Kelly, 2004). Howard and Gengler (2001, p. 190) posit that contagion theory could "have utility in explaining the effectiveness of word-of-mouth communication". Given that enduring emotions (rooted in pre-existing interpersonal bonds) influence decision making and consumption behaviours, the theory of emotional contagion provides a basis for explaining and understanding the intervening function of tie strength in VFR tourism, where image-generated word of mouth (iWOM) become objects that not only communicate attributes of destination image, but also transmit emotion or "essence" of the sojourner (Nemeroff \& Rozin, 1994, p. 159).

\subsection{Chapter summary}

Despite the increasingly critical role of UGI as representations of destinations, and of consumers as creators and broadcasters of visual information (Bakri et al., 2020; Ring et al., 2016), the literature review highlights the overlooked position of UGI in the extant literature. The literature review further highlights the paucity in research that explores the use of ICT in VFR tourism. This study, therefore, fills the following research gaps:

- Lack of empirical research that examines the role and nature of UGI as WOM, able to shape viewer impression

- Lack of empirical research investigating the role of sojourners as online ambassadors 
- Lack of empirical research examining the online interactions between sojourners and extended VFR markets, and the impact of tie strength as well as relationship type on online content.

Drawing on the theories of visual rhetoric and emotional contagion, the next chapter addresses the identified research gaps in the existing literature, by presenting the concept of iWOM and developing the research model. The research model is developed in order to investigate the phenomenon of the exchange of UGI as visual forms of WOM, and its potential implications on VFR tourism. 


\section{CHAPTER 3. Conceptual model and hypotheses}

Chapter 2 provided a review of the research literature and the underpinning theories that form the foundation for the current research and research model. This chapter expands on the extant literature established in destination image, WOM/eWOM and VFR tourism. The conceptual model and hypotheses to be tested are presented. The conceptual model takes into account the role of viewer Impression in mediating the relationship between sojourner iWOM and viewer Intention to visit. In addition, this study considers the moderating effects of Tie strength and Type of relationship between the sojourner and the iWOM viewer (friend/relative). The hypotheses tested in this study are also outlined in this chapter.

\subsection{Conceptual model}

Building on the theories of visual rhetoric and emotional contagion, this study introduces the concept of iWOM. Similar to verbal/textual forms of WOM, iWOM, derived from sojournerproduced UGI, is predicted to have the capacity to influence viewer impression and subsequent intention to visit. In addition, this model accounts for the moderating effects of tie strength and relationship type. The conceptual model tested for this study is presented in

Figure 3.1.

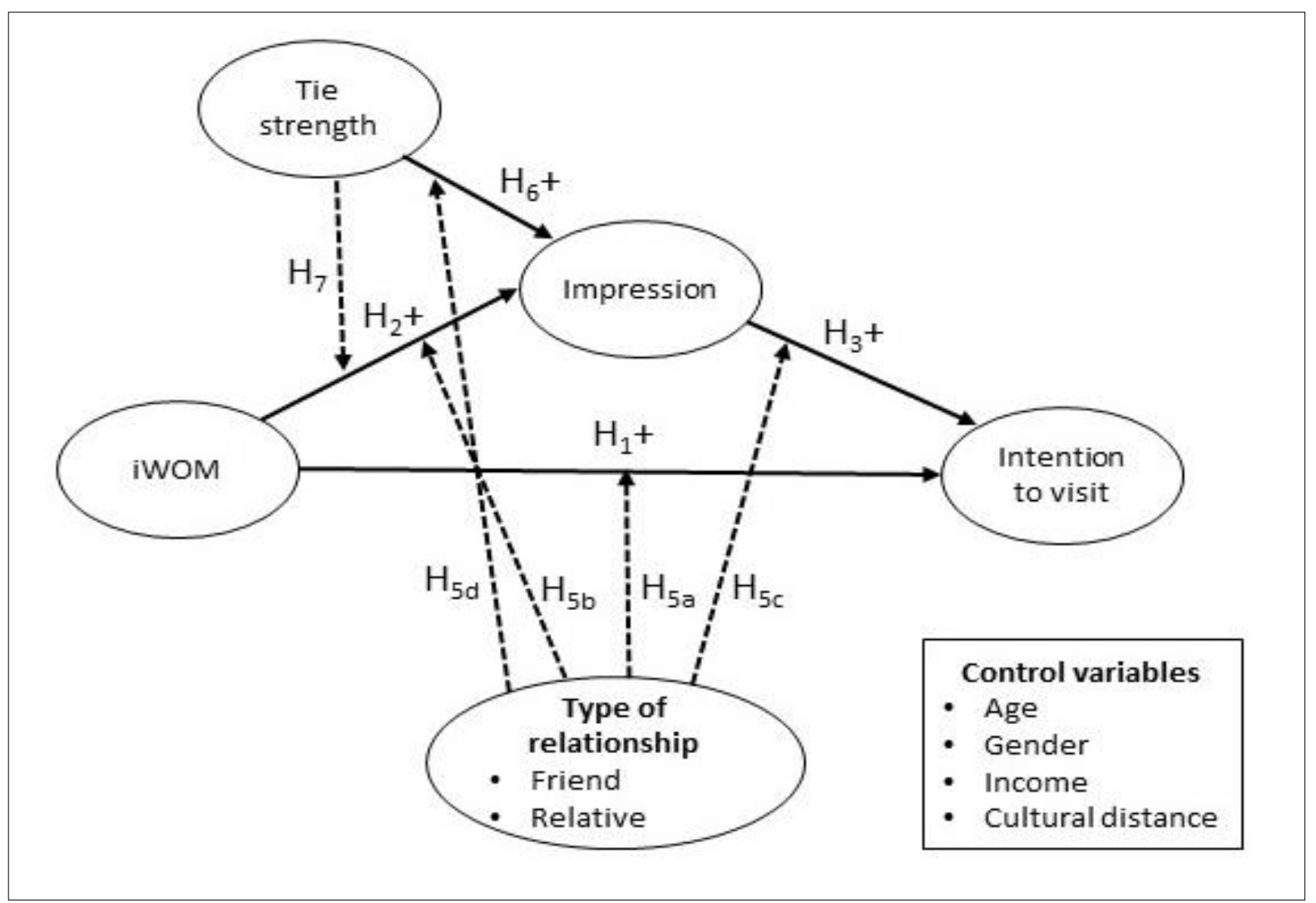

Figure 3.1: Conceptual model summary 


\subsection{1 iWOM and Intention to visit.}

Drawing from theory of visual rhetoric, visual images are more than analogues of reality, they are composed messages in symbolic form, where the coding and decoding of images is bound by cultural ideological conventions and vocabularies within a society (Barthes, 1977; Riffe, Lacy, \& Fico, 2005). The formation of connoted meanings of destination image is a result of the dynamic process of a viewer's interaction with visual stimuli (Boeriis \& Holsanova, 2012), where consumers have been found to gather meaning from visual images (MacKay \& Fesenmaier, 1997; Scott \& Vargas, 2007).

Consequently, akin to traditional verbal/textual forms of WOM, this study proposes that iWOM is able to carry messages of destination image that influence consumer decision making. Given that sojourners are found to create "positive narratives to defend their mobility" (Humbracht, 2015, p. 646), it is expected that iWOM pushed to friends and relatives would be positive in nature. Moreover, studies that examine visual images in tourism note the primarily positive depictions of destinations in tourist-produced images (Deng \& Li, 2018; Garrod, 2008). Similar to DMO produced images; "photographs showing litter or unattractive landscapes, for example ... are also a rarity" in images produced by tourists (Balomenou \& Garrod, 2019, p. 206).

According to Pellemans (1971, p. 15) the nature of information influences consumer intention or future behaviours, where "net favourable information is positively related to intention". Studies in WOM lend support to this argument: positive WOM is found to result in positive consumer outcomes, such as visit intentions (Chevalier \& Mayzlin, 2006; Choi \& Wu, 2018; Kwok, Xie, \& Richards, 2017; Jalilvand, Samiei, Dini, \& Yaghoubi Manzari, 2012). Thus, it is anticipated that the positive messages and attributes of destination image, communicated through sojourner shared iWOM, would have a positive effect on intention to visit. The following hypothesis is, therefore, proposed:

H1: Sojourner iWOM has a positive influence on viewer (friend/relative) Intention to visit.

\subsection{2 iWOM and Impression.}

Although positive iWOM is expected to result in intention to visit, the extent to which the intention occurs is dependent on viewer's impression or "learned disposition" of the attractiveness of the destination image conveyed through iWOM (Dichter, 1985; Fishbein \& Ajzen, 1975, p. 15). Scholars stress that the perceived attractiveness of the destination's 
image, built upon cognitive and affective attributes, plays an influential role in the overall attitudinal evaluation or global impression of tourism consumers towards a destination (Baloglu \& McCleary, 1999; Echtner \& Ritchie, 2003; Zhang et al., 2014). The overall image of the destination is conceptualised as a holistic impression of a destination (Beerli \& Martin, 2004a; Echtner \& Ritchie, 2003; Zhang et al., 2014). According to Ajzen and Fishbein (2000, p. 4) the overall attitudinal evaluation or global impression is "determined by the subjective values or evaluations of the attributes associated with the object and by the strength of these associations".

According to rhetorical theory, people have the agency to use language to "effect a change in knowledge, the understanding, the ideas, the attitudes, or the behaviour" of others (Bryant, 1972, p. 25). Studies in UGC make evident the ability of consumers in employing a variety of strategies in creating and sharing persuasive content (within a consumer-to-consumer context) that shape attitudes of their audience (Berger, 2014; Kozinets et al., 2010; Ludwig et al., 2013; Wang, 2011). Notably, the online space is viewed as a venue for the projection of the extended self, where possessions "serve as cues for others to form impressions" (Belk, 2013, p. 478). Aligned with Belk's reasoning, emergent studies in UGI make evident the role of UGI as an artefact of consumer culture, used for self-branding and impression management (Fox et al., 2018; Lo \& McKercher, 2015; Rokka \& Canniford, 2016). For example, even though tourists are found to share snapshots of food experiences online to stay socially connected, Wang, Kirillova, and Lehto (2017, p. 686) revealed that the images also functioned to project an ideal self-image of the sharer, where the sharing of images was noted to be a calculated effort "to ensure that they (tourists) were in control of their image". Moreover, tourists were found to expect "others to validate a certain image projected through the shared content" (p. 686). In addition, in a study of user-generated advertisements, Rossolatos (2017) illustrates how consumers are able to express themselves creatively, tapping cultural contexts, and embedding cultural codes into their arrangement of narratives. Likewise, sojourners collect, select and disseminate unique experiences in their interpersonal communication with their overseas network (Choi \& Wu, 2018), where sojourners are also found to justify their choice for moving (Humbracht, 2015), and display a sense of pride towards the host destination (Shani \& Uriely, 2012). Therefore, it is predicted that sojourners' motivation for impression management, coupled with their understanding of the audience, results in the careful and conscious construction of iWOM. Consequently, iWOM is predicted 
to have a positive influence on viewer impression towards the host destination. Hence, the following hypothesis is proposed:

H2: Sojourner iWOM has a positive influence on viewer Impression.

\subsubsection{Impression and Intention to visit.}

Prior research identifies the link between overall attitude and consumer intentions (e.g., Di Pietro, Di Virgilio, \& Pantano, 2012; MacKenzie, Lutz, \& Belch, 1986; Papadimitriou, Kaplanidou, \& Apostolopoulou, 2018; Ting, Fam, Jun Hwa, Richard, \& Xing, 2019). Destination image studies demonstrate the relationship between the overall impression/attitude towards a destination and travel intentions (Afshardoost \& Eshaghi, 2020; Beerli \& Martín, 2004a; Bigné Alcañiz et al., 2009; Chen \& Tsai, 2007; Choi, Tkachenko, \& Sil, 2011; Hudson et al., 2011; Jalilvand \& Heidari, 2017; Kim \& Stepchenkova, 2015; Papadimitriou et al., 2018). Collectively, these studies in destination image suggest that the more favourable the impression of the traveller has towards the destination and its perceived attributes, the greater the probability of an intention to visit.

Consumer intentions are subjective probabilities that a consumer would carry out an identified behaviour (Fishbein \& Ajzen, 1975), where a positive relationship between intention and actual purchase is noted in consumer decision-making literature (Pellemans, 1971). Unsurprisingly, behavioural intentions are used as proxies to measure future actual behaviour (Wang, 2011).

Notably, research in VFR tourism identify destination attractiveness as a motivating factor for driving visits of friends and relatives (Backer, 2008; Gafter \& Tchetchik, 2017; Tchetchik, 2015). Thus, it is anticipated that iWOM would stimulate an impression of the host destination, which affects the viewer's intention to visit. Specifically, given that the iWOM shared by sojourners are anticipated to communicate positive attributes of the destination, the following hypothesis is proposed:

H3: Viewer Impression has a positive influence on Intention to visit.

\subsubsection{Mediation effect of viewer Impression.}

Building on the proposed main effects, this study further predicts that viewer Impression mediates the relationship between iWOM and viewers' Intention to visit. This prediction is supported by prior research that examines the link between consumers' impression/attitude 
and intention (Ayeh et al., 2013; Bigné Alcañiz et al., 2009; Jalilvand \& Samiei, 2012; Papadimitriou et al., 2018; Stylidis, Belhassen, et al., 2017).

Howard and Sheth (1969, p. 135) explain that a mediator, in a buyer-behaviour context, can be viewed as a "structured sequence of internal stimuli and responses" or informationprocessing rules, where the stimuli and responses "become associated through either experience or information". According to Bramwell and Rawding (1996, p. 202), the projected destination image can be considered as "ideas and impressions of a place that are available for people's consideration". In this study, it is viewed that the overall impression garnered from the projected image attributes relayed via iWOM becomes information that mediates or facilitates the relationship between iWOM and intention to visit.

Following previous studies and the reasoning provided for the relationship between iWOM and Impression $\left(\mathrm{H}_{2}\right)$; and Impression and Intention to visit $\left(\mathrm{H}_{3}\right)$, this study proposes that the relationship between iWOM and Intention to visit is mediated by the impression that the iWOM receiver holds towards the host destination from exposure to the iWOM. This prediction is reflected in the following hypothesis:

H4: The relationship between sojourner iWOM and viewer Intention to visit is mediated by viewer Impression.

\subsubsection{Effect of Type of relationship on Intention to visit.}

Studies in VFR tourism make evident the differences in characteristics and behaviours of visiting friends (VFs) and relatives (VRs) (Backer, Leisch, \& Dolnicar, 2017; Lockyer \& Ryan, 2007; Seaton, 1997; Seaton \& Tagg, 1995; Seaton \& Tie, 2015). For example, Lockyer and Ryan (2007, p. 64) found visits from VFs were motivated by "excitement and fun", where friends were more likely to visit bars and nightclubs. In contrast, visits from VRs were motivated by "family relationships" that gravitated towards "the use of facilities that appeal to family outings with young children or older relatives" (p. 64). The authors further attributed the differences in activity patterns to characteristic variances between VFs and VRs, where VFs tended to be younger (Lockyer \& Ryan, 2007).

Similarly, age difference between VFs and VRs were noted by Seaton and Tagg (1995), who also observed different trip patterns of the two subgroups. Specifically, VRs were found to stay in the homes of the host in comparison to VFs; and VFs were found to make shorter trips than VRs, and consistent with Lockyer and Ryan's (2007) findings, "spent more on 
entertainment and drinks" than VRs that were noted to spend more on souvenirs and gifts (Seaton \& Tagg, 1995, p. 13). The differences in characteristics as well as behaviours between VFs and VRs resulted in suggestions for separate marketing strategies for the two subgroups (Backer et al., 2017). Collectively, the studies in VFR tourism that distinguish VF from VR, act as a reminder of the heterogeneity of the VFR tourism segment, where an aggregated view of the segment could "conceal important internal difference within the category" (Seaton, 1997, p. 55).

Incidentally, scholars in eWOM demonstrate utility in disaggregating different sources of eWOM in shaping marketing strategies, where formative product information can spread through a myriad of sources such as friends, family members and strangers, resulting in differing consumer behavioural outcomes (e.g., Baker, Donthu, \& Kumar, 2016; Narangajavana Kaosiri et al., 2019; Papadimitriou et al., 2018; Seo, Kim, Choi, \& Li, 2019). For example, Baker et al. (2016) examined the relationship between tie strength and purchase, as well as retransmission intentions. In their study, a strong tie was identified as a relationship with a spouse/partner, family member, best friends or personal friend, while weak tie was identified as a relationship with a co-worker, acquaintance or stranger. The results of the study indicate differences in the influence of the different groups on consumer behaviour, where eWOM spread by strong ties (i.e., family members and close friends) were found to result in a more substantive direct impact on purchase and retransmission intentions, in comparison to weak ties (i.e., acquaintances and strangers). Moreover, studies in VFR tourism highlight the distinction between the social interactions of friends and relatives, where friendships are noted to be voluntary and free from formal institutional bonds that are embedded in familial ties (Capistrano \& Weaver, 2017, 2018; Gafter \& Tchetchik, 2017).

The findings of prior research, specifically the characteristic and behavioural differences of VFs and VRs, as well as the arguments provided to examine the distinction between the subgroups, and among sources of WOM, solidify the pertinence of examining the role of relationship type on the evaluation of iWOM. The ability to disentangle the influence of iWOM on the friends and relatives of sojourners could provide insights into the influence of sojourners on the two subgroups, as well as the complex decision-making process of friends and relatives that could help shape targeted VFR marketing strategies. This study, therefore, hypothesises the following relationships: 
H5a: The strength of the relationship between sojourner iWOM and viewer Intention to visit is dependent on the Type of relationship between sojourner and the viewer of iWOM.

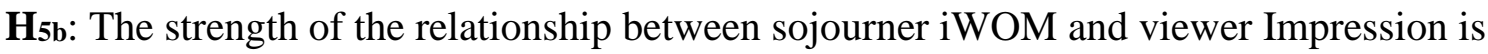
dependent on the Type of relationship between sojourner and the viewer of iWOM.

H5c: The strength of the relationship between viewer Impression and Intention to visit is dependent on the Type of relationship between sojourner and the viewer of iWOM.

H5d: The strength of the relationship between Tie strength and viewer Impression is dependent on the Type of relationship between sojourner and the viewer of iWOM.

\subsubsection{The moderating role of Tie strength}

Tie strength has been identified as a key antecedent of WOM that influences consumer behaviour and decision making (Bansal \& Voyer, 2000; Brown \& Reingen, 1987; Crompton, 1981; Narangajavana Kaosiri et al., 2019; Wang et al., 2018). Strong ties are perceived to be shared among friends as well as relatives (Berger, 2014; Blazevic et al., 2013; Narangajavana Kaosiri et al., 2019), where friends and relatives are consistently noted as preferred sources of travel information (Almeida-García et al., 2020; Hanlan \& Kelly, 2005; Marine-Roig \& Ferrer-Rosell, 2018).

Although the influence of tie strength in the online environment has come into question (Brown et al., 2007; Tham et al., 2013), research such as that conducted by Narangajavana Kaosiri et al. (2019), signals the continued relevance and influence of eWOM shared by strong ties, such as friends and relatives. In their study of 375 tourists in Valencia, Spain, Narangajavana Kaosiri et al. (2019) found that UGC produced by strong ties had more influence on tourist expectations and satisfaction with a destination compared to weak ties. Specifically, the authors observed that strong ties were instrumental in generating expectations of both core resources/main attractions that motivate travel (i.e., unique aspects tied to culture/history, key tourism events/festivals, and tourism superstructures/well-known architecture) and supporting/psychological factors (i.e., hospitality/friendliness of the locals, service quality and safety/security), while weak ties were only able to influence supporting factors. Thus, demonstrating the continued pertinence of strong ties in informing the overall impression of tourism consumers. 
In VFR tourism, the relationship between the sojourner and the friend or relative is a critical element in influencing visits, and differentiating VFR tourism from other forms of tourism (Munoz et al., 2017). Personal messages from friends and relatives, particularly among migrants are argued to carry "more weight" in shaping the overall impression of a destination's image (Boulding, 1956, p. 88), where information from strong ties is perceived to be more credible (Cheung, Luo, Sia, \& Chen, 2009) and more useful (Levin \& Cross, 2004) than information from impersonal sources or weak ties. Moreover, research in emotional contagion theory suggests greater emotional affinity among individuals with positive interpersonal ties, where emotions are capable of influencing judgments (Hess \& Fischer, 2013; Nemeroff \& Rozin, 1994).

Building on extant research, and drawing on emotional contagion theory, where studies demonstrate how objects and mere memories or reminders related to the source can shape attitudes (Hasford, Hardesty, \& Kidwell, 2015; Howard \& Gengler, 2001; Nemeroff \& Rozin, 1994), this study predicts that tie strength is an intrinsic determinant that influences the overall impression of the iWOM viewer towards the host destination. Hence, the following hypothesis is proposed:

H6: Tie strength has a positive effect on viewer Impression.

As established in section 3.1.2, objects and sensorial stimuli can act as vectors of emotional contagion (Coplan, 2006; Nemeroff \& Rozin, 1994). Jacobsen and Munar (2012) argue that eWOM allows not only the transference of knowledge but also emotional and experiential aspects of travel. Thus, as captured forms of WOM and sensorial stimuli shared online, iWOM becomes primed to transmit the knowledge, emotion and experiences of sojourners in the host destination. According to studies in visual rhetoric, visual images have an advantage over verbal or textual content in communicating "spatially oriented, nonlinear, multidimensional, and dynamic" experiences (Foss, 2005, p. 143) and emotional contexts (Birdsell \& Groarke, 2007).

In addition, Howard and Gengler (2001, p. 198) demonstrate how the degree of relational bonds and interpersonal liking results in "greater sensitivity and receptivity" of the receiver towards the sender of the emotion. Findings of Nemeroff and Rozin (1994) further illustrate the centrality of ties in influencing behaviour, where respondents reacted negatively towards a sweater that belonged to a person they disliked. The following quote from a participant in 
Nemeroff and Rozin's (1994) study describing an enemy's sweater provides context to this argument:

"I just don't want to be around him or his objects ... Because he'd give it cooties, not that I think he has cooties - but he's just a nasty person and oozes nastiness ... It's the fact that he came into contact with it (sweater)” (p. 178).

Building on the findings of prior studies in emotional contagion and the reasoning for $\mathrm{H}_{2}$, it is predicted that the impression held by the viewer of iWOM towards the host destination is contingent on the strength of the tie between the sojourner and the friend or relative.

Consequently, the relationship between impression and tie strength is anticipated to strengthen the subsequent positive effect on intention to visit, as proposed in $\mathrm{H}_{3}$. Given the chain of reasoning, the following hypothesis is proposed:

H7: The strength of the indirect relationship between sojourner iWOM and Intention to visit, via viewer Impression, is contingent on the intensity of Tie strength.

\subsubsection{Control variables.}

Control variables are included in research in order to control for potential confounding causal explanations of observed relationships (Klarmann \& Feurer, 2018). In the review of the literature, demographic characteristics such as age, gender and income are factors found to influence travel behaviours of consumers (Baloglu \& McCleary, 1999; Beerli \& Martín, 2004a; MacHado, 2010; San Martín \& Rodriguez del Bosque, 2008). Similarly, age, gender and income are identified as common control or explanatory variables used in VFR studies (Backer \& King, 2017; Gafter \& Tchetchik, 2017; Lockyer \& Ryan, 2007; Tchetchik, 2015). Beyond demographic variables such as age, gender and income, cultural distance is also noted to affect travel intentions (Manosuthi, Lee, \& Han, 2020; Ng, Lee, \& Soutar, 2007). Cultural distance is viewed as a derived construct of culture, and captures the extent to which the culture of the origin nation of the traveller differs from that of the host destination (Manosuthi et al., 2020; McKercher \& Chow So-Ming, 2001). Manosuthi et al. (2020) stress that it is "unrealistic" to ignore controlling for cultural distance, given that tourists are "culture-bound by nature" (p. 2). In account of the dispersed locations of the friends and relatives of sojourners, it was deemed necessary to include cultural distance as a control variable. In summary, this study controls for the following variables: age, gender, income and cultural distance. 


\subsection{Chapter summary}

Drawing on the theories of visual rhetoric and emotional contagion, this chapter described the proposed conceptual model - the main variables under investigation and control variables considered. The linkages between each main variable and hypotheses were proposed for testing. Table 3.1 provides an overview of the proposed hypotheses. This study examines iWOM as potential triggers of VFR tourism. Further, this study investigates the position of consumers, in particular sojourners as visual content creators, able to construct persuasive images that influence the decision making of potential overseas VFs and VRs. This chapter also takes into account the probable interaction and influence of tie strength with iWOM, in shaping viewer impression of the host destination. Further, the moderating role of relationship type is also considered. In Chapter 4, the research methodology used to carry out the research and answer the research questions will be discussed.

Table 3.1: Summary of hypotheses proposed

H1: Sojourner iWOM has a positive influence on viewer (friend/relative) Intention to visit. H2: Sojourner iWOM has a positive influence on viewer Impression.

H3: Viewer Impression has a positive influence on Intention to visit.

H4: The relationship between sojourner iWOM and viewer Intention to visit is mediated by viewer Impression.

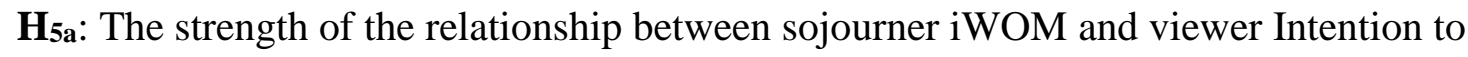
visit is dependent on the type of relationship between sojourner and the viewer of iWOM. H5b: The strength of the relationship between sojourner iWOM and viewer Impression is dependent on the type of relationship between sojourner and the viewer of iWOM.

H5c: The strength of the relationship between viewer Impression and Intention to visit is dependent on the type of relationship between sojourner and the viewer of iWOM. H5d: The strength of the relationship between Tie strength and viewer Impression is dependent on the type of relationship between sojourner and the viewer of iWOM.

H6: Tie strength has a positive effect on viewer Impression.

H7: The strength of the indirect relationship between sojourner iWOM and Intention to visit, via viewer Impression, is contingent on the intensity of Tie strength. 


\section{CHAPTER 4. Research methodology}

The purpose of this chapter is to specify the research setting, detail the rationale behind the choice of research paradigm, overarching mixed-methods design, as well as the data collection, sampling and analytical processes used in this study. Importantly, this chapter provides a detailed account of the steps taken in this research.

\subsection{The research setting}

As established in literature, VFR tourism is closely linked to migration. According to Provenzano and Baggio (2017), the larger the stock of immigrants in a country the higher the flow of incoming tourists. Destinations with high migrant populations, such as locations with international students and expatriate communities, therefore, become research settings for VFR tourism studies (e.g., Dutt \& Ninov, 2017; Janta \& Christou, 2019; Shanka \& Taylor, 2003).

In recent years, New Zealand has seen a steady increase in the number of migrants, in particular sojourners such as international students and migrant workers. Figure 4.1 provides an overview of the estimated number of sojourners entering New Zealand with a work or student visa between 2004 and 2019. Figure 4.1 highlights a steady increase in the number of work visa holders entering New Zealand. Although international student numbers have fluctuated, Figure 4.1 shows a general upward trend in the number of international students entering New Zealand, since 2004. VFR tourism is also noted to be an important tourism segment for New Zealand, and is demonstrated to be the second largest tourism segment after the leisure segment ("Key tourism statistics," 2020).

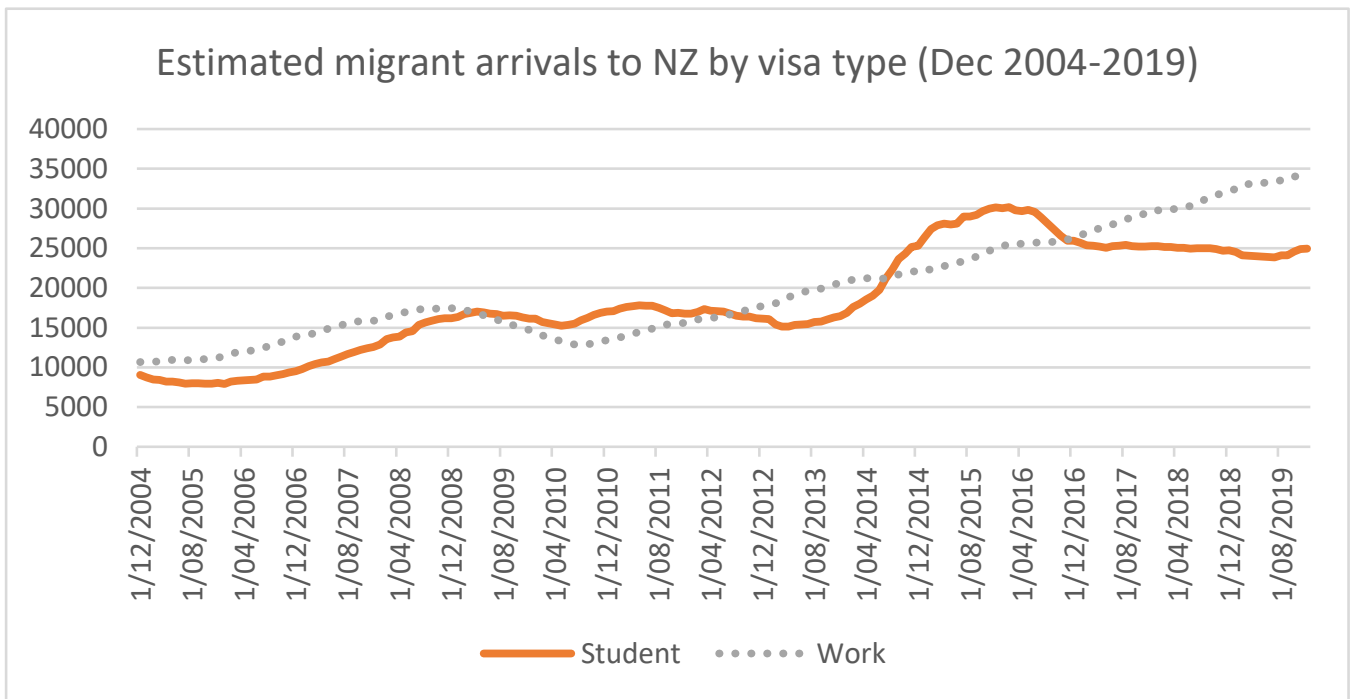

Figure 4.1: Estimated migrant arrivals by visa type (Source: Stats NZ, 2020) 
Densely populated conurbations (townships with urban centres) with modest tourist developments, have been the focus and setting for VFR tourism studies (e.g., Lockyer \& Ryan, 2007; McKercher, 1996; Stepchenkova et al., 2015); in particular urban conurbations that tend to fall outside popular tourism centres. For example, Stepchenkova et al. (2015) captured the importance of VFR tourism to Nizhni Novgorod, the fifth largest urban centre in Russia, where VFR tourism (40\%) exceeds arrivals from business (35\%) and leisure (25\%) segments. The city is described as a "multi-functional city" with resources able to cater to tourist needs but lacking the exposure of more developed tourism areas (p. 236).

The Greater Wellington Region (Wellington), is a conurbation and the capital city of New Zealand. Wellington has an estimated population of 527,800, and encompasses the following areas: Kāpiti, Hutt Valley, Porirua, Wairarapa and Wellington City ("The Wellington Region — current population estimate," 2019). Wellington has also seen gains in the number of skilled migrant workers and international students (Ministry of Business Innovation and Employment, 2018), offering a suitable sampling frame for this study. In addition,

Wellington is an emerging tourism destination, where tourism contributes significantly to the economic wellbeing of Wellington, and wider New Zealand (Kenny, 2018; Pearce et al., 2004).

With a number of growing tourist developments and events, such as Visa Wellington On A Plate, World of Wearable Art, Te Papa (New Zealand's National Museum), the Wellington Parliament House and the Martinborough Wine Village, the region has been steadily expanding its tourism prowess, and has set its sights on attracting extended tourism markets. In 2018, tourism spending in Wellington was reported at a record-breaking NZ\$2.5 billion (Hunt, 2018). Although named by Lonely Planet as "one of the coolest little capitals in the World", with an abundance of restaurants, cafes, events and an infrastructure for tourism, Wellington continues to compete with more established destinations in New Zealand, such as Auckland and Queenstown, for tourism revenue (Devlin, 2018). Research suggests that despite its available infrastructure, tourism distribution channels overlook Wellington as a marketable New Zealand destination (Pearce et al., 2004).

The growing migrant population and burgeoning tourism industry, therefore, signal the appropriateness of Wellington as a sampling frame for this study, where similar to the research conducted in Nizhni Novgorod, Russia by Stepchenkova et al. (2015), Wellington is a conurbation that has the resources to meet the needs of tourists but requires greater 
exposure as a tourism destination, and has the potential to benefit from the VFR tourism market.

\subsection{Research paradigm}

Paradigms are defined as worldviews that are "general philosophical orientations about the world and the nature of research" (Creswell, 2014, p.6). Paradigms inform and guide research, and differ largely in their philosophical assumptions of the nature of reality (ontology), knowledge (epistemology), values (axiology), research strategies (methodology) and procedures (methods) (Azzopardi \& Nash, 2014; Giddings \& Grant, 2006).

Two predominant paradigms used in the social sciences are positivism and interpretivism (Hudson \& Ozanne, 1988; Paré, Trudel, Jaana, \& Kitsiou, 2015). Positivism takes a realist view, where the assumption is that there is a single, objective reality independent of what individuals believe (Crotty, 1998; Harrison \& Reilly, 2011). Positivists seek relationships among constructs, through quantifiable measures, where their deterministic approach to the natural sciences is transposed onto the social sciences (Azzopardi \& Nash, 2014). These measures are used as instruments for making predictions that provide generalisable explanations of the phenomena under study (Hudson \& Ozanne, 1988; Hunt, 2003; O'Leary, 2004).

In contrast, interpretivists are driven by the need to understand, not predict, behaviour (Crotty, 1998). The interpretive researcher views "understanding as more of a process than an end product" (Hudson \& Ozanne, 1988, p. 510). Interpretivism acknowledges and explores the cultural and historical interpretations of the social world, which is perceived to be made up of multiple realities that are socially constructed (Harrison \& Reilly, 2011; O’Leary, 2004). Therefore, given the complexity of the social world, "one never achieves the understanding; one achieves an understanding” (Hudson \& Ozanne, 1988, p. 510). In consideration of the research objectives and questions of this thesis as well as the researcher's perspective on reality, the postpositivist paradigm, which is rooted in positivist perspectives of examining data to find strategic patterns, informs this research (Creswell, 2014). However, unlike positivism, postpositivism "turns away from the traditional understanding of scientific proof or verification to a discursive, contextual understanding of social inquiry" (Fischer, 1998, p. 130), where it rejects the certitude of the underlying principles of positivism that require the separation of facts and values. Instead of absolute 
certainty, postpositivism proposes presuppositions and probability, and positions truth as being tied to context (Alexander, 1983; Tanlaka, Ewashen, \& King-Shier, 2019).

According to Rakić (2012) the study of visual images in tourism can be rooted in a postpositivist perspective, where visual images are viewed as depictions of reality, able to provide objective knowledge and insights. Moreover, postpositivism is pluralist in nature and allows for the "exercise of a multi-methodological range of intellectual criteria, both qualitative and quantitative" (Fischer, 1998, p. 137), giving the researcher the flexibility to choose from multiple methods in accordance to the nature of the research (Cook, 1985; Giddings \& Grant, 2006; Panhwar, Ansari, \& Shah, 2017).

\subsection{Research methods and design}

This research employs a mixed-methods design, where quantitative and qualitative data, from interviews, surveys as well as images submitted by sojourners are used to gain a richer and deeper understanding surrounding the complex and social iWOM phenomenon in the marketing of destinations in extended VFR markets.

\subsubsection{The mixed-methods approach.}

Mixed method is broadly defined as a line of inquiry where the researcher "collects and analyses data, integrates the findings, and draws inferences using both qualitative and quantitative approaches or methods in a single study or a program of inquiry" (Tashakkori \& Creswell, 2007, p. 4). The goal of mixed-methods study is to gain a deeper, richer and more comprehensive understanding of the phenomenon of interest (Giddings \& Grant, 2006; Greene, 2007; Johnson \& Onwuegbuzie, 2004; Venkatesh, Brown, \& Bala, 2013). However, similar to other methods in research, mixed methods possess weaknesses that must be considered, such as: being resource intensive; difficult for a single researcher to administer; the need for the researcher to learn both quantitative and qualitative methods, as well as the challenge of educating others of the value of the mixed-methods - given the relative newness of the mixed-methods approach (Creswell \& Plano Clark, 2018; Johnson \& Onwuegbuzie, 2004).

Despite the identified weaknesses, the flexibility of mixed-methods designs enable researchers to leverage the depth and richness of qualitative methods, using text, narratives and visual images, and the strengths of quantitative techniques of inquiry that enhance validity and generalisability (Greene, Carcelli, \& Graham, 1989; Johnson \& Onwuegbuzie, 2004; Lieber \& Wesiner, 2010; Rakić, 2012). Further, when executed well, mixed-methods 
studies are capable of bringing "us closer to a full representation of social phenomena" (Lieber \& Wesiner, 2010, p. 560). Markedly, both marketing and tourism scholars have called for the application of more mixed-methods studies, highlighting the generative possibilities of mixed-methods research in unravelling complex social and behavioural phenomena rooted in both marketing and tourism disciplines (Azzopardi \& Nash, 2014; Davis et al., 2011; Hamilton, 2016; Harrison \& Reilly, 2011; Khoo-Lattimore et al., 2019; Molina-Azorín \& Font, 2015).

In consideration of the research objectives and questions, the dynamic social and behavioural nature of the iWOM phenomenon, together with the richness afforded by visual images as a form of data, this study is designed as a mixed-methods study, where the mixing of qualitative and quantitative methods allows for greater depth, breadth and comprehension of the construction, sharing and influence of iWOM on overseas VFR markets (Cook, 1985; Greene, 2007; Johnson \& Onwuegbuzie, 2004; Teddlie \& Tashakkori, 2009).

\subsubsection{The mixed-methods research design.}

Scholars offer suggestions for different designs of mixed-methods studies (Creswell \& Plano Clark, 2018; Giddings \& Grant, 2006; Teddlie \& Tashakkori, 2009). Creswell and Plano Clark (2018, p. 65) identify three core designs: convergent, explanatory sequential and exploratory sequential. The authors explain that the convergent design occurs when the researcher seeks to compare or combine the findings of qualitative and quantitative data to gain a more complete understanding of a phenomenon; explanatory sequential design on the other hand, occurs in two interactive phases, where the collection and analysis of quantitative data precedes a qualitative phase (QUAN $\rightarrow$ QUAL); and last, the exploratory sequential design, occurs chronologically, similar to the explanatory design. However, the exploratory sequential design, unlike the explanatory design, begins with a qualitative phase, which is then followed by a quantitative phase (QUAL $\rightarrow$ QUAN).

The findings of the qualitative phase, in an exploratory sequential design, are analysed in an interim or development stage. The findings become the foundation for the quantitative phase of the study (Creswell \& Plano Clark, 2018). For example, insights from qualitative interviews are used to inform the construction of new variables or the design of an instrument used in the subsequent quantitative phase.

The flexibility synonymous with mixed methods allows for more complex designs (Creswell \& Plano Clark, 2018; Greene, 2007; Teddlie \& Tashakkori, 2009). The iterative sequential 
mixed-methods design is a multi-strand design that provides the researcher freedom to go beyond two phases, and may occur as a result of a change in the research design, in order to gain a better understanding of the phenomenon under study (Teddlie \& Tashakkori, 2009). This current study adopts an iterative sequential mixed-methods design (see Figure 4.2).

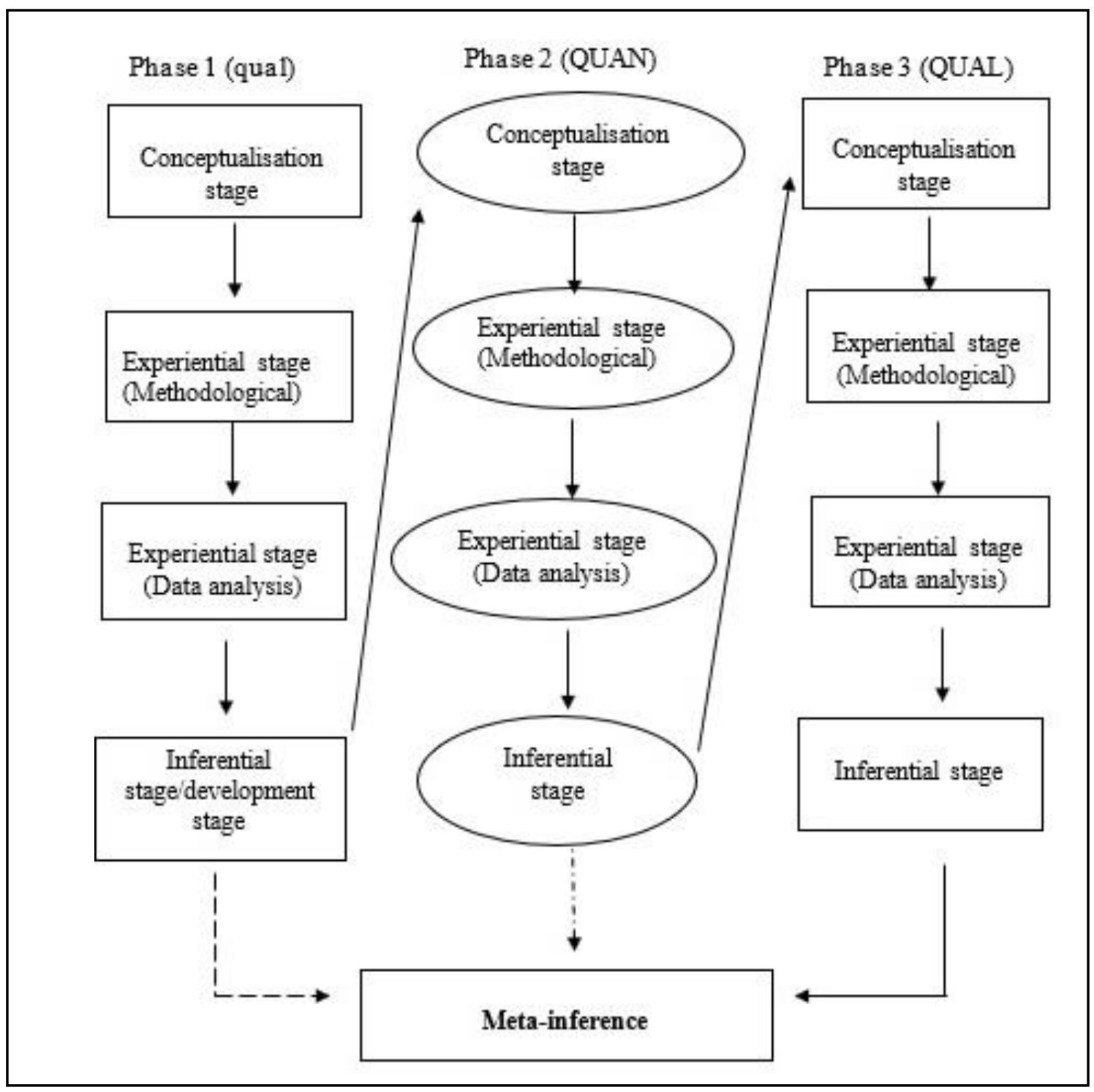

Figure 4.2: The iterative sequential design. (Adapted from Teddlie \& Tashakkori, 2009)

This study takes a qual $\rightarrow$ QUAN $\rightarrow$ QUAL approach, in which a smaller weight is given to Phase 1 (qual) of the study (Creswell \& Plano Clark, 2018; Teddlie \& Tashakkori, 2009). Following Morse's system of notations in mixed-method designs, the "less dominant" Phase 1 is presented in lower case in Figure 4.2 (Teddlie \& Tashakkori, 2009, p. 142). In Phase 1, the qualitative interviews served to validate the instructions given to participating sojourners, and guided sojourner UGI submission, where images used were embedded into the instrument of 
Phase 2 (QUAN). In addition, the findings of Phase 1 informed and validated elements of the items used in the instrument of Phase 2.

A qualitative strand (Phase 3) provided a fuller understanding of the nature of the images collected in Phase 1, where visual images are "rich and thick representation(s)" of experience (Kjeldsen, 2018, p. 79). The critical assessment of images submitted allowed for the elaboration of Phase 2 findings. Importantly, Phase 3 provided a chance to examine stylistic strategies (i.e., colour, form, focus) used in the composition of the submitted images, adding a more holistic understanding of the nature of iWOM, and the critical position sojourners play as key visual influencers. Table 4.1 provides an overview of each phase of the mixedmethods research design used in this study, summarising the purpose, methodology (data collection and sampling), methods of analysis, and inferences (findings).

Table 4.1: Overview of this study's iterative sequential mixed-methods design

\begin{tabular}{|c|c|c|c|}
\hline Stage & Phase 1 (qual) & Phase 2 (QUAN) & Phase 3 (QUAL) \\
\hline $\begin{array}{l}\text { Conceptualisation/ } \\
\text { purpose }\end{array}$ & $\begin{array}{l}\text { Elicit key cognitive } \\
\text { attributes for } \\
\text { development of QUAN } \\
\text { instrument and image } \\
\text { submissions. }\end{array}$ & $\begin{array}{l}\text { Build on the findings } \\
\text { of Phase } 1 . \\
\text { Test and generalise } \\
\text { the impact of iWOM. }\end{array}$ & $\begin{array}{l}\text { Examine taxonomy } \\
\text { of iWOM. Elaborate } \\
\text { Phase } 2 \text { findings, by } \\
\text { critically assessing } \\
\text { nature of iWOM. }\end{array}$ \\
\hline $\begin{array}{l}\text { Experiential } \\
\text { (Methodological) }\end{array}$ & $\begin{array}{l}\text { Expert interviews. } \\
\text { Purposive sampling. }\end{array}$ & $\begin{array}{l}\text { Web-survey. } \\
\text { Respondent-driven } \\
\text { sampling. }\end{array}$ & $\begin{array}{l}\text { Participant- } \\
\text { generated images. } \\
\text { Purposive sampling } \\
\text { (see section } 4.5 .1 \text { ). }\end{array}$ \\
\hline $\begin{array}{l}\text { Experiential } \\
\text { (Data analysis) }\end{array}$ & $\begin{array}{l}\text { Content analysis of } \\
\text { interview transcripts. }\end{array}$ & $\begin{array}{l}\text { Structural equation } \\
\text { modelling of Web- } \\
\text { survey results. }\end{array}$ & $\begin{array}{l}\text { Visual rhetorical } \\
\text { analysis of } \\
\text { submitted images. }\end{array}$ \\
\hline Inferential & $\begin{array}{l}\text { Qualitative interview } \\
\text { results and } \\
\text { visual data (for Phase } 2 \\
\text { instrument and Phase } 3 \\
\text { analysis). }\end{array}$ & Quantitative results. & $\begin{array}{l}\text { Qualitative visual } \\
\text { analysis results. }\end{array}$ \\
\hline
\end{tabular}

\subsection{Phase 1 (qual): Expert interviews}

The objective of Phase 1 is to gain an understanding of the focal cognitive attributes of Wellington, as well as elicit key subject areas in the internal and international marketing of 
Wellington, where the insights inform the development of measurement items for the Websurvey in Phase 2 (Creswell \& Plano Clark, 2018; Greene et al., 1989). Insights from the interviews with key informants to establish image categories typically used by Wellington marketers to perpetuate the idealised projected image of Wellington, where the projected image is "considered an attraction factor" that influences choice (Almeida-García et al., 2020, p. 2). The categories identified validated instructions given to participating sojourners, and guided sojourner UGI submissions.

\subsubsection{Data collection method.}

Tourism scholars stress the importance of including a qualitative component to ensure the validity of image constructs and attributes used to understand aspects linked to destination image (Crompton, 1979; Dolnicar \& Grün, 2013; Echtner \& Ritchie, 1993; Jenkins, 1999). According to Jenkins (1999), interviews are suitable for eliciting destination attributes. Given that the purpose of this research is to establish the position of sojourners as key online ambassadors/visual influencers, and iWOM as carriers of marketing messages, it was deemed necessary to approach key marketing Wellington stakeholders. The information garnered, provided a basis to assess the ability of sojourners in making paradigmatic and syntagmatic choices in articulating identified valued (and "valid") attributes of Wellington's image through the UGI pushed to overseas networks (Crompton, 1979, p. 19).

Data collection for Phase 1 took the form of expert interviews, where staff from the marketing teams of the primary DMO for Wellington and key partners of the organisation were approached (Bagozzi, Yi, \& Phillips, 1991; Kao, Yang, Wu, \& Cheng, 2016). The interviews were semi-structured in nature. Semi-structured interviews begin with some defined questions that later allow the interviewer a degree of flexibility to conduct a more conversational form of interviewing, and pursue interesting tangents that may develop during the interviews (O’Leary, 2004; Patton, 2002).

An interview guide was constructed following Castillo-Montoya's (2016) interview protocol framework (see Appendix A for interview guide). The process encompassed four phases: 1) alignment of interview questions to research purposes and questions; 2) devising an inquirybased conversation; 3 ) receiving feedback on the questions; and 4) piloting the interview guide. The guide was drafted based on "image attribute domains" (key concepts) found in destination image and tourism attraction literature (Assaker, 2014; Echtner \& Ritchie, 2003; Fakeye \& Crompton, 1991; Kim \& Stepchenkova, 2015; Lew, 1987; Pike \& Ryan, 2004). 
The interview guide was first reviewed by two marketing academics, piloted with two $\mathrm{PhD}$ marketing students, and a marketing professional from the author's network, to ensure clarity of the questions. Following university guidelines, ethics approval was sought before key informants were approached via email (VUW Ethics ID 0000025253).

\subsubsection{Sampling.}

Purposive sampling was used for this phase of the research. Purposive sampling is defined as "selecting units based on specific purposes associated with answering a study's research question" (Teddlie \& Tashakkori, 2009, p. 170). In this phase of the research, interviews were conducted with staff from Wellington Regional Economic Development Agency (WREDA), Wellington City Council and Wellington Regional Council. Established in 2014, WREDA is Wellington's primary DMO, and is in-charge of driving Wellington's destination marketing activities, on behalf of the Wellington City Council and the Greater Wellington Regional Council (Wellington Regional Economic Development Agency: annual report 2015, 2015). The Wellington City Council and the Wellington Regional Council have a vested interest in the economic growth of Wellington, and have $80 \%$ and $20 \%$ ownership of WREDA, respectively (Statement of intent 2019-2022, 2019). In addition, as individual entities, both the Wellington City Council and Wellington Regional Council actively manage the marketing activities within their purview.

Collectively, the organisations provide a more holistic understanding of the idealised image of Wellington that is projected internally and externally. The purpose of including multiple stakeholder organisations involved in the marketing of Wellington is to increase trustworthiness of the qualitative inquiry, where triangulation of sources is a recommended strategy in providing trustworthiness to qualitative data (Teddlie \& Tashakkori, 2009).

Interviewees from the various organisations were selected based on their formal roles and their closeness to the associated phenomenon under study (Bagozzi et al., 1991; Kumar, Stern, \& Anderson, 1993). In this instance, the phenomenon of interest involves understanding the value of sojourners as online ambassadors, able to help disseminate marketing messages through iWOM pushed to friends and relatives. Thus, an understanding of the idealised image conveyed through current marketing strategies is imperative as it provides insights into whether sojourners can be mobilised as visual online ambassadors. Campbell (1955) recommends that key informants should 1) be in a position that enables them to be well-informed of the subject of interest, and 2) have the capacity to articulate and 
share knowledge of the subject of interest with the researcher. Heeding Campbell's (1955) suggestions, as part of the selection criteria, interviewees had to at least hold a managerial position in marketing or marketing communications in the identified organisations, and be involved in the planning and execution of marketing strategies.

According to Hulland, Baumgartner and Smith (2018) a majority of studies in marketing that survey key informants, are found to survey only one or two informants. To gain a more accurate account, increase reliability and validity of findings, where possible, at least two informants from each organisation were interviewed for this study (Golden, 1992; Kumar et al., 1993). A general email was sent out to each organisation to nominate, where possible, two staff members that held a management role in marketing for the study. Once nominated, the researcher called and emailed the contact(s) to follow up and discuss details of the study. This follow-up step also provided an opportunity to determine if the nominated staff(s) met the criteria set by Campbell (1955), specifically their capacity to share knowledge of the marketing of Wellington to internal and/or external audiences.

\subsubsection{The interviews.}

Before the interviews, the interview guide (Appendix A), and information sheet (Appendix B) outlining the purpose of the study, responsibilities of the expert informants and details of information handling were emailed to the informants. All participation was voluntary, and participants were promised anonymity and confidentiality. Informants were given the opportunity to clarify any concerns about the research or decline the interview before the scheduled meeting and at the start of the interview. The interviews were conducted in the informants' places of business. All interviews lasted between 30 and 50 minutes. The interviews were voice recorded, with the consent of informants, and notes were taken during the interviews.

\subsubsection{Data analysis.}

The recorded interviews were later transcribed by the researcher. The textual data was managed using QSR NVivo 12 (“NVivo,” 2020). Following Jenkins' (1999) recommendations, content analysis was used to identify salient cognitive concepts from the interview data that served to inform the construction of the survey instrument, as well as the image categories sojourners were tasked to submit. The content analysis took a directed perspective that relied on existing theories and cognitive attribute measures established in 
destination image literature (Hsieh \& Shannon, 2005). In addition, similar to Kao et al. (2016), new attributes that surfaced from the interview data were also noted, and coded.

The iterative steps recommended by Hsieh and Shannon (2005) guided the analysis, which involved: identifying potential constructs, or in this instance attributes, from the literature; reading the transcripts and highlighting possible text that discussed potential attributes; data that cannot be coded into identified attributes found in literature were identified and analysed later; reviewing the data again; reviewing highlighted text and coding attributes.

\subsection{Instrument development}

In view of findings from the expert interviews, the objective of this stage was to collate sojourner-produced images for inclusion in the Phase $2 \mathrm{Web}$-survey instrument. The images were also used as part of Phase 3 visual analysis. The following sections (Sections 4.5.14.5.2) detail the procedures undertaken to collect and validate the visual data. In consideration of the involvement of other groups of participants (sojourners and their overseas networks) in the proceeding phases of this study, and the use of personal images, ethics approval was again sought (VUW Ethics ID 0000026008).

\subsubsection{Visual data collection method.}

This inferential or instrument development stage of Phase 1 is guided by studies that employ participant-generated images (PGI) as a method of collecting visual data (Balomenou \& Garrod, 2016; Balomenou \& Garrod, 2014; Stedman et al., 2004; Tussyadiah, 2010). PGI is a technique that involves placing cameras in the hands of the participants, who have the autonomy to capture images that are representative of a theme or topic (Balomenou \& Garrod, 2016). To simplify the process of data collection, sojourners were forwarded a link and instructed to upload their images via a Qualtrics form (see Appendix C). The method was deemed suitable given the nature of this study and its focus on digital images shared by sojourners. Other than allowing researchers to embed images or media files into surveys, Qualtrics (http://www. qualtrics.com) also allows respondents to upload media files. The form comprised five parts:

1. Information about the study

2. Section to provide details of their online image sharing habits (e.g., frequency of use)

3. Section to upload images from the identified categories (see results in Section 5.1)

4. Section to provide email addresses of nominated friends and relatives 
5. General respondent information (e.g. demographic details; visa type)

\subsubsection{Sampling.}

Purposive sampling was employed to recruit sojourners from Wellington, which include all areas of the region: Kāpiti, Hutt Valley, Porirua, Wairarapa and Wellington City (Teddlie \& Tashakkori, 2009). To participate, sojourners had to meet the following criteria: 1) must hold citizenship from outside New Zealand, 2) aged 18 and over, 3) reside in Wellington, 4) possess a non-tourist visa and 5) use online networking platforms to connect with overseas friends and relatives.

\subsubsection{Recruitment of sojourners.}

Sojourners were recruited through online networking sites, noticeboards in tertiary institutions, as well as speciality restaurants and shops frequented by members of the international sojourner community. Given that English might not be the first language of some members from the international sojourner community, recruitment advertisements and sojourner information sheet were submitted to a panel of international students for review to ascertain readability, and reduce ambiguity of the instructions (Lee \& King, 2016). The panel comprised 10 international students, enrolled in Victoria University of Wellington, New Zealand, from the following countries: Bangladesh (2), China (2), Ghana (1), Iran (1), Russia (1) and Vietnam (3). Based on the feedback received from the panel of international students, descriptions of categories in the instructions provided in the information sheet to sojourners, as well as information in advertisements targeting sojourners were reworded to improve readability.

Permission to the online community moderator (Appendix D) was sought, prior to posting on online networking sites such as:

- Multicultural Council of Wellington (https://www.facebook.com/MCWellingtonNZ/)

- New Zealand International Students' Association

(https://www.facebook.com/NZISA2018/)

- Wellington Newcomers Network

(https://www.facebook.com/wellington.newcomers.network/)

The sojourner recruitment advertisement (Appendix E) included the criteria to participate, as well as directed interested sojourners to email the researcher. 
The sojourner information sheet (Appendix F) was distributed to sojourners who emailed the researcher. The information sheet provided the following information:

- Project details: Implications and purpose of the research.

- UGI submission instructions: Sojourners were directed to submit images of Wellington that they have previously created and shared online, or to create new images they would consider sharing with overseas friends and relatives, under the predefined categories identified from Phase 1 findings (see Chapter 5). Sojourners were instructed to nominate friends and relatives to complete Phase 2 Web survey. All participation was voluntary, and anonymity and confidentiality were promised.

- Image handling details: Sojourners were assured that images submitted would only be viewed by their nominated friends and relatives (as part of Phase 2 Web survey), the author and the research team. In addition, other areas of image handling such as the blurring of identifiable features that link the participant to the image for use in publication, as well as image storage and destruction were covered.

- Link to a Qualtrics form: For sojourners to upload images.

- Raffle details: The objective of including a raffle was two-fold: 1) to boost sojourner participation, and 2) have sojourners encourage their overseas network of friends and relatives to complete the dyadic Web survey (Phase 2). It was explained in the sojourner information sheet that the more Web surveys completed by overseas friends and relatives in their network, the higher the chances for a sojourner to win the raffle. Incentives are often used to increase and sustain participation (Garrod, 2008; Stopher, 2012). However, because they "represent a chance to earn money", scholars caution the use of incentives as it could introduce respondent bias (Manzo \& Burke, 2012, p. 331; Stopher, 2012). Nonetheless, given that the Web surveys were to be completed by overseas friends and relatives of sojourners, who were not incentivised, it was deemed appropriate.

\subsubsection{Visual data validation.}

The purpose of this step in the development stage of Phase 1, was to screen images that did not meet the criteria (such as those that were unrelated to Wellington). The images were assessed for semantic, convergent and discriminant validity (Krippendorff, 2013).

Guided by Lacy, Watson, Riffe and Lovejoy (2015), three coders were recruited to code the submitted images. The authors argue that three or more coders would "help analyse the sources of coder disagreement" (p. 13). The three coders selected for this task were 
sojourners, not involved in any other part of the study, "familiar with the phenomena under consideration" (Krippendorff, 2013, p. 128). Each coder used online platforms, such as instant messengers and social networking sites, as a means of connecting with their overseas network. All coders, at the point of the coding, had lived in Wellington for at least a year, making the coders familiar with the destination and the events held there. Two of the sojourners were marketing professionals, and one was a tourism scholar with a background in architecture and design. All coders recruited were of different nationalities: Singaporean, Nepalese and British. A gift card was awarded to each coder for the time contributed to this study.

Prior to the actual coding, coders were briefed about the nature of the project, instructed on the mechanics of the coding exercise (i.e., dissemination of data and platform used to collect data), and coding themes. To improve objectivity and coding reliability, each coder was trained with the coding scheme and operational definitions (Kolbe \& Burnett, 1991). As part of the coder training, a pre-test was conducted to help the researcher refine coding protocol instructions (see Appendix G for coding protocol), and to ensure the ease of use of the recording system (Camprubí \& Coromina, 2016). Coders reviewed the images and selected the category that best represented each image. When an image fell outside the categories, the coder was instructed to select the "others" option.

To reduce recording and coding errors the images were embedded into five Qualtrics forms (see Appendix $\mathrm{H}$ for sample form) with well-labelled radio buttons that allowed coders the ability to return to previous coded images (Krippendorff, 2013). Other than coding the images into the specified content groups, in the distributed Qualtrics forms, the coders listed physical items manifest in each image. The listing of physical items by the coders aided the visual analysis (see Section 4.7.2 for expanded discussion). To ease the coding workload, the Qualtrics forms were distributed fortnightly to the coders. In addition, to maintain anonymity of participating sojourners to the coders, images with identifiable features were blurred by the author before inclusion into the Qualtrics forms (Prosser, 2005).

To establish reliability and validity of the images, Fleiss' kappa was calculated. Fleiss' kappa is a measure used to "determine the consistency in ranking items or classifying items into mutually exclusive categories", and is generally used when there are three or more coders (DeCuir-Gunby, Marshall, \& McCulloch, 2011, p. 149). The Fleiss' kappa results are reported in Chapter 5. Validated images were used as data for both quantitative (Phase 2) and 
qualitative (Phase 3) phases of the study. Images that had conflicting results were discussed with the coders and if unresolved, discarded.

\subsection{Phase 2 (QUAN): Web survey}

For Phase 2, a Web-based survey was used to collect data. This section describes the rationale behind the choice of data collection method, the design process and elements, sampling, as well as method used to analyse the observations yielded from the responses of overseas friends and relatives of sojourners.

\subsubsection{Data collection method.}

Web surveys simplify the data collection process to collect data from overseas friends and relatives of the sojourners. The advantages of Web surveys include low cost, short response times, ability to include multimedia in the surveys, reduce social desirability biases and flexibility in allowing respondents to complete the survey in multiple sittings (Cook, Heath, \& Thompson, 2000; Ilieva, Baron, \& Healey, 2002; Stopher, 2012; Wyatt, 2000). Despite the merits associated with Web surveys, the suggested challenges that could impact response rates such as: varied levels of Internet penetration, Web literacy of respondents, and potentially slow loading times, were considered (Manfreda, Bosnjak, Berzelak, Haas, \& Vehovar, 2008; Stopher, 2012). However, in view of the increasing prevalence of high-speed Internet access globally, the electronic focus and nature of the iWOM phenomenon, as well as the use of online platforms by sojourners (to connect with overseas networks), Web surveys were considered a suitable method for collecting data in this study.

The Web survey for this study was designed using Qualtrics, a survey platform that supports the inclusion of multimedia articles, such as the sojourner-produced images submitted as part of this study. To improve the rate and quality of response, recommended survey design aspects such as, appearance, sequence of questions and question wording of the Web survey were considered (Dillman, 2000; Lietz, 2010; Stopher, 2012)

The individual dyadic Web-surveys, to be completed by overseas friends and relatives of sojourners, comprised the following five parts (see Appendix I):

1. Information about the study (e.g., purpose and contact information)

2. Screening questions (e.g., age and visit)

3. Establishing influence of the shared iWOM on viewer perception and visit intention 
4. Questions about the relationship between the respondent and sojourner, to establish the strength of tie between sojourner and respondent

5. General respondent information (e.g., demographic information, current location)

\subsubsection{Measurement of constructs.}

This section details the measurement of constructs used in this study. The majority of measurements used in this study are derived from the existing research literature. The main constructs iWOM, Impression, Tie strength and Intention to visit, were measured using seven-point semantic-differential and Likert-type scales. However, nominal scales were used to measure the type of relationship (friend/relative) as well as control variables (e.g., demographic variables and cultural distance) used in this study.

\subsubsection{1 iWOM.}

iWOM is viewed as the visual form of WOM capable of articulating attributes of destination image, where destination image comprises both cognitive and affective components, triggered by the evaluation of the manifest content used to compose the UGI shared. In this study, iWOM is operationalised as a latent construct that adopts a cognitive-affective approach (Zhang et al., 2014), where the composite scores of the semantic-differential scales represent an overall evaluation of affective and cognitive components that make up the image of the host destination, conveyed through iWOM (Crompton, 1979). Similar to Molinillo et al. (2018), seven-point semantic differential scales were used.

The four affective measures primarily used in destination image studies are used in this study (Baloglu \& Brinberg, 1997; Molinillo et al., 2018):

Based on the photograph, I would describe the Greater Wellington Region as:
AFF_1
Pleasant-Unpleasant
AFF_2
Relaxing-Distressing
AFF_3
Exciting-Gloomy
AFF_4
Arousing-Sleepy

Although affective measures are fixed, cognitive measures are commonly adopted from different sources (Papadimitriou et al., 2018). In this study, the interview findings from Phase 1 were used to identify the cognitive measures of iWOM. The final list of items used to measure iWOM are discussed in Chapter 5. 


\subsubsection{Impression.}

A single-item, seven-point Likert scale $(1=$ not at all positive, $7=$ very much positive $)$, measure was used to capture the overall impression/viewer attitude towards the host destination (Kim \& Stepchenkova, 2015; Beerli \& Martin, 2004a). Despite much debate surrounding the use of single-item measures, in light of the dyadic/multi-actor nature of this research and the noted difficulties in recruiting respondents in dyadic/multi-actor studies, in particular within the VFR context (Capistrano \& Weaver, 2018), a single-item question was considered necessary and sufficient. The use of a single-item question was viewed as an appropriate strategy to reduce the length of the survey and respondent burden, in a bid to increase participation, and minimise attrition rates (Diamantopoulos, Sarstedt, Fuchs, Wilczynski, \& Kaiser, 2012; Fuchs \& Diamantopoulos, 2009; Hair, Hult, \& Sarstedt, 2017). Further, based on extensive literature reviews conducted, single-item measures are noted to be successfully used in international marketing (Petrescu, 2013) and tourism research (do Valle \& Assaker, 2016; Zhang et al., 2014). In support of the use of single-item measures, Bergkvist \& Rossiter (2007) found no difference in the predictive validity between singleand multiple-item measures. Additionally, common method variance was absent in both single- and multiple-item measures. Bergkvist and Rossiter (2007) further argue that concrete attributes such as beliefs or perceptions and attitude, would yield generalisable findings. In the case of this study, the question measured a simple concrete concept, pertaining to the impression of the consumer and was easily understood (Hair, William, Babin, \& Anderson, 2014; Petrescu, 2013). In addition, the overall impression of destination image has been successfully measured using a single-item scale (e.g., Beerli \& Martín, 2004a; Stylidis, Shani, \& Belhassen, 2017). The measure used in this study was adapted from the study conducted by Kim and Stepchenkova (2015), where impression is operationalised as the overall attitude towards the host destination.

IMP Based on this photo how positive is your impression of the Greater Wellington Region as a travel destination?

\subsubsection{Type of relationship (friends vs. relatives).}

The literature review highlights differences in the characteristics and behaviours of friends and relatives within the VFR tourism context (Capistrano \& Weaver, 2018; Gafter \& Tchetchik, 2017; Lockyer \& Ryan, 2007; Seaton \& Tagg, 1995). To better understand the 
implications of iWOM on the two groups, respondents selected the relationship type they had with the sojourner. The type of relationship between the sojourner and the receiver of the iWOM was measured using a nominal scale: 1 = Friend; 2 = Relative.

\subsubsection{Tie strength.}

Tie strength is a multi-faceted construct operationalised in a variety of ways, such as frequency of interaction (Arnaboldi, Conti, La Gala, Passarella, \& Pezzoni, 2016; Granovetter, 1973; Narangajavana Kaosiri et al., 2019); volume of communication (Risselada, Verhoef, \& Bijmolt, 2014); the type of social relations, such as acquaintances, friends and relatives (Brown \& Reingen, 1987; Marsden \& Campbell, 1984); and as a multidimensional construct that captures the emotional intensity of the relationship (Frenzen \& Davis, 1990; Zhang, Fam, Goh, \& Dai, 2018).

Given that the focus of this study is to understand the impact of emotional propinquity between the sojourner and the overseas friend/relative on the relationship between iWOM and Impression, measures used in the study conducted by Zhang, Fam, Goh, and Dai (2018) were adapted. Similar to Zhang et al. (2018), in this study, tie strength was operationalised as a multi-dimensional construct that encompasses closeness, intimacy, support and association.

TS_1 How likely would you be to share personal confidences with him/her?

TS_2 How likely would you be to perform a large favour for him/her?

TS_3 How likely are you to spend a free afternoon with him/her?

TS_4 Please rate your closeness to him/her.

Although a five-point Likert-type scale was used in the study conducted by Zhang et al. (2018), this study adopts a seven-point Likert-type scale, given its reliability and ability to provide respondents with the room to express themselves (Lietz, 2010; Preston \& Colman, 2000). TS_1-3 were measured using a seven-point Likert-type scale $(1=$ not at all likely, $7=$ very much likely). TS_4 was also measured with a seven-point Likert-type scale ( $1=$ not at all close, 7 = very close).

\subsubsection{Intention to visit.}

The dependent variable, Intention to visit was measured with five items (refer to Table 4.2), two of which (INT_1 and INT_2) were adapted from the study conducted by Shani, Chen, 
Wang, \& Hua, (2010). In view of the VFR context of the research, it was appropriate to include INT_3, INT_4 and INT_5; given the influence of hosts on trip planning (Stepchenkova et al., 2015), the choice of accommodation (Backer, 2008) as well as the centrality of relationships within the context of VFR tourism (Munoz et al., 2017). The items were measured on a seven-point Likert-type scale $(1=$ not all likely, $7=$ very much likely).

Table 4.2 Items used to measure Intention to visit

Based on this photo, please provide your opinion on the following questions.

INT_1 How likely are you to seek information about the Greater Wellington Region?

INT_2 How likely are you to visit the Greater Wellington Region in the near future?

INT_3 How likely are you to seek out this experience should you visit the Greater Wellington Region in the near future? (New)

INT_4 How likely are you to travel to the Greater Wellington Region to spend time with your friend/relative in the near future? (New)

INT_5 How likely are you to stay in a private accommodation (e.g. hotel) if you were to visit the Greater Wellington Region in the near future? (New)

\subsubsection{Control variables.}

\subsection{Demographic variables.}

Nominal scales were used to measure demographic variables age, income and gender:

Age: $\quad 1=18-24$ years; $2=25-34$ years; $3=35-44$ years; $4=45-54$ years; $5=55$ 64 years; $6=\geq 65$ years

Income: $\quad 1=$ no income; $2=<\mathrm{US} \$ 25,000 ; 3=\mathrm{US} \$ 25,000-49,999 ; 4=\mathrm{US} \$ 50,000$ 74,$999 ; 5=\geq$ US\$75,000.

Gender: $\quad 1=$ Male; 2 = Female

\subsection{Cultural distance.}

This study draws from the research of $\mathrm{Ng}$ et al. (2007). The authors tested five different cultural distance measures and their impact on the intentions of Australian tourists to visit a variety of destinations. The different measures compared were perceived cultural distance (Boyacigiller, 1990); cultural distance index (Kogut \& Singh, 1988); cultural cluster distance (Clark \& Pugh, 2001a); linguistic distance (West \& Graham, 2004); cultural diversity index (Jackson, 2001). Based on the findings of Ng et al's (2007) study, Clark and Pugh's (2001) 
cultural cluster distance measure was found to be the "strongest predictor of intentions" (p. 1504), and therefore, adopted in this study.

Clark and Pugh (2001, p. 296) define cultural distance as "the degree of difference of the cultural cluster to which the target foreign country belongs from the cultural cluster to which the home country belongs". Clark and Pugh's (2001) cultural cluster distance measure, presented in Table 4.3, was adopted in this study. The measure discerns differences between countries on the basis of "language, religion and geography" ( $\mathrm{Ng}$ et al., 2007, p. 1500). In this study, cultural distance is operationalised as the extent to which the cultural cluster of the country of residence of the traveller is different from the focal country, the host destination.

Table 4.3: Clark and Pugh's (2001) cultural clusters and their 'cultural distance' from Britain ANGLO cluster (cultural distance $=1$ )

Australia, Canada, Ireland, New Zealand, South Africa, USA

NORDIC cluster (cultural distance $=2$ )

Denmark, Finland, Netherlands, Norway, Sweden

GERMANIC cluster (cultural distance $=3$ )

Austria, Germany, Luxemburg, Switzerland

LATIN cluster (cultural distance $=4$ )

Argentina, Belgium, France, Italy, Mexico, Portugal, Spain

REST OF THE WORLD cluster (cultural distance $=5$ )

Egypt, Greece, Hungary, India, Indonesia, Japan, Kuwait, Nigeria, Pakistan, Poland, Saudi Arabia, Singapore, Sudan, Taiwan, Thailand, Turkey, UAE, Zambia, Zimbabwe

Since New Zealand, the focal country, is part of the Anglo cluster, this study, similar to the study conducted in Australia by Ng et al. (2007), replicated the cultural cluster distance measures used by Clark and Pugh (2001). A nominal scale of 1-5, mirroring the cultural distance values in Table 4.3 was used.

In the Web survey, participating friends and relatives of sojourners were tasked to indicate their current country of residence. Hence, following the scale established by Clark and Pugh (2001) the more culturally distant the current country of residence from the focal Anglo cultural cluster, the larger the value on the nominal scale. 


\subsubsection{Pre-test.}

Pre-tests are crucial in research as they provide an opportunity to identify potential problems with survey items and/or data collection protocols prior to the actual study (Hulland et al., 2018; Lewis-Beck, Bryman, \& Futing Liao, 2004). In addition, pre-tests help improve clarity and readability of questions, as well as eliminate redundant or ambiguous items in the quantitative survey that contribute to method bias (Hunt, Sparkman, \& Wilcox, 1982; Lee \& King, 2016; Moore \& Benbasat, 1991; Peterson, 2000; Podsakoff, MacKenzie, Lee, \& Podsakoff, 2003).

In light of the merits of a pre-test, the survey for this study was pre-tested. According to Stopher (2012), the sample for the pre-test could be drawn from the researcher's own network, and can have as few as five to 10 individuals. Thirteen friends and relatives of the researcher from various international backgrounds [Bangladeshi (1), Indonesian (1), Vietnamese (2), Filipino (1), American (1), Singaporean (7)], participated in the pre-test of the survey, which was embedded with the researcher's personal images. Through the pre-test, the researcher was able to establish face validity of the items being tested (Cavana, Delahaye, $\&$ Sekaran, 2001). Face validity serves to ensure that the questions reflect what the researcher intended to measure (Mooi \& Sarstedt, 2011).

In addition, two marketing academic staff members were approached prior to the pre-test, to review the survey. Feedback received from the pre-test, identified elements of the survey for improvement. The changes include alteration of the image size used, improvement of the wording of the instructions, and inclusion of a progress bar.

\subsubsection{Sampling and survey implementation.}

Respondent-driven sampling (RDS) is useful for studies where the target population is geographically dispersed, and difficult to penetrate (Heckathorn, 1997). RDS has been used for surveying migrant populations, where it relies on network structures (Reichel \& Morales, 2017). Sojourners were given the option of providing the email addresses of friends and relatives (for the researcher to follow-up); or requesting and forwarding (to friends and relatives) the cover letter that provided information about the study (Appendix J), as well as a generated Qualtrics link to the specific sojourner's dyadic survey, embedded with their specific set of submitted images. Participating sojourners were assured that images submitted would only be reviewed by nominated friends and relatives. A follow-up email was sent out two weeks after the first email to nominated friends and relatives of the sojourners. In 
instances where the sojourner opted for a direct link to the Web survey, to be completed by their overseas friends and relatives, the fortnightly reminders were sent to the sojourner (Stopher, 2012). The veracity of Web surveys submitted for analysis were checked and compared against the Internet Protocol (IP) addresses of sojourner submissions, to ensure that sojourners were not completing the Web surveys meant for overseas friends and relatives to improve their position to win the raffle prizes, discussed in Section 4.5.3.

\subsubsection{Unit of analysis.}

The unit of analysis for Phase 2 is the number of observations received for each image embedded in the dyadic surveys (friends/relatives survey responses), given the objective of this thesis is to examine the role of sojourners as online ambassadors, and iWOM as potential triggers of VFR tourism.

\subsubsection{Data analysis.}

\subsubsection{Structural equation modelling.}

Structural equation modelling (SEM) is a second-generation multivariate analysis technique that allows for the examination of multidimensional concepts (latent variables), and the relationships between these concepts (Chin, Peterson, \& Brown, 2008; Hair et al., 2017). The adoption of SEM in marketing (Reinartz, Haenlein, \& Henseler, 2009), and tourism (do Valle $\&$ Assaker, 2016) research is widespread and is used to overcome limitations of firstgeneration methods (Gefen, Straub, \& Boudreau, 2000; Richter, Sinkovics, Ringle, \& Schlägel, 2016), where a noted benefit of SEM is its ability to directly account for measurement error in unobservable variables (Hair et al., 2017).

Two types of SEM methods are commonly used: maximum likelihood, covariance-based SEM (CB-SEM) and variance-based partial least squares SEM (PLS-SEM) (Ryan, 2020). CB-SEM is conducted using software such as LISREL, Amos, and Mplus; while SmartPLS or PLS-Graph are used for PLS-SEM. The fundamental distinctions between CB-SEM and PLS-SEM are in their objectives of analysis, statistical assumptions and the nature of the statistics used to assess the model (Hair et al., 2017). Specifically, CB-SEM is used in research that seeks to confirm or reject theories. In CB-SEM, "strong theory drives model development", where the correctness or fit of the theoretical model underlies the CB-SEM approach (Richter, Sinkovics, et al., 2016, p. 381). 
In addition, CB-SEM demands that a set of assumptions, such as a minimum number of samples (100-150 depending on number of constructs), and the multivariate normality of data is met (Hair et al., 2014). Conversely, PLS-SEM is used in research that focuses on theory development and prediction, where the statistical objective of PLS-SEM is to maximise the explained variance for all endogenous constructs through a series of ordinary least square (OLS) regressions, instead of minimising the differences between observed covariance matrices, which is central to CB-SEM (Hair et al., 2017; Richter, Cepeda, Roldán, \& Ringle, 2016; Ryan, 2020).

\subsubsection{Partial least squares-structural equation modelling (PLS-SEM).}

Described as a soft modelling approach (Wold, 1982), PLS-SEM reduces the demands or “impractical assumptions” (Streukens \& Leroi-Werelds, 2016, p.618) associated with CBSEM, such as data distribution, sample size and measurement scale of indicators (Hair, Risher, Sarstedt, \& Ringle, 2019; Vinzi, Trinchera, \& Amato, 2011). Thus, if CB-SEM assumptions cannot be met, or the research objective is prediction rather than confirmation of relationships between constructs, PLS-SEM is a preferred alternative (Hair, Ringle, \& Sarstedt, 2011). PLS-SEM is a non-parametric statistical approach, designed to complement CB-SEM (Wold, 1982). Moreover PLS-SEM's higher levels of statistical power outperform CB-SEM in studies with small sample sizes or complex models, in particular models that contain formative constructs, a combination of formative and reflective constructs, and more complex models (Hair et al., 2017; Rungtusanatham, Miller, \& Boyer, 2014; Sarstedt, Nitzl, \& Howard, 2020).

Notably, recent "improvements, extensions and methodological advances" (Richter, Cepeda, et al., 2016, p.591) add to PLS-SEM's usefulness in examining increasingly complex marketing and tourism phenomena (do Valle \& Assaker, 2016; Hair, Sarstedt, \& Ringle, 2019; Richter, Cepeda, et al., 2016; Sarstedt et al., 2019). For example, the inclusion of complementary methods such as multi-group analysis (Ting et al., 2019); and methods for assessing discriminant validity, unobserved heterogeneity (Hair, Sarstedt, Matthews, \& Ringle, 2016) and moderators (Becker, Ringle, \& Sarstedt, 2018). Further, SmartPLS version 3.2.9 (used in this study), allows for conducting a two-tailed test using the PLS-MGA (PLSMulti-Group Analysis) approach (“SmartPLS release notes," 2020), where prior versions could only perform a one-tailed test. 
In view of the requirements of this study, as well as guidelines in choosing between PLSSEM and CB-SEM, PLS-SEM was considered more appropriate (Hair et al., 2019; Henseler, Müller, \& Schuberth, 2018; Streukens \& Leroi-Werelds, 2016; Vinzi et al., 2011). Specifically, the reasons for choosing PLS-SEM are as follows:

- Anticipated non-normal distribution of data particularly for the construct Tie strength - in light of the relationship between the sojourner and his/her network of friends and relatives, which can be corrected through bootstrapping.

- The use of single-item measure in this study, as well as a continuous moderator, captured using a multi-item scale (Ali Memon et al., 2019; Hair et al., 2017; Matthews, Hair, \& Matthews, 2018).

- Ability to assess complex models, such as conditional process models that integrate mediation and moderation, similar to that found in this study. Therefore, allowing the researcher to overcome the limitations of regression and factor-based SEM analyses (Matthews et al., 2018; Sardeshmukh \& Vandenberg, 2017; Sarstedt et al., 2020).

- Inclusion of MICOM (measurement invariance of composite models), and multigroup feature add to the suitability of using PLS-SEM for this study. In this study, the multi-group feature helped discern the significance of relationship type (friend/relative) in the iWOM phenomenon. In addition, the MICOM feature is typically adopted as an a priori test for multi-group analyses, where it provides surety that the variations in path relationships between variables is due to structural relationships, and not meanings associated to measures (Matthews et al., 2018).

- Exploratory and predictive nature of this study, which aims to investigate the relationships between the constructs, predict the implications of iWOM on viewer impression and intention to visit or engage in VFR tourism, where the theorising of sojourner-images as a source of WOM has been overlooked (Henseler et al., 2018).

SmartPLS 3.2.9 was used for the main analysis of this study (Ringle, Wende, \& Becker, 2015). SmartPLS is a popular statistical software used in academic research (Sarstedt \& Cheah, 2019). SPSS version 25 was used to compute remainder analyses, such as data summaries, Fleiss' kappa results, and Harman single factor test. 


\subsection{Phase 3 (QUAL): Visual rhetorical analysis}

In this phase, the images collected from sojourners were used to "expand the breadth and range of the inquiry" and elaborate the findings from Phase 2 (Greene et al., 1989).

Concomitantly, the role of sojourners as key visual influencers is examined, where persuasion strategies in conveying destination experiences and connoted meanings of the destination through visual displays are identified. Specifically, this phase attempts to further unravel the nature of iWOM by critically assessing the semantic and syntactic composition of the images to identify elements that contribute to the persuasive nature of iWOM, and the viewer's interpretation of meanings conveyed of the destination by the iWOM received (Foss, 1994). Further, the analysis provides insights into the interactions of the sojourner with the host destination, without any intervention from the researcher (Hunter, 2012; Paül i Agustí, 2018).

\subsubsection{Unit of analysis.}

Images submitted by sojourners and reviewed by external coders (see Section 4.5.4), were used as the unit of analysis for Phase 3.

\subsubsection{Data analysis.}

A plethora of methods are designed, and used for the analysis of images (Rakic, 2012; Rose, 2016). Methods such as photo elicitation; volunteer-employed photography; and content analysis are primarily used in tourism research (Balomenou \& Garrod, 2019). This phase of the study adopted Foss' (1994) rhetorical schema as the principal guiding framework for the analysis of sojourner-generated images in order to understand the nature of sojournerproduced images, and the role of sojourners as adept visual communicators that reinforce or rival destination marketing images.

Visual rhetorical analysis is primarily qualitative in nature, used to examine firm-created images or objects (e.g., Chryslee, Foss, \& Ranney, 1996; Kenney, 2002). The schema focuses on examining the function or connotative meanings of visual images, where the concept of function, in a rhetorical perspective, is determined by the viewer's interpretation of the image, rather than the intentions of the producer of the visual image (Barthes, 1977; Deng \& Li, 2018; Foss, 1994, 2005). Foss (2005, p. 146) defends the functionalist perspective by arguing that scholars may not have access to "evidence about the intentions" of the image producer and at times, the image producer is unable to provide clear verbal accounts of his or her intentions, stressing that some "may even be mistaken about what motivated them". In addition, given the "intricate relationship between description and interpretation" of visual 
images, which requires knowledge of descriptive visual variables such as colour, form and focus (Schroeder, 2006, p. 304), studies that apply this method, are typically critiqued by scholars (e.g., Chryslee et al., 1996; Kenney, 2002; Zhao \& Belk, 2008). This method was deemed appropriate given that English might not be the first language of the international participants in this study.

Foss' (1994) framework involves 1) identification of function communicated, 2) assessment of how well the function is communicated, and 3) evaluation of the legitimacy of the function. Scholars highlight that there is no "one received view" of how visual rhetoric should be approached (Bateman, 2014, p. 120). In this study, Foss' (1994) framework was expanded to include content analysis to systematically identify physical items found in the images (Collier, 1967; Hunter, 2012; Rose, 2016; Tussyadiah, 2010). Content analysis, a qualitative method of analysing data (Miles \& Huberman, 1984), is commonly used to identify the manifest content of photographs (Deng \& Li, 2018), where it provides a "basis for responsible judgments and verbal concepts" (Collier, 1967, p. 72).

Table 4.4 provides an illustration of the expanded application of Foss' (1994) rhetorical schema used in the analysis of the images, in this study. This is then followed by detailed descriptions of each stage taken in the analysis. At each stage of the analysis, the findings were critically reviewed with two academics, trained in qualitative research, where one of the academics held expertise in analysing multi-modal data in tourism research.

Table 4.4: An expanded application of Foss' (1994) rhetorical schema

1. Identify physical/manifest items

- Coders listed manifest or physical items found in images.

- Content compiled and used alongside images in identification of subcategories. Visual and text content managed using NVivo 12.

- Creation of subcategories.

2. Identify and assess how well the function is communicated

- Identify and note stylistic and substantive elements that contribute to the appeal of the image and support the function/connoted meanings (i.e., colour, composition and context of images).

- Compare images to identify different stylistic strategies used to articulate the function. 
- Identify the function/connoted meanings implied through interplay of manifest and stylistic elements.

3. Scrutiny of the function

- Reflect on the function and soundness of the assessment.

- Identify emergent/alternative functions.

\subsubsection{Identifying physical/manifest items.}

Content analyses of the various categories were conducted to capture the manifest content found in the images. Collier (1967, p. 72) argues for the need of "some orderly process" when examining visual data, stressing the importance of taking inventory as a first step to identify significant concepts. The coders assisted with the content analyses of the images. As described in Section 4.5.2, each coder listed physical items that were manifest in the images found in each category. The purpose of having the coders identify manifest/physical items in each image was to triangulate findings, and to improve trustworthiness of the analysis. Moreover, the use of multiple coders reduces the "threat of hidden variables, micro-analysis and the confusion of visual elements" (Collier, 1967; Hunter, 2012, p. 427). Further, the listing of physical elements aided in identifying substantive physical elements used in the composition of images. The data generated by the coders were compiled, and were used alongside the coding of the images, where subcategories were identified, following the iterative steps provided by Gleeson (2011) that involves looking at the images over and over again, noting brief descriptions and creating proto-themes, as well as evaluating and clustering substantive subthemes/subcategories that were manifest in each category. Analysis of images was conducted on using NVivo 12.

\subsubsection{Identifying and assessing how well the function is communicated.}

This stage examined how well the function or connoted meaning of the image was conveyed, and the support available for that function. Data garnered from the preceding stage of the rhetorical analysis (Section 4.7.2.1), which focussed on the physical elements, was used as a foundation to decode the function or connotative meaning of the image. In this phase, stylistic elements of the images were considered. For example, Foss' (1994) recommendation of comparing images that establish similar functions against each other to uncover different strategies that are available in communicating the function, were followed. Recommendations from other visual studies were also followed in the identification of substantive stylistic 
elements that contribute to the function or connoted meanings of the images (Foss, 1994), such as colour, composition and context that contribute to an understanding of the function as well as appeal of the images (e.g., Kress \& van Leeuwen, 2006; Rose, 2016; Tussyadiah, 2010; Yang, Kim, \& Ro, 2007).

\subsubsection{Scrutiny of the function.}

This stage in Phase 3 entails scrutinising the function or connotative meanings derived from the composition of the image of the previous stage and identifying emergent or alternative functions or connotative representations of the images (Foss, 1994).

\subsection{Chapter summary}

This chapter outlined the research method used in this research. This iterative sequential mixed-methods study is divided into three phases (qual $\rightarrow$ QUAN $\rightarrow$ QUAL):

Phase 1 (qual): Expert interviews were conducted to gain a better understanding of the idealised image of Wellington projected through internal and international marketing efforts. The findings from this phase were used to devise themes that guided participating sojourners in their image submission. This chapter further summarises the methods employed for the recruitment of sojourners, as well as collection and validation of visual images, which were used as stimuli embedded into the instrument used for Phase 2, and the unit of analysis in Phase 3. The results from this phase were also used to develop, inform and validate the research instrument for Phase 2.

Phase 2 (QUAN): This phase of the research involved the development and dissemination of dyad-specific Web surveys. The Web surveys designed for the respective sojourner dyads, embedded with submitted images specific to each participating sojourner, were distributed to corresponding overseas friends and relatives nominated by the sojourner. The unit of analysis of this phase was the number of observations received for the images rated by overseas friends and relatives of sojourners. In consideration of the expected non-normal distribution of data, use of a single-item measure, the complex moderated-mediation of the proposed model, the need to conduct multi-group analysis to discern the different outcomes between friends and relatives, as well as exploratory and predictive nature of this study, PLS-SEM was chosen as method of data analysis to test the research hypotheses.

Phase 3 (QUAL): The purpose of this phase, which involves the use of Foss' (1994) visual rhetorical schema, is to gain a more holistic understanding of the nature of the images shared 
by sojourners, as well as to elaborate the findings of Phase 2. This chapter provides a detailed description of the method used to systematically examine the images.

In summary this chapter provides an overview of methods used to gather and analyse data in the various phases of this study. Results of the analyses of the three phases are presented in the next chapter. 


\section{CHAPTER 5. Data analysis and results}

This chapter presents results from the various phases in this study. Key results of Phase 1 expert interviews were used to inform items of the Web survey in Phase 2. PLS-SEM was used to analyse the quantitative data yielded from the Web survey. This chapter also presents key findings from the visual rhetorical analysis conducted in Phase 3. The section closes with a chapter summary that outlines key findings from all three phases.

\subsection{Phase 1 (qual): Expert interviews}

Expert interviews were conducted for Phase 1 of the study with staff members from Wellington Regional Development Agency (WREDA), Wellington City Council (WCC) and Wellington Regional Council (WRC). All interviewees held managerial positions in marketing or marketing communications within the organisations and identified being involved in the planning and execution of marketing strategies to internal and external audiences of Wellington. Thus, meeting the sampling criteria. Further, each of the interviewees possessed more than five years of experience in senior marketing roles.

The semi-structured interviews lasted between 30 and 50 minutes, and were conducted between November 2017 and March 2018, at the interviewees' places of business. In light of their schedules, two informants from WREDA and WCC requested to be interviewed together. Similar to the study conducted by Peirce and Ritchie (2007), it was decided that it would be beneficial to interview the informants together, allowing informants to draw comparisons from each other. Table 5.1 provides a summary of details of the interviews.

Table 5.1: Summary of interview details

\begin{tabular}{ll}
\hline Interview & Duration \\
\hline Wellington Regional Economic Development Agency (WREDA) & \\
Interview 1: WREDA A and WREDA B & 50 minutes \\
Interview 2: WREDA C & 30 minutes \\
Wellington City Council (WCC) & \\
Interview 1: WCC D and WCC E & 45 minutes \\
Wellington Regional Council (WRC) & \\
Interview 1: WRC F & 30 minutes \\
Interview 2: WRC G & 45 minutes \\
\hline
\end{tabular}


The interviews were conducted to understand the cognitive attributes that contribute to the idealised destination image of Wellington, and the means by which these attributes are projected in the marketing activities of the respective organisations. The findings from the interviews aided the development of measures for iWOM, which consists of cognitive and affective dimensions of destination image. Unlike the affective dimension, there is no one standard measure for the cognitive dimension of destination image (Papadimitriou et al., 2018). In addition, the findings allowed the researcher to determine content categories used to guide the image submissions of sojourners.

A directed content analysis approach was adopted for this study, where the researcher relied on prior theory and research to identify key concepts and attributes (e.g. Assaker, 2014; Beerli \& Martín, 2004a; Echtner \& Ritchie, 2003; Fakeye \& Crompton, 1991; Kim \& Stepchenkova, 2015; Lew, 1987; Pike \& Ryan, 2004). The directed content analysis was guided by the iterative steps recommended by Hsieh and Shannon (2005), which also took into account potential new concepts that could emerge from the data analysis. Discussions surrounding the salient cognitive attributes and content areas identified are provided in section 5.1.1 and 5.1.2.

\subsubsection{Key cognitive attributes identified.}

This section provides an overview of key cognitive attributes identified and used as part of measuring iWOM. In addition, following the recommendations of Miles and Huberman (1994), Table 5.2 is included to provide an illustrative overview of findings as well as highlight the salience of cognitive attributes used to describe Wellington's idealised destination image during the expert interviews. 
Table 5.2: Summary of interview findings (key cognitive attributes)

\begin{tabular}{|c|c|c|c|c|c|c|c|c|}
\hline \multirow{2}{*}{$\begin{array}{l}\text { Cognitive } \\
\text { constructs }\end{array}$} & \multicolumn{3}{|c|}{ WREDA } & \multicolumn{2}{|c|}{ WCC } & \multicolumn{2}{|c|}{ WRC } & \multirow[t]{2}{*}{ Illustrative quotes } \\
\hline & A & $\mathrm{B}$ & $\mathrm{C}$ & $\mathrm{D}$ & $\mathrm{E}$ & $\mathrm{F}$ & G & \\
\hline Attractive & $\mathrm{X}$ & $\mathrm{X}$ & $\mathrm{X}$ & $\mathrm{X}$ & & & $\mathrm{X}$ & $\begin{array}{l}\text { "We've got this wonderful town belt, gorgeous waterfront, you're never far away from } \\
\text { nature in Wellington." (WREDA A) } \\
\text { "If Auckland is the big smoke in the South Pacific, Wellington is New Zealand's city ... } \\
\text { and that Wellington is a city set in a very picturesque harbour, surrounded by wild New } \\
\text { Zealand scenery." (WREDA C) } \\
\text { "We have beautiful parks." (WRC G) }\end{array}$ \\
\hline Creative & $X$ & $\mathrm{X}$ & & $\mathrm{X}$ & $X$ & & & $\begin{array}{l}\text { "Number one is creative ... And in general, we are a place of wild ideas ... you know ... a } \\
\text { lot of restless minds doing wonderful things..." (WREDA A) } \\
\text { "... it's creative, innovative, and youthful." (WCC E) }\end{array}$ \\
\hline Developed & $X$ & $\mathrm{X}$ & $\mathrm{X}$ & $\mathrm{X}$ & $X$ & $\mathrm{X}$ & $\mathrm{X}$ & $\begin{array}{l}\text { "We need to be seen as part of an urban world." (WREDA C) } \\
\text { "We're not this little isolated pocket but we're functioning as a connected city ... and with } \\
\text { cities around the world." (WCC E) } \\
\text { "It's a very small city that has a big city offering." (WCC D) }\end{array}$ \\
\hline Friendly & $X$ & $\mathrm{X}$ & & $\mathrm{X}$ & $\mathrm{X}$ & & & $\begin{array}{l}\text { "The Wellingtonians are really friendly, they celebrate and embrace diversity, they are } \\
\text { very accepting, they are very caring and really you know ... nice" (WREDA A) } \\
\text { "... inclusive city." } \\
\text { "... a people centred city." (WCC D) }\end{array}$ \\
\hline Unique & $\mathrm{X}$ & $\mathrm{X}$ & & $\mathrm{X}$ & $\mathrm{X}$ & & & $\begin{array}{l}\text { "We are alternative because we are a cool kinda hipster, grungy place... we have a } \\
\text { counter-culture community..." (WREDA A) } \\
\text { "We're probably unlike other destinations, you'll understand what it's like being a Kiwi } \\
\text { by coming to Wellington, to truly live and embrace that. And it's got that cool, creative, } \\
\text { compact thing that Auckland doesn't have." (WREDA A) }\end{array}$ \\
\hline Vibrant & $\mathrm{X}$ & $\mathrm{X}$ & $\mathrm{X}$ & $\mathrm{X}$ & & & $\mathrm{X}$ & $\begin{array}{l}\text { "Vibrant and connected, resilient region to live in and visit." (WRC G) } \\
\text { "Dynamic central city." (WCC E) } \\
\text { "... exciting and happening place. That they can celebrate". (WRC G) } \\
\text { "... we try and show some of that vibrancy and creativity a lot more by making the images } \\
\text { that we use a lot more dynamic." (WREDA A) }\end{array}$ \\
\hline
\end{tabular}


A prominent concept that emerged during all seven interviews, as presented in Table 5.2, was the need to position Wellington as a developed destination - a "connected city" that is "on par with any major city in the world". According to respondent WREDA C, the concept of a developed city is a key focus in the overarching marketing strategy of Wellington:

"With a city like Wellington, a good place to live and visit are interchangeable. So, the stories we're telling for marketing should be able to appeal to people to come for a weekend away just as much as to come to study or spend a part of their life here. So, the marketing strategy, at a very high level is purely about making Wellington famous so that it competes with other places in the world that people might choose to visit, study or live ... if we want people to be inspired to come and study here and we think that our universities are serious ... We need to be seen as part of an urban world." (Respondent WREDA C)

The notion of a developed region was also present during the interviews with respondents WRC F and WRC G, who in their marketing campaigns for the region focus on articulating narratives of a resilient region with sound infrastructure that supports the needs of a developed region:

"It is definitely infrastructure, but if you go back to that connected, resilient and vibrant, the resilient is protecting residents from floods, and the connected is improving the transport links ... at the same time we're doing that infrastructure with NZTA.” (WRC G)

Intertwined with the category of a developed destination, the notion of a creative Wellington also emerged in four out of the seven interviews. In the interview, Respondent WREDA A described Wellington as the "creative heart of New Zealand". Echoing the theme of creativity, Respondent WREDA B described how the theme of a creative Wellington is weaved into the international marketing of Wellington:

"In the UK we're talking about some of the cultural messages ... how Wellington tells the stories of New Zealand, with the cultural institutions that we have, for example Te Papawhich feeds into the creativity message." (WREDA B)

In addition, the message of creativity feeds into the image of a unique Wellington, as highlighted by four of the experts, where Wellington is described to possess a "counterculture community”, different from the rest of New Zealand: 
“We're probably unlike other (New Zealand) destinations, you'll understand what it's like being a Kiwi by coming to Wellington, to truly live and embrace that. And it's got that cool, creative, compact thing that Auckland doesn't have." (WREDA A)

Friendly was another construct that recurred during four of the interviews, where words such as "community", “collaborative” and "people centred" were used to describe Wellington. The following excerpts further stress the concept of friendliness in the marketing of Wellington:

"We try and make sure that it' optimistic, friendly, and vibrant. Those are the three words that we go to when we're trying to say this is Wellington City Council and this is Wellington City.” (WCC E)

"Because of that size and because of how people are really friendly, people like to work together to make stuff happen." (WREDA A)

Another salient concept identified across all seven expert interviews (from the three organisations) was a vibrant Wellington, where words such as "dynamic”, "colour”, "vibrant" and "exciting" were used to describe Wellington. The multitude of activities described during the interviews, further brought forth the intended image of a vibrant Wellington:

"We try and show some of that vibrancy and creativity a lot more by making the images that we use a lot more dynamic. We definitely use a lot of eating and drinking out images ... of waterfront images, but we try and show as much colour as possible. (WREDA A)

"We kind of see ourselves much more as a, um ... almost like a European city destination ... where you come and participate in the life of the city. So, you go and enjoy great restaurants and hospitality. There are shopping opportunities. There's art galleries and museums. You can take a stroll on the waterfront ... But equally, if you wanted to do some of the outdoor adventure stuff, you can do it right next to the city. So, tying the mountain bike ride down from top of a hill to a cup of coffee and to craft brewery, so you're linking those activities... Yes, so that you kind of linking those to urban sprawl. That's most people's life experience across the one." (WREDA C).

The myriad of activities offered and the ability to transition between city offerings of Wellington and the outdoor splendour synonymous with New Zealand were described as adding to the uniqueness of Wellington as a destination. As presented in Table 5.2, the 
beauty of New Zealand, with its scenic landscape was highlighted by the experts in all three organisations, to provide a backdrop for projecting an image of an attractive destination:

“We've got active nature. We've got this wonderful townbelt, gorgeous waterfront, you're never far away from nature in Wellington ... .it's a big part of the liveability story here, a big part of the international story, it is a big part of the doing business and working story, cause you'll hear a lot of from the top talent, who like to nip off on their mountain bike for lunch. That part of Wellington is quite special. Cause other urban destinations you got to get in a car and drive an hour or two to access it. Here you don't." (WREDA A)

"Very much about sharing words, pictures, stories about the way people live here and the way they live in a city and use the environment around it as part of that playground. And that close proximity between the city environment that gives you some of your needs, and the wide-open spaces that people want from New Zealand." (WREDA C)

"The connection between nature and city life, that's something that we've been really promoting, especially with somewhere like Zealandia, you know, where it is, you know, less than a 10-minute drive from the city. But once you're in there you could really be in the middle of, well not quite in the middle of nowhere ... If you're visiting Wellington, you could be in that place and not be aware that how much else I think we do quite a lot with juxtapositions of here's Zelandia and here's a New Zealand arts festival event going on ... You can have both of those experiences in the same day when you come to Wellington." $(W C C D)$

"If you were to be just blind folded and dropped into the middle of it, you would not necessarily think you're that close to the city. Which I think is pretty special." (WCC E)

\subsubsection{Key content areas identified.}

As part of the interviews, respondents were asked to discuss the different content areas typically used in the marketing of Wellington. Through the course of the seven interviews, it was noted that a primary emphasis of the different organisations in the marketing of Wellington both locally and overseas, was to establish the position of Wellington as a developed, vibrant and creative region, as demonstrated in Table 5.3. 
Table 5.3: Summary of interview findings (key content areas)

\begin{tabular}{|c|c|c|c|c|c|c|c|c|}
\hline \multirow[t]{2}{*}{ Content areas } & \multicolumn{3}{|c|}{ WREDA } & \multicolumn{2}{|c|}{ WCC } & \multicolumn{2}{|c|}{$\underline{\mathrm{WRC}}$} & \multirow[t]{2}{*}{ Illustrative quotes } \\
\hline & A & $\mathrm{B}$ & $\mathrm{C}$ & $\mathrm{D}$ & $\mathrm{E}$ & $\mathrm{F}$ & G & \\
\hline Events & $\mathrm{X}$ & $X$ & $\mathrm{X}$ & $X$ & & & $X$ & $\begin{array}{l}\text { “... amazing events." (WREDA A) } \\
\text { "Culture we got it as that place to learn about the NZ stories as well as } \\
\text { events and museums, galleries that whole creativity." (WCC D) } \\
\text { "We have nine regional parks, and we have images of people attending } \\
\text { events in those parks, maps to get to these parks, and the facilities at } \\
\text { them." (WRC G) }\end{array}$ \\
\hline Food and drinks/dining & $\mathrm{X}$ & $\mathrm{X}$ & $\mathrm{X}$ & $\mathrm{X}$ & & & & $\begin{array}{l}\text { “... depending on the work markets... I'd talk about Wellington being a } \\
\text { good food city.” (WREDA B) } \\
\text { “... our hospitality scene is a big part of that ... images in this area that } \\
\text { show people out and about eating all times of day.” (WCC D) } \\
\text { “... although we don't have as many Michelin starred restaurants as other } \\
\text { places ... but, it's the number one experience people look for in a short } \\
\text { break. And we've got really good casual dining or smart casual dining - } \\
\text { good food trucks, great markets.” (WREDA A) }\end{array}$ \\
\hline Nature/scenic landscape & $X$ & $\mathrm{X}$ & $X$ & $\mathrm{X}$ & $\mathrm{X}$ & $\mathrm{X}$ & $\mathrm{X}$ & $\begin{array}{l}\text { "And that's our top performing Wellington region image because there's } \\
\text { the lighthouse, and it's just this beautiful curve of land and water, it is } \\
\text { stunning." (WREDA A) } \\
\text { "Beautiful landscapes" (WRC G) }\end{array}$ \\
\hline Urban city & $\mathrm{X}$ & $\mathrm{X}$ & & $\mathrm{X}$ & $\mathrm{X}$ & & & $\begin{array}{l}\text { "Tell more of that story of a colourful urban break, we look purposely for } \\
\text { businesses, or hospitality businesses, or retail businesses that tell the story } \\
\text { of a sophisticated, urban, creative place ... We are starting to use an ever- } \\
\text { increasing amount of street art images... to again show that creativity." } \\
\text { (WREDA A) } \\
\text { "Within those big objectives. You can see how transport or infrastructure } \\
\text { plays into that." (WCC E) }\end{array}$ \\
\hline
\end{tabular}


Salient content areas described were of events, food and drinks/dining, and scenes of an urban city:

“Hannah's laneway because that tells our food story really well. We do kind of craft beers, so we may choose Rouge \& Vagabond, Goldings Free Dive as a way to tell that story ... But really that's around the key things ... you know - great food, lots of shopping, amazing events." (WREDA A)

"It's the arts and culture event images ... and that this is a place where things happen, and people come together to experience these things. Um, our hospitality scene is a big part of that ... people out and about eating all times of day in the city, and meeting friends, doing all those kinds of things." (WCC D).

As illustrated in Table 5.3, all seven respondents reported landscapes and the natural environment of New Zealand as key content areas in the marketing of Wellington.

"We've got our hero shot and they do tend to skew to the landscape version ... The reason being is that it's just the worldwide truth of destinations - marketing those beautiful scenery shots is just what people instantly like." (WREDA A)

For WCC and WRC, landscapes and nature were central to the internal marketing of Wellington, where the goal is to communicate the importance of protecting, and preserving the natural environment and beauty of Wellington:

"No, any kind of project really... how it affects people is concern... And eco city. Our environment is really important. How do we protect our environment, how do we make sure that we've got the sense that you live in this cosmopolitan city, but in 10 minutes you can be in an amazing wild location?" (WCC D)

"More natural, more environmental images. Images of our landscape ... A lot of it is educational, about small things people do that have an impact." (WRC F)

\subsubsection{Summary of key findings.}

Figure 5.1 provides an overview of Phase 1 findings, where key cognitive attributes identified, as well as content areas used to project the cognitive attributes are presented. The results of the expert interviews provided the foundation for the instrument development stage that allowed for 1) themes of images submitted by sojourners to be established and 2) items used to measure iWOM to be confirmed. 


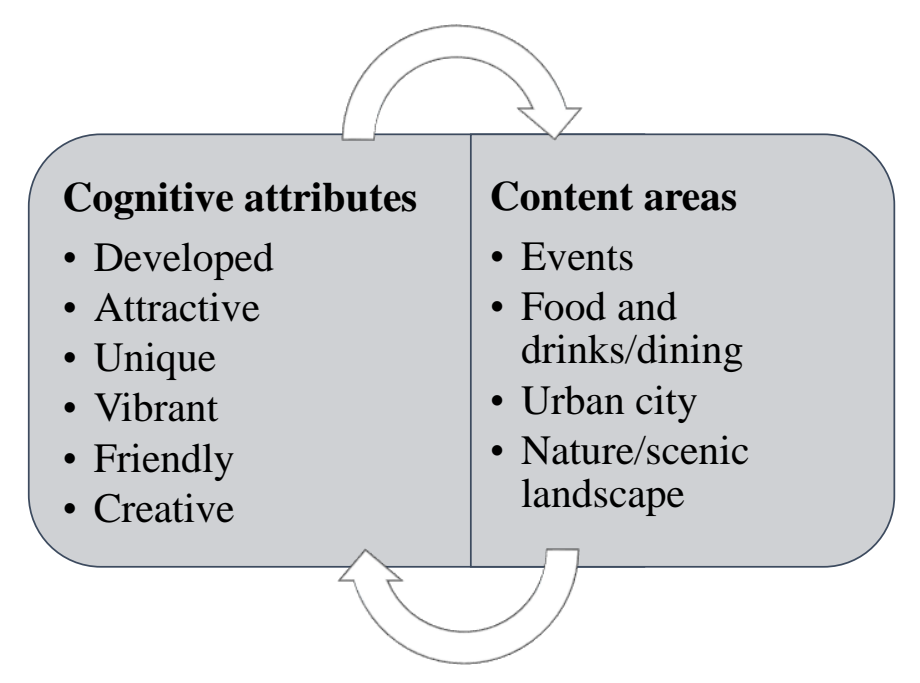

Figure 5.1: Overview of Phase 1 findings (Source: developed for this research from results from Sections 5.1.1 and 5.1.2)

\subsection{Instrument development}

Based on the results of the expert interviews, four themes (Events, Food and drinks/dining, Nature/scenic landscape and Urban city) and one general category (Your pick) were established. The category "Your pick" was included to offer an opportunity to tap experiences of sojourners, to uncover and examine valued concepts and categories tied to the destination, not specified by the researcher. Visual data collection and validation took place between May and July 2018.

\subsubsection{Demographic overview of participating sojourners.}

As presented in Table 5.4, a total of 33 qualified sojourners participated in the study. All participating sojourners held citizenship from outside New Zealand, resided in Wellington, possessed a non-tourist visa and used online networking platforms to connect with overseas friends and relatives (see Appendix K for full participant profile). Thus, meeting the criteria of the study.

Thirty-three per cent of the participating sojourners were male and $66.7 \%$ were female. The proportion of male and female participants in this study is consistent with findings of the Pew Research Center, where women were found to prefer engaging on social media platforms that are more visual compared to men (Anderson, 2015). The images were submitted by nationals from 24 countries across Asia (63.7\%), Africa (9.1\%), Europe (18.2\%), North (6.1\%) and South America (3.0\%). The proportions reflect migration numbers in New Zealand, where a majority of international students and work visa holders are reported to originate from countries in Asia (Immigration New Zealand, 2020). However, within the work visa category, 
New Zealand has also seen an influx of nationals from Europe (Immigration New Zealand, 2020). Collectively, the official statistics provide support for the larger proportion of participants who are nationals of Asia and Europe.

Table 5.4: Participating sojourner details $(N=33)$

\begin{tabular}{|c|c|c|}
\hline Profile & Description & $\%$ \\
\hline \multirow[t]{2}{*}{ Gender } & Male & 33.3 \\
\hline & Female & 66.7 \\
\hline \multirow[t]{5}{*}{ Age } & $20-24$ & 12.1 \\
\hline & $25-29$ & 33.3 \\
\hline & $30-34$ & 42.4 \\
\hline & $35-39$ & 9.1 \\
\hline & $40-44$ & 3.0 \\
\hline \multirow{5}{*}{$\begin{array}{l}\text { Annual income } \\
\text { (before tax) }\end{array}$} & No income & 27.3 \\
\hline & NZD 1-25,000 & 27.3 \\
\hline & NZD 25,001-50,000 & 15.2 \\
\hline & NZD 50,001-70,000 & 18.2 \\
\hline & $\geq$ NZD 70,001 & 12.1 \\
\hline \multirow[t]{4}{*}{ Highest qualification } & Bachelor's degree & 27.3 \\
\hline & Postgraduate diploma & 9.1 \\
\hline & Postgraduate degree & 60.6 \\
\hline & $\begin{array}{l}\text { Other (Overseas, NCEA level } 3 \\
\text { equivalent) }\end{array}$ & 3.0 \\
\hline \multirow[t]{7}{*}{ Occupation } & Administrative & 12.1 \\
\hline & Analyst & 3.0 \\
\hline & Policy advisor & 3.0 \\
\hline & Programmer & 6.1 \\
\hline & $\mathrm{PhD}$ researcher & 36.4 \\
\hline & Researcher & 6.1 \\
\hline & Student & 33.3 \\
\hline \multirow[t]{5}{*}{ Region of origin } & Africa & 9.1 \\
\hline & Asia & 63.7 \\
\hline & Europe & 18.2 \\
\hline & North America & 6.1 \\
\hline & South America & 3.0 \\
\hline \multirow[t]{5}{*}{ Time in Wellington } & $<6$ months & 18.2 \\
\hline & 6-12 months & 9.1 \\
\hline & $1-2$ years & 39.4 \\
\hline & $3-5$ years & 27.3 \\
\hline & $>5$ years & 6.1 \\
\hline
\end{tabular}

Figure 5.2 provides an overview of the birthplaces of people living in Wellington born outside of New Zealand, which is indicative of the diversity of the sample of participating 
sojourners. The data further supports the higher proportion of Asian and European participants in this study, where a majority of people living in Wellington born outside of New Zealand were predominantly born in Asia and Europe (including United Kingdom and Ireland). A majority of participating sojourners were also found to fall within the age categories of 30-34 (42.4\%) and 25-29 (33.3\%), mirroring data retrieved from Stats NZ (2020).

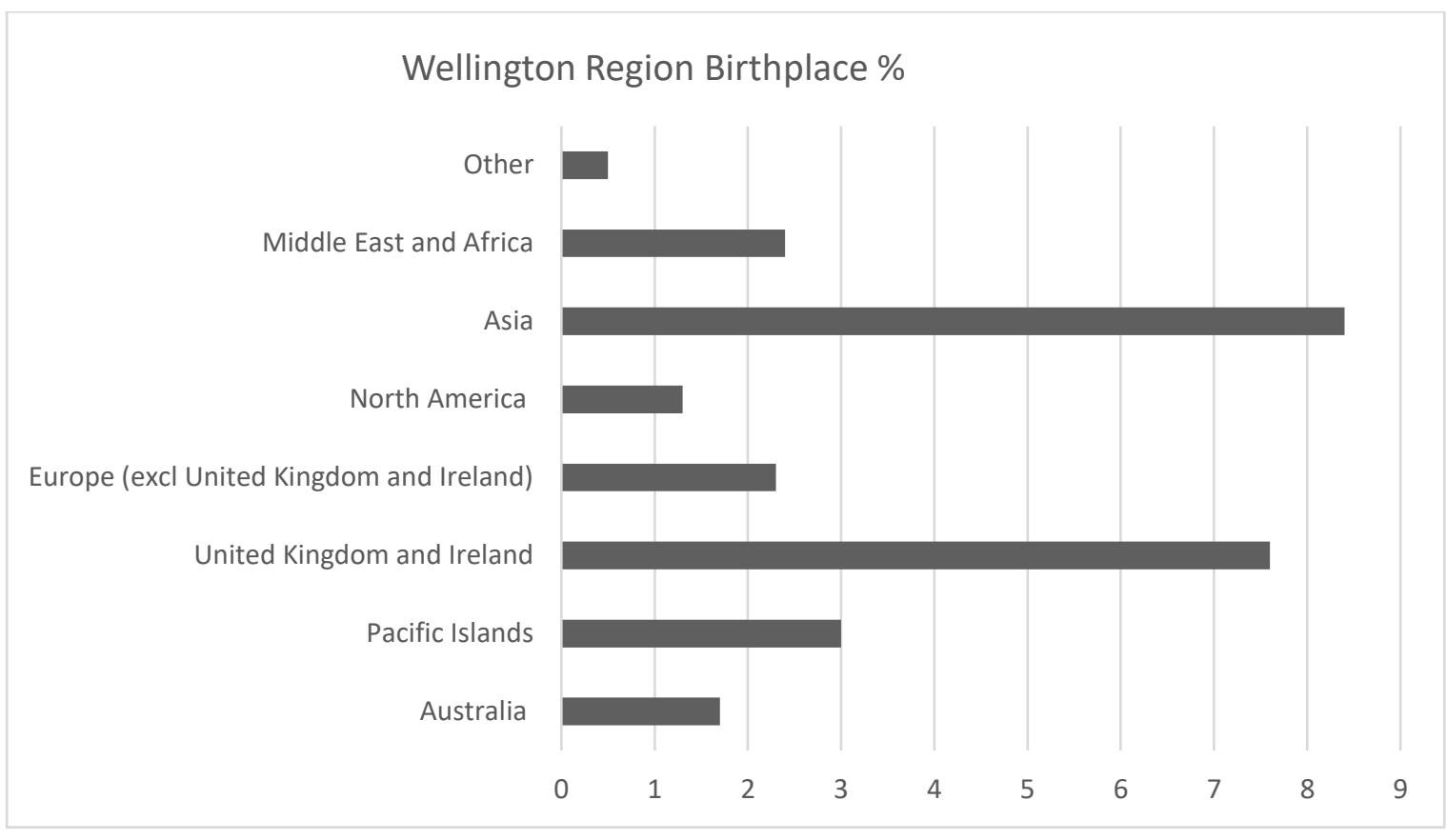

Figure 5.2: Birthplace for people in Wellington Region, 2018 Census (Source: Stats NZ) The majority of participants were also noted to be university graduates, with $69.7 \%$ holding a postgraduate qualification. Wellington's workforce is "knowledge intensive" and has the highest concentration of digital-based firms, as well as research institutions, where Wellington is home to four universities and three polytechnics (Wellington Regional Strategy Committee, 2012, p. 3). Thus, explaining the educated sample and number of student participants.

Information on the online UGI sharing behaviour of sojourners with overseas friends and relatives was also collected. As shown in Table 5.5, instant messaging platforms, such as WhatsApp and Facebook messenger, were found to be popular among sojourners for pushing UGI to overseas networks. As presented in Table 5.5, 39.4\% of sojourners shared UGI through instant messaging platforms a few times a week. Table 5.5 also shows that all sojourners shared images on instant messaging platforms, signalling the significance of closed group networks for the dissemination of UGI. 
Table 5.5: Sojourner UGI sharing habits

\begin{tabular}{|c|c|c|c|c|c|c|}
\hline & \multicolumn{6}{|c|}{ Frequency of UGI sharing } \\
\hline & \multicolumn{2}{|c|}{$\underline{\text { Email }}$} & \multicolumn{2}{|c|}{ Instant messaging } & \multicolumn{2}{|c|}{$\underline{\text { Social media platforms }}$} \\
\hline & No. & $\%$ & No. & $\%$ & No. & $\%$ \\
\hline Daily & 1 & 3.0 & 8 & 24.2 & 7 & 21.2 \\
\hline A few times a week & 2 & 6.1 & 13 & 39.4 & 8 & 24.2 \\
\hline A few times a month & 8 & 24.2 & 8 & 24.2 & 11 & 33.3 \\
\hline$<$ once a month & 13 & 39.4 & 4 & 12.1 & 6 & 18.2 \\
\hline Never & 9 & 27.3 & 0 & 0.0 & 1 & 3 \\
\hline Total & 33 & - & 33 & - & 33 & - \\
\hline
\end{tabular}

\subsubsection{Visual data validation.}

Balomenou and Garrod (2016) stress that the number of PGI participants is arguably less important than the number of photographs submitted by participants. A total of 495 images were submitted by sojourners. Thus, falling within the typical 100-500 photograph range of prior studies that utilise PGI (Balomenou \& Garrod, 2016). The images submitted were coded by three coders, not part of the research project. From the results of the coding exercise, Fleiss' kappa was calculated to establish reliability and validity of the images. Fleiss' kappa is generally used when there are three or more coders (DeCuir-Gunby et al., 2011).

Landis and Koch (1977) suggest scores below zero (0), .0 - .20, .41 - .60 and .61 - .80 indicate poor, slight, moderate, substantial and almost perfect agreement. The overall Fleiss kappa was .77 above the desired level of 0.61 (Appendix L). Images that had conflicting results were discussed with coders and if unresolved, images were discarded. In some instances, sojourners provided duplicates, and images not of Wellington. For example, an image of an American football game was submitted, and discarded. In total 453 images became the root stimuli assessed in the quantitative (Phase 2) and qualitative (Phase 3 ) phases of this study.

\subsubsection{Measures of iWOM.}

Conceptualised as visual articulations of destination experience and image that have the capacity to shape attitudes and behaviours, iWOM is measured through the affective and cognitive items found in destination image measures. The expert interviews were conducted to elicit key cognitive destination attributes, which in literature are not fixed (Papadimitriou 
et al., 2018) and primarily derived through exploartory qualitative findings (Beerli and Martin, 2004a).

On account of the findings of the Phase 1 expert interviews (Section 5.1) and items established in the destination image literature (e.g. Crompton, 1979; Kim \& Stepchenkova, 2015; Molinillo, Liébana-Cabanillas, Anaya-Sánchez, \& Buhalis, 2018; Walmsley \& Young, 1998), semantic-differential scale items COG 1-5 were found to fit the research context of Wellington. Given the salience of a "creative Wellington" during the expert interviews, the item creative-unimaginative (COG 6) was added. To the knowledge of this author, "creative" has not been used as a cognitive attribute in the extant destination image literature. However, given the prominence of the attribute, it was included. Consequently, the six cognitive (COG) items identified were used to measure iWOM, alongside the four commonly used affective (AFF) items in the assessment of destination image (Molinillo et al., 2018; Papadimitriou et al., 2018). The response scales comprised a seven-point semantic differential scale.

Based on the photograph, I would describe the Greater Wellington Region as:

\begin{tabular}{|c|c|c|c|}
\hline Construct & Variable & Item & Source selected literature \\
\hline \multirow{10}{*}{ iWOM } & COG_1 & Developed-Underdeveloped & Kim \& Stepchenkova (2015) \\
\hline & COG_2 & Attractive-Unattractive & Walmsley \& Young (1998) \\
\hline & COG_3 & Unique-Ordinary & $\begin{array}{l}\text { Crompton (1979) ; Kim \& } \\
\text { Stepchenkova (2015) }\end{array}$ \\
\hline & COG_4 & Vibrant-Dull & Young (1995) \\
\hline & COG_5 & Friendly-Unfriendly & $\begin{array}{l}\text { Martínez \& Alvarez (2010); } \\
\text { Young (1995) }\end{array}$ \\
\hline & COG_6 & Creative-Unimaginative & New \\
\hline & AFF_1 & Pleasant-Unpleasant & \multirow{4}{*}{$\begin{array}{l}\text { Hosany et al., (2006); Molinillo } \\
\text { et al. (2018) }\end{array}$} \\
\hline & AFF_2 & Relaxing-Distressing & \\
\hline & AFF_3 & Exciting-Gloomy & \\
\hline & AFF_4 & Arousing-Sleepy & \\
\hline
\end{tabular}

The composite scores of the semantic-differential scales represent an overall evaluation of affective and cognitive components that make up the image of the host destination, conveyed through iWOM (Crompton, 1979).

\subsection{Phase 2 (QUAN): Web survey}

From the results of the expert interviews, items used to measure iWOM were confirmed, and included in the Web survey that was completed by overseas friends and relatives of 
sojourners. The images provided by the sojourners were embedded into the respective Web surveys and served as iWOM stimuli.

\subsubsection{Data screening and preliminary analysis.}

\subsubsection{Data screening and missing data.}

Links to the dyadic Web surveys were distributed in September 2018, and the data collection continued until the end of December 2018. In total 240 surveys were received. The surveys were first screened to ensure that all respondents met the age and online use criteria. All participants were aged 18 and over and used online platforms to communicate with the sojourner. The surveys were then screened for missing values. Although a pre-test was conducted to minimise the ambiguity of survey questions, and to encourage respondents to complete the survey, missing data was still observed in the results. The Hair et al. (2014) guidelines for deleting cases or variables, includes the conundrum that researchers must be prepared to "compromise between the gains from deleting variables and/or cases with missing data versus the reduction in sample size and variables" (p. 46).

In this study, cases with missing values were deleted. Therefore, 134 usable surveys, from 28 dyads were received out of 33 possible dyads (approximately $84 \%$ response rate). Out of the 134 surveys, 14 respondents were found to have visited Wellington. To minimise confounding effects, results from the 14 respondents were removed from the analysis, reducing the data set to 120 completed surveys from the overseas network of sojourners.

\subsubsection{Demographic overview of participating overseas friends and relatives.}

Table 5.6 shows the demographic profile of respondents to the Web survey. There were approximately $69 \%$ female and $31 \%$ male respondents. Sixty-seven percent of the respondents were located in Asia, 19\% in Europe, 12\% in North America, 10\% in Africa, and a smaller proportion in the Pacific (1.6\%) and South America $(0.8 \%)$. The percentages of male and female respondents corresponded with the number of male and female participating sojourners, where a higher percentage of female $(66.7 \%)$ than male $(33.3 \%)$ participants were observed in the Web survey. 
Table 5.6: Web survey respondent profile $(N=120)$

\begin{tabular}{|c|c|c|c|}
\hline Profile & Description & No. & $\%$ \\
\hline \multirow[t]{2}{*}{ Gender } & Male & 37 & 30.83 \\
\hline & Female & 83 & 69.17 \\
\hline \multirow[t]{6}{*}{ Age } & $18-24$ & 9 & 7.50 \\
\hline & $25-34$ & 75 & 62.50 \\
\hline & $35-44$ & 24 & 20.00 \\
\hline & $45-54$ & 4 & 3.33 \\
\hline & $55-64$ & 4 & 3.33 \\
\hline & $\geq 65$ & 4 & 3.33 \\
\hline \multirow[t]{7}{*}{ Annual income } & No income & 11 & 9.17 \\
\hline & Under USD 25,000 & 60 & 50.00 \\
\hline & USD 25,000-49,999 & 25 & 20.83 \\
\hline & USD 50,000-74,999 & 12 & 10.00 \\
\hline & USD 75,000-99,999 & 7 & 5.83 \\
\hline & USD 100,000-199,999 & 3 & 2.50 \\
\hline & USD 200,000 and higher & 2 & 1.67 \\
\hline \multirow{6}{*}{ Highest qualification } & Secondary education & 5 & 4.17 \\
\hline & Trade/technical/vocational training & 4 & 3.33 \\
\hline & Some tertiary education & 9 & 7.50 \\
\hline & Bachelor's degree & 51 & 42.50 \\
\hline & Postgraduate degree & 48 & 40.00 \\
\hline & Other (undisclosed) & 3 & 2.50 \\
\hline \multirow[t]{4}{*}{ Marital status } & Single & 47 & 39.17 \\
\hline & Married & 62 & 51.67 \\
\hline & Separated/divorced & 5 & 4.17 \\
\hline & Other (e.g. engaged, partner) & 6 & 5.00 \\
\hline \multirow[t]{6}{*}{ Location } & Africa & 12 & 10.00 \\
\hline & Asia & 67 & 55.83 \\
\hline & Europe & 23 & 19.17 \\
\hline & North America & 15 & 12.50 \\
\hline & Pacific & 2 & 1.67 \\
\hline & South America & 1 & 0.83 \\
\hline \multirow[t]{5}{*}{ Ethnicity } & African & 14 & 11.67 \\
\hline & Asian & 76 & 63.33 \\
\hline & Caucasian & 27 & 22.50 \\
\hline & Middle Eastern & 2 & 1.67 \\
\hline & Pacific Islander & 1 & 0.83 \\
\hline \multirow[t]{11}{*}{ Occupation } & Civil servant & 2 & 1.67 \\
\hline & Clerical/sales & 12 & 10.00 \\
\hline & Craftsman/factory worker & 1 & 0.83 \\
\hline & Manager/executive & 8 & 6.67 \\
\hline & Professional/technical & 68 & 56.67 \\
\hline & Retired & 2 & 1.67 \\
\hline & Self-employed/freelancer & 6 & 5.00 \\
\hline & Service Staff & 3 & 2.50 \\
\hline & Student & 13 & 10.83 \\
\hline & Unemployed & 3 & 2.50 \\
\hline & Undisclosed & 2 & 1.67 \\
\hline
\end{tabular}


Similarly, the location of participating friends and relatives mirrored the country of origin of participating sojourners, where a greater percentage of participating sojourners originated from Asia (63.6\%) and Europe (18.2\%). Given that the majority of participants were located in Asia, it was expected that the ethnicity of participants of the Web survey would be predominantly Asian (63\%). In addition, $62.5 \%$ of participants were between the ages of 25 and 34, corresponding to the age groups of the sojourner. Moreover, based on the results of a global survey conducted by market research firm Statista (2019), a majority of social media users fall within the age bracket of 25 and 34 years, further support the high proportion of respondents aged between 25 and 34 .

In line with the trend observed in recent studies, a large proportion of respondents were graduate $(42.5 \%)$ and postgraduate $(40 \%)$ degree holders (e.g. Bruwer, Pratt, Saliba, \& Hirche, 2017; Jalilvand \& Heidari, 2017; Phau, Shanka, \& Dhayan, 2010; Whang, Yong, \& Ko, 2016). According to findings of a recent study conducted by the Organisation for Economic Co-operation and Development (OECD), of member states across Asia, North America and Europe, the proportion of 25-34 year olds with higher-education qualifications was larger than the proportion of people with only upper secondary education (ICEF Monitor, 2019). Thus, providing a potential explanation for the upward trend in the number of graduate and postgraduate degree holders seen in recent studies, as well as this study — where $62.5 \%$ of participants were within the age bracket of 25-34.

\subsubsection{Unit of analysis.}

The unit of analysis for Phase 2 is the number of total observations. Observations are instances when an image embedded in the Web survey is rated by overseas friends/relatives of sojourners. Table 5.7 provides a summary of the number of observations, derived from the 120 surveys received from 28 networks, across the four fixed categories.

Table 5.7: Total number of observations

\begin{tabular}{lccc}
\hline \multirow{2}{*}{ Image category } & \multicolumn{3}{c}{ Number of observations } \\
\cline { 2 - 4 } & Friends & Relatives & Complete \\
\hline Events & 231 & 130 & 361 \\
Food and drinks/dining & 222 & 106 & 328 \\
Urban city & 293 & 152 & 445 \\
Nature/scenic landscape & 282 & 149 & 431 \\
Total observations & $\mathbf{1 , 0 2 8}$ & $\mathbf{5 3 7}$ & $\mathbf{1 , 5 6 5}$ \\
\hline
\end{tabular}


To minimise confounding results, images that could not be classified into the four fixed categories were not included in the Web survey. From the visual data validation exercise (section 5.2.2), a large number of images from "your pick" were recoded by the researcher into one of the existing fixed categories and included in the Web survey.

\subsubsection{Sample size and power.}

According to Hair et al. (2017), an insufficient sample size could result in Type II errors (underestimation of effect size). The 10-times rule is a common a-priori method cited to determine appropriate sample sizes for PLS-SEM analyses (Hair et al., 2017). Based on the 10-times rule, the minimum number of observations required for this study would be 100 observations, given that the largest number of structural paths directed at the construct of iWOM is 10 (Barclay, Higgins, \& Thompson, 1995). However, the 10-times approach is described as a rough guide, and is criticised for producing inaccurate estimations from the minimum sample size required (Hair et al., 2017; Kock \& Hadaya, 2018). Researchers are advised to determine sample size by means of power analysis (Hair et al., 2017), to ensure representativeness of their sample (do Valle \& Assaker, 2016). Power analysis determines the minimum sample size by considering the part of the model with the greatest number of predictors (Memon et al., 2020).

In this study, G*Power, a power analysis programme, was used as an a-priori method to determine the minimum number of observations required for analysis (Faul, Erdfelder, Buchner, \& Lang, 2009; Mayr, Erdfelder, Buchner, \& Faul, 2007; Memon et al., 2020). Based on the results, and following the steps provided by Memon et al. (2020) a minimum number of 98 observations was required to achieve $80 \%$ power, with a medium effect size (0.15). Table 5.7 shows that the total number of observations surpassed the minimum of 98 .

\subsubsection{Common method variance.}

Common method variance (CMV) is "variance that is attributable to the measurement method rather than to the constructs the measure represents" (Podsakoff et al., 2003, p. 879). CMV has been linked to measurement error that threatens the validity of observed relationships between constructs, which result in Type I and Type II errors (Chang, Van Witteloostuijn, \& Eden, 2010; Podsakoff et al., 2003). In particular, self-reported or cross-sectional surveys, such as the one used in this study, are noted to be prone to CMV (Chang et al., 2010; Rindfleisch, Malter, Ganesan, \& Moorman, 2008). 
Scholars suggest several remedies to control and check for CMV, which are implemented exante research design and ex-post statistical analyses (Chang et al., 2010; Podsakoff, MacKenzie, \& Podsakoff, 2012). To mitigate issues relating to CMV, the following recommended ex-ante remedies were applied: 1) different response formats were used, where the survey applied both semantic differential and Likert type scales; 2) a pre-test was conducted to reduce ambiguity; and 3) participants were assured that there were no right or wrong answers and urged to provide honest responses that reflected their own opinions. Moreover, to reduce respondent apprehension of completing the online survey, respondents were guaranteed confidentiality (Podsakoff et al., 2003). Harman's single-factor test was conducted ex-post to determine the degree of CMV present (Chang et al., 2010). The results from the Harman's single factor test indicate no single factor accounted for more than $50 \%$, where the largest factor accounted for $47.2 \%$ of the variance of items (Harman, 1976). Thus, common method variance is not an issue in this study (see Appendix $\mathrm{M}$ for results).

\subsubsection{Non-response bias.}

Another form of bias that requires consideration is non-response bias, where significant differences between results of response and non-response surveys, threaten the validity and generalisability of the results obtained (Bosnjak, Tuten, \& Wittmann, 2005; O'Leary, 2004). According to Fowler (2014) non-response occurs largely when: 1) the survey does not reach intended respondents, thereby not giving them a chance to respond; 2) the respondent refuses to participate; and 3) those asked to complete the survey might have problems completing the survey. To test for non-response bias, early respondents (responses received after first mailing of the survey link) were compared against late respondents (responses received after a reminder was sent). A person who responds late is viewed to be similar to non-respondents, where without reminders, it would be likely that a response would not be received (Armstrong \& Overton, 1977; Groves, 2006). Similar to the study conducted by Riefler, Diamantopoulos and Siguaw (2012) early and late respondents made up of approximately one third of the total number of respondents.

Results from 40 early respondents and 33 late respondents were analysed. According to Pallant (2013), to determine significant differences between groups, the equality of mean scores is assessed, through an independent $t$-test. The results of the $t$-test are presented in Appendix N. The results indicate no significant differences between early (ER; $n=40)$ and late respondents $(\mathrm{LR} ; n=33)$ for the variable TS $\left(\mathrm{Mean}_{\mathrm{ER}}=6.26 ; \operatorname{Mean}_{\mathrm{LR}}=5.89 ; t(73)=\right.$ 
$1.691, p=.095$, two-tailed). The tested constructs iWOM, IMP and INT were also checked for non-response bias for the image categories: Events, Food and drinks/dining, Nature/scenic landscape and Urban city.

Using the observations of early and late respondents, the constructs iWOM, IMP and INT were statistically non-significant $(p>.05)$ for a majority of the image categories tested. However, significant differences were observed in the category Nature/scenic landscape. As presented in Appendix N, early respondents responded more positively than late respondents. The "interest hypothesis" offers an explanation for the significant difference, where early survey respondents are assumed to respond in accordance to their interest (Armstrong \& Overton, 1977, p. 397). Overall, it is reasonable to conclude that non-response bias is not a substantial issue in this study.

\subsubsection{Normality of data.}

Normal distributions of data are fundamental starting points for multivariate analyses, and are among the factors used to inform the researcher's choice of statistical technique (O'Leary, 2004). Normal distributions of data are represented by a symmetrical bell-shaped curve, where the greatest frequency of scores cluster in the middle, while smaller frequencies are found towards the ends of the bell-shaped curve (Pallant, 2013). To assess normality, skewness and kurtosis values were checked, using descriptive statistics. The skewness indicates the symmetry of the distribution, while kurtosis provides information on the "peakedness" of the distribution (Pallant, 2013).

In sum, the two measures of distributions allowed the researcher to infer the extent into which the data deviated from normality. Burns and Burns (2008) suggest a violation of normality occurs when skewness and kurtosis values surpass \pm 2 and \pm 3 , respectively. Given the relationship between the sojourner and his/her overseas network, it was anticipated that friends and relatives of the sojourner would respond more positively than negatively, when asked about their relationship with the sojourner potentially resulting in a skewed data distribution, in particular for items used to measure tie strength.

As seen in Table 5.8, only the data distribution for the "spend free time" item relating to tie strength was slightly skewed with corresponding high kurtosis. The "Closeness" tie strength item for relatives showed high level of kurtosis, as did "Perform large favour" tie strength item for friends. Violations of normality assumptions is often found in the social sciences, and can be overcome through sophisticated data analysis techniques such as bootstrapping, a 
feature found in PLS-SEM (Hair et al., 2011). Bootstrapping is a robust "non-parametric resampling procedure that assesses the variability of a statistic by examining the variability of the sample data rather than using parametric assumptions" to examine accuracy of the estimates (Streukens \& Leroi-Werelds, 2016, p. 619). Therefore, given the relatively few items exhibiting high skewness and kurtosis, and using PLS-SEM, with bootstrapping, data normality was not considered a significant issue. 
Table 5.8: Descriptive statistics

\begin{tabular}{|c|c|c|c|c|c|c|c|c|c|}
\hline \multirow[t]{2}{*}{ Data set } & \multirow[t]{2}{*}{ Construct } & \multirow[t]{2}{*}{ Variable } & \multirow[t]{2}{*}{ Item } & \multirow{2}{*}{$\begin{array}{l}\text { Mean } \\
\text { Statistic }\end{array}$} & \multirow[t]{2}{*}{ Std. Deviation } & \multicolumn{2}{|l|}{ Skewness } & \multicolumn{2}{|l|}{ Kurtosis } \\
\hline & & & & & & Statistic & $\begin{array}{l}\text { Std. } \\
\text { Error }\end{array}$ & Statistic & $\begin{array}{l}\text { Std. } \\
\text { Error }\end{array}$ \\
\hline \multirow[t]{20}{*}{$\begin{array}{l}\text { Complete } \\
(N=1,565)\end{array}$} & \multirow[t]{10}{*}{ iWOM } & COG_1 & $\begin{array}{l}\text { Developed- } \\
\text { Underdeveloped }\end{array}$ & 5.335 & 1.433 & -0.509 & 0.062 & -0.347 & 0.124 \\
\hline & & COG_2 & Attractive-Unattractive & 5.452 & 1.506 & -0.818 & 0.062 & 0.119 & 0.124 \\
\hline & & COG_3 & Unique-Ordinary & 5.156 & 1.548 & -0.569 & 0.062 & -0.189 & 0.124 \\
\hline & & COG_4 & Vibrant-Dull & 5.169 & 1.500 & -0.556 & 0.062 & -0.177 & 0.124 \\
\hline & & COG_5 & Friendly-Unfriendly & 5.505 & 1.389 & -0.666 & 0.062 & -0.158 & 0.124 \\
\hline & & COG_6 & Creative-Unimaginative & 5.213 & 1.457 & -0.458 & 0.062 & -0.286 & 0.124 \\
\hline & & AFF_1 & Pleasant-Unpleasant & 5.678 & 1.470 & -1.098 & 0.062 & 0.746 & 0.124 \\
\hline & & AFF_2 & Relaxing-Distressing & 5.580 & 1.462 & -0.972 & 0.062 & 0.489 & 0.124 \\
\hline & & AFF_3 & Exciting-Gloomy & 5.318 & 1.486 & -0.631 & 0.062 & -0.100 & 0.124 \\
\hline & & AFF_4 & Arousing-Sleepy & 5.104 & 1.492 & -0.448 & 0.062 & -0.243 & 0.124 \\
\hline & $\begin{array}{l}\text { Impression towards } \\
\text { destination }\end{array}$ & IMP & Impression & 5.510 & 1.290 & -0.671 & 0.062 & 0.070 & 0.124 \\
\hline & \multirow[t]{5}{*}{ Intention to visit } & INT_1 & Seek information & 5.112 & 1.500 & -0.743 & 0.062 & 0.037 & 0.124 \\
\hline & & INT_2 & Visit in the near future & 5.145 & 1.460 & -0.690 & 0.062 & 0.020 & 0.124 \\
\hline & & INT_3 & Seek out experience & 5.204 & 1.502 & -0.770 & 0.062 & 0.080 & 0.124 \\
\hline & & INT_4 & Travel to spend time & 5.338 & 1.354 & -0.745 & 0.062 & 0.294 & 0.124 \\
\hline & & INT_5 & $\begin{array}{l}\text { Stay in private } \\
\text { accommodation }\end{array}$ & 5.231 & 1.484 & -0.791 & 0.062 & 0.082 & 0.124 \\
\hline & \multirow[t]{4}{*}{ Tie strength } & TS1 & Share confidences & 6.125 & 1.037 & -1.358 & 0.062 & 1.956 & 0.124 \\
\hline & & TS2 & Perform large favour & 6.239 & 1.003 & -1.982 & 0.062 & 6.207 & 0.124 \\
\hline & & TS3 & Spend free time & 6.378 & 1.041 & -2.424 & 0.062 & 7.827 & 0.124 \\
\hline & & TS4 & Closeness & 5.914 & 1.232 & -1.280 & 0.062 & 1.867 & 0.124 \\
\hline
\end{tabular}


Table 5.8: (continued)

\begin{tabular}{|c|c|c|c|c|c|c|c|c|c|}
\hline \multirow[t]{2}{*}{ Data set } & \multirow[t]{2}{*}{ Construct } & \multirow[t]{2}{*}{ Variable } & \multirow[t]{2}{*}{ Item } & \multirow{2}{*}{$\begin{array}{l}\text { Mean } \\
\text { Statistic }\end{array}$} & \multirow{2}{*}{$\begin{array}{l}\text { Std. Deviation } \\
\text { Statistic }\end{array}$} & \multicolumn{2}{|l|}{ Skewness } & \multicolumn{2}{|l|}{ Kurtosis } \\
\hline & & & & & & Statistic & $\begin{array}{l}\text { Std. } \\
\text { Error }\end{array}$ & Statistic & $\begin{array}{l}\text { Std. } \\
\text { Error }\end{array}$ \\
\hline \multirow[t]{20}{*}{$\begin{array}{l}\text { Friends } \\
(n=1,028)\end{array}$} & \multirow[t]{10}{*}{ iWOM } & $\mathrm{COG}_{-} 1$ & $\begin{array}{l}\text { Developed- } \\
\text { Underdeveloped }\end{array}$ & 5.204 & 1.414 & -0.415 & 0.076 & -0.334 & 0.152 \\
\hline & & COG_2 & Attractive-Unattractive & 5.260 & 1.529 & -0.662 & 0.076 & -0.110 & 0.152 \\
\hline & & COG_3 & Unique-Ordinary & 4.962 & 1.516 & -0.436 & 0.076 & -0.214 & 0.152 \\
\hline & & $\mathrm{COG}_{-}^{-} 4$ & Vibrant-Dull & 4.987 & 1.490 & -0.440 & 0.076 & -0.229 & 0.152 \\
\hline & & COG_5 & Friendly-Unfriendly & 5.349 & 1.397 & -0.501 & 0.076 & -0.355 & 0.152 \\
\hline & & COG_6 & Creative-Unimaginative & 5.112 & 1.437 & -0.341 & 0.076 & -0.361 & 0.152 \\
\hline & & AFF_1 & Pleasant-Unpleasant & 5.486 & 1.516 & -0.936 & 0.076 & 0.373 & 0.152 \\
\hline & & AFF_2 & Relaxing-Distressing & 5.413 & 1.495 & -0.839 & 0.076 & 0.210 & 0.152 \\
\hline & & AFF_3 & Exciting-Gloomy & 5.156 & 1.481 & -0.543 & 0.076 & -0.132 & 0.152 \\
\hline & & $\mathrm{AFF}_{-} 4$ & Arousing-Sleepy & 4.982 & 1.464 & -0.356 & 0.076 & -0.173 & 0.152 \\
\hline & $\begin{array}{l}\text { Impression towards } \\
\text { destination }\end{array}$ & IMP & Impression & 5.328 & 1.300 & -0.382 & 0.076 & -0.469 & 0.152 \\
\hline & \multirow[t]{5}{*}{ Intention to visit } & INT_1 & Seek information & 4.839 & 1.515 & -0.522 & 0.076 & -0.273 & 0.152 \\
\hline & & INT_2 & Visit in the near future & 4.895 & 1.461 & -0.497 & 0.076 & -0.261 & 0.152 \\
\hline & & INT_3 & Seek out experience & 4.989 & 1.500 & -0.587 & 0.076 & -0.130 & 0.152 \\
\hline & & INT_4 & Travel to spend time & 5.112 & 1.341 & -0.508 & 0.076 & -0.071 & 0.152 \\
\hline & & INT_5 & $\begin{array}{l}\text { Stay in private } \\
\text { accommodation }\end{array}$ & 5.105 & 1.507 & -0.654 & 0.076 & -0.177 & 0.152 \\
\hline & \multirow[t]{4}{*}{ Tie strength } & $\mathrm{TS} 1$ & Share confidences & 6.033 & 1.108 & -1.326 & 0.076 & 1.778 & 0.152 \\
\hline & & $\mathrm{TS} 2$ & Perform large favour & 6.129 & 1.122 & -1.879 & 0.076 & 5.033 & 0.152 \\
\hline & & TS3 & Spend free time & 6.399 & 0.937 & -2.015 & 0.076 & 5.393 & 0.152 \\
\hline & & TS4 & Closeness & 5.701 & 1.247 & -1.084 & 0.076 & 1.545 & 0.152 \\
\hline
\end{tabular}


Table 5.8: (continued)

\begin{tabular}{|c|c|c|c|c|c|c|c|c|c|}
\hline \multirow[t]{2}{*}{ Data set } & \multirow[t]{2}{*}{ Construct } & \multirow[t]{2}{*}{ Variable } & \multirow[t]{2}{*}{ Item } & \multirow{2}{*}{$\begin{array}{l}\text { Mean } \\
\text { Statistic }\end{array}$} & \multirow{2}{*}{$\begin{array}{l}\text { Std. Deviation } \\
\text { Statistic }\end{array}$} & \multicolumn{2}{|l|}{ Skewness } & \multicolumn{2}{|l|}{ Kurtosis } \\
\hline & & & & & & Statistic & $\begin{array}{l}\text { Std. } \\
\text { Error }\end{array}$ & Statistic & $\begin{array}{l}\text { Std. } \\
\text { Error }\end{array}$ \\
\hline \multirow[t]{20}{*}{$\begin{array}{l}\text { Relatives } \\
(n=537)\end{array}$} & \multirow[t]{10}{*}{ iWOM } & $\mathrm{COG}_{2} 1$ & $\begin{array}{l}\text { Developed- } \\
\text { Underdeveloped }\end{array}$ & 5.587 & 1.438 & -0.739 & 0.105 & -0.156 & 0.210 \\
\hline & & COG_2 & Attractive-Unattractive & 5.821 & 1.389 & -1.198 & 0.105 & 1.100 & 0.210 \\
\hline & & COG_3 & Unique-Ordinary & 5.527 & 1.543 & -0.921 & 0.105 & 0.318 & 0.210 \\
\hline & & COG_4 & Vibrant-Dull & 5.518 & 1.457 & -0.845 & 0.105 & 0.278 & 0.210 \\
\hline & & COG_5 & Friendly-Unfriendly & 5.804 & 1.323 & -1.048 & 0.105 & 0.708 & 0.210 \\
\hline & & COG_6 & Creative-Unimaginative & 5.406 & 1.478 & -0.707 & 0.105 & 0.037 & 0.210 \\
\hline & & $\mathrm{AFF}_{-} 1$ & Pleasant-Unpleasant & 6.045 & 1.302 & -1.498 & 0.105 & 2.110 & 0.210 \\
\hline & & AFF_2 & Relaxing-Distressing & 5.899 & 1.341 & -1.286 & 0.105 & 1.460 & 0.210 \\
\hline & & AFF_3 & Exciting-Gloomy & 5.628 & 1.448 & -0.857 & 0.105 & 0.202 & 0.210 \\
\hline & & AFF_4 & Arousing-Sleepy & 5.337 & 1.519 & -0.666 & 0.105 & -0.168 & 0.210 \\
\hline & $\begin{array}{l}\text { Impression towards } \\
\text { destination }\end{array}$ & IMP & Impression & 5.858 & 1.198 & -1.379 & 0.105 & 2.573 & 0.210 \\
\hline & \multirow[t]{5}{*}{ Intention to visit } & INT_1 & Seek information & 5.635 & 1.323 & -1.334 & 0.105 & 1.947 & 0.210 \\
\hline & & INT_2 & Visit in the near future & 5.624 & 1.334 & -1.209 & 0.105 & 1.637 & 0.210 \\
\hline & & INT_3 & Seek out experience & 5.616 & 1.419 & -1.256 & 0.105 & 1.286 & 0.210 \\
\hline & & INT_4 & Travel to spend time & 5.771 & 1.270 & -1.400 & 0.105 & 2.424 & 0.210 \\
\hline & & INT_5 & $\begin{array}{l}\text { Stay in private } \\
\text { accommodation }\end{array}$ & 5.471 & 1.41 & -1.095 & 0.105 & 0.927 & 0.210 \\
\hline & \multirow[t]{4}{*}{ Tie strength } & TS1 & Share confidences & 6.302 & 0.859 & -1.119 & 0.105 & 0.512 & 0.210 \\
\hline & & $\mathrm{TS} 2$ & Perform large favour & 6.449 & 0.676 & -0.832 & 0.105 & -0.471 & 0.210 \\
\hline & & TS3 & Spend free time & 6.337 & 1.214 & -2.646 & 0.105 & 8.182 & 0.210 \\
\hline & & TS4 & Closeness & 6.322 & 1.094 & -1.970 & 0.105 & 4.325 & 0.210 \\
\hline
\end{tabular}




\subsubsection{Assessment of the model.}

A two-stage approach, comprising a systematic examination of the measurement and structural models was used to analyse the data (Hair, Risher, Sarstedt, \& Ringle, 2019; Sarstedt, Ringle, \& Hair, 2017a). The two-stage approach, as illustrated in Figure 5.3, begins with distinguishing between reflective and formative measured constructs, assessing the reliability and validity of the constructs used in the measurement model, and ends with an examination of the aspects of the structural model such as its predictive capacity and the relationships between constructs.

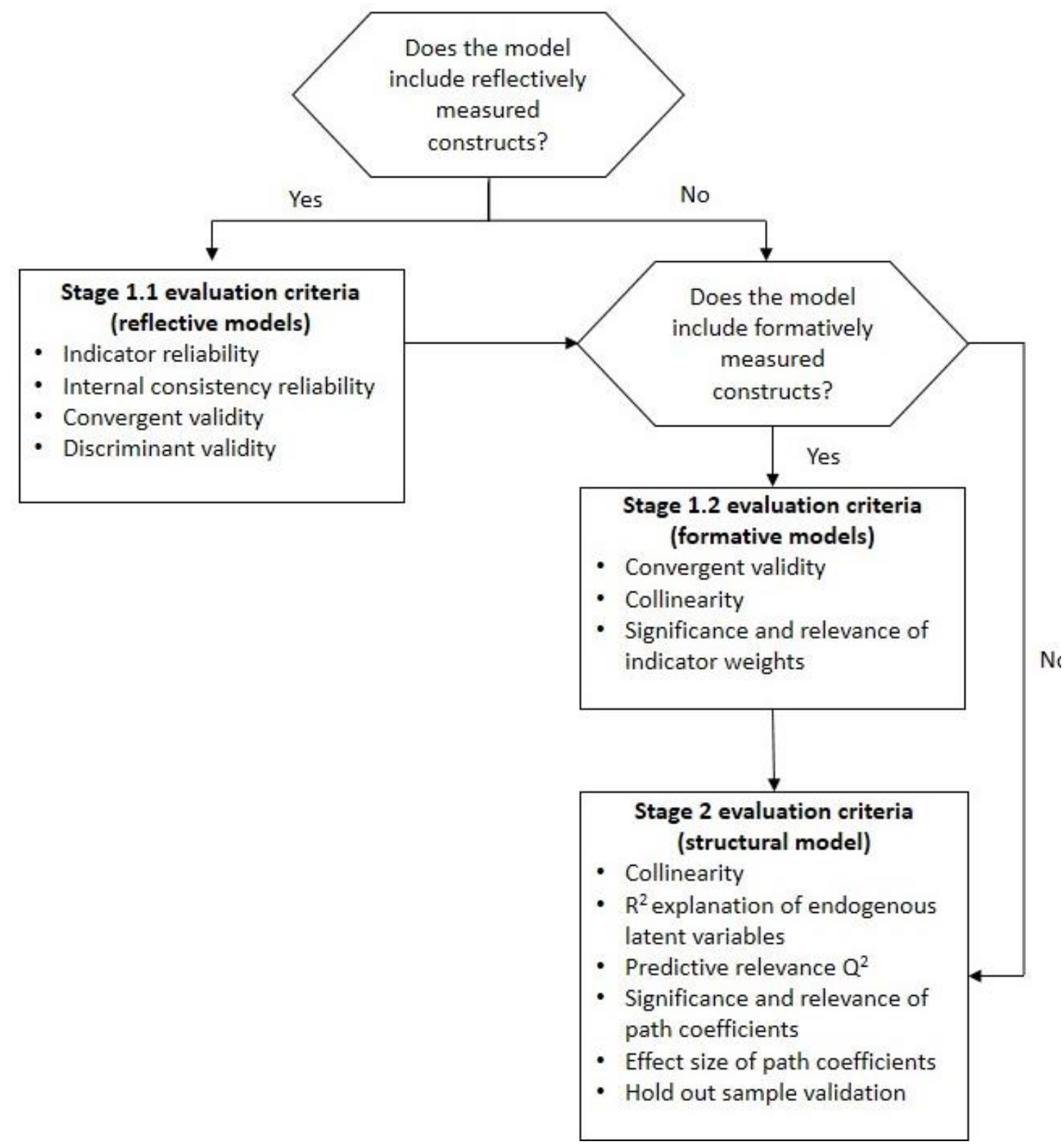

Figure 5.3 PLS-SEM model evaluation (Source: Sarstedt et al., 2017a) 


\subsubsection{Assessment of the measurement model}

The criteria used to assess a PLS measurement model is dependent on whether the model comprises reflective or formative constructs (Hair et al., 2017). Adopting appropriate measurement criteria is necessary to avoid erroneous conclusions (Fornell \& Larcker, 1981). In a model with reflective constructs, the indicators represent manifestations or effects of the reflective construct, and the direction of causality is from the construct to its indicators (Henseler, Ringle, \& Sinkovics, 2009; Jarvis, MacKenzie, \& Podsakoff, 2003). Further, the indicators of a reflective construct are highly correlated, interchangeable, and any single indicator can generally be left out without altering the meaning of the construct (Hair, Sarstedt, Ringle, \& Gudergan, 2018; Jarvis et al., 2003).

In comparison, the indicators of a model with a formative construct would "form the construct by means of a linear combination" (Hair et al., 2017, p. 47). Unlike reflective indicators, formative indicators are not interchangeable and, collectively, the indicators represent relevant dimensions of the construct (Reinartz, Haenlein, \& Henseler, 2009). Given that the measures used are reflective, this study follows the steps in Figure 5.3 used to assess a reflective model.

\subsection{Examining reliability.}

Assessing a reflective measurement model begins with evaluating the indicator loadings, where loadings above .708 signal that the construct explains more than $50 \%$ of the indicator's variance, and is recommended (Hair et al., 2019; Sarstedt et al., 2017a). However, scholars suggest that a value between .40 and .70 is also acceptable (Hair et al., 2017; Hulland, 1999), provided that the impact of deleting the indicator improves the measure(s) composite reliability (CR) or average variance extracted (AVE) scores above recommended thresholds of .70 and .50 , respectively. Loading values from all data sets that were $\leq .70$ (bolded in Table 5.9), were assessed. The deletion of indicators that were $\leq .70$ did not increase the AVE and CR scores above the thresholds. Thus, the indicators from all data sets were retained.

Reliability and validity are central in the assessment of the quality of a reflective measurement model (Hair et al., 2017), and are important to theory building and testing (Bacharach, 1989). Internal consistency reliability is concerned with the homogeneity of items in a scale (DeVellis, 2012). Cronbach's alpha $(\alpha)$ is largely used as a criterion to assess reliability (e.g., Dutt \& Ninov, 2017; Jang, Yu, \& Pearson, 2003; Kim \& Tussyadiah, 2013; 
VanMeter, Grisaffe, \& Chonko, 2015), where internal consistency reliability is estimated through the intercorrelations of the observed indicator variables (Cronbach, 1951).

Generally, Cronbach's $\alpha$ coefficients should be greater than .70 (Ali, Rasoolimanesh, Sarstedt, Ringle, \& Ryu, 2018). However, Cronbach's $\alpha$ is regarded as a conservative indicator of internal consistency reliability (Hair et al., 2017). Composite reliability (CR) was, therefore, used as a supplementary test to establish reliability. CR provides a better means of assessing reliability than Cronbach's $\alpha$ because items are weighted based on the actual loadings of individual indicators of a construct (Oliver, Liehr-gobbers, \& Krafft, 2010). CR values range between 0 and 1, where values above .70 are deemed acceptable (Ali et al., 2018; Hair et al., 2011). As seen in Table 5.9, Cronbach's $\alpha$, and CR values were above the specified thresholds of .70 , indicating reliability.

\subsection{Examining convergent validity.}

The next step taken in evaluating the measurement model was to examine the validity of the construct. To achieve construct validity, convergent and discriminant validity must be established (Bacharach, 1989; DeVellis, 2012). Convergent validity occurs when indicators that measure the same concept are in agreement, whereby in a reflective model, it can be argued that the indicators represent different methods of measuring a latent construct (Oliver et al., 2010).

The AVE was used to determine convergent validity, where AVE represents a common metric used in research reporting (Oliver et al., 2010; Richter, Sinkovics, Ringle, \& Schlägel, 2016). AVE is the squared value of indicators associated with the construct, divided by the total number of indicators (Hair et al., 2017). The minimum threshold for AVE is .50, indicating that the construct explains at least $50 \%$ of the variance of its indicators (Hair et al., 2019). As shown in Table 5.9, all AVEs in each data set are above .50, meeting the requirement for convergent validity. 
Table 5.9: Assessment of measurement model on loading, $\alpha, \mathrm{CR}$ and AVE

\begin{tabular}{|c|c|c|c|c|c|c|c|}
\hline Data Set & Construct & Variable & Item & Loading & $\alpha$ & $\mathrm{CR}$ & AVE \\
\hline \multirow[t]{20}{*}{$\begin{array}{l}\text { Complete } \\
(N=1,565)\end{array}$} & iWOM & COG_1 & $\begin{array}{l}\text { Developed- } \\
\text { Underdeveloped }\end{array}$ & 0.750 & 0.950 & 0.960 & 0.710 \\
\hline & & COG_2 & $\begin{array}{l}\text { Attractive- } \\
\text { Unattractive }\end{array}$ & 0.920 & & & \\
\hline & & COG_3 & Unique-Ordinary & 0.850 & & & \\
\hline & & COG_4 & Vibrant-Dull & 0.860 & & & \\
\hline & & COG_5 & Friendly-Unfriendly & 0.810 & & & \\
\hline & & COG_6 & $\begin{array}{l}\text { Creative- } \\
\text { Unimaginative }\end{array}$ & 0.800 & & & \\
\hline & & AFF_1 & Pleasant-Unpleasant & 0.850 & & & \\
\hline & & AFF_2 & $\begin{array}{l}\text { Relaxing- } \\
\text { Distressing }\end{array}$ & 0.830 & & & \\
\hline & & AFF_3 & Exciting-Gloomy & 0.900 & & & \\
\hline & & AFF_4 & Arousing-Sleepy & 0.850 & & & \\
\hline & Impression & IMP & Impression & 1.000 & 1.000 & 1.000 & 1.000 \\
\hline & $\begin{array}{l}\text { Intention } \\
\text { to visit }\end{array}$ & INT_1 & Seek information & 0.930 & 0.930 & 0.950 & 0.790 \\
\hline & & INT_2 & Visit in near future & 0.950 & & & \\
\hline & & INT_3 & Seek out experience & 0.920 & & & \\
\hline & & INT_4 & Travel to spend time & 0.930 & & & \\
\hline & & INT_5 & $\begin{array}{l}\text { Stay in private } \\
\text { accommodation }\end{array}$ & 0.680 & & & \\
\hline & $\begin{array}{l}\text { Tie } \\
\text { strength }\end{array}$ & TS1 & Share confidences & 0.880 & 0.850 & 0.900 & 0.690 \\
\hline & & $\mathrm{TS} 2$ & $\begin{array}{l}\text { Perform large } \\
\text { favour }\end{array}$ & 0.890 & & & \\
\hline & & TS3 & Spend free time & 0.750 & & & \\
\hline & & TS4 & Closeness & 0.800 & & & \\
\hline
\end{tabular}


Table 5.9: (continued)

\begin{tabular}{|c|c|c|c|c|c|c|c|}
\hline Data Set & Construct & Variable & Item & Loading & $\alpha$ & $\mathrm{CR}$ & AVE \\
\hline \multirow[t]{20}{*}{$\begin{array}{l}\text { Friends } \\
(n=1,028)\end{array}$} & iWOM & COG_1 & $\begin{array}{l}\text { Developed- } \\
\text { Underdeveloped }\end{array}$ & 0.730 & 0.950 & 0.960 & 0.700 \\
\hline & & COG_2 & $\begin{array}{l}\text { Attractive- } \\
\text { Unattractive }\end{array}$ & 0.920 & & & \\
\hline & & COG_3 & Unique-Ordinary & 0.830 & & & \\
\hline & & COG_4 & Vibrant-Dull & 0.850 & & & \\
\hline & & COG_5 & Friendly-Unfriendly & 0.810 & & & \\
\hline & & COG_6 & $\begin{array}{l}\text { Creative- } \\
\text { Unimaginative }\end{array}$ & 0.790 & & & \\
\hline & & AFF_1 & Pleasant-Unpleasant & 0.840 & & & \\
\hline & & AFF_2 & Relaxing-Distressing & 0.820 & & & \\
\hline & & AFF_3 & Exciting-Gloomy & 0.900 & & & \\
\hline & & AFF_4 & Arousing-Sleepy & 0.840 & & & \\
\hline & Impression & IMP & Impression & 1.000 & 1.000 & 1.000 & 1.000 \\
\hline & $\begin{array}{l}\text { Intention to } \\
\text { visit }\end{array}$ & INT_1 & Seek information & 0.930 & 0.930 & 0.950 & 0.790 \\
\hline & & INT_2 & Visit in near future & 0.950 & & & \\
\hline & & INT_3 & Seek out experience & 0.993 & & & \\
\hline & & INT_4 & Travel to spend time & 0.993 & & & \\
\hline & & INT_5 & $\begin{array}{l}\text { Stay in private } \\
\text { accommodation }\end{array}$ & 0.680 & & & \\
\hline & Tie strength & TS1 & Share confidences & 0.890 & 0.900 & 0.930 & 0.760 \\
\hline & & TS2 & Perform large favour & 0.900 & & & \\
\hline & & TS3 & Spend free time & 0.850 & & & \\
\hline & & TS4 & Closeness & 0.850 & & & \\
\hline
\end{tabular}


Table 5.9: (continued)

\begin{tabular}{|c|c|c|c|c|c|c|c|}
\hline Data Set & Construct & Variable & Item & Loading & $\alpha$ & $\mathrm{CR}$ & AVE \\
\hline \multirow[t]{21}{*}{$\begin{array}{l}\text { Relatives } \\
(n=537)\end{array}$} & iWOM & COG_1 & $\begin{array}{l}\text { Developed- } \\
\text { Underdeveloped }\end{array}$ & 0.750 & 0.960 & 0.960 & 0.720 \\
\hline & & COG_2 & $\begin{array}{l}\text { Attractive- } \\
\text { Unattractive }\end{array}$ & 0.910 & & & \\
\hline & & COG_3 & Unique-Ordinary & 0.870 & & & \\
\hline & & COG_4 & Vibrant-Dull & 0.870 & & & \\
\hline & & COG_5 & Friendly-Unfriendly & 0.810 & & & \\
\hline & & COG_6 & Creative- & 0.820 & & & \\
\hline & & & Unimaginative & & & & \\
\hline & & AFF_1 & Pleasant-Unpleasant & 0.870 & & & \\
\hline & & AFF_2 & Relaxing-Distressing & 0.820 & & & \\
\hline & & AFF_3 & Exciting-Gloomy & 0.900 & & & \\
\hline & & AFF_4 & Arousing-Sleepy & 0.850 & & & \\
\hline & Impression & IMP & Impression & 1.000 & 1.000 & 1.000 & 1.000 \\
\hline & Intention & INT_1 & Seek information & 0.920 & 0.920 & 0.940 & 0.760 \\
\hline & to visit & INT_2 & Visit in near future & 0.940 & & & \\
\hline & & INT_3 & Seek out experience & 0.900 & & & \\
\hline & & INT_4 & Travel to spend time & 0.910 & & & \\
\hline & & INT_5 & $\begin{array}{l}\text { Stay in private } \\
\text { accommodation }\end{array}$ & 0.660 & & & \\
\hline & Tie strength & TS1 & Share confidences & 0.830 & 0.730 & 0.830 & 0.560 \\
\hline & & $\mathrm{TS} 2$ & Perform large favour & 0.850 & & & \\
\hline & & TS3 & Spend free time & 0.740 & & & \\
\hline & & TS4 & Closeness & 0.530 & & & \\
\hline
\end{tabular}




\subsection{Examining discriminant validity.}

Discriminant validity provides distinction among the measures of constructs (Bacharach, 1989; Campbell \& Fiske, 1959), where a latent construct should share more variance with its indicators than with the indicators of other latent constructs (Fornell \& Larcker, 1981). To assess discriminant validity, the Fornell-Larcker criterion is typically used (Voorhees, Brady, Calantone, \& Ramirez, 2016). However, the performance of the Fornell-Larcker criterion is increasingly questioned due to the likelihood of yielding overestimated item loadings, particularly in variance-based SEM methods such as PLS (Henseler, Ringle, \& Sarstedt, 2015; Richter et al., 2016; Ringle, Sarstedt, Mitchell, \& Gudergan, 2018; Rönkkö \& Evermann, 2013; Voorhees et al., 2016).

In response to the limitations of the Fornell-Larcker criterion, the heterotrait-monotrait ratio of correlations (HTMT ratio) was introduced. The HTMT ratio is a robust (Franke \& Sarstedt, 2019), and more reliable measure than the Fornell-Larcker criterion in identifying discriminant validity (Henseler et al., 2015; Voorhees et al., 2016). The HTMT criterion involves calculating a ratio of the average correlations among constructs to the geometric mean of the average correlations among items of the same constructs (Voorhees et al., 2016).

The HTMT ratio was used to establish discriminant validity in this study. An HTMT value above 0.90 suggests the absence of discriminant validity (Henseler et al., 2015). Following recommendations made by Hair et al. (2017), a bias-corrected and accelerated bootstrapping procedure, with 5,000 samples, was conducted to assess the confidence intervals (CIs) of the HTMT statistics. As seen in Table 5.10, all the HTMT values were below the cut off value 0.90, and none of the CIs included the value of 1. Henseler et al. (2015) stress that if the CI contains the value of 1, this signals a lack of discriminant validity. The results, shown in Table 5.10, therefore, indicate discriminant validity among constructs. 
Table 5.10: Assessment of discriminant validity using HTMT criterion

\begin{tabular}{|c|c|c|c|c|c|}
\hline Data set & Construct & iWOM & Intention to visit & Impression & Tie strength \\
\hline \multirow{4}{*}{$\begin{array}{l}\text { Complete } \\
(N=1,565)\end{array}$} & iWOM & & & & \\
\hline & Intention to visit & $\begin{array}{l}0.520 \\
{[0.470,0.570]}\end{array}$ & & & \\
\hline & Impression & $\begin{array}{l}0.600 \\
{[0.560,0.650]}\end{array}$ & $\begin{array}{l}0.770 \\
{[0.740,0.800]}\end{array}$ & & \\
\hline & Tie strength & $\begin{array}{l}0.210 \\
{[0.160,0.260]}\end{array}$ & $\begin{array}{l}0.400 \\
{[0.350,0.450]}\end{array}$ & $\begin{array}{l}0.320 \\
{[0.270,0.370]}\end{array}$ & \\
\hline \multirow{4}{*}{$\begin{array}{l}\text { Friends } \\
(n=1,028)\end{array}$} & iWOM & & & & \\
\hline & Intention to visit & $\begin{array}{l}0.500 \\
{[0.430,0.560]}\end{array}$ & & & \\
\hline & Impression & $\begin{array}{l}0.590 \\
{[0.530,0.650]}\end{array}$ & $\begin{array}{l}0.770 \\
{[0.730,0.800]}\end{array}$ & & \\
\hline & Tie strength & $\begin{array}{l}0.180 \\
{[0.120,0.240]}\end{array}$ & $\begin{array}{l}0.420 \\
{[0.360,0.480]}\end{array}$ & $\begin{array}{l}0.340 \\
{[0.280,0.390]}\end{array}$ & \\
\hline \multirow{4}{*}{$\begin{array}{l}\text { Relatives } \\
(n=537)\end{array}$} & iWOM & & & & \\
\hline & Intention to visit & $\begin{array}{l}0.500 \\
{[0.440,0.590]}\end{array}$ & & & \\
\hline & Impression & $\begin{array}{l}0.580 \\
{[0.480,0.670]}\end{array}$ & $\begin{array}{l}0.740 \\
{[0.670,0.800]}\end{array}$ & & \\
\hline & Tie strength & $\begin{array}{l}0.210 \\
{[0.140,0.300]}\end{array}$ & $\begin{array}{l}0.270 \\
{[0.190,0.350]}\end{array}$ & $\begin{array}{l}0.190 \\
{[0.100,0.290]}\end{array}$ & \\
\hline
\end{tabular}




\subsubsection{Assessment of the structural model.}

\subsection{Examining collinearity.}

The assessment of the structural model involves examining the predictive capacity and the relationships between constructs (Hair et al., 2017; Henseler, Hubona, \& Ray, 2017). Before testing the hypotheses, collinearity among constructs was examined. In PLS path models, the estimation of path coefficients is based on ordinary least squares (OLS) regressions of each endogenous latent construct on a specified exogenous construct. Thus, similar to ordinary multiple regressions, critical levels of collinearity could result in biased path coefficients (Hair et al., 2017; Mason \& Perreault, 1991). To identify collinearity issues, the variance inflation factor (VIF) of each construct was examined. According to Hair et al. (2019), VIF values should be $<3$. The VIF values, as seen in Table 5.11, fall between 1.030 and 1.540. The VIF scores meet the recommended value of $<3$, indicating collinearity is not a critical issue in this study.

Table 5.11: Collinearity assessment

\begin{tabular}{lll}
\hline Data set & Relationship & VIF \\
\hline $\begin{array}{l}\text { Complete } \\
(N=1,565)\end{array}$ & IWOM $\rightarrow$ Intention to visit & 1.540 \\
& IWOM $\rightarrow$ Impression & 1.040 \\
& Impression $\rightarrow$ Intention to visit & 1.540 \\
& Tie strength $\rightarrow$ Impression & 1.040 \\
\hline $\begin{array}{l}\text { Friends } \\
(n=1,028)\end{array}$ & IWOM $\rightarrow$ Intention to visit & 1.500 \\
& IWOM $\rightarrow$ Impression & 1.030 \\
& Impression $\rightarrow$ Intention to visit & 1.500 \\
\hline $\begin{array}{l}\text { Relatives } \\
(n=537)\end{array}$ & Tie strength $\rightarrow$ Impression & 1.030 \\
& IWOM $\rightarrow$ Intention to visit & 1.490 \\
& IWOM $\rightarrow$ Impression & 1.040 \\
\hline
\end{tabular}

\subsection{Predictive power and model fit.}

The coefficient of determination ( $\boldsymbol{R}^{2}$ values) of the endogenous constructs was assessed to determine the predictive power of the structural model (Chin, 2010; Hair et al., 2017). $R^{2}$ 
values range between 0 and 1, where greater values signal greater "predictive accuracy" (Hair et al., 2017, p.199). As a rule of thumb, $R^{2}$ values of $.25, .50$, and .75 are considered weak, moderate and strong, respectively (Hair et al., 2011). As shown in Table 5.12, the endogenous constructs in each data set achieved $R^{2}$ values between .330 and .390 for Impression; and .530 and .570 for the focal construct Intention to visit.

Table 5.12: Explained variance and prediction relevance test

\begin{tabular}{llll}
\hline Data set & Endogenous construct & $R^{2}$ & $Q^{2}$ \\
\hline $\begin{array}{l}\text { Complete } \\
(N=1,565)\end{array}$ & Intention to visit & 0.570 & 0.440 \\
& Impression & 0.390 & 0.380 \\
\hline $\begin{array}{l}\text { Friends } \\
(n=1,028)\end{array}$ & Intention to visit & 0.570 & 0.440 \\
\hline $\begin{array}{l}\text { Relatives } \\
(n=537)\end{array}$ & Impression & 0.390 & 0.380 \\
\hline
\end{tabular}

Following the rules of thumb, the values of Impression and Intention to visit would be considered to offer weak and moderate predictive accuracy, respectively. However, the criteria in examining $R^{2}$ is not fixed. According to Hair et al. (2017, p. 199), it is "difficult to provide rules of thumb for $R^{2}$ values", and results depend on factors such as the study's discipline, research area and the complexity of the model, where in some instances, the $R^{2}$ value can be .10. Cohen (1992), in his statistical power analyses for multiple regression models, on the other hand, suggests that an $R^{2}$ value of .0196 can be significant. Thus, following Cohen's criteria, constructs in this study provide substantial predictive power. Although the significance of the relationships among constructs has been largely established using the $R^{2}$, scholars highlight that the $R^{2}$ technique of assessing the model only provides insample explanatory power of the model, and does not assess the out-of-sample predictive power or relevance of the model (Ali et al., 2018; Shmueli, Ray, Velasquez Estrada, \& Chatla, 2016). The Stone-Geisser $\left(Q^{2}\right)$ blindfolding procedure supplements the limitations of the $R^{2}$ (Geisser, 1975; Stone, 1974). Moreover, the blindfolding procedure is used when assessing endogenous single-item constructs (Hair et al., 2017).

The $Q^{2}$ blindfolding procedure omits part of the data matrix, estimates the parameters of the model, and then predicts the omitted part with the previously generated estimates (Ringle et 
al., 2018). A $Q^{2}$ value larger than 0 signals the predictive relevance of the model (Chin, 2010; Hair, Risher, et al., 2019; Henseler et al., 2009), where, as a rule of thumb, $Q^{2}$ values larger than $0, .025$ and .50 indicate small, medium and large predictive accuracy of the path model (Hair, Risher, et al., 2019). Following the recommendation of Hair et al. (2017), the crossvalidated redundancy method was used to calculate the $Q^{2}$ value. As shown in Table 5.12, the constructs in each data set achieved $Q^{2}$ values between .320 and .440 , signalling significant levels of predictive power.

5.2.2.2.3 Testing measurement invariance of composites (MICOM).

Measurement invariance or measurement equivalence refers to "whether or not, under different conditions of observing and studying phenomena, measurement operations yield measures of the same attribute" (Horn \& Mcardle, 1992, p. 117). By establishing measurement invariance, researchers ensure that group-specific differences in model estimates are not a product of distinctive content and/or meanings of latent variables (Hair, Sarstedt, Matthews, \& Ringle, 2016). Scholars caution that the absence of measurement invariance could reduce the power of statistical tests, influence the accuracy of estimators and provide potentially biased or erroneous results (Hair et al., 2017; Steenkamp \& Baumgartner, 1998). Hence, measurement invariance is a prerequisite for group analyses (Cheah, Ting, Cham, \& Memon, 2019; Sarstedt, Ringle, \& Hair, 2017b). Thus, prior to hypotheses testing, and examining the differences between the friends and relatives data sets, measurement invariance was assessed.

Several approaches have been proposed to examine measurement invariance for covariancebased SEM (e.g. Steenkamp \& Baumgartner, 1998; Vandenberg \& Lance, 2000). However, covariance-based SEM methods, such as the commonly adopted common-factor based approach proposed by Steenkamp and Baumgartner (1998), "are not readily transferred" to PLS-SEM's composite models (Hair et al., 2017, p. 299). To address the need for an approach that allows for the assessment of measurement invariance in PLS composite models, the sequential three-step MICOM procedure was introduced (Henseler, Ringle, \& Sarstedt, 2016). The MICOM procedure, as illustrated in Figure 5.4, entails establishing: 1) configural invariance; 2) compositional invariance; and 3) equal mean values and variances. 


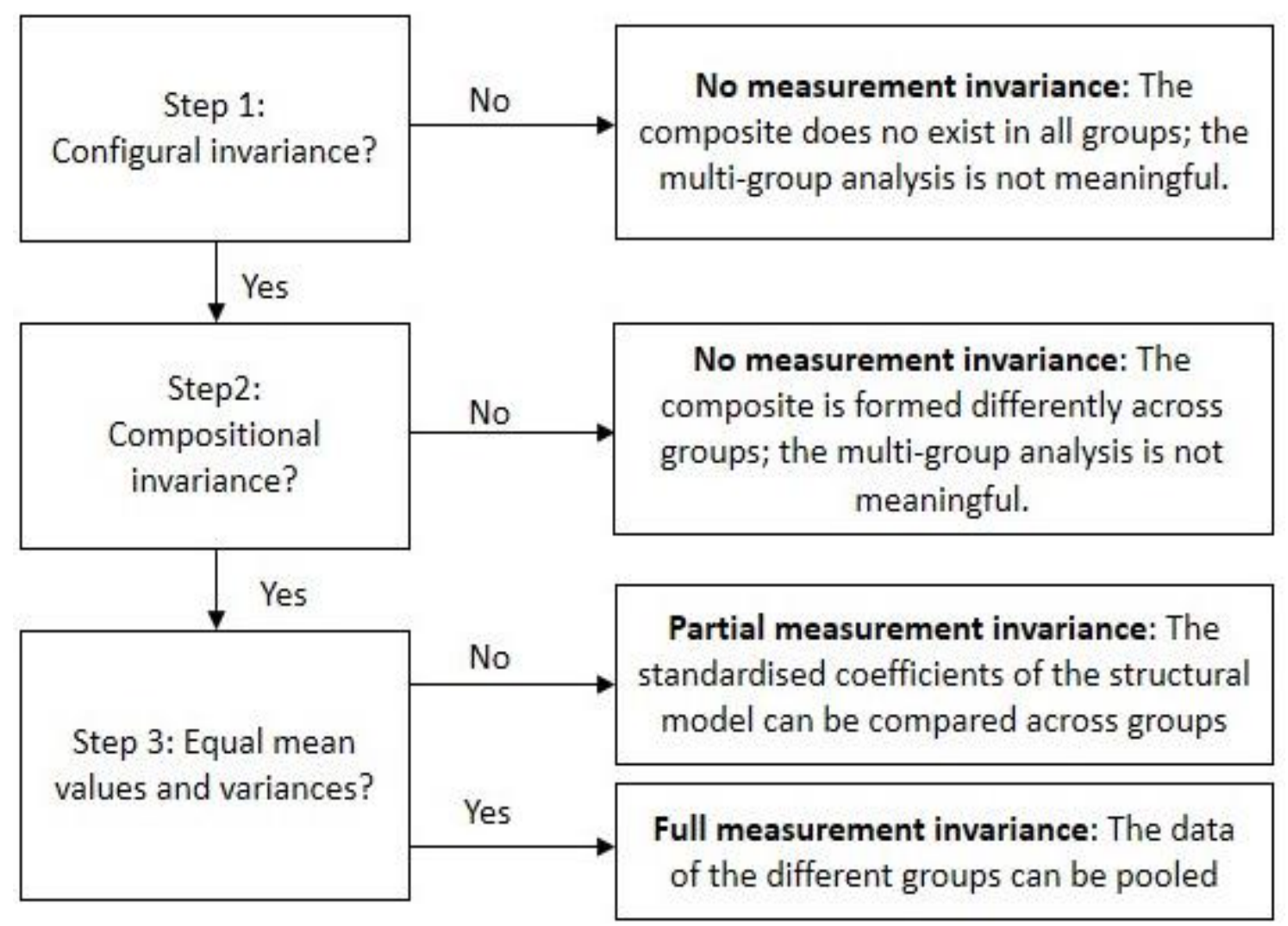

Figure 5.4: MICOM 3-step procedure (Source: Henseler et al., 2016)

The MICOM procedure is a "hierarchically-interrelated" set of steps, where configural invariance is a prerequisite for compositional invariance, which is consequently a prerequisite for examining equality of composite mean value and variances (Hair et al., 2018, p. 140). In step 1 configural invariance is established when identical indicators are used; data is treated similarly; and identical algorithm settings are employed when assessing data across all groups (Hair et al., 2018). As shown in Table 5.9, identical indicators were used across both groups. All data sets were treated similarly, with identical methods of data coding and handling. In addition, algorithm settings for each data set were similar. Having satisfied the recommended criteria, configural invariance in this study was achieved, allowing the researcher to move to step 2.

Step 2 involves determining compositional invariance. The presence of compositional invariance is determined when composite scores (estimated indicator weights) are consistent across groups. The statistical test identifies whether there are significant differences in the composite scores among all the groups, where $c$ the correlation between composite scores, $\mathrm{Y}^{(1)}$ and $\mathrm{Y}^{(2)}$ is assessed (Hair et al., 2018):

$$
c=\operatorname{cor}\left(Y^{(1)}, Y^{(2)}\right)
$$


The purpose of the procedure is to test acceptance of the null hypothesis. If $c$ is significantly different from 1, then compositional invariance is absent, and the null hypothesis is rejected (Henseler et al., 2016). In the MICOM procedure a permutation test is performed. The permutation test is a non-parametric test that is similar to a bootstrap, and was proposed by Henseler et al. (2016) to establish measurement invariance in PLS composite models. In this study, permutation of data was between the friends and relatives data sets $(5,000$ permutation runs). As shown in Table 5.13, the $c$ value is 1, and greater than the 5\% quantile, straddling between the upper and lower bounds of the CI (Hair et al., 2018). Thus, compositional invariance is established. 
Table 5.13: Measurement invariance test using MICOM

\begin{tabular}{|c|c|c|c|c|c|c|c|c|c|c|}
\hline \multirow[b]{2}{*}{ Data set } & \multirow[b]{2}{*}{ Construct } & \multicolumn{3}{|c|}{ Compositional Invariance } & \multicolumn{3}{|c|}{ Equal Mean Variance } & \multicolumn{3}{|c|}{ Equal Variance } \\
\hline & & $\begin{array}{l}c \text { value } \\
(=1)\end{array}$ & $\begin{array}{c}95 \% \\
\text { Confidence } \\
\text { Interval }\end{array}$ & Invariance & Delta & $\begin{array}{c}95 \% \\
\text { Confidence } \\
\text { Interval }\end{array}$ & $\begin{array}{l}\text { Equal } \\
\text { Mean } \\
\text { Values }\end{array}$ & Delta & $\begin{array}{c}95 \% \\
\text { Confidence } \\
\text { Interval }\end{array}$ & $\begin{array}{c}\text { Equal } \\
\text { Variance } \\
\text { Values }\end{array}$ \\
\hline \multirow{4}{*}{$\begin{array}{l}\text { Friends } \\
\text { vs. } \\
\text { Relatives }\end{array}$} & iWOM & 1.000 & {$[1.000 ; 1.000]$} & Yes & 0.380 & {$[-0.100 ; 0.110]$} & No & -0.040 & {$[-0.160 ; 0.160]$} & Yes \\
\hline & $\begin{array}{l}\text { Intention to } \\
\text { visit }\end{array}$ & 1.000 & {$[1.000 ; 1.000]$} & Yes & 0.500 & {$[-0.100 ; 0.110]$} & No & -0.200 & {$[-0.160 ; 0.150]$} & No \\
\hline & Impression & 1.000 & {$[1.000 ; 1.000]$} & Yes & 0.410 & {$[-0.110 ; 0.110]$} & No & -0.160 & {$[-0.150 ; 0.150]$} & No \\
\hline & Tie strength & 1.000 & {$[1.000 ; 1.000]$} & Yes & 0.330 & {$[-0.100 ; 0.110]$} & No & -0.710 & {$[-0.300 ; 0.280]$} & No \\
\hline
\end{tabular}


Having satisfied step 1 and step 2 of the MICOM procedure, partial measurement invariance is established. However, to run statistical analysis at the pooled-data level, step 3 must be satisfied. Nonetheless, according to Hair et al. (2018) once partial measurement invariance is achieved, researchers can compare path coefficients by means of a multi-group analysis, which is critical to this study, given the two groups examined (friends/relatives).

Step 3 requires that the equality of the mean values and variances of the composites are established. In this stage, similar to step 2, permutation tests were conducted on the friends and relatives data sets, and empirical distributions were generated to assess differences in mean values and logarithms of variances between construct scores of groups (Hair et al., 2018). According to Henseler et al. (2016), if the CIs of differences in mean values and logarithms of variances (between the construct scores of tested grouping pairs) include 0 , it can be assumed that the composite mean values and variances are equal.

As shown in Table 5.13, the equal mean values and variances of composites across the two data sets did not achieve non-significant difference. Specifically, the difference of mean values and variances of composites did not fall within the upper and lower bounds of the CI. Zero (0) was, therefore, not included within the CIs. Full measurement invariance was not achieved. However, given that the criteria for steps 1 and 2 were met, partial invariance was established, allowing for comparisons to be made between paths of friends and relatives data sets/models.

\subsection{Hypotheses testing.}

The findings of the path analyses of the two data sets (friends/relatives) are presented in this section. Path coefficients $(\beta)$ have a standardised value of approximately \pm 1 , where the closer the value is to +1 or -1 , the stronger the relationship (Hair et al., 2017). To infer significance, bias-corrected bootstrap CIs, $t$ - or $p$-values can be used. Guided by Hair et al. (2017), the following criteria was used to infer significance:

- $\quad$-values $<.05$

- confidence interval does not include zero (0)

\section{Direct effects}

Hypothesis 1 (iWOM $\rightarrow$ Intention to visit) posits that sojourner iWOM has a positive influence on viewer Intention to visit. As shown in Table 5.14, the findings in both data sets indicate the presence of a positive significant relationship between sojourner iWOM and 
viewer Intention to visit, $\beta_{\text {friends }}=.070, p<.05$, $\beta_{\text {relatives }}=.100, p<.05$. In addition, the lower and upper bounds of the CIs did not include 0 . Hence, hypothesis 1 is supported. To gain a deeper understanding of the impact of sojourner iWOM on viewer Intention to visit, the effect sizes $\left(f^{2}\right)$ were examined. The $f^{2}$ is used to assess a construct's impact on the focal endogenous construct, and is independent of sample size (Benitez, Henseler, Castillo, \& Schuberth, 2020). The $f^{2}$ values of $0.02,0.15$ and 0.35 represent: small, medium and large effect sizes, respectively (Cohen, 1988). In the friends model had a trivial effect $\left(f^{2}=0.010\right)$. In the relatives model, however, the impact of sojourner iWOM on viewer Intention to visit had a small $f^{2}(0.020)$.

Hypothesis 2 proposes a positive effect between sojourner iWOM and viewer Impression. As shown in Table 5.14, the direct effect of $\mathbf{i W O M} \rightarrow$ Impression, is positive and significant for both models: $\beta_{\text {friends }}=.540, p<.001, \beta_{\text {relatives }}=.560, p<.001$. In both models, sojourner iWOM had a large effect on impression, where the friends model had an $f^{2}$ of 0.460 and the relatives model had an $f^{2}$ of 0.450 . Therefore, hypothesis 2 is supported.

Hypothesis 3 proposes the positive influence of viewer Impression on Intention to visit. As shown in Table 5.14, the direct effect of Impression $\rightarrow$ Intention to visit, is positive and significant for both models: $\beta_{\text {friends }}=.720, p<.001, \beta_{\text {relatives }}=.660, p<.001$. In addition, the effect size for both models were substantial $\left(f_{\text {friends }}=0.790, f_{\text {relatives }}=0.630\right)$, indicating the large impact viewer Impression has on Intention to visit. The results support hypothesis 3.

Hypothesis 6 proposes Tie strength's positive effect on viewer Impression. The findings, as shown in Table 5.14 indicate a positive significant relationship between Tie strength $\rightarrow$ Impression for the friends model $\left(\beta_{\text {friends }}=.230, p<.001\right)$. In contrast, the results indicate that although the relationship between Tie strength $\rightarrow$ Impression is positive in the relatives model $\left(\beta_{\text {relatives }}=.060, p>.05\right)$, the result is not significant. The effect size of Tie strength in the friends model $\left(f^{2}\right.$ friends $\left.=0.630\right)$ was large. However, Tie strength had a trivial effect on Impression in the relatives model $\left(f^{2}\right.$ relatives $\left.=0.010\right)$. 
Table 5.14: Direct effects

\begin{tabular}{|c|c|c|c|c|c|c|}
\hline Data set & Parameters & $\beta$ & Std. Error & t-values & $\begin{array}{l}95 \% \text { Confidence } \\
\text { Interval }\end{array}$ & $f^{2}$ \\
\hline \multirow{4}{*}{$\begin{array}{l}\text { Complete } \\
(N=1,565)\end{array}$} & $\mathrm{iWOM} \rightarrow$ Intention to visit (c') & 0.080 & 0.020 & $3.610 * * *$ & {$[0.040 ; 0.130]$} & 0.010 \\
\hline & iWOM $\rightarrow$ Impression & 0.550 & 0.020 & $22.12 * * *$ & {$[0.500 ; 0.600]$} & 0.480 \\
\hline & Impression $\rightarrow$ Intention to visit & 0.700 & 0.020 & $35.660 * * *$ & {$[0.660 ; 0.740]$} & 0.750 \\
\hline & Tie strength $\rightarrow$ Impression & 0.200 & 0.020 & $10.110^{* * *}$ & {$[0.160 ; 0.230]$} & 0.060 \\
\hline \multirow{4}{*}{$\begin{array}{l}\text { Friends } \\
(n=1,028)\end{array}$} & $\mathrm{iWOM} \rightarrow$ Intention to visit & 0.070 & 0.030 & $2.400^{*}$ & {$[0.010 ; 0.120]$} & 0.010 \\
\hline & iWOM $\rightarrow$ Impression & 0.540 & 0.030 & $18.550 * * *$ & {$[0.480 ; 0.590]$} & 0.460 \\
\hline & Impression $\rightarrow$ Intention to visit & 0.720 & 0.020 & $34.250 * * *$ & {$[0.670 ; 0.750]$} & 0.790 \\
\hline & Tie strength $\rightarrow$ Impression & 0.230 & 0.020 & $10.170 * * *$ & {$[0.190 ; 0.270]$} & 0.080 \\
\hline \multirow{4}{*}{$\begin{array}{l}\text { Relatives } \\
(n=537)\end{array}$} & $\mathrm{iWOM} \rightarrow$ Intention to visit & 0.100 & 0.040 & $2.470^{*}$ & {$[0.030 ; 0.190]$} & 0.020 \\
\hline & iWOM $\rightarrow$ Impression & 0.560 & 0.050 & $11.520 * * *$ & {$[0.460 ; 0.650]$} & 0.450 \\
\hline & Impression $\rightarrow$ Intention to visit & 0.660 & 0.040 & $16.050 * * *$ & {$[0.580 ; 0.740]$} & 0.630 \\
\hline & Tie strength $\rightarrow$ Impression & 0.060 & 0.040 & 1.770 & {$[-0.010 ; 0.120]$} & 0.010 \\
\hline
\end{tabular}

Note: Values in brackets represent the lower and upper bounds of the $95 \%$ bias-corrected CIs from bootstrapping 5,000 samples; $* p<0.05 ; * * p<0.01$, $* * * p<0.001$ 


\section{Indirect effect (mediation)}

Mediators are conceptual variables that are often used in research to "account for differences in peoples' behaviour" (Baron \& Kenny, 1986, p.1173). In general, mediators address the mechanisms by which an effect occurs (MacKinnon, Coxe, \& Baraldi, 2012). According to MacKinnon et al. (2012), observational variables can function as a predictor or antecedent variable, where mediation provides scholars a means to explore and explain the mechanisms that hinder or facilitate desired outcomes (Hair et al., 2017; MacKinnon, Lockwood, Hoffman, West, \& Sheets, 2002; Nitzl, Roldan, \& Cepeda, 2016).

Hypothesis 4 (iWOM $\rightarrow$ Impression $\rightarrow$ Intention to visit) proposes that viewer Impression mediates the relationship between sojourner iWOM and viewer Intention to visit. The Baron and Kenny (1986) causal-steps approach is typically used to test mediation effects (Zhao, Lynch, \& Chen, 2010). Increasingly, however, scholars call for a reconsideration of the use of the causal-steps approach, highlighting its conceptual and methodological limitations (Fritz, Taylor, \& MacKinnon, 2012; Hayes, 2009; MacKinnon et al., 2012; Memon, Hwa, Ramayah, \& Ting, 2018; Zhao et al., 2010). Zhao et al. (2010) argue that the causal-steps approach is cumbersome when determining mediation effects, stressing "all that matters is that the indirect effect is significant" (p. 204).

Prior testing to determine the significance of indirect effects relied on the Sobel (1982) test. However, the results of the test were found to be low in statistical power (MacKinnon et al., 2002; Zhao et al., 2010). The low statistical power of the Sobel test is attributed to the assumption that the sampling distribution of an indirect effect is normally distributed, resulting in conservative estimates - particularly for studies with small sample sizes and non-normal data (MacKinnon et al., 2002). Bootstrapping, a more robust means for testing mediation, is recommended specifically for PLS-SEM studies (Hair et al., 2017; Memon et al., 2018; Nitzl et al., 2016). Unlike the Sobel test, bootstrapping makes no assumption about the statistical distribution of the variables or the sample (Hair et al., 2017; Matthews, Hair, \& Matthews, 2018; Preacher, Rucker, \& Hayes, 2007). In addition, bootstrapped-based tests, such as the bias-corrected bootstrap confidence interval, yields higher statistical power compared to the Sobel test (Hayes \& Scharkow, 2013; Mackinnon, Lockwood, \& Williams, 2004), and is considered a "powerful method to detect mediation" (Memon et al., 2018, p.vi). Bias-corrected bootstrapping of 5,000 samples was used in this study to assess the significance of the indirect effect of the proposed mediation (Nitzl et al., 2016). This study 
adopts the recommendations outlined by Carrion, Nitzl, and Roldan (2017) as well as Hair et al. (2017) in assessing the effects of the hypothesised mediation.

As presented in Table 5.15, the indirect effects of sojourner iWOM on viewer Intention to visit are positive and significant in both models: $\beta_{\text {friends }}=.390, p<.001, \beta_{\text {relatives }}=.370, p<$ .001 models. The results support hypothesis 4 (iWOM $\rightarrow$ Impression $\rightarrow$ Intention to visit). Thus, viewer Impression mediates the relationship between sojourner iWOM and viewer Intention to visit. Following the steps of Zhao et al.'s (2010) decision tree, complementary mediation was achieved for both friends and relatives data sets. A complementary mediation signals the presence of the hypothesised mediator. However, a complementary mediation also suggests the "possible existence of some omitted second mediator" that can be examined in future research (Zhao et al., 2010, p.201).

Table 5.15: Indirect effects $(a \times b)$

\begin{tabular}{lllllll}
\hline Data set & Parameters & $\beta$ & $\begin{array}{l}\text { Std. } \\
\text { Error }\end{array}$ & t-values & $\begin{array}{l}95 \% \\
\text { Confidence } \\
\text { Interval }\end{array}$ & VAF \\
\hline $\begin{array}{l}\text { Complete } \\
(N=1,565)\end{array}$ & $\begin{array}{l}\text { iWOM } \rightarrow \text { Impression } \\
\rightarrow \text { Intention to visit }\end{array}$ & 0.390 & 0.020 & $18.620 * * *$ & {$[0.350 ; 0.430]$} & 0.830 \\
\hline $\begin{array}{l}\text { Friends } \\
(n=1,028)\end{array}$ & $\begin{array}{l}\text { iWOM } \rightarrow \text { Impression } \\
\rightarrow \text { Intention to visit }\end{array}$ & 0.390 & 0.020 & $16.950^{* * *}$ & {$[0.340 ; 0.430]$} & 0.848 \\
\hline $\begin{array}{l}\text { Relatives } \\
(n=537)\end{array}$ & $\begin{array}{l}\text { iWOM } \rightarrow \text { Impression } \\
\rightarrow \text { Intention to visit }\end{array}$ & 0.370 & 0.040 & $8.460 * * *$ & {$[0.290 ; 0.460]$} & 0.787 \\
\hline
\end{tabular}

Note: Values in brackets represent the lower and upper bounds of the $95 \%$ bias-corrected CIs from bootstrapping 5,000 samples; $* p<0.05 ; * * p<0.01 ; * * * p<0.001$

The variance accounted for (VAF) scores were also calculated to determine the extent to which the mediation explains the variance of the dependent variable (Nitzl et al., 2016). The VAF value is assessed by calculating the ratio of the indirect $(a \times b)$ to total $(a \times b+c)$ effect (Carrion et al., 2017; Hadi, 2016):

$$
\mathrm{VAF}=\frac{a \times b}{a \times b+c^{\prime}}
$$

The VAF results presented in Table 5.15, magnify the critical role of viewer Impression as a mediator between sojourner iWOM and viewer Intention to visit, where in the friends model $(\mathrm{VAF}=0.848)$ the mediating role of Impression accounts for approximately $85 \%$ of the variance of Intention to visit, and $79 \%$ in the relatives model (VAF $=0.787)$. The results 
support the overall position of this thesis, which identifies sojourners as critical visual communicators, able to compose persuasive images that significantly influence viewer impression and visit intentions.

\section{Control variables}

Results of the path analyses of control variables for the models are presented in Table 5.16. Gender and Income had no significant effect on Intention to visit, with CIs that contained 0 and $p>.05$.

Table 5.16: Control variables

\begin{tabular}{|c|c|c|c|c|c|c|}
\hline Data set & Parameters & $\beta$ & $\begin{array}{l}\text { Std. } \\
\text { Error }\end{array}$ & t-values & $\begin{array}{l}\text { 95\% Confidence } \\
\text { Interval }\end{array}$ & $f^{2}$ \\
\hline \multirow{4}{*}{$\begin{array}{l}\text { Complete } \\
(N=1,565)\end{array}$} & Age $\rightarrow$ Intention to visit & -0.010 & 0.020 & 0.500 & {$[-0.040 ; 0.020]$} & 0.000 \\
\hline & $\begin{array}{l}\text { Cultural distance } \rightarrow \\
\text { Intention to visit }\end{array}$ & 0.070 & 0.020 & $3.820 * * *$ & {$[0.030 ; 0.110]$} & 0.010 \\
\hline & Gender $\rightarrow$ Intention to visit & -0.030 & 0.020 & 2.100 & {$[-0.060 ; 0.000]$} & 0.000 \\
\hline & Income $\rightarrow$ Intention to visit & 0.000 & 0.020 & 0.220 & {$[-0.030 ; 0.040]$} & 0.000 \\
\hline \multirow{4}{*}{$\begin{array}{l}\text { Friends } \\
(n=1,028)\end{array}$} & Age $\rightarrow$ Intention to visit & -0.090 & 0.020 & $4.480 * * *$ & {$[-0.130 ;-0.050]$} & 0.020 \\
\hline & $\begin{array}{l}\text { Cultural distance } \rightarrow \\
\text { Intention to visit }\end{array}$ & 0.020 & 0.020 & 0.900 & {$[-0.020 ; 0.060]$} & 0.000 \\
\hline & Gender $\rightarrow$ Intention to visit & -0.030 & 0.020 & 1.770 & {$[-0.070 ; 0.000]$} & 0.000 \\
\hline & Income $\rightarrow$ Intention to visit & 0.030 & 0.020 & 1.530 & {$[-0.010 ; 0.070]$} & 0.000 \\
\hline \multirow{4}{*}{$\begin{array}{l}\text { Relatives } \\
(n=537)\end{array}$} & Age $\rightarrow$ Intention to visit & 0.090 & 0.040 & $2.490 *$ & {$[0.020 ; 0.017]$} & 0.020 \\
\hline & $\begin{array}{l}\text { Cultural distance } \rightarrow \\
\text { Intention to visit }\end{array}$ & 0.260 & 0.050 & $5.540 * * *$ & {$[0.170 ; 0.350]$} & 0.110 \\
\hline & Gender $\rightarrow$ Intention to visit & -0.020 & 0.020 & 0.860 & {$[-0.070 ; 0.030]$} & 0.000 \\
\hline & Income $\rightarrow$ Intention to visit & 0.010 & 0.030 & 0.250 & {$[-0.060 ; 0.070]$} & 0.000 \\
\hline
\end{tabular}

Note: Values in brackets represent the lower and upper bounds of the $95 \%$ bias-corrected CIs from bootstrapping 5,000 samples; ${ }^{*} p<0.05 ; * * p<0.01 * * * p<0.001$

In contrast, Cultural distance had a significant positive relationship to Intention to visit in the relatives model $\left(\beta_{\text {relatives }}=.260, p<.001\right)$. However, Cultural distance was not found to be significant in the friends model $\left(\beta_{\text {friends }}=.020, p>.05\right)$. Age on the other hand, was found to be significant in both models, but in opposite directions: $\beta_{\text {friends }}=-.090, p<.001, \beta_{\text {relatives }}=$ $.090, p<.05$. In both models, Age had a significant but small effect on Intention to visit $\left(f^{2}=\right.$ 0.020), while Cultural distance was found to have a greater effect on Intention to visit in the 
relatives model $\left(f_{\text {relatives }}^{2}=0.110\right)$ compared to the friends model $\left(f_{\text {friends }}^{2}=0.00\right)$. As a result of the insignificant relationship that Gender and Income have with Intention to visit, both control variables were dropped from the analysis (Byrne, 2010).

\section{Multi-group analysis}

\section{Moderating role of relationship type (friend vs. relative)}

A moderator is a variable that influences the direction and/or strength of the link between an independent variable and a dependent variable (Baron \& Kenny, 1986), and can either be continuous or categorical variables (Ali Memon et al., 2019). A categorical moderator (i.e. gender) is typically evaluated using multi-group analysis, which allows for comparisons against groups (Hair et al., 2017). Insights into group differences allow for more accurate assessments, and strategy development (Matthews, 2017). Hypothesis 5a-5d proposes the assessment of the moderating role of relationship type between the sojourner and viewer of the image.

Multi-group analysis is used to assess differences between groups, where it tests the null hypothesis to determine the presence of statistically significant differences (Hair et al., 2017). In PLS-SEM scholars can choose between the permutation or PLS-MGA methods to infer differences (Matthews, 2017). Drawing from guidelines provided by Hair et al. (2018) and recent advances in SmartPLS (“SmartPLS release notes," 2020), the PLS-MGA approach was adopted. The primary reason for choosing the PLS-MGA was due to the size difference between the friends and relatives data sets, where the relatives data set (537 observations) was slightly over $50 \%$ of the friends data set. According to Hair et al. (2018), in instances where the differences between subsamples are substantial, the PLS-MGA approach is recommended. The PLS-MGA approach assesses the differences of the subsamples through distributions of bootstrap outcomes (Henseler et al., 2009). The results of the PLS-MGA are presented in Table 5.17.

Table 5.17: PLS-MGA comparison test results (friends vs. relatives)

\begin{tabular}{lll}
\hline Parameters & $\mid$ diff $\mid$ & $p$-value \\
\hline $\mathrm{iWOM} \rightarrow$ Intention to visit & -0.061 & 0.205 \\
$\mathrm{iWOM} \rightarrow$ Impression & -0.021 & 0.705 \\
Impression $\rightarrow$ Intention to visit & 0.098 & 0.048 \\
Tie strength $\rightarrow$ Impression & 0.168 & $<0.001$ \\
Note: Path coefficient estimated differences $\mid$ diff $\mid$ & & \\
\hline
\end{tabular}


The results shown in Table 5.17 indicate statistically significant differences in the main model between both data sets in the following paths: Impression $\rightarrow$ Intention to visit $(p=$ $.048)$; and Tie strength $\rightarrow$ Impression to visit $(p<.001)$. The findings, therefore, support hypothesis $\mathbf{5}$ and $\mathbf{5}$ d. Hypothesis $\mathbf{5}$ c posits that the strength of the relationship between viewer Impression and Intention to visit (Impression $\rightarrow$ Intention to visit) is dependent on the Type of relationship between sojourner (producer/sender of iWOM) and the viewer of the iWOM (friend/relative). In the same vein, hypothesis 5d (Tie strength $\rightarrow$ Impression) predicts that the strength of the relationship between Tie strength and Impression is dependent on the Type of relationship between the sojourner and the viewer of iWOM.

Conversely, the results between the following paths: $\mathrm{iWOM} \rightarrow$ Intention to visit $(p=.205)$ and $\mathrm{iWOM} \rightarrow$ Impression $(p=.705)$ are not statistically significant. Thus, hypothesis $\mathbf{5}$ a (iWOM $\rightarrow$ Intention to visit), which predicts that the strength of the positive effect sojourner iWOM has on viewer Intention to visit is dependent on the type of relationship between the sojourner and the viewer of the iWOM is not supported. Correspondingly, hypothesis $\mathbf{5}_{\mathbf{b}}(\mathbf{i W O M} \rightarrow$ Impression), which posits that the strength of the positive relationship between sojourner iWOM and viewer Impression is dependent on the Type of relationship between the sojourner and viewer of iWOM, is not supported.

\section{Additional analysis: differences among content categories}

Given the different content categories used in this study, a further multi-group analysis was conducted to examine the differences, if any, between content groups in both friends and relatives data sets. Table 5.18 shows the results of the multi-group comparisons of images that fall within the four fixed content categories tested. The results in Table 5.18 present the differences in path coefficient estimates (|diff $\mid$ ) of six pairwise comparisons (Events vs. Food and drinks/dining; Events vs. Urban city; Events vs. Nature/scenic landscape; Food and drinks/dining vs. Urban city; Food vs. Nature/scenic landscape; Urban city vs. Nature/scenic landscape), conducted for each data set (friends and relatives). Researchers are cautioned of an inflation in the alpha value when multiple pairwise comparisons are conducted; which increases the probability of a Type I error (i.e., familywise error rate) (Hair et al., 2018).

To control for the familywise error rate, the Šidák procedure, which adjusts for the inflation in the alpha value, was implemented in each of the hypotheses tests (Hair et al., 2018). The Šidák procedure is calculated using the following formula: $1-(1-\text { alpha })^{1 / m}$, where $m=$ the number of comparisons (Hair et al., 2018; Ting et al., 2019). As there are four fixed 
categories in this study, six pairs of comparisons were made. Using the formula, a significance level of $1-(1-0.05)^{\frac{1}{6}}=.009$ is adopted instead of .05 , to correct the inflated familywise error rate when multiple comparisons are made for four fixed image categories.

The results in Table 5.18 indicate differences among the four fixed categories in the friends data set. In particular, significant differences were noted in the path iWOM $\rightarrow$ Impression (values bolded). The differences were evident in comparisons that included Nature/scenic landscape. For example, Food vs. Nature/scenic landscape. As seen in Table 5.18, in the friends data set, iWOM $\rightarrow$ Impression for Food vs. Nature/scenic landscape had a significant difference $(\mid$ diff $\mid=0.253, p<.009)$. Similarly, a significant difference was observed for Tie strength $\rightarrow$ Impression in the comparison Food vs. Nature/scenic landscape ( $\mid$ diff $\mid=-0.181, p$ $<.009)$. However, no significant differences were found for any of the comparisons in the relatives data set.

Table 5.18: Multi-group comparison test results

\begin{tabular}{lllll}
\hline Data set & Parameters & Comparison & $\mid$ diff $\mid$ & $p$-value \\
\hline $\begin{array}{l}\text { Friends }(n=1,028) \\
\text { iWOM } \rightarrow\end{array}$ & Events vs. Food and drinks/dining & -0.043 & 0.670 \\
& Intention to visit & Events vs Urban city & -0.077 & 0.354 \\
& & Events vs. Nature/scenic landscape & 0.003 & 0.971 \\
& & Food and drinks/dining vs. Urban city & -0.034 & 0.690 \\
& Food vs. Nature/scenic landscape & 0.046 & 0.541 \\
& iWOM $\rightarrow$ & Urban city vs. Nature/scenic landscape & 0.080 & 0.213 \\
& Events vs. Food and drinks/dining & -0.012 & 0.879 \\
& Impression & Events vs Urban city & -0.077 & 0.354 \\
& Events vs. Nature/scenic landscape & $\mathbf{0 . 2 4 1}$ & $\mathbf{0 . 0 0 8}$ \\
& Food and drinks/dining vs. Urban city & -0.013 & 0.842 \\
& Food vs. Nature/scenic landscape & $\mathbf{0 . 2 5 3}$ & $\mathbf{0 . 0 0 5}$ \\
& Impression $\rightarrow$ & Events vs. Food and drinks/dining & 0.110 & 0.158 \\
& Intention to visit & Events vs Urban city & 0.046 & 0.453 \\
& Events vs. Nature/scenic landscape & 0.009 & 0.871 \\
& Food and drinks/dining vs. Urban city & -0.064 & 0.355 \\
& Food vs. Nature/scenic landscape & -0.102 & 0.089 \\
& Urban city vs. Nature/scenic landscape & -0.037 & 0.463
\end{tabular}

Note: Path coefficient estimated differences |diff| 
Table 5.18: (continued)

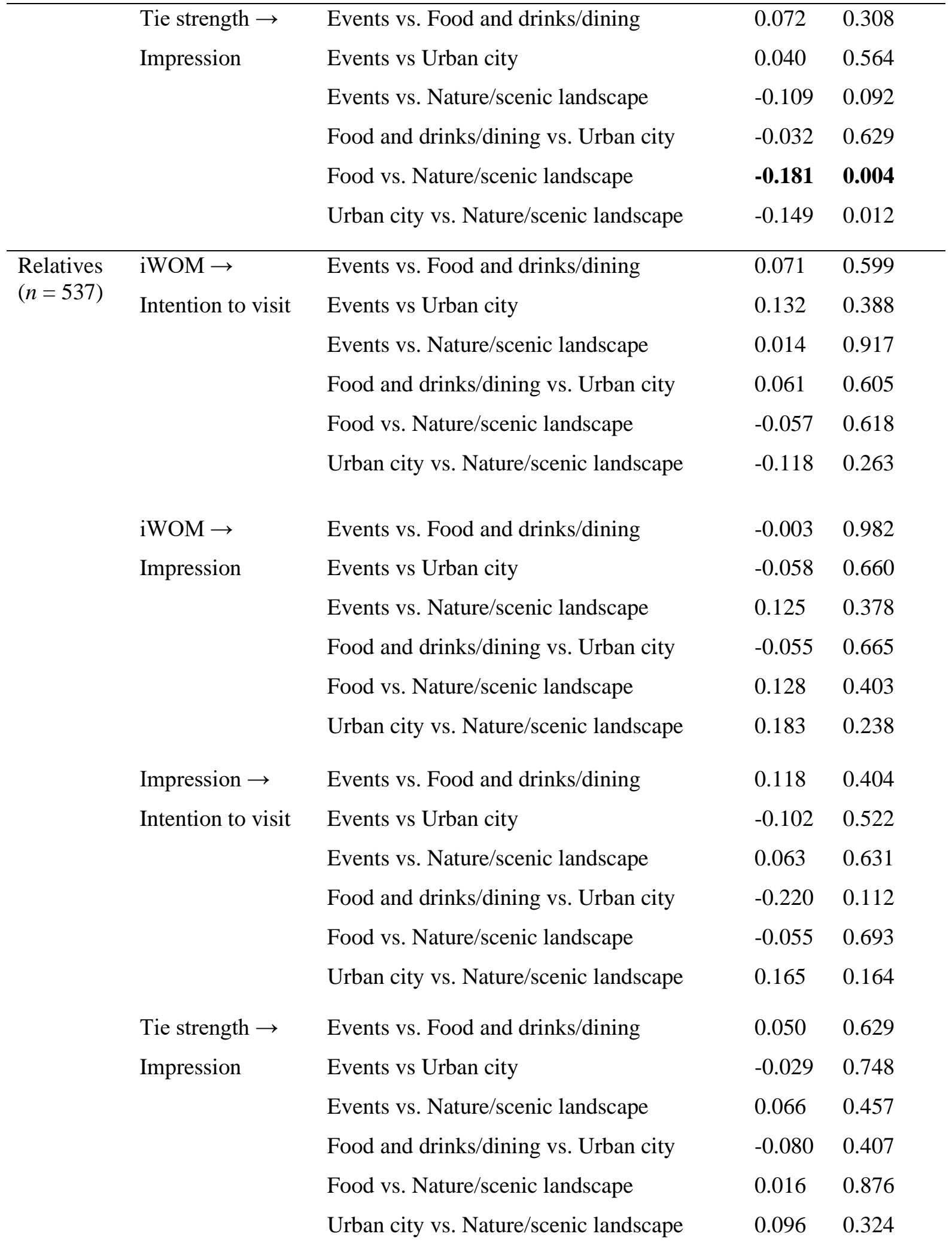

Note: Path coefficient estimated differences |diff| 


\section{Interaction effect (moderated mediation)}

Moderated mediation or "conditional indirect effect" takes place when a "moderator variable interacts with a mediator variable such that the value of the indirect effect changes depending on the value of the moderator variable" (Hair et al., 2017, p. 259). In this study, hypothesis 7 proposes that the strength of the indirect relationship between sojourner iWOM and Intention to visit, via viewer Impression, is contingent on the intensity of Tie strength (iWOM $\mathbf{x}$ Tie strength $\rightarrow$ Impression $\rightarrow$ Intention to visit). According to Hair et al. (2017) the same procedures of testing a moderator on PLS-SEM should be taken when assessing moderated mediation. By doing so, the interaction term of the indicators measuring the moderator variable and the exogenous variable would be established. Hair et al. (2017, p. 260) add that to claim a mediation is moderated, "there needs to be evidence of significant moderation" of the path linking the exogenous construct to the mediating variable. Therefore, the interaction effect $\mathrm{iWOM} \times$ Tie strength $\rightarrow$ Impression is tested.

Three approaches are largely advocated to analyse PLS-path models to calculate the interaction term: 1) the product-indicator approach; 2) orthogonalising approach and 3) twostage approach (Hair et al., 2017; Henseler \& Chin, 2010). Among the three enumerated methods, the two-stage approach yields the "highest statistical power" and benefit studies that seek to assess the significance of an interaction term (Henseler \& Chin, 2010, p. 101). The two-stage approach is also "suitable for reflective and formative moderators, and additional exogenous constructs in the path model" (Matthews et al., 2018).

Given that this study sought to determine the significance of the interaction term (iWOM $\times$ Tie strength), the two-stage approach was adopted. The first step of the two-stage approach involves obtaining estimates for the latent variable scores, which are then saved. The saved scores are then multiplied to create a single-item measure used to derive the interaction term (Hair et al., 2017). However, given recent developments, SmartPLS automatically computes the latent scores, allowing for researchers to omit the first step and proceed to generating the interaction term (Ramayah, Cheah, Chuah, Ting, \& Memon, 2018).

Hair et al. (2017) caution researchers to account for the direct relationship between the moderator and endogenous construct, where the consequence of omitting the path would inflate the score of the moderating effect. In this study, Hypothesis 6 (Tie strength $\rightarrow$ Impression), controls for the inflation. Steps enumerated by Ramayah et al. (2018) were adopted to test the interaction effect. Results from Table 5.19 demonstrate that the interaction 
effect for $\mathrm{iWOM} \times$ Tie strength $\rightarrow$ Impression is only significant in the friends model ( $\beta_{\text {friends }}$ $=.080, p<.05)$. The results in the friends model indicate a positive relationship between $\mathrm{iWOM} \times$ Tie strength $\rightarrow$ Impression. Although positive, the results for the relatives model did not yield statistically significant results $\left(\beta_{\text {relatives }}=.080, p>.05\right)$.

Table 5.19: Interaction effects

\begin{tabular}{lllllll}
\hline Data set & Parameters & $\beta$ & Std.Error & t-values & $\begin{array}{l}\text { 95\% Confidence } \\
\text { Interval }\end{array}$ & $f^{2}$ \\
\hline $\begin{array}{l}\text { Complete } \\
(N=1,565)\end{array}$ & $\begin{array}{l}\text { iWOM } \times \text { Tie } \\
\text { strength } \rightarrow \\
\text { Impression }\end{array}$ & 0.060 & 0.030 & 2.080 & {$[0.000 ; 0.110]$} & -0.0016 \\
& $\begin{array}{l}\text { iWOM } \times \text { Tie } \\
\text { Friends }\end{array}$ & 0.080 & 0.003 & $2.390 *$ & {$[0.020 ; 0.150]$} & 0.0033 \\
$(n=1,028)$ & $\begin{array}{l}\text { strength } \rightarrow \\
\text { Impression }\end{array}$ & & & & & \\
& iWOM $\times$ Tie & 0.080 & 0.060 & 1.300 & {$[-0.030 ; 0.210]$} & 0.0016 \\
$\begin{array}{l}\text { Relatives } \\
(n=537)\end{array}$ & $\begin{array}{l}\text { strength } \rightarrow \\
\text { Impression }\end{array}$ & & & & &
\end{tabular}

Note: Values in brackets represent the lower and upper bounds of the $95 \%$ bias-corrected CIs from bootstrapping 5,000 samples; $* p<0.05 ;{ }^{* *} p<0.01 * * * p<0.001$

To determine the strength of the interaction, the effect size $\left(f^{2}\right)$ was examined (Hair et al., 2017). The significant interaction effect in the friends model had a value $\left(f_{\text {friends }}=0.0033\right)$ below the typical thresholds (Cohen, 1988; Hair et al., 2017; Henseler \& Fassott, 2010). However, when assessing interaction effects, scholars argue that the values typically used to examine the $f^{2}$ are unrealistic (Aguinis, Beaty, Boik, \& Pierce, 2005; Chin, Marcelin, \& Newsted, 2003; Kenny, 2016), stressing that "even a small interaction effect can be meaningful" (Chin et al., 2003, p. 211). Further, Aguinis et al. (2005) found that a median effect size used in the reviewed applied psychology and management research, was 0.002 . Thus, the effect size of the friends model $\left(f_{\text {friends }}^{2}=0.0033\right)$ is deemed acceptable.

To further probe the extent of the moderating effect of Tie strength in the friends model, a simple slope analysis was conducted (Hayes, 2018). The simple slope analysis involves examining the low, moderate and high values of the moderation, through the standard deviation below the mean; the mean; and standard deviation above the mean, respectively (Hair et al., 2017; Hayes, 2018). In Figure 5.5, the blue, red and green lines represent low, moderate and high values of the moderation or interaction effect between iWOM $\times$ Tie strength and Impression. 


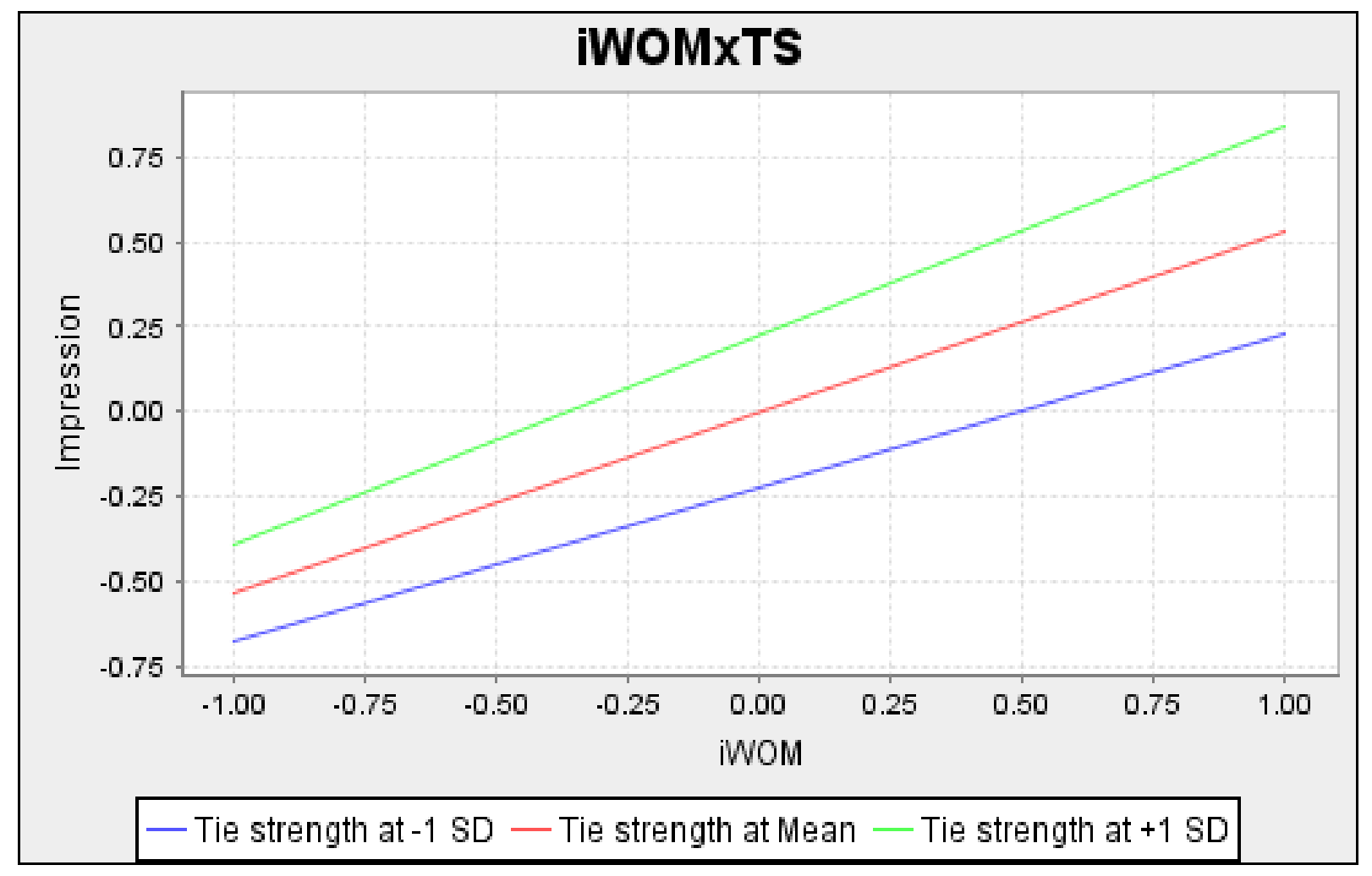

Figure 5.5: Simple slope plot of conditional interaction effect [iWOM $\times$ Tie strength (TS)] As shown in Figure 5.5, the green line is steeper than the blue line, providing support to the results of the friends data set presented in Table 5.19 that indicate a positive moderating relationship between the interaction term $\mathrm{iWOM} \times$ Tie strength and the indirect effect iWOM $\rightarrow$ Impression. The relationship between iWOM and Impression would, therefore, be stronger when Tie strength is higher. The results of the simple slope analysis support hypothesis $\mathbf{7}$ for the friends model.

\subsection{PLSpredict.}

Although scholars report the $Q^{2}$ values to infer a model's predictive power, recent studies suggest limitations in adopting the $Q^{2}$ as an out-of-sample test, such as over-estimation of predictive ability, and therefore suggest the application of PLSpredict (Danks \& Ray, 2018; Hair et al., 2019; Shmueli et al., 2016). The PLSpredict procedure produces holdout samples, data that is outside the analysis sample, which is used to evaluate the predictive performance of the PLS model. PLSpredict helps determine the predictive capacity of the model to predict beyond the sample data, and to new cases in the wider target population (Cheah et al., 2019; Shmueli et al., 2019).

$Q^{2}$ was assessed in this study, however, given recent scholarly recommendations, the PLSpredict procedure was conducted to further examine the predictive power of the models 
(Danks \& Ray, 2018; Shmueli et al., 2019). The $Q^{2}$ predict values, as well as the differences between root mean square errors (RMSE) of the PLS prediction statistics and LM (linear regression model) of endogenous constructs Impression (IMP) and Intention to visit (INT), were assessed (Ng, Lim, Cheah, Ho, \& Tee, 2020; Shmueli et al., 2019).

As presented in Table 5.20, both friends and relatives models obtained $Q^{2}$ predict $>0$, where $Q^{2}$ predict is considered the most naïve benchmark in assessing a model's predictive power. For a majority of indicators, the LM RMSE values were equal to or greater than the PLS RMSE values, signalling that PLS-SEM analysis yields lower prediction errors, and substantial levels of predictive power for both friends and relatives models (Danks \& Ray, 2018; Shmueli et al., 2019).

Table 5.20: PLSpredict assessment

\begin{tabular}{|c|c|c|c|c|c|}
\hline Data set & Item & PLS RMSE & $\mathrm{Q}^{2}$ predict & LM RMSE & LM-PLS RMSE \\
\hline \multirow{6}{*}{$\begin{array}{l}\text { Complete } \\
(N=1,565)\end{array}$} & INT_1 & 1.000 & 0.560 & 0.990 & -0.010 \\
\hline & INT_2 & 1.020 & 0.510 & 1.020 & 0.000 \\
\hline & INT_3 & 1.030 & 0.530 & 1.030 & 0.000 \\
\hline & INT_4 & 0.990 & 0.460 & 0.990 & 0.000 \\
\hline & INT_5 & 1.340 & 0.180 & 1.340 & 0.000 \\
\hline & IMP & 1.010 & 0.380 & 1.010 & 0.000 \\
\hline \multirow{6}{*}{$\begin{array}{l}\text { Friends } \\
(n=1,028)\end{array}$} & INT_1 & 1.050 & 0.520 & 1.040 & -0.010 \\
\hline & INT_2 & 1.010 & 0.530 & 1.000 & -0.010 \\
\hline & INT_3 & 1.040 & 0.520 & 1.040 & 0.000 \\
\hline & INT_4 & 0.940 & 0.510 & 0.940 & 0.000 \\
\hline & INT_5 & 1.370 & 0.170 & 1.370 & 0.000 \\
\hline & IMP & 1.020 & 1.030 & 1.030 & 0.010 \\
\hline \multirow{6}{*}{$\begin{array}{l}\text { Relatives } \\
(n=537)\end{array}$} & INT_1 & 0.830 & 0.610 & 0.830 & 0.000 \\
\hline & INT_2 & 0.960 & 0.480 & 0.960 & 0.000 \\
\hline & INT_3 & 0.990 & 0.510 & 1.000 & 0.010 \\
\hline & INT_4 & 1.010 & 0.370 & 1.010 & 0.000 \\
\hline & INT_5 & 1.280 & 0.180 & 1.280 & 0.000 \\
\hline & IMP & 0.990 & 0.320 & 1.030 & 0.000 \\
\hline
\end{tabular}




\subsubsection{Summary of quantitative findings.}

This section outlined the steps adopted to examine and test the hypotheses proposed in this study. The models tested had substantial predictive power and a majority of the proposed hypotheses were supported, as summarised in Table 5.21. In summary, six out of the 10 hypotheses were fully supported in both the friends and relatives models. Notably, the findings demonstrate the critical role of Impression in mediating the relationship between iWOM and Intention to visit, where VAF scores were found to account for $85 \%$ of the variance of Intention to visit in the friends model, and $79 \%$ in the relatives model. Tie strength was also found to be an important moderating factor that influences the relationship between iWOM and Impression - specifically in the friends model. The results signal the critical position of sojourners as persuasive visual communicators, as well as influential conduits between the host destination and their overseas networks. The next section expands on the findings of this phase, where a visual analysis was conducted to examine the nature of the images composed. 
Table 5.21: Summary of hypotheses testing

\begin{tabular}{|c|c|c|}
\hline Hypotheses & Friends & Relatives \\
\hline $\mathbf{H}_{1}$ : Sojourner iWOM has a positive influence on viewer (friend/relative) Intention to visit. & Supported & Supported \\
\hline $\mathbf{H}_{2}$ : Sojourner iWOM has a positive influence on viewer Impression. & Supported & Supported \\
\hline H3: Viewer Impression has a positive influence on Intention to visit. & Supported & Supported \\
\hline $\begin{array}{l}\text { H4: The relationship between sojourner iWOM and viewer Intention to visit is mediated by viewer } \\
\text { Impression. }\end{array}$ & Supported & Supported \\
\hline $\begin{array}{l}\text { H5a: The strength of the relationship between sojourner iWOM and viewer Intention to visit is } \\
\text { dependent on the type of relationship between sojourner and the viewer of iWOM. }\end{array}$ & Not supported & Not supported \\
\hline $\begin{array}{l}\text { Hsb: The strength of the relationship between sojourner iWOM and viewer Impression is dependent } \\
\text { on the type of relationship between sojourner and the viewer of iWOM. }\end{array}$ & Not supported & Not supported \\
\hline $\begin{array}{l}\text { Hsc: The strength of the relationship between viewer Impression and Intention to visit is dependent } \\
\text { on the type of relationship between sojourner and the viewer of iWOM. }\end{array}$ & Supported & Supported \\
\hline $\begin{array}{l}\text { H5d: The strength of the relationship between Tie strength and viewer Impression is dependent on } \\
\text { the type of relationship between sojourner and the viewer of iWOM. }\end{array}$ & Supported & Supported \\
\hline H6: $_{\text {Tie strength has a positive effect on viewer Impression. }}$ & Supported & Not supported \\
\hline $\begin{array}{l}\text { H7: The strength of the indirect relationship between sojourner iWOM and Intention to visit, via } \\
\text { viewer Impression, is contingent on the intensity of Tie strength. }\end{array}$ & Supported & Not supported \\
\hline \multicolumn{3}{|l|}{ Additional findings } \\
\hline Does content type result in significant differences in both friends and relatives models? & Yes & No \\
\hline
\end{tabular}




\subsection{Phase 3 (QUAL): Visual rhetorical analysis}

In this phase, a visual rhetorical analysis was conducted on the 453 sojourner-produced images. The images were critically assessed to establish the role of sojourners as key destination online ambassadors and visual influencers of VFR tourism. In addition, this phase of the study expands on the findings of Phase 2, where it identifies rhetorical strategies used by sojourners in articulating destination attributes and constructing images that are able to persuade, and influence decision making.

\subsubsection{Identification of physical or manifest items.}

In this first phase, data garnered through the coding exercise were populated into NVivo 12. Using the data of manifest items identified by the coders, a word-frequency query was conducted for each content category. The NVivo-generated word clouds in Figure 5.6 provide an overview of the results of the word-frequency analyses, where words most frequently used by the coders, when coding the physical items in the images, are prominently displayed. For example, articles such as people (17.06 weighed percentage), lights $(5.44 \%)$ and performers (3.37\%) were apparent in the category "events", while words such as sky $(8.57 \%)$, sea $(8.57 \%)$ and hills $(6.43 \%)$ appear prominently in the category "nature/scenic landscape".

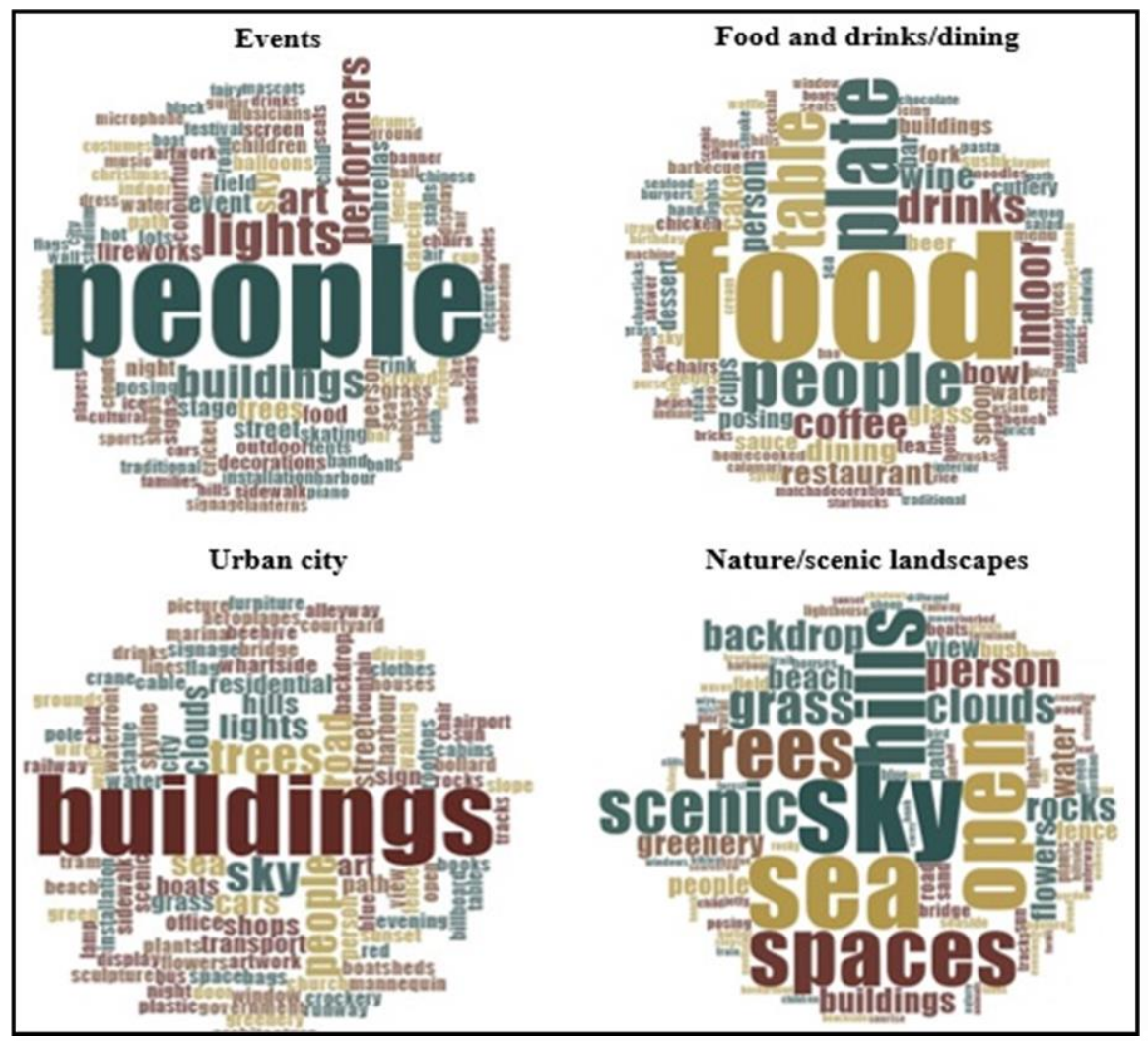

Figure 5.6: Results of NVivo word-frequency analyses for predetermined categories 
The results of the word-frequency analyses provided an initial understanding of substantive manifest items; where the distribution of different physical articles that support the basic function or meaning of each category were identified. The results exemplify how physical elements act as visual vernaculars in the visual composition of concepts (Barthes, 1977; Riffe, Lacy, \& Fico, 2005). The list of items generated by the coders was used alongside the content analyses of images, in the identification of subcategories/substantive dimensions. The data were compiled, managed and analysed using NVivo 12.

\subsubsection{Identification and assessment of the function.}

The results of the content analyses, presented in Table 5.22, provided the foundation for this phase, where the purpose of this stage is to examine the interplay of physical and stylistic elements that result in connoted meanings of Wellington. In Table 5.22, " $N$ " denotes the total number of images in each category. The values for each subcategory represent instances or frequency in which the subcategory was manifest in the images, within the category.

Table 5.22: Summary results of content analyses

\begin{tabular}{|c|c|c|c|}
\hline Categories and subcategories & Frequency & Percentage & Coder produced sample keywords \\
\hline Events & $N=88$ & & \\
\hline Public events & 74 & $84.09 \%$ & $\begin{array}{l}\text { half marathon, cricket match, fireworks } \\
\text { display, dragon dance, art event }\end{array}$ \\
\hline Personal events & 14 & $15.90 \%$ & $\begin{array}{l}\text { picnic, graduation, informal gathering, } \\
\text { informal event, bonfire, lecture }\end{array}$ \\
\hline Food and drinks/dining & $N=93$ & & \\
\hline Servicescape & 24 & $25.81 \%$ & $\begin{array}{l}\text { restaurant, indoor, dining, bar, } \\
\text { farmland, scenic, mobile bar }\end{array}$ \\
\hline Drinks & 15 & $16.13 \%$ & coffee, matcha, wine, beer, cocktail \\
\hline Cuisine & 54 & $58.06 \%$ & $\begin{array}{l}\text { Asian food, sashimi, eggs benedict, } \\
\text { waffles, burger, cakes, pasta }\end{array}$ \\
\hline Urban city & $N=88$ & & \\
\hline Buildings & 33 & $37.50 \%$ & $\begin{array}{l}\text { office building, houses, residential } \\
\text { buildings, shopping buildings, beehive }\end{array}$ \\
\hline Cityscape & 21 & $23.87 \%$ & $\begin{array}{l}\text { roads, shops, sidewalk, people, boats, } \\
\text { harbour, marina, wharfside, waterfront }\end{array}$ \\
\hline Shopping & 4 & $4.55 \%$ & $\begin{array}{l}\text { Shopfront, people, mannequins, } \\
\text { clothes, books, sunglasses, display, } \\
\text { shop interior, shelves, photo }\end{array}$ \\
\hline Transport infrastructure & 19 & $21.59 \%$ & $\begin{array}{l}\text { train tracks, cars, roads, street light, } \\
\text { aeroplanes, airport, cable car, railway }\end{array}$ \\
\hline Urban art & 11 & $12.50 \%$ & $\begin{array}{l}\text { street art, art installation, sculpture, art } \\
\text { sculpture, artwork, statue }\end{array}$ \\
\hline
\end{tabular}


Table 5.22: (continued)

\begin{tabular}{|c|c|c|c|}
\hline Nature/scenic landscape & \multicolumn{3}{|c|}{$N=91$} \\
\hline Coast & 43 & $47.25 \%$ & $\begin{array}{l}\text { beach, seaside, sea, coastline, open } \\
\text { water, sea, rocks, beach view }\end{array}$ \\
\hline Greenscape/flora & 44 & $48.35 \%$ & $\begin{array}{l}\text { grass, hills, trees, greenery, hillside, } \\
\text { bush, green hills, nature backdrop, } \\
\text { flowers }\end{array}$ \\
\hline Fauna & 4 & $4.40 \%$ & wildlife, birds, fauna, sheep \\
\hline Your pick & \multicolumn{3}{|c|}{$N=93$} \\
\hline City & 30 & $32.26 \%$ & $\begin{array}{l}\text { building, beehive, art, path, bus-stop, } \\
\text { roads, cars, wharf, urban space, } \\
\text { residential building, railway station }\end{array}$ \\
\hline Events & 12 & $12.90 \%$ & $\begin{array}{l}\text { art, performer, gathering, people, } \\
\text { guitar, flags, tent, stalls, cake, candles, } \\
\text { celebration }\end{array}$ \\
\hline Food and drinks/dining & 5 & $5.38 \%$ & $\begin{array}{l}\text { noodles, restaurant, dining, drinks, } \\
\text { plate, fork, glass, chocolates }\end{array}$ \\
\hline Nature/scenic landscape & 31 & $33.33 \%$ & $\begin{array}{l}\text { bird, hillside, sea, sky, gull, greenery, } \\
\text { garden, stream, tress, flowers }\end{array}$ \\
\hline Other & 15 & $16.13 \%$ & $\begin{array}{l}\text { magazine, bench plaque, note on } \\
\text { bench, rifles, gun shop }\end{array}$ \\
\hline
\end{tabular}

The percentage was calculated based on the ratio between the subcategory and category. In this phase of analysis, elements such as colour, composition and context were also noted, examined and compared (Foss, 1994; Rose, 2016; Tussyadiah, 2010). Given the exploratory nature of this study, and number of images received, this phase of analysis provides only a broad overview of key findings.

Events: From the content analysis (Table 5.22), 84.09\% of the events were of public events, such as sporting, cultural and other local community events hosted in Wellington. Beyond public events, $15.90 \%$ of event images submitted were of personal events and get-togethers such as graduation, informal picnics, international association gatherings and barbecues (Figure 5.7, Images 2 and 4). Sojourners exercised variety in the composition of the images, where all 10 photo regions identified by Yang et al. (2007) were observed. A majority of the images in this category featured people performing or engaging in the events, where the inclusion of others adds to the atmosphere, conveying the notion of a fun, friendly, vibrant and active community (Schmallegger, Carson, \& Jacobsen, 2010; Urry, 1992). 


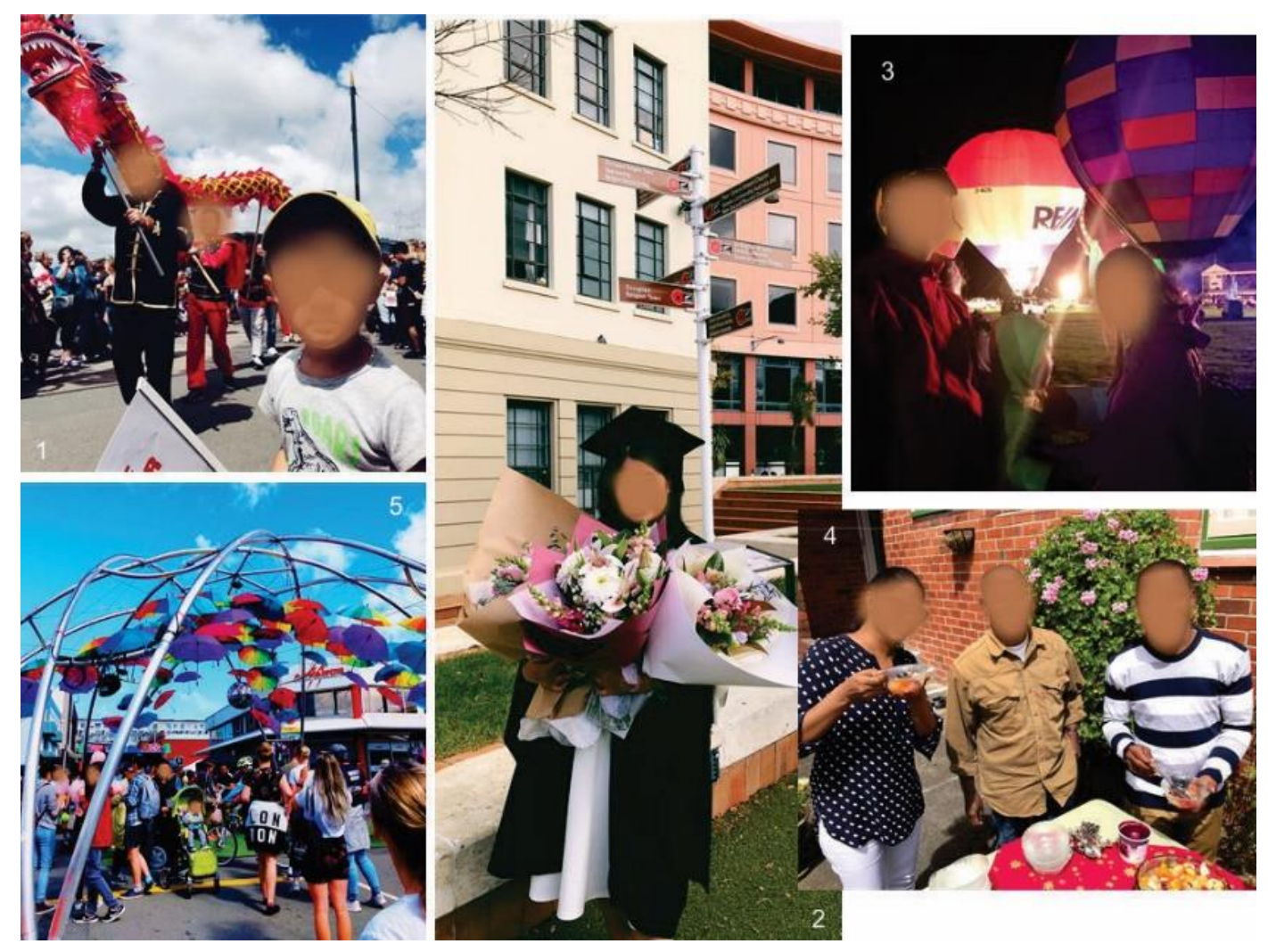

Figure 5.7: Examples of images submitted for Events

Colour captured from the costumes worn by performers, artwork on display and the decorations found in events add to the sense of vibrancy and friendliness. In addition, the diverse demographic of people, in differing life stages and cultures, coupled with the variety of both public and private events, articulate the concept of inclusiveness, and demonstrate the plethora of possible experiences and activities available for different groups of visitors. Within the event category images of self or significant others (i.e., friends, spouses and children) were found embedded in the UGI, demonstrating further the inclusiveness of the city, where sojourners were more than mere spectators but active participants. Images of smiling sojourners and their significant others, within the context of the event, add emotional appeal to the images (Ertimur \& Gilly, 2012). Further, characters embedded in the event images become credible endorsers who demonstrate a variety of possible experiences offered by the destination (Schroeder, 2013).

Food and drinks/dining: The region is reported to "have more cafes, bars and restaurants per capita than New York" (Hudoyo, 2019). As shown in Table 5.22, salient images in this category were of different cuisines offered in Wellington $(58.06 \%)$ that describe and support the notion of Wellington as a food destination. In addition, the range of international cuisine pictured articulates the concepts of diversity and multi-culturalism. Images provided also 
presented aspects of servicescapes (Bitner, 1992) that offer a window into the range of dining options available (see Figure 5.8). The furnishing of the restaurants and bars as well as the artful plating of food and drinks captured, describe a modern and creative cosmopolitan city.
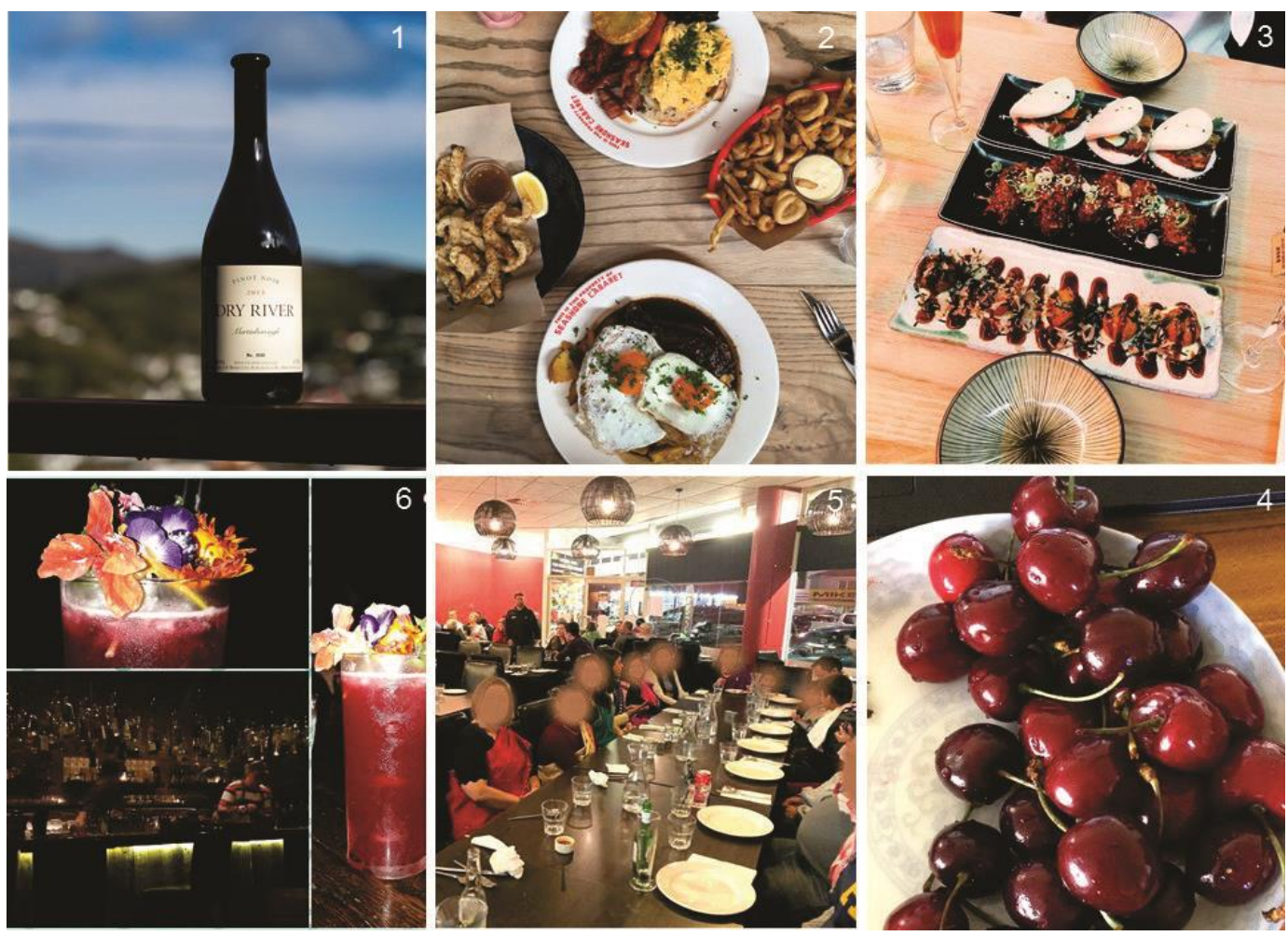

Figure 5.8: Examples of images submitted for Food and drinks/dining

People also featured in a number of images, adding to the atmosphere of the surroundings and conveying the concept of friendliness and the ability to enjoy different dining options with significant others. In addition, sojourners provided images of home meals and fresh fruit that demonstrate the use of fresh produce, and the availability of ingredients to recreate meals reminiscent of home that echo the concept of a diverse and cosmopolitan city.

As presented in Figure 5.8, images in this category focused on the centre and whole region of the image (Tussyadiah, 2010; Yang et al., 2007). The positioning of the artfully plated food and drinks in the centre and whole region of the images, intensify the vivid colour and detail that seek to arouse the senses, and engage the viewer (Kress \& van Leeuwen, 2006; Lofgren, 1999). The strategy of metaphoring was also observed in the food and drinks/dining images submitted, where the qualities of an object is transposed to a dissimilar object by way of implied comparison (Mick, 1986). For example, Image 1 (Figure 5.8), shows a bottle of wine labelled Martinborough strategically photographed against a scenic background, where the viewer draws parallels between the tranquil and peaceful backdrop of Wellington and the bottle of wine, which collectively communicates the sense of leisure and respite (Urry, 1992). 
Collages were also used to add to the appeal of the images, where the deliberate association of images provides commentary to the context (Phillips, Miller, \& McQuarrie, 2014). As shown in Image 6 (Figure 5.8), a collage was used to describe an experience at a local bar, which captures aspects of the servicescape.

Urban city: Buildings were the focal point of $37.5 \%$ of images submitted in this category, and comprised images of commercial, residential and iconic buildings. Iconic buildings tell the history and heritage unique to New Zealand, and serve to capture the identity of the destination (Hunter, 2012). Among the images submitted for iconic buildings was the Parliament building, which communicates Wellington's position as New Zealand's capital city (see Image 4, Figure 5.9). Images of tall commercial buildings as well as those that capture aspects of transport and infrastructure (21.59\%), bolster the capital city narrative. Few urban city images (4.55\%) showcased aspects of shopping, suggesting the lack of pertinence of shopping as a valued attribute. Images in this category tended to be in landscape form and focussed on the horizontal region (Tussyadiah, 2010), where images of clusters of residential and commercial buildings convey the idea of a dense, compact city. Images of bright city lights against the night sky further articulate the concept of a modern capital city — electric and charged with activity.

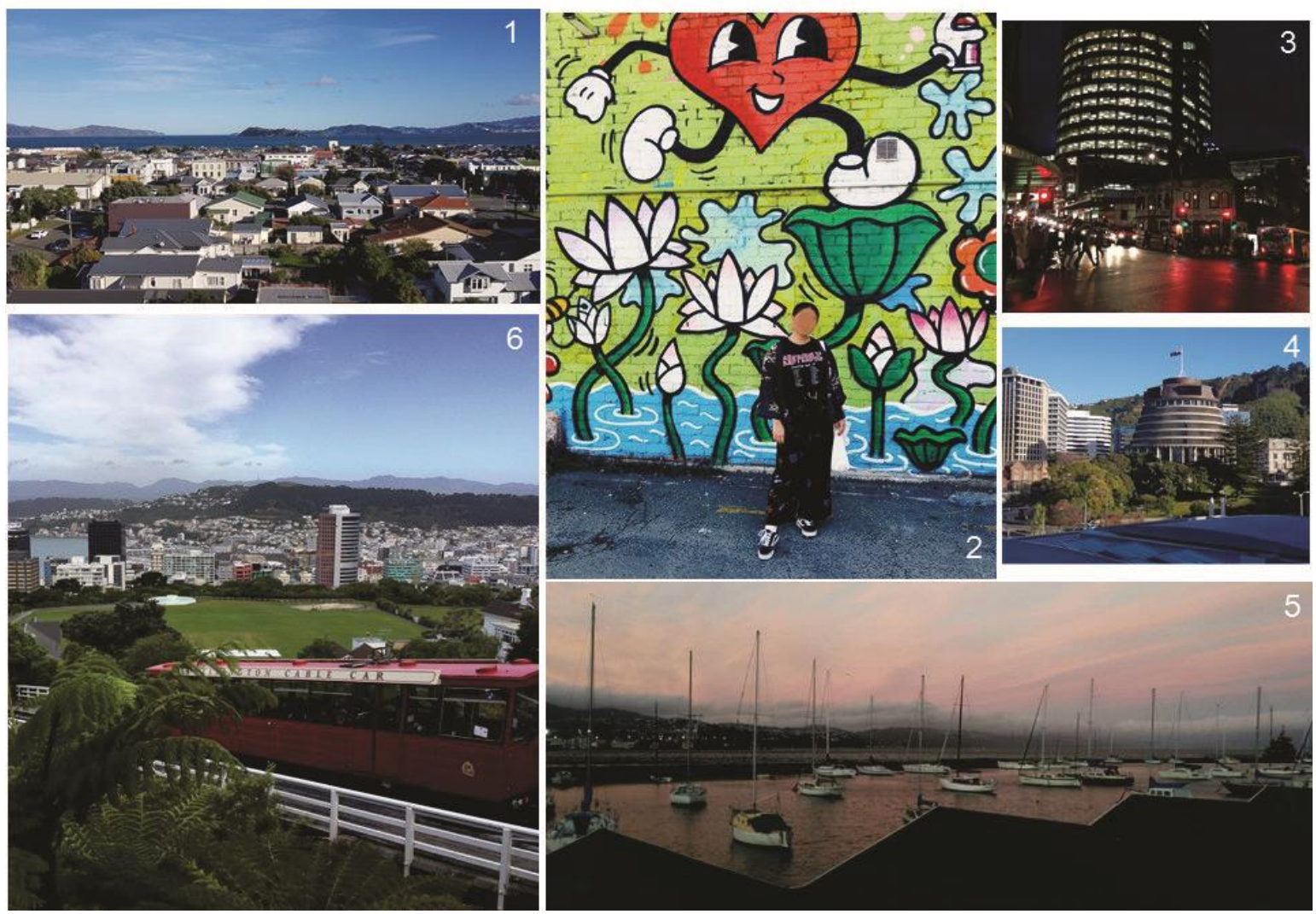

Figure 5.9: Examples of images submitted for Urban city. 
Other than buildings, the urban city images submitted featured urban art (12.50\%), such as sculptures and wall art that convey the narrative of a colourful and creative urban destination, countering notions of 'stuffy' and 'dull' that are linked to capitals and government cities (Peirce \& Ritchie, 2007). Sojourners also provided a variety of perspectives of the city, with images that capture the city against different backdrops or scapes $(23.87 \%)$. For example, a number of urban city images included the picturesque waterfront, and green hills that surround the city, which situates Wellington within the New Zealand context, famous for its landscapes and natural beauty (Sun, Zhang, \& Ryan, 2014). In addition, the presence of greenery that envelopes Wellington in the images submitted, communicates the proximity, and access between city and nature. Figure 5.9 provides an overview of images submitted in the Urban city category.

Nature/scenic landscape: Salient images found in this category, as presented in Table 5.22, are of the coast (47.25\%) and greenscapes (48.35\%) that fit into the $100 \%$ Pure New Zealand rhetoric, where the natural beauty of New Zealand become drivers for tourism (Sun, Ryan, \& Pan, 2014). Images capturing people were predominantly of solo individuals (Figure 5.10, Image 1,2 and 3) - conveying the sense of seclusion, and vastness of unspoilt nature that situates Wellington in the overarching New Zealand narrative.
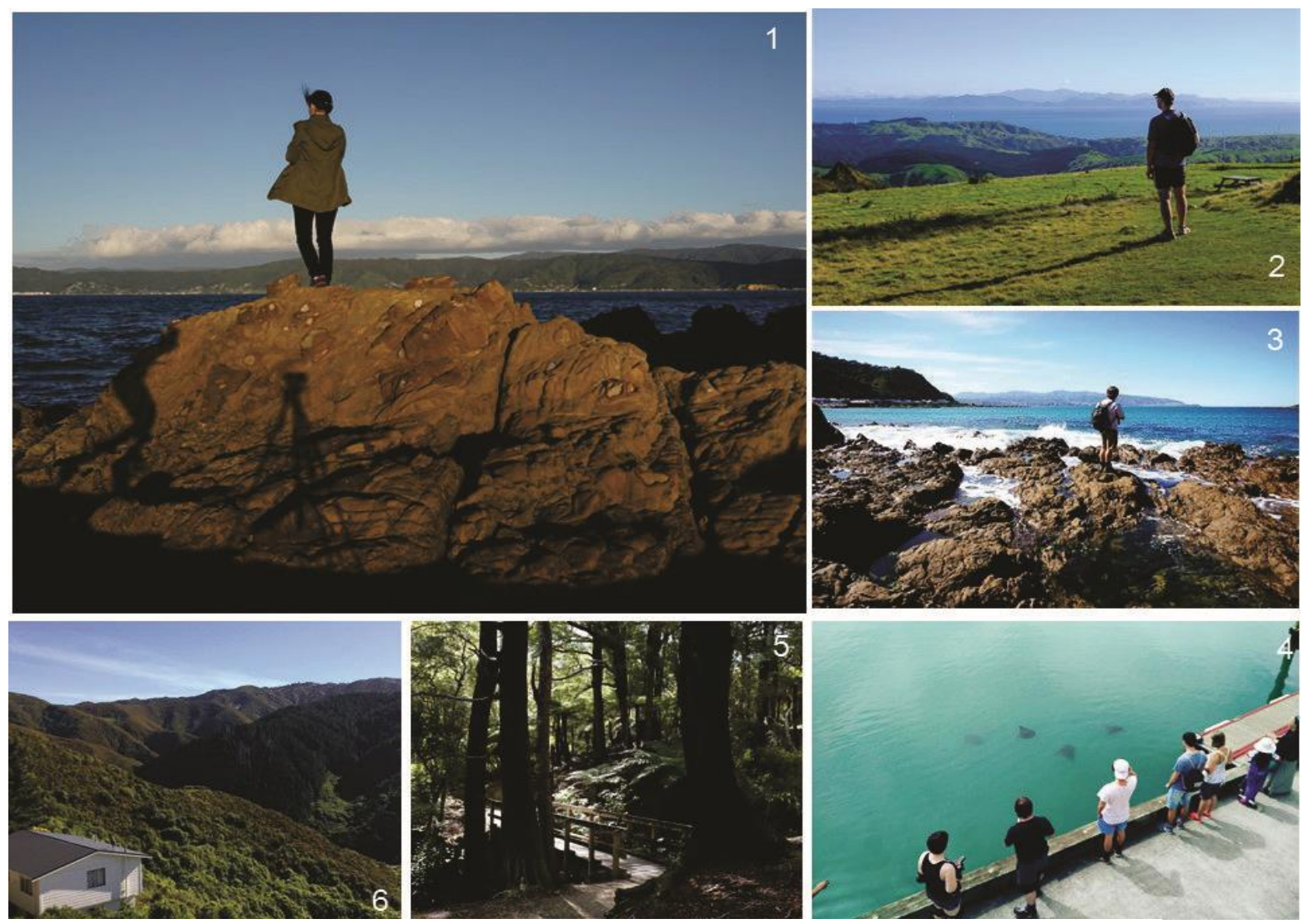

Figure 5.10: Examples of images submitted for Nature/scenic landscape. 
In the nature/scenic landscape images that contained people, the character/s tended to be photographed in the corner region of the image (Figure 5.10, Image 2). This deliberate choice in positioning provides primacy and focus on scenic landscapes. Hues such as blues and greens were dominant in the images, strengthening the argument of the vastness of space (Rose, 2016). To demonstrate further the vastness of the landscape, a majority of images were composed focusing on the horizontal region of the image. Images of walking trails and the outdoor attire worn by those photographed describe the opportunity for outdoor activity and adventure. A small number of the nature/scenic landscape images (4.40\%) captured New Zealand's fauna (Figure 5.10, Image 4), supporting the notion of proximity to nature and the centrality of nature to Wellington.

Your pick: From the results of the word-frequency and content analysis, a majority of images submitted in "your pick", portray physical articles such as buildings, events and scenery, and could fall under one of the earlier identified fixed categories. Only a small number of images fell outside the fixed categories; and given the disparate concepts portrayed, a global category or theme could not be constructed. Examples of the "your pick" images submitted were of close-up shots of items that situate the sojourner in New Zealand. For example, a quote on a bench that made reference to Gandalf from the movie Lord of the Rings (Figure 5.11, Image 3), which was filmed in New Zealand, an image of a wall with text that says: "This Is New Zealand" (Figure 5.11, Image 1), and another of a close up shot of a sign written in Te Reo Māori, the second official language of New Zealand, accompanied by caricatures of a Māori man and woman, as shown in Figure 5.11, Image 2.
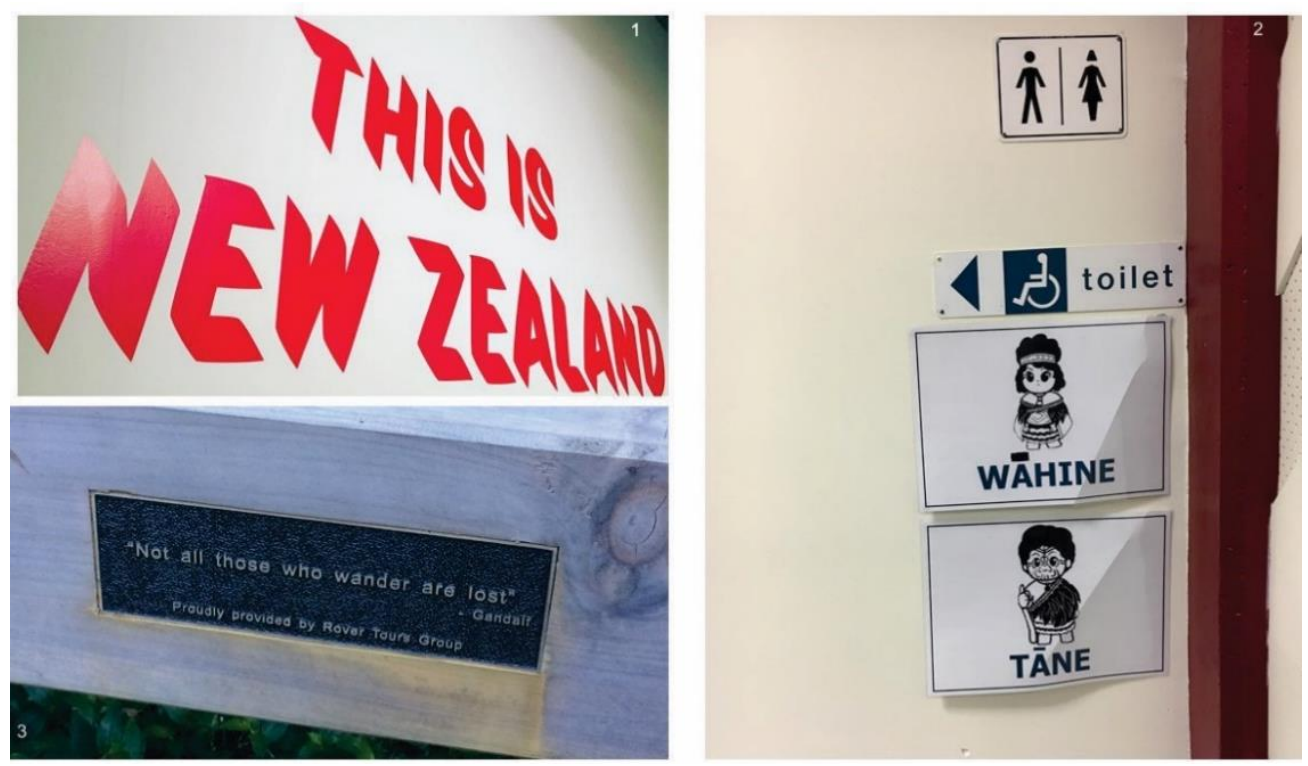

Figure 5.11: Examples of images submitted for Your pick. 


\subsubsection{Scrutiny of the function and emergent meanings.}

Sojourners' familiarity and extended duration of stay in the host destination enable them to seek, perform and frame photogenic experiences that communicate destination attributes. The paradigmatic and syntagmatic choices of sojourners (Mick, 1986), highlight their authority and power to choreograph information, where sojourners are found to "attract visitors through selective destination information sharing" (Choi \& Fu, 2018, p. 53).

The images submitted suggest that sojourners draw from the fluidity of their roles, shifting between tourist and resident when composing images that function to provide vivid descriptions of the host destination. According to Urry and Larsen (2011, p. 179), "tourists not only frame and explore, they are also framed and fixed", seeking out images seen on brochures and social networking sites. As tourists, sojourners become part of the hermeneutic circle - seeking, consuming, capturing and sharing images of iconic markers (Jenkins, 2003), identified to be unique and different from their home environment (Huang, King, \& Suntikul, 2017; Jenkins, 2003). In this study, images of iconic markers such as the Parliament Building, and the Wellington Cable Car were submitted (Figure 5.9, Images 4 and 6).

Conversely, as residents, they provide breadth in the types of images created, offering perspectives from personal spaces, such as neighbourhoods they live in or inside homes, where everyday encounters provide an opportunity to frame extraordinary sights for dispersed audiences. Further, sojourners embed images of themselves, significant others and personal articles (Figure 5.7, Images 2 and 3) contributing to the atmosphere, and injecting authenticity and emotional appeal into the images, where photographs have "significant rhetorical advantages, such as appealing more effectively to pathos" (Birdsell \& Groarker, 2007, p.108). In support of this argument, studies demonstrate how emotions shape perceptions and resulting behaviours (Holbrook \& Batra, 1987; Leisen, 2001). The emotions embedded and relational propinquity between sojourner and their overseas connection, as well as the context in which the visual communication is pushed and 'read' (on personal devices), illuminate the function of UGI as authentic depictions of the host destination, unfiltered for marketing collateral, and difficult to replicate by DMOs (Lutz \& Collins, 1991), where authenticity improves message receptivity (Labrecque, Markos, \& Milne, 2011).

Several images were laced with symbols that connect to sojourners' home cultures. The symbols, such as traditional clothes worn, home meals, selection of dining options and events that were culturally specific, were evident in images submitted. This strategy was pronounced 
in the "events" and "food and drinks/dining" categories (Figure 5.7, Image 1 and Figure 5.8, Image 5). Further, research highlights that one of the factors that encourage VFR tourism is the ability for the visiting friend or family member to feel at home while away (Shani, 2013). Thus, familiar contexts of events and objects, are likely to be received with "delight, affection, nostalgia or other positive attributes" (Foss, 1993, p. 216).

On closer assessment, as "detailed personal scripts" of experiences that reflect new and normal life patterns of sojourners (Ryan, 2010; Tussyadiah, 2010, p. 157), the images submitted function to articulate the blending of the concept of home and away. Scholars highlight that the "temporary between-society" status sojourners hold, results in sojourners having to experience a period of cultural adjustment (Brown, 2009, p. 504). Robinson (2014, p.180) points to the pertinence of photography, arguing for its vital role in "social integration, and family membership". A child, whose family originated from Vietnam, is seen posing in front of a Chinese dragon at a Lunar New Year parade (Figure 5.7, Image 1), exemplifying how home traditions such as cultural celebrations are observed and perpetuated in the host destination. In the same vein, emergent studies in UGI identify the ability to engage with friends and family back home as one of the reasons tourists share UGI (Nikjoo \& Bakhshi, 2019; Wang, Kirillova, \& Lehto, 2017). For sojourners, UGI become symbolic articles of performance that help maintain their personal identity as well as social and emotional ties with connections back home, during the liminal period of the sojourn.

Moreover, the images allow sojourners to demonstrate their construction of home in the host destination, where visual articulations of home as a physical place of dwelling, building of routines, and a space for fostering social connections were observed from the UGI (White \& White, 2007). Figure 5.7, Image 4 provides the viewer access into a private backyard barbecue, where personal social interactions and integration of the sojourner in the host destination are communicated. Further, the images of culturally diverse activities and food captured (see Figures 5.7 and 5.8), convey the state of the cultural landscape of Wellington, where often the "collective activity, behaviour, and influence" of migrant communities "affect the culture and tourism offerings" available for residents and tourists (Griffin \& Dimanche, 2017, p. 109).

Beyond images that reinforce mainstream touristic representations, two images submitted could be interpreted as negative. One image captured the interior of a hunting store, focussed on a wall of rifles, which could convey concepts of danger and risk, given reports in media on gun violence. Another image showed a grey, rainy day in Wellington, which connotes the 
sense of dreariness. Thus, UGI could function as articles of value co-destruction, where the negative connotations could affect viewers' perception of the destination.

\subsubsection{Summary of findings from the visual analysis.}

This section outlined the steps used to critically examine images composed by sojourners. The objective of this phase is to assess the nature of the iWOM shared, and the functions or meanings conveyed. Building on findings of Phase 2, Phase 3 strengthens the position of sojourners as critical online ambassadors and visual influencers, where it demonstrates the ability of sojourners in making syntagmatic choices in their visual compositions to articulate concepts that connote meanings that influence viewer impression of the host destination.

Figure 5.12 provides an overview of denoted and connoted content that emerged during the visual analysis. On closer scrutiny of the images, findings from the visual analysis further demonstrate how iWOM also articulated the liquid position of sojourners, as tourists/residents and their reconciliation of being home/away.

\section{Coder-produced sample keywords (denoted content)}

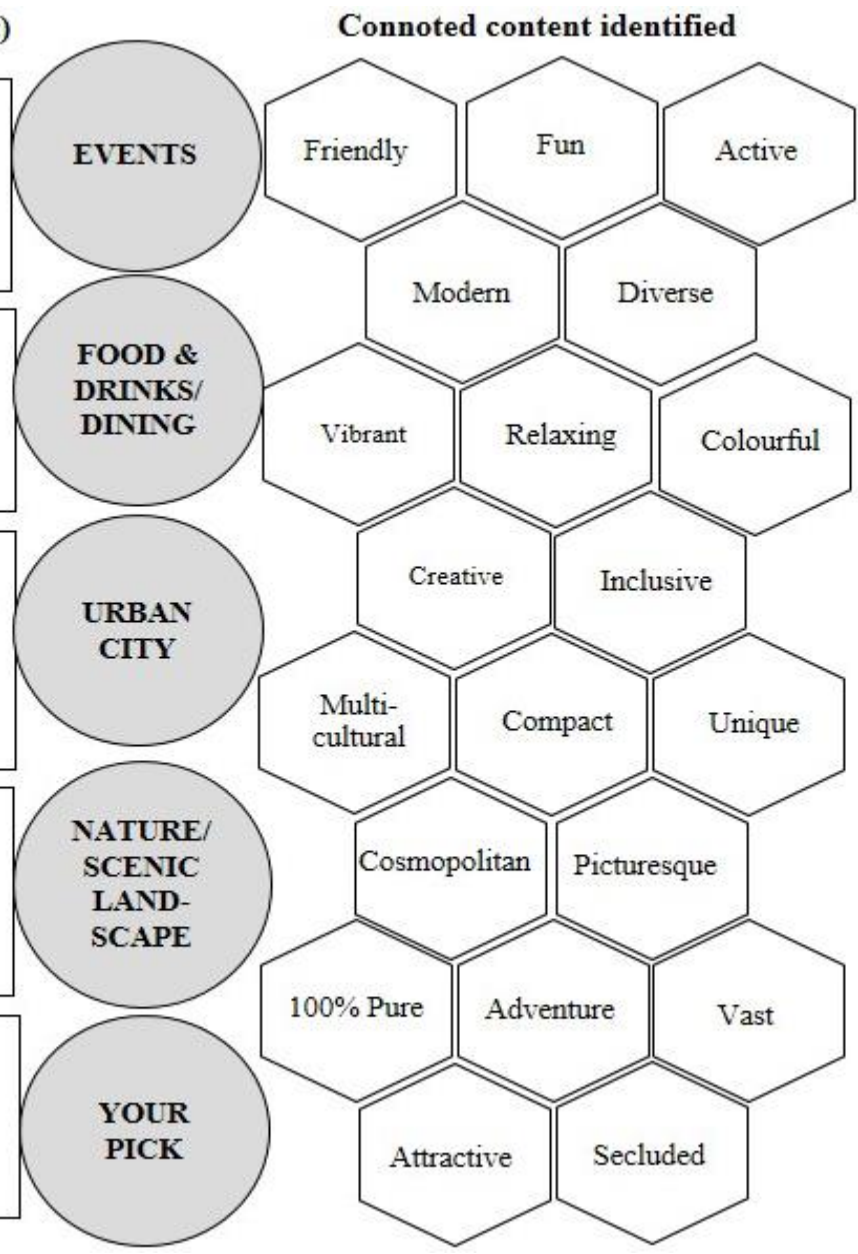

half marathon, cricket match, fireworks display,

dragon dance, art event, picnic, graduation,

informal gathering, informal event, bonfire, lecture, people, person, children, actors, performers, mascots, family

restaurant, indoor, dining, bar, farmland, scenic, mobile bar, people, person, coffee, matcha, wine, beer, cocktail, Asian food, sashimi, eggs benedict, waffles, burger, cakes, pasta

office building, houses, residential buildings, shopping buildings, beehive, roads, shops, sidewalk, people, boats, harbour, marina, wharfside, waterfront, people, person, boats, marina, train tracks, cars, roads, street light, aeroplanes, airport, street art, art installation, sculpture, art sculpture

people, person, child, beach, seaside, sea, coastline, open water, sea, rocks, beach view, grass, hills, trees, greenery, hillside, bush, green hills, nature backdrop, flowers, wildlife, birds, fauna, sheep

veteran cemetery, words, pool, magazine, bench plaque, note on bench, rifles, gun shop, drawing, buildings, events, person posing, scenic backdrop, seaside, open spaces, cars, street lights, food

Figure 5.12: Overview of denoted and connoted content identified (Source: developed for this research from Section 5.4.2). 


\subsection{Chapter summary}

This chapter presented findings yielded from the various phases of the study. In Phase 1, expert interviews involving key staff members from WREDA, and both Wellington City and Regional councils were conducted. The organisations were instrumental in providing insights into the idealised image used in the marketing of Wellington. Salient attributes derived from the interviews informed the cognitive items used to measure iWOM. The chapter also described the collection and validation of images submitted, as well as provided descriptions of participating sojourners. Web-survey data collected for Phase 2, and the process of examining the measurement and structural models for this thesis were detailed in this chapter. Notably, the results of the hypotheses testing, demonstrate the role of Tie strength and Impression as variables that facilitate the relationship between iWOM and Intention to visit between the different groups (friends/relatives). The visual analysis conducted in Phase 3 expands on the quantitative findings of Phase 2, where the nature of the images was critically assessed. The syntagmatic and paradigmatic choices made by sojourners in the composition of the images were examined to understand the functions of the images/connotative meanings relayed that add to the persuasive nature of iWOM. A detailed discussion that bridges the findings of the different phases is provided in the following final chapter of this thesis. 


\section{CHAPTER 6. Discussion and conclusion}

\subsection{Discussion}

Recognising the multitude of user-generated images (UGI) shared online among consumers, this study was conducted to better understand the role of sojourner shared UGI as critical forms of word of mouth (WOM) that can shape the perceptions and behaviours of overseas VFR (visiting friends and relatives) markets. This study is important as it addresses research gaps in the following areas: 1) the role of UGI as critical forms of WOM, 2) the use of ICT, specifically online social platforms, in VFR tourism, and 3) the role of sojourners as critical online ambassadors that link the host destination to extended VFR markets (Backer \& King, 2015; Backer et al., 2017; Bakri et al., 2020).

The objectives of this thesis, therefore, were to 1) better understand the value of UGI, in particular sojourner-produced images, in spreading persuasive image-generated WOM (iWOM), able to shape viewer perception, and stimulate VFR tourism; 2) investigate the underlying role of tie strength, relationship type and impression as mechanisms that affect the link between iWOM and intention to visit; and 3) explore the role of sojourners as key online destination ambassadors, able to frame and shape destination perceptions in overseas VFR markets, through the visual mode.

Building on the theories of visual rhetoric and emotional contagion, an iterative sequential mixed-methods design, comprising expert interviews, a dyadic Web survey and a rhetorical visual analysis, was conducted to examine the iWOM phenomenon. The research questions and objectives, pertinent to the marketing of destinations (in particular, conurbations found to benefit from VFR tourism), were addressed:

RQ 1: How effective are sojourners as visual communicators, and of their images pushed to overseas friends and relatives as persuasive forms of word of mouth?

RQ 2: Given the centrality of relationships in VFR tourism, what roles do tie strength and relationship type play in shaping the perception of the iWOM receiver (friend/relative) towards the host destination?

RQ 3: What is the nature of iWOM shared by sojourners to their overseas networks?

RQ 4: How are destination attributes framed, and what functions or meanings do the iWOM shared by sojourners convey? 
Following guidelines for mixed-methods research, key results from Chapter 5 are integrated into the discussion of this final chapter, where integration could take the form of "comparing, contrasting, building on, or embedding one type of conclusion with the other" (Bryman, 2007; Tashakkori \& Creswell, 2007, p. 108). The results of the qualitative visual analysis are embedded in the discussion of the quantitative findings of this study. Moreover, this chapter outlines similarities and differences between this study and prior research. The theoretical and methodological contributions of this study are also detailed. Limitations of this study as well as areas for future research are also discussed in this concluding chapter.

\subsubsection{Sojourner iWOM and viewer Intention to visit (iWOM $\rightarrow$ Intention to visit)}

Hypothesis 1 predicts that sojourner iWOM would positively influence viewer intention to visit, given that sojourners are found to spread positive messages in their communication to overseas friends and relatives (Humbracht, 2015). Results of the visual analysis (Phase 3) support this finding, where only two images submitted could be viewed to connote negative meanings. The results of Phase 3 are consistent with findings of prior research that highlights that tourism consumers tend to capture and share positive depictions of the destination (Deng \& Li, 2018; Garrod, 2008). Thus, explaining the significant results yielded in this study that demonstrate the positive relationship between sojourner iWOM and the intention of friends and relatives to visit. The results of this study align with prior research in WOM that link positive WOM to positive behavioural intentions, such as intention to visit (Chevalier \& Mayzlin, 2006; Choi \& Wu, 2018; Kwok et al., 2017; Jalilvand et al., 2012). The results broaden the scope of WOM, revealing the importance of sojourner iWOM disseminated to overseas VFR markets in determining visit intentions.

\subsubsection{Sojourner iWOM and viewer Impression (iWOM $\rightarrow$ Impression)}

The results of hypothesis $\mathbf{2}$ confirm that overall viewer impression of the host destination is positively influenced by sojourner iWOM. Moreover, sojourner iWOM had a large effect on viewer impression in both models $\left(f^{2}\right.$ friends $=0.460 ; f^{2}$ relatives $\left.=0.450\right)$. The results in this study, magnify the ability of sojourners in composing and disseminating persuasive iWOM that can influence viewer impression/overall attitude towards the host destination. The findings in this study corroborate the results of prior research that illustrate the awareness of consumers in arranging positive narratives, and drawing from cultural contexts shared to appeal to their online audience (Boulding, 1956; Kim \& Tussyadiah, 2013; Kozinets et al., 2010; Rossolatos, 2017). 
Interestingly, the results of this study are in contrast to those of the study of tourist photographs conducted by Kim and Stepchenkova (2015), which failed to produce a strong positive overall impression on respondents recruited through MTurk, who had no prior relationship with the producers of the tourist images. Similar to this study, overall impression in Kim and Stepchenkova's (2015) study was operationalised as the viewers' overall attitude towards the host destination. The difference in findings could be attributed to the pre-existing relationship between the sojourner and their overseas friend or relative viewing the images, where pre-existing relationships are built on personal trust that contribute to the power of WOM communication (Howard \& Gengler, 2001; Schmallegger, et al., 2010). Another plausible reason for the difference in the results between this study and that of Kim and Stepchenkova's (2015) is the influence of homophily — "communication between similar consumers" (Brown \& Reingen, 1987, p. 351). Scholars point to the positive relationship between homophily and tie strength, usually found in pre-existing relationships (Brown et al., 2007; Mcpherson et al., 2001). Thus, homophily could have contributed to the positive impression derived from sojourner-pushed iWOM.

The syntagmatic and paradigmatic choices made by sojourners in their construction of iWOM, amplify the competence of sojourners as visual communicators that result in a positive link between sojourner iWOM and viewer impression of the host destination further support the findings of hypothesis 2. The findings of the visual analysis (Phase 3), specifically highlight the variety of persuasion strategies applied by sojourners in their composition of iWOM. For example: 1) deliberate stylistic elements such as the framing of the images and the use of colour; 2) the inclusion of significant others as well as the self, that add to the authenticity of iWOM, and appealing to pathos or emotions of the viewer (Iqani \& Schroeder, 2016); and 3) leveraging their broad experience and personal interactions (as tourists/residents) with the host destination to construct meaning of place that articulate attributes of the destination (Stokowski, 2002; Trauer \& Ryan, 2005). Consequently, the positive results support prior research that suggest sojourners primarily engage in impression management strategies when selecting and disseminating information to overseas connections (Choi \& Wu, 2018; Humbracht, 2015).

In summary, the results of this study indicate that iWOM composed and shared by sojourners is a critical precursor to a viewer's overall impression or attitude towards the host destination. The results of this study are consistent with the literature surrounding the theory of visual rhetoric, where iWOM, similar to verbal/textual WOM, are forms of informal communication 
that can carry meaning and shape the impression of the receiver (Durgee, 2003; Ehninger, 1972; Olson, 2007; Scott \& Vargas, 2007). Moreover, the results of this study suggest that similar to DMOs, sojourners are well-versed in composing images that can influence the perceptions of their audience. Hence, the findings strengthen the critical position of sojourners as discerning online visual ambassadors and communicators for destinations, particularly conurbations outside popular tourism areas.

\subsubsection{Viewer Impression and Intention to visit (Impression $\rightarrow$ Intention to visit)}

The result of hypothesis 3 supports the perspective that a positive viewer impression of the host destination (derived from exposure to iWOM) has a positive impact on viewer intention to visit. The result underscores the relevance of viewer impression as a critical outcome of sojourner iWOM, and a key antecedent in encouraging a desire to engage in VFR tourism. Moreover, the results of this study support the prevailing view that a positive impression or overall attitude towards the destination is necessary for influencing positive consumer behaviour intentions, such as visit intentions (Joo, Seok, \& Nam, 2020; Stylidis et al., 2017; Wang \& Hsu, 2010). The results are also consistent with Backer's (2008) findings that destination attractiveness motivates VFR visits.

The finding of this study further accentuates the critical value of sojourner iWOM in articulating positive experiences in shaping viewer perception of the host destination, resulting in positive behavioural outcomes, specifically the desire to visit the host destination. The results amplify the importance of engaging sojourners in producing iWOM to heighten awareness of the host destination in overseas VFR markets, where iWOM become vivid evocations that facilitate elaboration and evaluation of potential benefits of conurbations (Dichter, 1985; Phillips et al., 1995; Roggeveen et al., 2015).

\subsubsection{Mediating effect of viewer Impression (iWOM $\rightarrow$ Impression $\rightarrow$ Intention to visit)}

The results of this study provide support for hypothesis 4, which predicted the relationship between sojourner iWOM and viewer intention to visit is mediated by viewer impression. The indirect effects of sojourner iWOM on viewer intention to visit are positive and significant in both models $\left(\beta_{\text {friends }}=.390, p<.001, \beta_{\text {relatives }}=.370, p<.001\right)$, with substantial corresponding variance accounted for $(\mathrm{VAF})$ scores $\left(\mathrm{VAF}_{\text {friends }}=0.848 ; \mathrm{VAF}_{\text {relatives }}=0.787\right)$. Thus, similar to narratives in marketing as well as traditional WOM, iWOM become 
powerful visual depictions of rich tourism experiences that can significantly influence viewer impression and travel intentions (Govers \& Go, 2005; Jalilvand, 2017).

An interpretation of these results is that viewer impression is a key underlying mechanism, which facilitates the relationship between sojourner iWOM and desire to visit, where overall positive impression is an effective predictor of destination choice (Jalilvand \& Samiei, 2012). The results imply that sojourners' iWOM can arouse visit intentions from friends and relatives, provided the friend or relative develops a positive overall impression of the host destination from the attributes conveyed through iWOM. The implication is that neither iWOM nor viewer impression is sufficiently valuable alone, and to yield the greatest potential value, both factors must work in tandem. Hence, the results highlight the value of engaging sojourners as key marketing stakeholders, as well as providing opportunities to create and push positive iWOM to overseas networks.

\subsubsection{Differences between relationship type (friends vs. relatives)}

Research in VFR tourism cites differences between visiting friends (VFs) and visiting relatives (VRs) (Backer et al., 2017; Lockyer \& Ryan, 2007; Seaton \& Tie, 2015). This section addresses hypotheses $\mathbf{5} \mathbf{a}-\mathbf{5} \mathbf{d}$ that examine the consequence of relationship type on the decision-making process of friends and relatives, exposed to sojourner iWOM.

Type of relationship between the sojourner and the overseas contact did not result in statistically significant differences in the links between; 1) sojourner iWOM and viewer intention to visit (hypothesis 5a) and 2) sojourner iWOM and viewer impression (hypothesis $\mathbf{5}$ ). However, hypothesis $\mathbf{5}$ c results suggest relationship type significantly influences viewer impression towards the host destination, and subsequent intention to visit the host destination. In this study, viewer impression had a significantly greater positive influence on intention to visit for friends, than on relatives ( $|\operatorname{diff}|=.098 ; p=.048)$. The findings align with the results of Gafter and Tchetchik's (2017) study that demonstrates a positive relationship between destination attractiveness and the decision of VFs to engage in VFR tourism. Similarly, the findings of Lockyer and Ryan (2007) lend support to results in this study, where differences such as age of VFs and VRs influenced the perception and activity selection of the two groups. Therefore, the findings of hypothesis $\mathbf{5}$ imply that the type of relationship (friend/relative) between sojourner and the receiver of iWOM can result in variances in the complex VFR decision-making process. 
Hypothesis $5 \mathrm{~d}$ and hypothesis 6 results indicate contrasting outcomes between the effect of tie strength on viewer impression. Hypothesis 6 is partially supported. The results indicate no significant relationship between tie strength and the destination impression of relatives. In contrast, tie strength had a positive and significant influence on the overall impression of friends exposed to the iWOM. Consequently, as indicated in the results for hypothesis $\mathbf{5} d$, tie strength was found to have a significantly substantial positive influence on the overall impression of friends than on relatives $(\mid$ diff $\mid=.168 ; p<.001)$. The difference in the social relationship between friends and relatives identified by scholars could explain the results of this study. Friendships unlike kinship ties, are not linked to familial structures bound by institutional bonds, but are relationships built on choice (Capistrano \& Weaver, 2017; Gafter $\&$ Tchetchik, 2017). Thus, tie strength would play a more critical role in friendships.

Perhaps the most critical implication of hypothesis $\mathbf{5} \mathbf{d}$ is that it distils the difference in the influence of tie strength in WOM interactions between friends and relatives. At times strong ties can be attributed to friends and relatives, in which case tie strength results in similar patterns of influence on the WOM receiver (Baker et al., 2016; Brown \& Reingen, 1987; Granovetter, 1983; Narangajavana Kaosiri et al., 2019). However, the results of this study confirm the claims of Aral and Walker (2014), who argue against using relationship categories as a means of examining the influence of tie strength in social interactions. The authors explain that the adoption of categorical classifications of tie strength based on social relations "obscures meaningful differences in the type, quality, and context of relationships" (Aral \& Walker, 2014, p. 1357).

The results expand current understanding surrounding the role of tie strength in shaping attitudes and behaviours in interpersonal interactions. This study highlights the utility of disaggregating WOM behaviours of close friends and relatives, to better inform targeted WOM marketing strategies. Moreover, the findings suggest a need for scholars to reconsider the operationalisation of tie strength as merely a distinction of types of social relations, but instead a multi-dimensional construct. The difference between the effect of tie strength within the two groups is further discussed in the following section.

\subsubsection{Tie strength interaction effect (iWOM x Tie strength $\rightarrow$ Impression $\rightarrow$ Intention to visit)}

Phase 3 findings illustrate how the images distributed by sojourners become vivid displays of destination experience, where the host destination provides the backdrop to capture special 
moments, spectacular sights and personal interactions of the sojourner with the host destination - that generate a bricolage of positive meanings and associations of the host destination. In addition, the images shared were found to function as symbolic articles of performance, which allow sojourners to negotiate their personal identity as well as maintain their social and emotional relations with their overseas friends and relatives. The images, therefore, act as vectors of emotional contagion, emotionally charged with complex personal meanings that become powerful sources of influence (Trauer \& Ryan, 2005; Van Kleef, Van Doorn, Heerdink, \& Koning, 2011).

The theory of emotional contagion explains that emotions are transferred during social interactions and have the capacity to influence consumer perception and behaviour (Hatfield et al., 2014; Howard \& Gengler, 2001). The effect of emotional contagion is found to be most pervasive in interactions among individuals with interpersonal bonds - where a greater degree of interpersonal liking results in corresponding high receptivity of the focal object and synchrony of emotions (Howard \& Gengler, 2001). Thus, hypothesis 7 predicted that the strength of the indirect relationship between sojourner iWOM and Intention to visit, via viewer Impression, is contingent on the intensity of Tie strength between the sojourner and the receiver of the iWOM. However, hypothesis 7 results were mixed. The influence of tie strength was only observed within the friends data set.

The results imply that the stronger the relationship between sojourner and the friend receiving the iWOM, the greater the impact iWOM would have on the overall impression of the friend towards the host destination, which subsequently stimulates the desire of friends to visit. Although positive, the result for relatives was not significant. Thus, the findings of this study are not fully consistent with the predicted outcome of the theory of emotional contagion. The difference in the social premise of the friends and relatives relationship provides a plausible explanation for the results of this study, where friendship ties unlike kinship ties, are voluntary and chosen (Capistrano \& Weaver, 2017; Wiseman, 1986). The findings of this study, therefore, echo the old adage: "you can choose your friends, but you can't choose your family", suggesting the intervening role of tie strength is less critical for persuading relatives than for friends.

The findings imply that to achieve an optimal outcome specifically when targeting friends of sojourners through VFR campaigns, iWOM, tie strength and overall impression must work in 
synchrony. In addition, the findings support the argument for the need to employ differentiated marketing strategies, when targeting friends and relatives (Backer et al., 2017).

\subsubsection{Effect of control variables age and cultural distance on intention to visit}

In this study, the control variable age was found to influence the visit intentions of both friends and relatives - however, with contrasting effects. The significant negative relationship between age and the intention of friends to visit, suggests that younger friends would have less desire to visit Wellington. According to Lockyer and Ryan (2007) VFs tended to be younger than VRs, and age was a determining factor in the types of activities undertaken during the trip. The scholars add that visits by VFs were motivated by entertainment and enjoyment, where visits to bars, nightclubs and shopping were activities identified to interest VFs. Given that few images captured aspects of shopping and nightclubs, the findings of Lockyer and Ryan (2007), could provide a possible explanation for the effects of age on visit intentions of friends and relatives.

Concomitantly, the findings of Lockyer and Ryan (2007) also offer an explanation for the positive relationship between age and the desire of relatives to visit the host destination, where VRs are motivated towards family-oriented activities, which were largely present in the images submitted. Older international travellers could also be more apprehensive about cultural barriers or differences, which is a possibility given that a majority of participants were from Asia and countries outside of the Anglo cluster. Thus, providing a possible explanation for the positive relationship between age and the desire of relatives to visit and engage in VFR tourism.

Interestingly, the control variable culture was found to have a significant positive relationship on intention to visit, only in the relatives data set. The results suggest that the captured images of diverse activities as well as food that convey the cultural landscape of Wellington could have eased apprehensions tied to culture by reinforcing "traditional ideas and ... their attached values" (Pellemans, 1971, p. 19). The results strengthen the position of sojourners as international communicators able to construct images that resonate with their overseas relatives, where prior research demonstrates a negative relationship between cultural distance and visit intentions ( $\mathrm{Ng}$ et al., 2007). 


\subsubsection{Additional findings: differences in content type}

Given the results of the expert interviews in Phase 1, images from the content types/image categories were tested to examine the iWOM phenomenon:

1. Events

2. Food and drinks/dining

3. Urban city

4. Nature/scenic landscape

The results in this study indicate that content type resulted in no significant differences when the iWOM were received by the relatives of sojourners, suggesting that content type has no effect on the way iWOM shared in this study influenced the decision-making processes of relatives. However, when iWOM recipients were friends of sojourners, differences in viewer impression were found - specifically, when the content involved "Nature/scenic landscapes". For example, when the content type "Events" was compared against "Nature/scenic landscape", the difference between iWOM and the overall impression among friends towards the host destination was greater for the content type "Events" than for "Nature/scenic landscape" $(|\mathrm{diff}|=.241 ; p=.008)$. The results were consistent in other content types compared against "Nature/scenic landscape" (Food and drinks/dining: |diff| $\mid=$ $.253 ; p=.005$; Urban city: $\mid$ diff $\mid=.266 ; p<.001)$. The findings in this study suggest that images portraying "Nature/scenic landscape" resulted in friends having a less positive impression towards the host destination than when exposed to other content types.

The findings were surprising, considering much of the appeal of New Zealand has been attributed to its natural landscapes (Liu \& Ryan, 2011; Sun, Ryan, \& Pan, 2014). Perhaps the contrast in the results could be attributed to the internationally diverse sample in this study, which differ from studies conducted by Liu and Ryan (2011) as well as Sun et al. (2014) that solely focussed on the Chinese market. Nonetheless, the results of this study corroborate the findings of Lockyer and Ryan (2007, p. 64) that indicate that VFs were motivated by "excitement and fun", where categories such as "Urban city" and "Events" performed better than "Nature/scenic landscape".

Another interesting finding that surfaced in the results, specifically in the friends data set, was the relationship between tie strength and impression (Tie strength $\rightarrow$ Impression) of friends towards the host destination, for the content type "Nature/scenic landscape". The results for the friends data set indicate that tie strength and overall destination impression of friends was 
greater for the content type "Nature/scenic landscape" when compared to other content areas (i.e.., Events vs. Nature/scenic landscape: $|\operatorname{diff}|=-.109$; Urban city vs. Nature/scenic landscape: $\mid$ diff $\mid=-.149)$. However, it is important to note only the comparison of content type "Food and drinks/dining" vs. "Nature/scenic landscape" was found to be significant (|diff $\mid=-.181 ; p=.004)$. This finding suggests tie strength is a critical factor when influencing the impression of friends towards the host destination, specifically for content types that may be less favourable. Given that marketing policies of DMOs largely depend on knowledge of how the destination is perceived by potential visitors (Stepchenkova \& Mills, 2010), the results of this study are therefore illuminating, as they highlight not only the usefulness of leveraging sojourner-produced UGI as a source of market intelligence for DMOs, but also the importance of tie strength among friends in influencing consumer perceptions.

\subsection{Contributions}

The results of this study provide several contributions to theory, research and practice. The contributions are discussed in the following sections.

\subsubsection{Theoretical contributions}

\section{An expanded view of WOM}

This study introduces and tests the image-generated word of mouth (iWOM) conceptual model that helps explain and predict iWOM's ability to influence viewer impression and intention to visit destinations. The findings of Phase 2 provide empirical evidence of the ability of sojourners in constructing persuasive iWOM, akin to verbal/textual WOM, that influences viewer impression and visit intentions of overseas friends and relatives. This study, therefore, augments the focus of research in WOM and UGC from text/verbal to visuals, where textual content "cannot record an experience in a landscape" (Balomenou \& Garrod, 2019, p.206). Specifically, this study adds to the existing marketing and tourism literature in WOM and UGC, where studies that examine consumer constructed images as articles of WOM are limited - despite the multitude of images exchanged online (Bakri et al., 2020; Lu \& Stepchenkova, 2015; Scott \& Vargas, 2007).

Moreover, the syntactic breakdown of images through the visual rhetorical analysis, in Phase 3 provides a nuanced understanding into the abilities of sojourners to skillfully structure visual images as rhetorical devices, and illuminates the different appeals and strategies used by sojourners in strengthening the persuasive influence of iWOM. In addition, the findings of 
this study reflect the ability of sojourners in making deliberate paradigmatic and syntagmatic choices in their visual compositions, framing images to articulate concepts. The patterns found in the rhetorical analysis of this study, contribute to research by identifying visual norms, strategies and vocabularies used to convey concepts in portraying authentic destination experience. The findings of the visual analysis of this study, therefore, provide a better understanding of the use of linguistics in consumer behaviour, where language spans both text and visuals (Carnevale, Luna, \& Lerman, 2017; Goransson \& Fagerholm, 2018; Ordenes, Ludwig, De Ruyter, Grewal, \& Wetzels, 2017).

Further, by building on prior studies in destination image, the quantitative (Phase 2) component of this study heeds the call for applying testable constructs, in particular, those that link visual images to conceptual cognitive constructs, to examine the role of visual images as rhetorical devices that influence consumer perception (Phillips \& McQuarrie, 2004). Consequently, this study contributes theoretically by expanding the application of visual rhetorical theory from primarily examining firm-created images to consumer-generated images (e.g. Campelo et al., 2011; Peterson, 2019; Scott \& Vargas, 2007; Zhao \& Belk, 2008), which are increasingly shaping market meanings and consumer decisions.

\section{ICT and the role of sojourners as online ambassadors in VFR tourism marketing}

This study addresses a research gap in the VFR literature, where the use of ICT in VFR tourism is neglected, resulting in a lack of conceptual understanding of online interactions between sojourners and their overseas networks (Backer \& King, 2015; Palovic, Kam, Janta, Cohen, \& Williams, 2014). Collectively, the results of this iterative sequential mixedmethods study identify the ability of sojourners in using ICT, in relaying destination experiences to overseas networks, through carefully crafted iWOM that communicate aspects of destination image.

To the best of this author's knowledge, this study is the first to demonstrate sojourners as skilled online destination ambassadors, where the results of this study suggest that sojournerproduced images are persuasive forms of eWOM, capable of easing the effects of cultural distance, influencing the impression of potential VFR tourists and encouraging VFR tourism. By establishing and examining the role of IWOM as a driver of VFR tourism, this study provides a fresh perspective in understanding VFR phenomena, where prior studies, as demonstrated in the extensive literature review conducted, predominantly focus on outcomes of VFR tourism. The attention on outcomes ignores the shifting role of consumers, 
specifically sojourners, in employing ICT in creating and disseminating persuasive content, which as identified in this study, has the capacity to arouse visit desires (Larsen, Urry, \& Axhausen, 2007). Consequently, this study contributes to the limited understanding of marketing to the VFR segment (Yousuf \& Backer, 2015), where recent research signals the importance of destination attractiveness in VFR tourism (Backer, 2008), and the opportunity of leveraging resident-generated content in the online marketing of destinations (Uchinaka et al., 2019).

\section{Role of tie strength and relationship type (friend vs. relative)}

This study is novel as it provides insights into intervening mechanisms that clarify the link between behaviours and determinants in online communications that influence VFR tourism, an area overlooked in the extant literature (Gafter \& Tchetchik, 2017). The uniqueness of VFR tourism as a segment, provides an opportunity to evaluate the implication of social media posts shared by individuals within their own networks (Errmann, Seo, Choi, \& Yoon, 2019), allowing for a keener understanding of the interplay between iWOM shared and tie strength, as well as the role of relationship type in shaping viewer perceptions.

Prior WOM studies predominantly examined the rate by which tie strength drives the spread of adoption (Baker et al., 2016; Brown \& Reingen, 1987; De Bruyn \& Lilien, 2008). Similarly, tie strength has been investigated in VFR tourism as a factor influencing visits. However, little is known of the role of tie strength in strengthening online communication/ actual WOM content that are increasingly facilitating the complex pre-travel decision making process of tourism consumers (Gafter \& Tchetchik, 2017). This study provides an understanding of the interplay between tie strength and iWOM shared by sojourners to overseas friends and relatives and its influence in shaping pre-travel decision making.

This study further distinguishes the differences between the relationship of tie strength and online content of friends and relatives. Prior research is noted to group friends and relatives as strong ties, perceived to have similar effects and influence on WOM interactions (Baker et al., 2016; Brown \& Reingen, 1987; Granovetter, 1983; Narangajavana Kaosiri et al., 2019). The results identified the need to reevaluate how tie strength is operationalised in future WOM studies.

In addition, this study is aligned to prior studies in VFR tourism that highlight the differences in the behaviours between VFs and VRs (Backer et al., 2017; Lockyer \& Ryan, 2007; Seaton 
\& Tagg, 1995). However, this study extends prior VFR research, by providing evidence of the implications of relationship type (friends vs. relatives) on the effects of WOM in shaping the pre-travel decision-making process of overseas friends and relatives of sojourners.

In summary, the study contributes to the conversations in WOM, UGC, destination image and VFR tourism. Markedly, this study contributes to a greater understanding of VFR tourism, which has been largely underestimated, and underrepresented in tourism marketing discourse, as discussed in the literature review.

Key theoretical contributions of this thesis, therefore, are as follows:

1. Introduces and tests the concept of iWOM, providing an expanded view of WOM.

2. Provides an enhanced understanding of the impact of sojourners and ICT in VFR tourism marketing.

3. Establishes and disentangles the roles of tie strength and relationship type as intervening variables in the influence of iWOM on overseas VFR markets.

\subsubsection{Methodological contributions}

\section{Sojourner-produced UGI as a source of rich research data}

This iterative sequential mixed-methods study contributes methodologically to literature in eWOM, UGC and VFR tourism. The literature review of eWOM and UGC within tourism, demonstrates the literature is replete with studies that focus on textual content and rating scales (e.g. Dinçer \& Alrawadieh, 2017; Guo et al., 2017; Hu \& Trivedi, 2020; Huang, 2017). The findings of the literature review identified the overlooked status of UGI, where the results of the review align with findings of other marketing and tourism reviews in eWOM and UGC (Bakri et al., 2020; Litvin et al., 2018; Lu et al., 2018). In contrast to prior studies, this study draws insights that inform marketing strategy through images shared, and produced by sojourners (consumers).

To the best of the author's knowledge, this study is the first to collect and examine UGI created, and shared by sojourners that provide insights into the online interactions (WOM) disseminated by a critical group acknowledged to spur VFR tourism (Liu \& Ryan, 2011; Young et al., 2007). Thus, answering calls for new research methods to examine phenomena surrounding VFR tourism (Palovic et al., 2014; Seaton, 2017). The qualitative method used in this study employed an expanded Foss' visual rhetorical schema. The expanded framework, 
that includes a content analysis, provides a comprehensive and rigorous framework to tap consumer-to-consumer visual communications, allowing marketers to establish valued and personal consumer experiences that are difficult to extract (Ostrom et al., 2010), and are instrumental in designing strong tourism experiences and destination image.

\section{Examining VFR phenomena using an iterative sequential mixed-methods design}

VFR studies predominantly adopt either a quantitative (e.g., Backer et al., 2017; Cave, Ryan, \& Panakera, 2003; Seaton \& Palmer, 1997) or qualitative approach (e.g. Griffin, 2017; Janta \& Christou, 2019). In the review of literature, mixed-methods studies in VFR studies have been limited to interview data. This iterative sequential mixed-methods study went beyond the use of interview data and examined UGI as rich sources of qualitative data. The use of mixed methods in this thesis contributes to the robustness and rigour of this study. The mixed-methods approach enhanced the generalisability of the findings of this study, and provided a richer understanding of the iWOM phenomenon within VFR tourism; in particular the role of sojourners as expert visual online ambassadors and critical conduits in the marketing of destinations to extended VFR markets. In a recent review of tourism journals, Khoo-Lattimore et al. (2019) found 96 articles in 37 tourism journals, adopting the mixedmethods approach, with a majority published in Tourism Management (22\%) and Journal of Sustainable Tourism (11\%). This study demonstrates the potential and possibilities of adopting a mixed-methods approach that incorporates a visual analysis, yielding a more nuanced understanding of tourism phenomena.

\section{Dyadic data in understanding online interactions of international sojourners}

The study provides guidance in collecting dyadic data to examine VFR phenomena. Through sojourner-receiver (friend/relative) dyadic data, this study provides an understanding of 1) the role and influence of sojourners as primary organic sources of WOM, and 2) the perceptions of receivers of WOM. Notably, prior studies in eWOM and VFR tourism did not attempt to obtain dyadic/paired data, citing difficulties in obtaining dyadic data (Choi \& Wu, 2018; Gafter \& Tchetchik, 2017; Marine-Roig \& Ferrer-Rosell, 2018). The dyadic/multi-actor nature of the data in this study reduces ambiguity associated with data collected on open collaborative websites such as TripAdvisor, Twitter and blogs, adding to the robustness of this study (Lu \& Stepchenkova, 2015). Scholars in tourism highlight the value of paired primary data, asserting that connected samples would enhance understanding of the impact of sojourners' online communications on the information recipient, in VFR tourism (Choi \& 
Wu, 2018; Gafter \& Tchetchik, 2017). In addition, the multi-actor nature of this study further contributes to VFR tourism by providing an integrated perspective in examining VFR phenomena, which is scarce in the extant VFR literature.

In brief, the key methodological contributions of this thesis are:

1. Provides a framework to gain insights from UGI as a source of research data.

2. Contributes to mixed-methods research in tourism, by adopting an iterative sequential mixed-methods design that introduces the use of a visual rhetorical analysis.

3. Provides guidance in collecting dyadic/multi-actor data from international participants.

\subsubsection{Managerial implications}

This thesis highlights several implications for Destination Marketing Organisations (DMOs), hospitality marketers and city councils/planners. For DMOs and hospitality marketers, the findings of this study cast light on the ability of sojourners in drawing from their fluid position, as tourists/residents and consumers/producers of tourism experiences, to package and articulate a variety of authentic destination and hospitality experiences for a diverse online audience of overseas connections. Moreover, through this study, the images are identified as providing the capacity to influence consumer impression and intentions. Results of Phase 2 provide empirical proof to support the importance of iWOM as persuasive forms of WOM, and of sojourners as key online destination ambassadors, and potential marketing allies.

The results of the quantitative phase of this study further suggest the critical role of tie strength in influencing the perceived overall impression of friends towards the destination. Drawing from the results, DMOs and hospitality marketers could devise marketing strategies that target close friendship dyads. For example, hashtag campaigns or competitions that encourage sojourners to tag close friends in their UGI during local events or when visiting local hospitality sites and attractions. The results in this study also suggest that younger friends who receive iWOM prefer images that depict excitement and activity instead of images of "Nature/scenic landscape". Visual marketing programmes should, therefore, focus less on the portrayal of scenery, when targeting younger sojourners, such as students. 
In contrast, tie strength was not a critical determinant for relatives. However, for both relatives and friends, positive impression towards the destination was a critical factor, which mediated the relationship between iWOM and the desire to engage in VFR tourism. Hence, reaffirming the importance of engaging and providing sojourners with opportunities to construct and disseminate positive iWOM. Consistent with other studies, images received from sojourners in this study, were found to be predominantly positive in nature (e.g. Deng \& Li, 2018; Garrod, 2008), indicating the viability of seeding initiatives or visual engagement strategies in yielding iWOM that bolster marketing and branding efforts. DMOs of conurbations such as Wellington that have "relatively low inclusion ... in many packaged itineraries of international tour companies (Pearce et al., 2004, p. 405) could, therefore, benefit from the reach provided by sojourners to improve awareness in global VFR markets. Consequently, to some degree, sojourners provide DMOs with greater control in etching a more representative image of the destination, in comparison to large scale national-level campaigns that might not be representative of the conurbation or under-represent the conurbation. WOM can be particularly difficult to control or influence (Allsop, Bassett, \& Hoskins, 2007; Ring et al., 2016). However, local/regional DMOs could manage the informal communication of sojourners and their overseas networks, by connecting with sojourners through community groups, such as international student associations and expatriate communities or by starting online groups that involve and inform sojourners about local sites or events. Local DMOs and hospitality marketers could also provide promotional discounts to engage more participation among sojourners, which could consequently result in more sharing of iWOM. Pop-up environments that are designed to encourage the creation and sharing of images online could also be set up in areas frequented by sojourners.

On a macro level, investing in internal marketing strategies through communities, such as sojourners, could help national-level DMOs in the management of tourism flows, allowing for tourism receipts to spread into regions, and deeper into the local economy, where VFR tourism is found to contribute significantly to sectors such as services and retail (Seaton \& Palmer, 1997). In addition, adopting an internal marketing strategy focussed on international sojourner communities could alleviate the management of overtoursim and undertourism. Marketing internally to sojourners could also reduce high costs involved in large overseas campaigns. Thus, affording resource poor conurbations the opportunity to compete with top destinations for market share (Morgan et al., 2003). 
Moreover, the findings of the visual analysis demonstrate how sojourners illustrate their destination experiences by incorporating elements of home, and articulating their construction of home and away, linking old and new worlds through the images shared; where familiar contexts and objects have the tendency to be received with affection, nostalgia and other positive qualities (Foss, 1993). In addition, the blurring of home and away reduces the perceived cultural distance between the host destination and the potential visitor, where prior research demonstrates the negative link between cultural distance and intention to visit (Ng et al., 2007). Marketers must, therefore, aim to leverage the social capital and position of sojourners in the marketing of destinations.

Through patterns found in the submitted images, the study identified the 'what, when and where' images were taken — providing "valuable implications" for marketing practice (Lu et al., 2018, p. 111). The examination of the taxonomy of sojourner-produced images provides actionable communication ideas in reconceptualising aesthetic notions, and designing communication messages that are relatable, and resonate with consumers (Bakri et al., 2020; Foss, 1994). For example, the presentation of shopping is limited in the depiction of Wellington as an urban city, suggesting more focus should be given to strengthen the position of shopping as a destination offering. Alternatively, the DMO could focus their marketing on areas that are deemed more important in articulating the concept of an urban city - identified through the images shared by sojourners, where sharing images online is linked to selfbranding (Rokka \& Canniford, 2016).

Further, the images found in this study project diverse ways in framing different aspects of destinations and service offerings. For instance, time of day was used to convey the concept of urban city, where sojourners not only submitted images that were taken during the day but at different times of day. Deng and Li (2018) argue that the selection of marketing images is imperative for destination promotion. This is in line with the assertion of a recent article, published by the American Marketing Association that encourages marketers to draw meanings derived from visual images to create communication strategies that resonate with consumers (Murtell, 2020). DMOs, therefore, should consider the content areas produced within themes as well as the deliberate choices applied in framing iWOM, where the ability to harness insights from iWOM contributes to the shift towards a knowledge-based form of destination management and marketing (Hu \& Trivedi, 2020).

For city councils/planners, the images produced by sojourners provide windows into personal consumer experiences and interactions with destination offerings — in particular, the 
activities and spaces sojourners engage in. The insights drawn could be used to identify mechanisms that facilitate the acculturation of sojourners or new migrants to inform community engagement, and urban planning strategies. For example, through the images, sojourners in this study sought and participated in cultural and local-level events hosted in Wellington. Moreover, the insights could help with the planning and marketing of other sectors such as the international education sector, where in New Zealand, the sector is the country’s fifth largest export earner (“Advancing international education,” 2020).

As countries navigate through volatilities and uncertainties, such as the Coronavirus pandemic and political events that impinge on the normal flow of tourism, this thesis highlights the role of sojourners as valuable stakeholders, and "international communicators" (Choi \& Fu, 2018, p. 49), with the potential to support post crisis/disaster tourism marketing efforts, where iWOM composed and publicised to online networks represent compelling communication artefacts that could facilitate trust building (Backer \& Ritchie, 2017).

\subsection{Limitations and future research}

Although a mixed-methods approach provided greater insights into the iWOM phenomenon, some limitations that offer opportunities for future research are noted and discussed in this section of the thesis. For example, even though this study provides a first look into understanding iWOM composing and sharing behaviours of sojourners, in view of the predetermined categories, and the positive framing of instructions given to sojourners as part of data collection, the images received cannot be viewed as representative of all sojourner images shared. However, it must be noted that the category "your pick" was provided to allow sojourners freedom to submit images of their choice, and a small number of negative images were received.

Moreover, in examining the composition of the images in Phase 3, this study adopted a functionalist view, due to the "intricate relationship between description and interpretation" of visuals that require knowledge of descriptive visual variables (Schroeder, 2006, p. 304). Moreover, given the diverse cultural and language backgrounds of the participants, the demands of having to articulate themselves in English could prove challenging for some participants. Commonly employed in marketing and advertising research in the reading of images (e.g. Phillips et al., 2014; Zhao \& Belk, 2008), the functionalist view takes the perspective that the interpretations of the images are those of the viewer. Hence in this study, the interpretations of the images are those of the author, which could be perceived as a 
limitation. Nonetheless, every effort was taken to ensure trustworthiness of the analysis of images. For example, through the triangulation of data provided by external coders.

Scholars are encouraged to build on this study to fully understand the potential of iWOM as triggers of VFR tourism. For example, scholars could investigate the role iWOM play in conversations between sojourners and their overseas networks, as well as the impact iWOM have on the activity planning of friends and relatives prior to visits. Moreover, although emergent studies in user-generated images (UGI) have sought to examine the reasons behind the sharing of online images among tourists (Wang, Kirillova, \& Lehto, 2017), there are no studies that investigate or theorise the reasons for the sharing of iWOM by sojourners.

Another limitation of this study is its cross-sectional nature, which only captures a snapshot of the iWOM phenomenon between sojourners and their extended overseas network. A longitudinal study could be conducted to enhance understanding of the evolving relationship between the sojourner and the host destination over the course of their sojourn, and the impact it has on the images shared, or perception of their overseas networks.

The context and location of this study is also a limiting factor of this thesis. This study was focused on the sojourner population in Wellington, New Zealand and the context of the conurbation. Although the population was representative of the international sojourner population in Wellington, a high percentage of Asian participants were noted. Images received and survey finding results of Phase 2 may vary in other conurbations that have a higher Western sojourner population, where studies draw attention to distinctions between Western and Asian cultures (Errmann et al., 2019; Li, 2020; Wheeler, Reis, \& Bond, 1989). Scholars are encouraged to apply the model to other contexts, and conduct studies that place greater emphasis on cross-cultural comparisons of online communication and dissemination behaviour of international sojourners (King, Racherla, \& Bush, 2014). Moreover, the focus of this thesis was on assessing the impact of iWOM on international VFR tourism, scholars could also build on this study and investigate the role of iWOM within the domestic VFR tourism market or even, the wider tourism or services contexts.

\subsection{Conclusion}

This study introduces and tests the concept of iWOM, where the intent of this study is to stimulate ideas concerning the under-conceptualised phenomenon of UGI as critical forms of WOM. This study is important given the burgeoning trend of the exchange of UGI in online 
interactions, and the blurring of the role of sojourners as consumers/producers of tourism experiences. This thesis further magnifies the uniqueness of the relationship in VFR tourism between sojourners and their overseas network, where tie strength and relationship type shared are examined as intervening factors in online interpersonal communications between sojourners and extended VFR markets. An iterative sequential mixed-methods approach was adopted to address the questions set out in this thesis.

In Phase 1, expert interviews were conducted to inform and validate items used in the Phase 2 instrument. In Phase 2, a quantitative dyadic Web survey was conducted to provide generalisability as well as an understanding of mechanisms surrounding the iWOM phenomenon that facilitate the influence of sojourner-produced iWOM on the visit intentions of overseas friends and relatives of sojourners. As predicted, similar to WOM, sojourner iWOM in this study had a statistically significant impact on the impression and visit intentions of friends and relatives overseas. The substantially significant mediating role of viewer impression further stresses the effectiveness of sojourners as visual communicators, and their ability to construct and share persuasive iWOM.

Phase 2 results confirmed the role of tie strength in adding to the persuasive nature and influence of sojourner-produced iWOM, particularly on the impression of friends towards the host destination. This finding is interesting, given that studies in marketing largely group close friends and relatives as strong ties, assumed to have similar effects on behavioural outcomes of the receiver of WOM (Baker et al., 2016). This study provides contrasting results, calling into question the appropriateness of using simplified categories to define tie strength, when examining WOM phenomena. A positive impression towards the host destination was also found to play a greater role in driving the desire of friends to visit the host destination than for relatives. Moreover, the results suggest that sojourner-pushed iWOM helps alleviate cultural distance among older relatives.

The results from Phase 2 address the research questions:

RQ 1: How effective are sojourners as visual communicators, and of their images pushed to overseas friends and relatives as persuasive forms of word of mouth?

RQ 2: Given the centrality of relationships in VFR tourism, what roles do tie strength and relationship type play in shaping the perception of the iWOM receiver (friend/relative) towards the host destination? 
Phase 3 found that sojourners appeal through emotion, by making references to home cultures, as well as capturing significant moments such as graduations and birthdays. The emotions embedded and the relational ties between sojourner and their overseas connection, highlight the role of iWOM as authentic depictions of the host destination, difficult to replicate by DMOs (Lutz \& Collins, 1991). Sojourners in this study were also found to utilise a variety of stylistic strategies, tapping their broad knowledge of the host destination as residents and tourists, when framing images that communicated attributes of the host destination to overseas VFR markets.

The results of Phase 3, therefore, address the following research questions:

RQ 3: What is the nature of iWOM shared by sojourners to their overseas networks?

RQ 4: How are destination attributes framed, and what functions or meanings do the iWOM shared by sojourners convey?

In summary, the results support the objectives of this thesis:

1. Better understand the value of UGI, in particular sojourner-produced images, in spreading persuasive image-generated WOM (iWOM), able to shape viewer perception, and stimulate VFR tourism.

2. Investigate the underlying role of tie strength, relationship type and impression as mechanisms that affect the link between iWOM and intention to visit.

3. Explore the role of sojourners as key online destination ambassadors, able to frame and shape destination perceptions in overseas VFR markets, through the visual mode.

Importantly, this study comes at a critical period for tourism economies, when at the time of writing, the global Coronavirus pandemic has disrupted the normal flow of tourism, magnifying the volatility of the industry. A recent expert article in popular press advocates leveraging the VFR segment to promote local travel ("Advice for a recovering tourism industry," 2020). This thesis extends the line of argument, and provides critical insights that demonstrate the importance of sojourners in shaping the perceptions of extended VFR markets. The images pushed by sojourners, through the use of ICT, provide tourism economies the continued visibility that build momentum towards corporeal travel (Larsen et al., 2007) - necessary for the revival of international tourism post disaster/crisis. 
APPENDICES

\section{Appendix A: Interview guide (expert interviews)}

Category/concept

Guide/questions

Evaluation of current marketing strategies/campaigns

Description of idealised image and images (manifest content)

distributed through marketing mix
- Can you tell me more about current strategies/campaigns?

- Based on these campaigns what image is it that the agency aims to project of the region as a destination?

How is this image being projected in the current campaign? Would you be able to provide specific examples?

- What groups/segments are being targeted in your campaigns?

Is there an internal/VFR marketing strategy in place?

- Is there a visual strategy that is in place? What type of images do you use in your promotions? Are there specific areas/unique themes of images you tend to focus on for specific markets? Would you be able to provide examples?

- What attributes would you want them to associate to Wellington?

- How are these images spread? 


\title{
Appendix B: Information sheet (expert interviews)
}

\author{
Participant Information Sheet \\ VICTORIA UNIVERSITY OF WELLINGTON \\ Te Whare Wānanga o te Ūpoko o te Ika a Māui
}

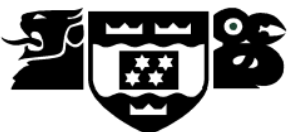

More than words: Decoding the influence of user-generated images on VFR (visiting

friends \& family) tourism
\end{abstract}

(VUW Ethics ID 0000025253)

Thank you for showing an interest in this project. Please read this information sheet carefully before deciding whether or not to participate.

\section{What is the purpose of this research project?}

The project investigates the potential of members of the international/migrant community living in Wellington Region as key mavens, able to spread marketing rhetoric through their composed user generated images (UGI). It also explores the value of these images as persuasive forms of word of mouth, able to influence perceptions of destination image and trigger an intention to visit the destination. This research has been reviewed and approved by the Pipitea Human Ethics Committee, Victoria University of Wellington.

\section{What will your role and responsibilities be if you agree to take part in this research?}

Participation would involve being interviewed by me once in a mutually determined setting. During the interview we will discuss your thoughts regarding the destination image of the Greater Wellington Region. The audio-recorded interview would take approximately 1 hour but will only begin with your consent, and it can be terminated at any time, without providing reasons. You can withdraw from the study up to seven days after the interview, and any data provided by you will be destroyed or returned to you.

\section{What will happen to the information you provide?}

The interview will be transcribed with an agreement of confidentiality from the transcriber. The information you provide will then be reviewed by the researcher (named below). This research is completely confidential. Your name will not be used in any articles resulting from the research, a pseudonym will be used instead, and any information traceable to you will be excluded from analysis. The interview transcripts, summaries and digital recordings will be securely stored for two years after the research is complete (estimated June 2021) and then destroyed.

\section{Outputs of the research}

The findings from this research will be used for the sole purpose of academic publication (journal article and conference presentation). You can be reassured that your name will be kept confidential, and that any information or opinions that could be traceable to you will not be reported in the written publication.

Thank you.

Marlini Bakri 


\section{Appendix C: Qualtrics form visual data collection (sojourner)}

\footnotetext{
Consent to Participate in Research

More than words: Decoding the influence of user-generated images on VFR (visiting friends \& relatives) travel

(NWW Ethics ID 0000026008)

Thank you for showing interest in this research. Before we begin, please read the following points carefully:

- I have been provided with adequate information relating to the nature and objectives of this research project

- I have understood this information and have been given the opportunity to seek further clarification or explanations

- I understand that the researcher will not include any information that identifies me or my nominated friends and relatives in any reporting for publishing

- I understand that the images submitted must be taken, and owned by me. The researcher may request my permission to use the images provided in the study. The images that have identifiable features attributable to me will be obscured or pixelated during publication

- I understand that 1 may withdraw from this study within seven days of submitting this form, and any data that I have provided will be returned to me or destroyed

- I understand only the researcher and her supervisors will have complete access to the data provided. However, the submitted digital images will also be vieved by my nominated friends and relatives

- 1 understand that three years after this research is completed (June 2021) the raw data obtained will be destroyed.

- By completing this form I consent to participate in this study.
}

For further information please contact:

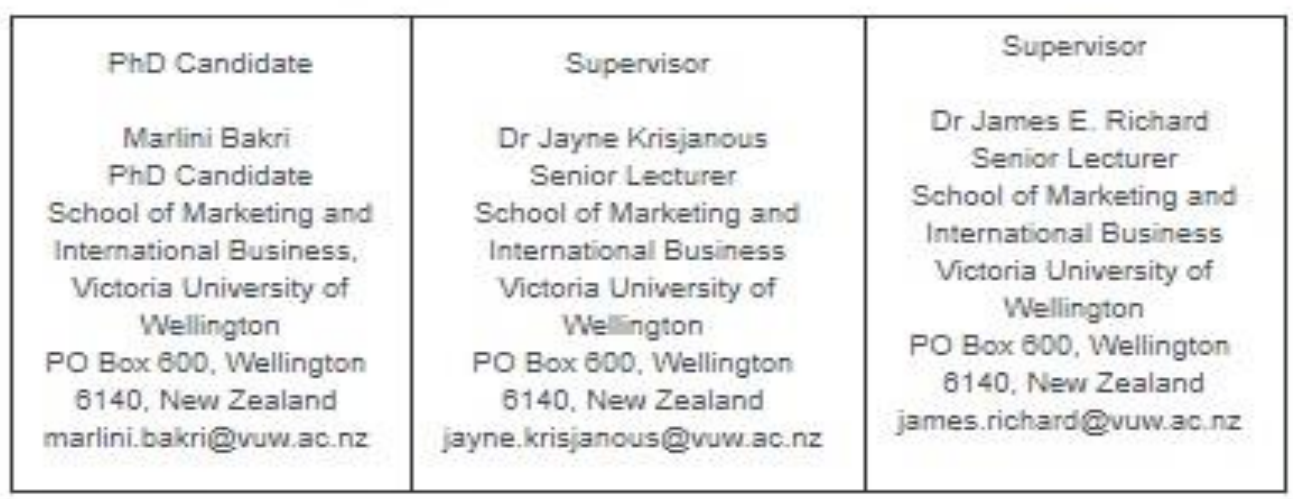

Human ethics committee information

If you have any concerns about the ethical conduct of the research you may contact the Victoria University HEC Central Convenor: Dr Judith Loveridge. Email hec@vuw. ac.nz or telephone $+64-4-4639451$. 
Thank you for participating in this study. The objective of this study is to understand the marketing implications of images created and shared online by members of the international community, with overseas friends and relatives. There are six short sections to this form, which would include requiring you to provide three photos from the following themes:

- Food/drinks \& dining

- Nature/scenic landscapes

- Urban city

- Events

- Your pick

There are no right or wrong answers, and your participation is greatly valued.

$0 \%$ 
Section 1: The following statements concern your social media use. Please fill out this questionnaire by selecting the responses that best represent your use of social media.

What platforms do you use to communicate with your friends and relatives overseas? (You can choose more than one option).

$\square$ Personal email (e.g. gmail, yahoo, outlook)

$\square$ Social media/micro-blogging sites (e.g. Snapchat, Facebook, Instagram)

$\square$ Instant messenger (e.g. Whatsapp, Viber, Facebook messenger)

$\square$ Others (please specify)

How often do you share images taken by you (photos or videos) on this type of channel?

Daily A few times A few times
a week a month $\begin{gathered}\text { Less than } \\ \text { once } a \\ \text { month }\end{gathered} \quad$ Never

\begin{tabular}{lcc} 
Personal email & 0 & 0 \\
$\begin{array}{l}\text { Social media/micro } \\
\text { blogging sites }\end{array}$ & 0 & 0 \\
\hline Instant messenger & 0 & 0 \\
Other & 0 & 0 \\
\hline
\end{tabular}

$\bigcirc$

$\bigcirc \quad \bigcirc$

$0 \%$ 
Section 2: In this section of the form you would be required to upload 3 images for each identified theme:

- Food \& drinks/dining

- Nature/scenic landscapes

- Urban city

- Events

- Your pick

- Images uploaded must be taken by you and are of the Greater Wellington Region. The form accepts files, no bigger than 100MB, in the following formats: JPG/JPEG, PNG, GIF

Food 8 drinks/dining: The Wellington Region has many cafés, craft breweries, food trucks, restaurants and weekend markets. Share with us some photos of foodidrinks that you have enjoyed, and your favourite food spots throughout the Greater Wellington Region.

Food \& drinks/dining: Upload Image 1

\section{Drap fles or click here ba upload}

Food \& drinks/dining: Upload image 2

$$
\text { Drop files or dick here ba uplosid }
$$

Food \& drinks/dining: Upload image 3

$$
\text { Drap fles or click here to uplesad }
$$


Nature/scenic landscapes: In between green hills and harbour, the Greater Wellington Region allows residents to be within reach of nature trails, wildlife reserves, parks and beautiful scenery. Show us some of your favourite green trails and views of the Greater Wellington Region.

Nature/scenic landscapes: Upload image 1

Drop files or click here to upload

Nature/scenic landscapes: Upload image 2

Drop files or click here to upload

Nature/scenic landscapes: Upload image 3

Drop files or click here to upload

Survey Completion

$0 \%$ 
Urban city: Capture the city feel in this cool little capital. From hidden boutiques, shopping streets to urban buildings, show us what you think contributes to the region's city feel.

Urban city: Upload image 1

\section{Drop files or click here to upload}

Urban city: Upload image 2

Drop files or click here to upload

Urban city: Upload image 3

Drop files or click here to upload

$0 \%$ 
Events: There is always something happening in the Greater Wellington Region. Send in some of your photographs from events that you have attended. This can include (but is not limited to) festivals, concerts, exhibitions, sporting events and fairs.

Events: Upload image 1

Drop files or click here to upload

Events: Upload image 2

Drop files or click here to upload

Events: Upload image 3

Drop files or click here to upload

$0 \%$

Survey Completion 
Your pick: Here is your chance to showcase things/activities/moments that you think is unique to your Wellington experience, and not captured in the themes above.

Your pick: Upload image 1

Drop files or click here to upload

Your pick: Upload image 2

Drop files or click here to upload

Your pick: Upload image 3

Drop files or click here to upload

$0 \%$

Survey Completion 
Section 3 : In this section you will be tasked to submit the email addresses of your overseas friends and relatives. Nominated friends and relatives must be 18 years and over, and preferably have not visited the Greater Wellington Region. You are advised to inform your friends and relatives about the submission of their email addresses for this study. Their email addresses will only be used to invite them to complete a survey, and will be kept confidential by the researcher

Should you prefer a survey link you could forward to your friends and relatives, please ignore the next two questions, and go to the final section, Section 4 , of this form.

Please provide the current email addresses of at least three friends living overseas who you are in contact with through social media (includes instant messengers and email).

\begin{tabular}{|c|c|c|}
\hline & \multicolumn{2}{|c|}{$\begin{array}{c}\text { Is this persan able to complete a } \\
\text { sirvey in English? }\end{array}$} \\
\hline & Yes & Na \\
\hline Friend 1 & 0 & 0 \\
\hline Friend 2 & 0 & 0 \\
\hline Friend 3 & 0 & 0 \\
\hline Friend 4 & 0 & 0 \\
\hline Friend 5 & 0 & 0 \\
\hline Friend 6 & 0 & 0 \\
\hline Friend 7 & 0 & 0 \\
\hline Friend 8 & 0 & 0 \\
\hline Friend 9 & 0 & $\mathrm{O}$ \\
\hline Friend 10 & 0 & 0 \\
\hline
\end{tabular}

Please provide the current email addresses of at least three relatives living overseas who you are in contact with through social media (includes instant messengers and email).

\begin{tabular}{|c|c|c|}
\hline & \multicolumn{2}{|c|}{$\begin{array}{c}\text { Is this persan able to complets a } \\
\text { survey in English? }\end{array}$} \\
\hline & Yes & No \\
\hline Retiative 1 & 0 & $\mathrm{O}$ \\
\hline Relative 2 & 0 & 0 \\
\hline Relative 3 & 0 & 0 \\
\hline Relative 4 & 0 & 0 \\
\hline Relative 5 & 0 & $\mathrm{O}$ \\
\hline Reiative 6 & 0 & $\mathrm{O}$ \\
\hline Retafive 7 & 0 & 0 \\
\hline Ratative 8 & 0 & 0 \\
\hline Retative 9 & 0 & 0 \\
\hline Relative to & 0 & 0 \\
\hline
\end{tabular}


Section 4 : In this section, please tell us about yourself

What is your name? (Your name will be included in the invitation email to your friends and relatives, and will not be used in any reporting).

What is your email address? (Your email address will be kept confidential and will only be used for correspondence between you and the researcher).

What is your age? (Please specify).

What is your occupation? (Please specify)

What is your nationality? (Please specify).

What visa type do you hold? (If you are not sure which category you are in, please select "Others" and specify the type of visa).
O Student visa
O Work vise
O Residence visa
O Permanunt resident visa
O Visitur visa
Others, Please specify

Please tell us your gender.
O Male
O Fenale

How long have you lived in the Greater Wellington Region?
O Up to 6 manths
O 6.12 morths
O 1.2 years
O 3.5 years
O Mare than 5 years 
In which of the following categories does your current annual income fall? (Before tax).

O Zero incorne

O NZST-NZS5,000

O NZ85,001-NZs 10,000

NZS $10,001-N Z S 15,000$

O NZs 15,001 NZS20,000

O NZ\$20,001-NZ\$25,000

O NZ\$25,00t-NZs30,000

O NZ\$ 30,001 NZ\$ 35,000

NZS35,001*NZS40,000

O NZS40,001+NZS50,000

O NZS50,001-NZS80,000

O NZS60,001-NZS70,000

NZ\$70,001*NZ\$100,000

O NZS $100,001+N Z \$ 150,000$

O NZ\$150,001 ar mart

Please indicate your highest education level. (If you are not sure which category you are in, please select "Other qualification" and specify the type of qualification, e.g. overseas secondary schoolf.

No qualification

Primary education

O Luvel 1 certificalts

O Lavel 2 cerificatre

0 Level 3 certificait:

O Level 4 certificain

O Level 5 diplama

O Level 6 diplema

Bachelor's degree or level 7 qualification

Bachelor honours degres or postgraduate cerlificateidiploma

O Master's degree

$O$ PHD

Other qualification (please soecify)

Please indicate your marital status

O Single

O Married

O Divorced/Seperaled

$\mathrm{O}$ other 
This is the end of the form. Thank you for your time and cooperation! Your nominated friends and relatives will be emailed shortly inviting them to complete a survey. For more information, contact marlini.bakri@vuw.ac.nz. 
Appendix D: Permission to the online community moderator

VICTORIA UNIVERSITY OF WELLINGTON

Te Whare Wānanga o te Ūpoko o te Ika a Māui

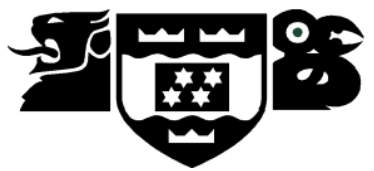

E-MAIL PERMISSION TO THE INTERNET COMMUNITY MODERATOR

(VUW Ethics ID 0000026008)

Thesis title: More than words: Decoding the influence of user-generated images on VFR (visiting friends \& relatives) tourism

Dear (Internet Community Moderator)

My name is Marlini Bakri and I am a Doctor of Philosophy $(\mathrm{PhD})$ candidate in Marketing at Victoria University of Wellington (VUW). I would like permission to post the announcement attached to this request within your international group. The aim is to contact members of Wellington's international community/Wellington-based expatriates in order to obtain participants in my doctoral study, which is titled, "More than words: Decoding the influence of user-generated images on VFR (visiting friends \& relatives) tourism".

As a doctoral candidate in Marketing at VUW, I have discovered that many people from the international community rely on online platforms/messaging apps to connect with friends and relatives overseas. Despite the growing use of technology in mediating relationships across borders, understanding about the potential marketing implications of user-generated images is still limited. The aim of this project is to understand the ability of the expatriate/migrant in framing the Greater Wellington Region as a destination, and to investigate the potential of such images as being triggers for visits by their overseas connections.

Participants of this research will have the opportunity to win the following Prezzy cards:

- $\$ \mathbf{1 0 0}$ Prezzy Cards (2 winners)

- $\$ \mathbf{5 0}$ Prezzy Cards (4 winners)

- $\$ 25$ Prezzy Cards (8 winners)

It is a requirement for all university research involving people to be approved by the Human Ethics Committee of Victoria University of Wellington, and this study has received this approval. Should you require further information about the study, please contact my supervisors or myself. I look forward to your reply.

Thank you.

Marlini Bakri 


\section{Appendix E: Recruitment advertisement (announcement of study)}

\section{VICTORIA UNIVERSITY OF WELLINGTON \\ Te Whare Wānanga o te Ūpoko o te Ika a Māui}

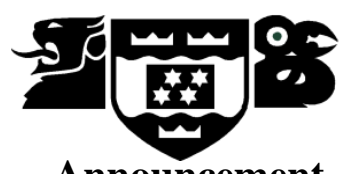

\section{More than words: Decoding the influence of user-generated images on VFR (visiting friends \& relatives) tourism}

Do you use online platforms to connect with friends and relatives overseas? Do you enjoy taking photographs? Aged 18 and over? Are you based in the Greater Wellington Region, and are you part of its international community (e.g. international student, skilled migrant, Permanent Resident)? If you answered yes to all the questions, I would like to invite you to participate in my $\mathrm{PhD}$ research titled, "More than words: Decoding the influence of usergenerated images on VFR (visiting friends \& relatives) tourism". Participating in this research would also mean a chance to win Prezzy Cards (prepaid visa gift cards) with the following values:

- $\quad$ NZ\$100 Prezzy Cards (2 winners)

- $\quad$ NZ\$50 Prezzy Cards (4 winners)

- $\quad$ NZ\$25 Prezzy Cards (8 winners)

If you are interested in participating in this research, email me at marlini.bakri@vuw.ac.nz Thank you.

Marlini Bakri

PhD Candidate

School of Marketing and International Business

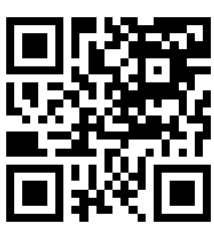

Victoria University of Wellington

Note: This study has received approval from the Human Ethics Committee of VUW.

If you have any concerns about the ethical conduct of the research, you may contact the Victoria University HEC Central Convenor: Dr Judith Loveridge. Email hec@vuw.ac.nz or telephone +64-4-4639451 


\title{
Appendix F: Information sheet (sojourner)
}

Participant Information Sheet

VICTORIA UNIVERSITY OF WELLINGTON

Te Whare Wānanga o te Ūpoko o te Ika a Māui

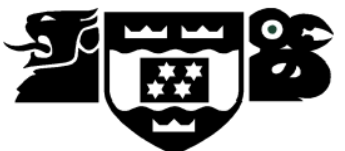 \\ More than Words: Decoding the influence of user-generated images \\ on VFR (visiting friends \& relatives) tourism
}

(VUW Ethics ID 0000026008)

Hi there,

Thank you for showing interest in my study. As a doctoral candidate in Marketing at VUW, I have found that many people from the international community use online platforms to keep in touch with friends and relatives overseas. However, there is limited understanding about the implications of digital images, shared online by members of the international community, on the image of the destination. The aim of this project is to understand if photos you create, and share with overseas friends and relatives can spread key features of the destination.

For this research, you would need to submit three digital photographs for each of the themes listed below and email addresses of at least three friends and three relatives living outside of New Zealand, (who preferably have not visited the Greater Wellington Region). The photos must be taken by you, and be of the Greater Wellington Region, which includes Kapiti, Hutt Valley, Porirua, Wairarapa and Wellington. The photos can be those that you have already shared on social media platforms (includes but not limited to: instant messaging chats, apps such as Facebook and emails), or new photos, you plan to take. Enhanced photos are accepted. This task should be similar to how you would create and share photos online. Please submit your photos through the online link found below.

\section{Themes:}

- Food/drinks \& dining: The Wellington Region has many cafés, craft breweries, food trucks, restaurants and weekend markets. Share some photos of food/drinks that you have enjoyed, and your favourite food spots in the Greater Wellington Region.

- Nature/scenic landscape: In between green hills and harbour, the Greater Wellington Region allows residents to be within reach of nature trails, wildlife reserves, parks and beautiful scenery. Share some photos of your favourite green trails and views of the Greater Wellington Region.

- Urban city: Capture the big city feel in this cool little capital. From hidden boutiques, shopping streets to urban buildings share what you think contributes to the region's city feel.

- Events: There is always something happening in the Greater Wellington Region. Send in some photos of the different events that you have attended. This can include (but is not limited to) festivals, concerts, exhibitions, sporting events and fairs. 
- Your pick: Here is your chance to showcase things/ activities/moments that you think is unique to your Wellington experience, and not captured in the themes above.

\section{Your chance to win preloaded Prezzy cards (prepaid Visa gift cards):}

- NZ\$100 Prezzy Cards (2 winners)

- $\quad$ NZ\$50 Prezzy Cards (4 winners)

- NZ\$25 Prezzy Cards (8 winners)

For a chance to win, you will need to submit:

1) Three digital photos from each theme and complete the online form. Once the form is completed, and accepted your name will be included in a Prezzy card draw, for a chance to win one of the preloaded Prezzy Cards. You can only submit one entry.

2) Provide email addresses of at least three friends and three relatives living overseas (who preferably have not visited the Greater Wellington Region). As part of this research, you would also need to provide email addresses of friends and relatives who have never visited the Greater Wellington Region, and are 18 years old and over. Your chosen friends and relatives will be invited to rate the photos you submitted in a simple online survey. Please ask your friends and family members if it is okay to submit their email addresses before participating in this study. Alternatively, a link to your individual Web survey can be forwarded for you to distribute to friends and relatives. For each survey completed by your friend or relative, your name will again be included in the Prezzy card draw, giving you more chances to win. Names will be randomly drawn once all surveys are complete, and winners will be contacted via email.

\section{What will happen to the information you provide and who will view the photographs?}

The digital photos will only be seen by your chosen friends and relatives completing the survey, the researcher, and the research team. You may withdraw from the study within seven days of completing the online form. Your name, as well as those of your friends and relatives will not be used in any publications. I may request your permission to use the digital photos submitted. However, photos that have identifiable features attributable to you will be blurred or pixelated during publication. The information collected will be securely stored for three years after the research is completed (estimated June 2021) and then destroyed. The findings from this research will be used only for a $\mathrm{PhD}$ thesis and possible academic publication (journal article and conference presentation).

\section{Are you ready to participate?}

The online form can be completed on desktop and mobile devices (e.g. mobile phones and tablets), and accepts photos in the following formats: JPEG, JPG and GIF. Photos can also be uploaded through mobile devices. Once you have the three digital photos that match each of the five themes, and email addresses of at friends and three relatives ready, click here Qualtrics link here. 


\section{Appendix G: Coding protocol}

This protocol is designed for the analysis of images submitted by participants of the Greater Wellington Region. In this research, participants were tasked to provide images according to given categories: Food/drinks \& dining; nature/scenic landscape; urban city; events. Participants were also given the option to upload any images they felt were representative of their experience in the Greater Wellington Region.

The task of the coder is to:

1. Review the images on the given link and select the category that each image best represents, based on the provided descriptions in Table 1. If the coder feels that the image does not fall within the listed categories, the coder is to select the option "others". The definitions for each option are listed in Table 1.

2. Each image will come with a free text question. Here, the coder would be required to describe/list things they see in the image (i.e., people, buildings, urban space, open space, hills, roads, food, sunsets, bus, car, blue sky, clouds).

Table 1. Category descriptions

\begin{tabular}{ll}
\hline Category & Description \\
\hline Food and drinks/dining & $\begin{array}{l}\text { Images where the focus is on food/drinks, dining environments (i.e., restaurant/bar settings and food } \\
\text { trucks) }\end{array}$ \\
Nature/scenic landscape & $\begin{array}{l}\text { Elements of nature (flora/fauna). Green spaces and landscapes with minor human-related elements } \\
\text { (i.e., buildings), and where the focus of the image is on open spaces. }\end{array}$ \\
Urban city & $\begin{array}{l}\text { Urban spaces, city skylines, infrastructure and residential areas (i.e., shopping streets, buildings, } \\
\text { housing areas, street art installations, graffiti art, transport) }\end{array}$ \\
Images taken from official local events (i.e., fireworks at the waterfront, Chinese New Year, \\
markets/festivals, exhibitions, art/cultural performances, sports events) and unofficial gatherings \\
(i.e., barbecues, lectures, birthdays)
\end{tabular}




\section{Appendix H: Sample Qualtrics form (coders)}

Thank you for helping with this research: "More than words: Decoding the influence of user-generated images on VFR tourism". The task of the coder is to review the images in this form, and select the answer that best represents the description provided in the coding protocol. The answers you submit in this coding form will be automatically saved. Coders can return to the form, using the same device at different times of the day. 


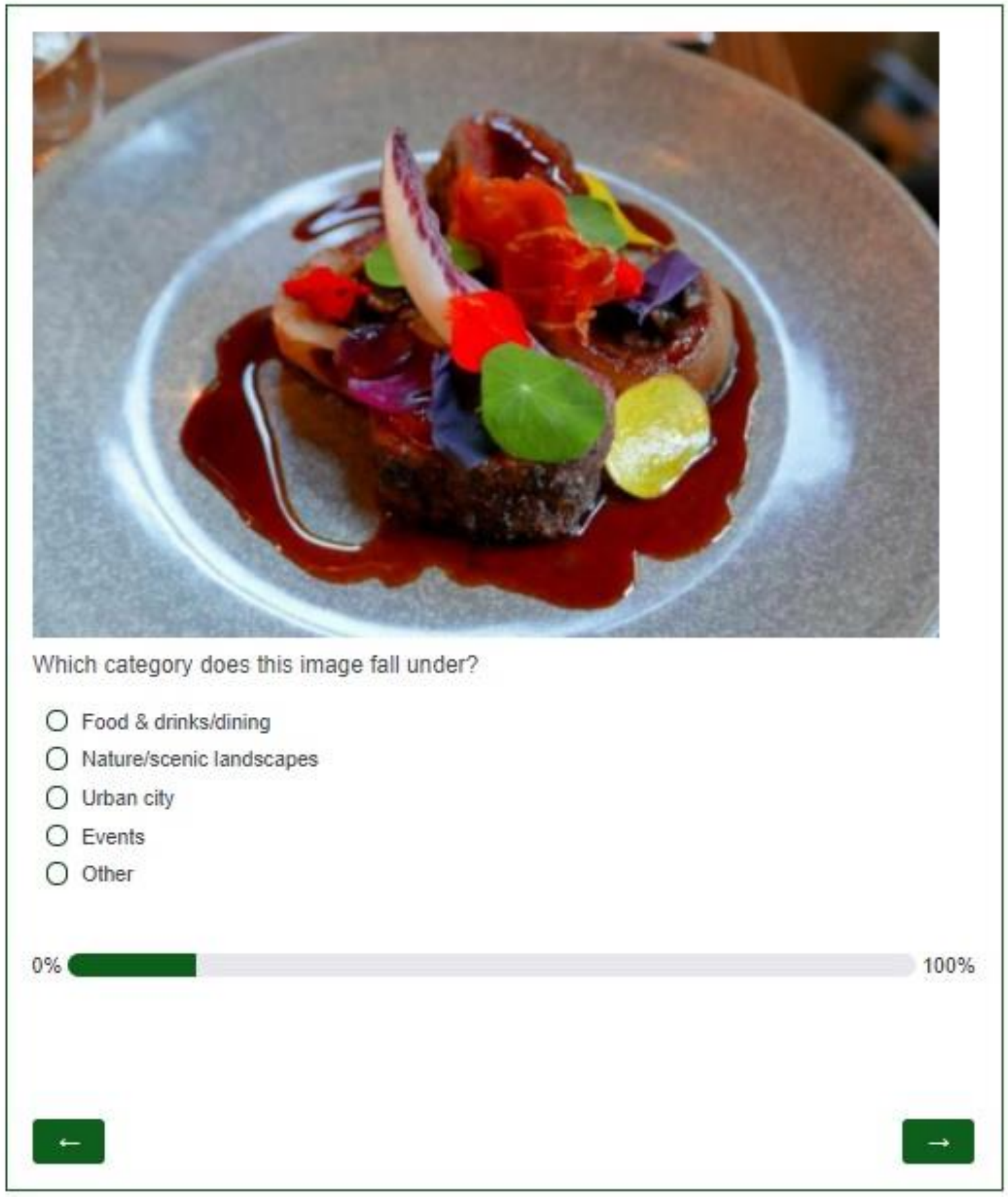




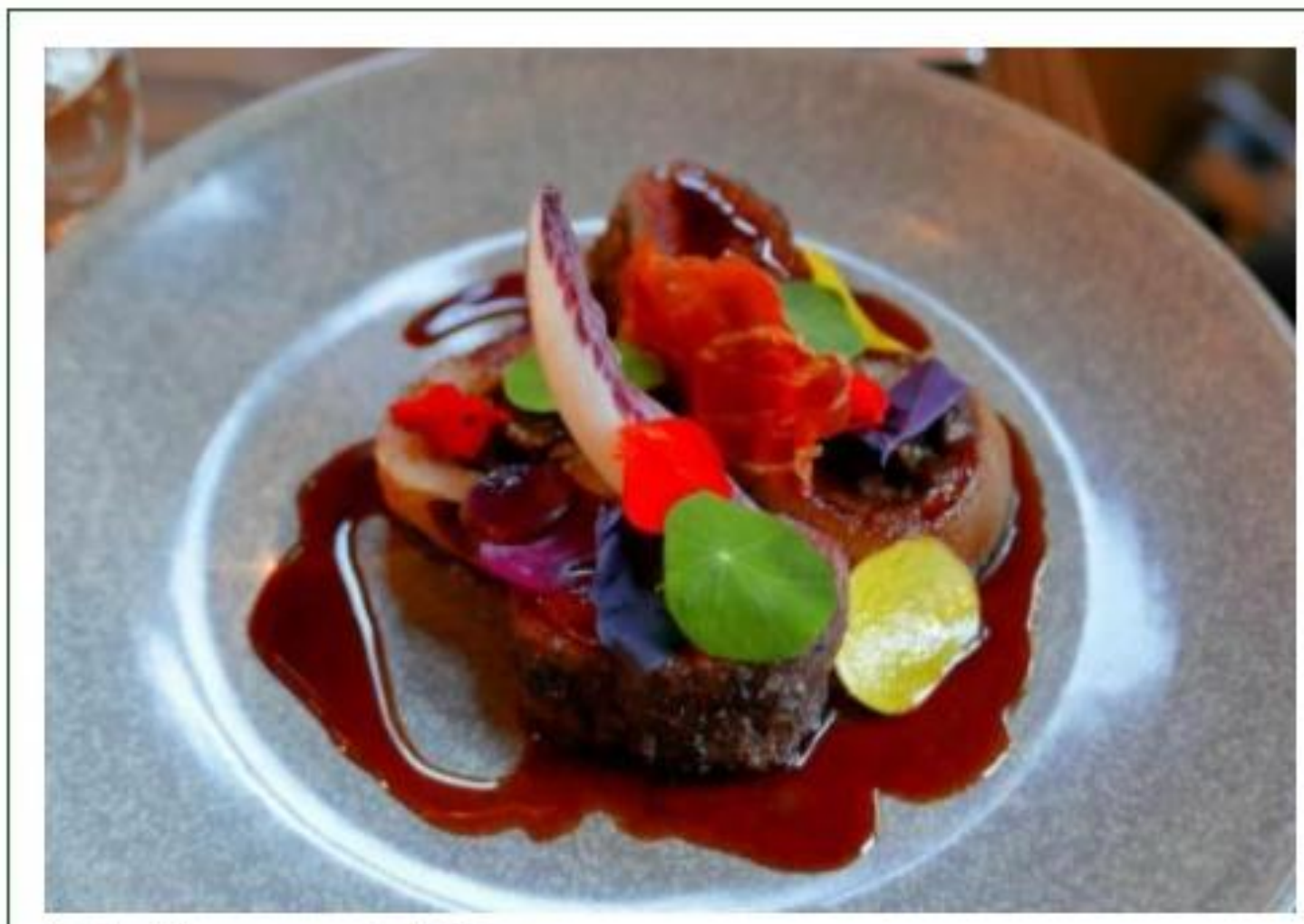

List the things you see in this image

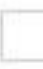

$0 \%$ 


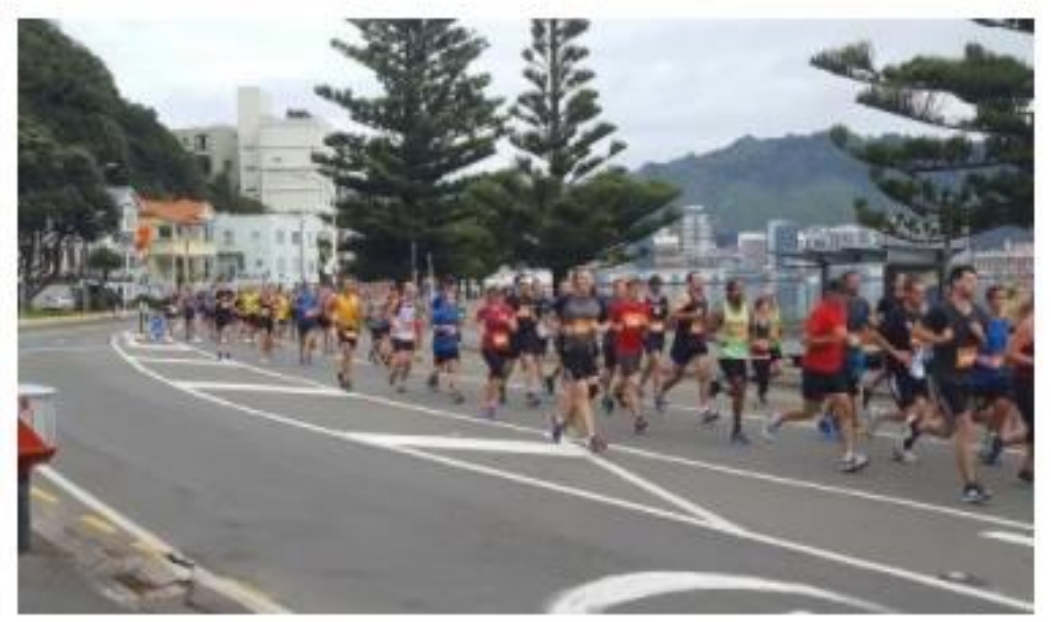

Which category does this image fall under?

Food \& drinks/dining

Nature/scenic landscapes

Urban city

$\mathrm{O}$ Events

Other

$0 \%$ 


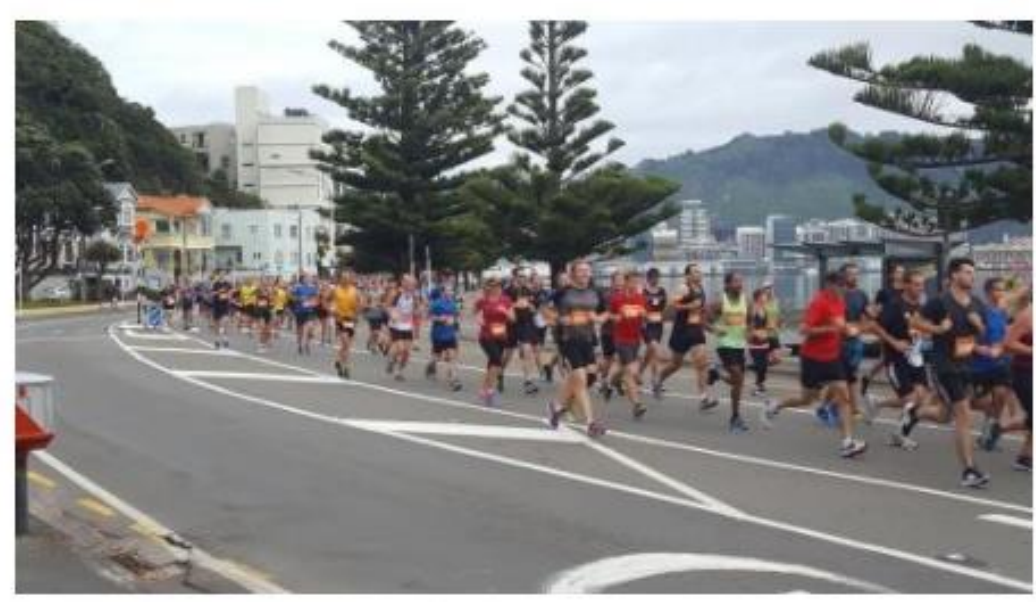

List the things you see in this image

$0 \%$ 


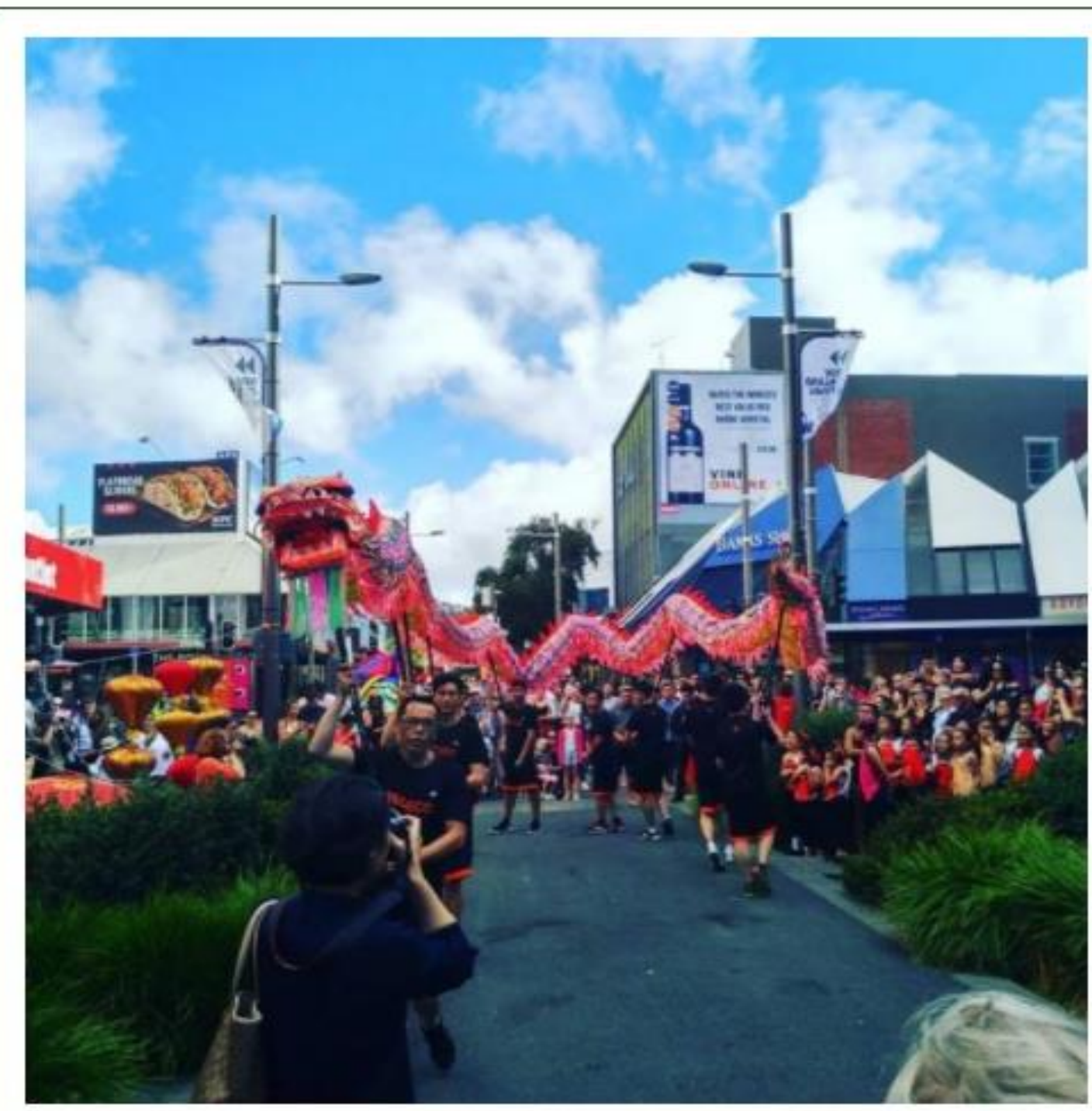

Which category does this image fall under?
Food \& drinks/dining
Nature/scenic landscapes
Urban city
$O$ Events
$O$ other

$0 \%$ 


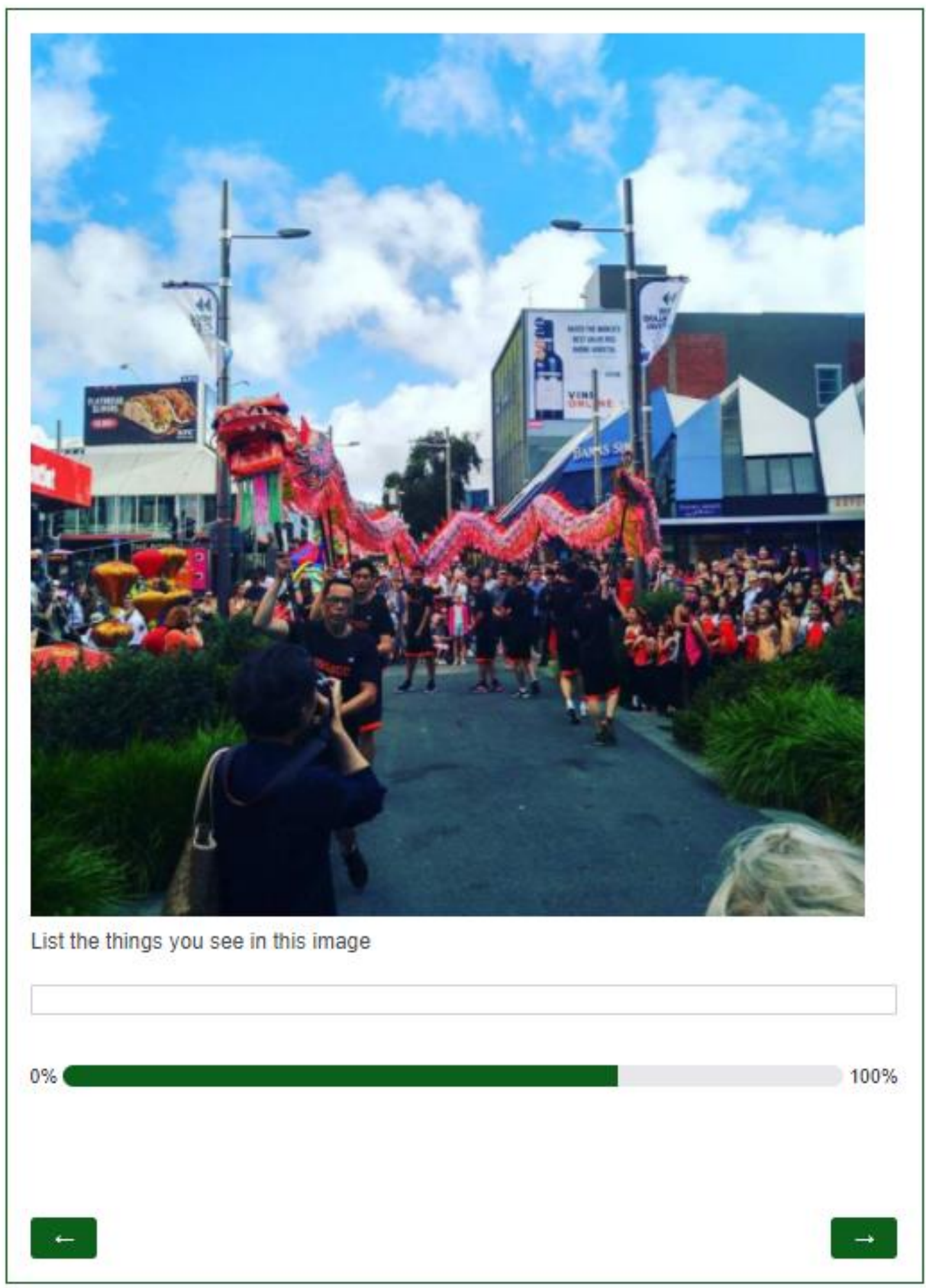


We thank you for your time spent taking this survey. Your response has been recorded. 


\section{Appendix I: Sample Web survey (friends \& relatives)}

\section{Consent to Participate in Research}

More than words: Decoding the influence of user-generated images on VFR (visiting friends \& relatives) tourism

(VUW Ethics ID 0000028008)

Thank you for showing interest in this research. Before we begin, please read the following points carefully:

- I have been provided with adequate information ralating to the nature and objectives of this research project.

- I have understood this information and have been given the opportunity to seek further clarification or explanations.

- I understand that the researcher will not include any information that identifies in any reporting for publishing.

- I understand that I may withdraw from this study within seven days of completing this survey, and any data that I have provided will be returned to me or destroyed.

- I understand only the researcher and her supervisors will have complete access to the data provided. I understand that three years after this research is completed (estimated June 2021) the raw data obtained will be destroyed.

- By completing and submitting this survey I consent to participate in this study.

\section{For further information please contact:}

\begin{tabular}{|c|c|c|}
\hline PhD Candidate & Supervisor & Supervisor \\
\hline Marlini Bakri & Dr Jayne Krisjanous & Dr James E. Richard \\
\hline PhD Candidate & $\begin{array}{l}\text { Senior Lecturer } \\
\text { Schor }\end{array}$ & $\begin{array}{l}\text { Senior Lecturer } \\
\text { Sohol }\end{array}$ \\
\hline $\begin{array}{l}\text { International Business, } \\
\text { Victoria University of } \\
\text { Wellington }\end{array}$ & $\begin{array}{c}\text { International Business } \\
\text { Victoria University of } \\
\text { Wellington }\end{array}$ & $\begin{array}{l}\text { International Business } \\
\text { Victoria University of } \\
\text { Wellington }\end{array}$ \\
\hline PO Box 600 , Wellington & PO Box 600 , Wellington & PO Box 800 , Wellington \\
\hline 6140, New Zealand & 6140, New Zealand & 6140, New Zealand \\
\hline marininibakngevuw.ac.nz & jayne.knisjanous@vuw.ac.nz & james,richard@vuw.ac.nz \\
\hline
\end{tabular}

\section{Human ethics information}

If you have any concerns about the ethical conduct of the research you may contact the Victoria University HEC Central Convenor. Dr Judith Loveridge. Email hec@vuw. ac.nz or telephone $+84-4-4639451$. 
Thank you for participating in this study. The objective of this study is to understand if digital photographs shared through online platforms can communicate information about a destination. Please read through the survey carefully. Your answers will be automatically saved when you respond to each statement, allowing you to return to the survey at any time.

$0 \%$ 
Are you aged 18 or above?
$\mathrm{O}$ Yes
$\mathrm{O}$ No

$0 \%$

Have you ever visited the Greater Wellington Region?

$\mathrm{O}$ Yes

No

$0 \%$ 
In this section of the research please rate the photographs taken by your friend or relative who is based in the Greater Wellington Region. Please fill out the questionnaire by selecting the responses that best represent your opinion of the Greater Wellington Region, in relation to the photographs you see. The research is conducted in a scientific manner. Therefore, you may find some of the questions similar. There is no right or wrong answer. It is your opinion that is important.

$0 \%$ 


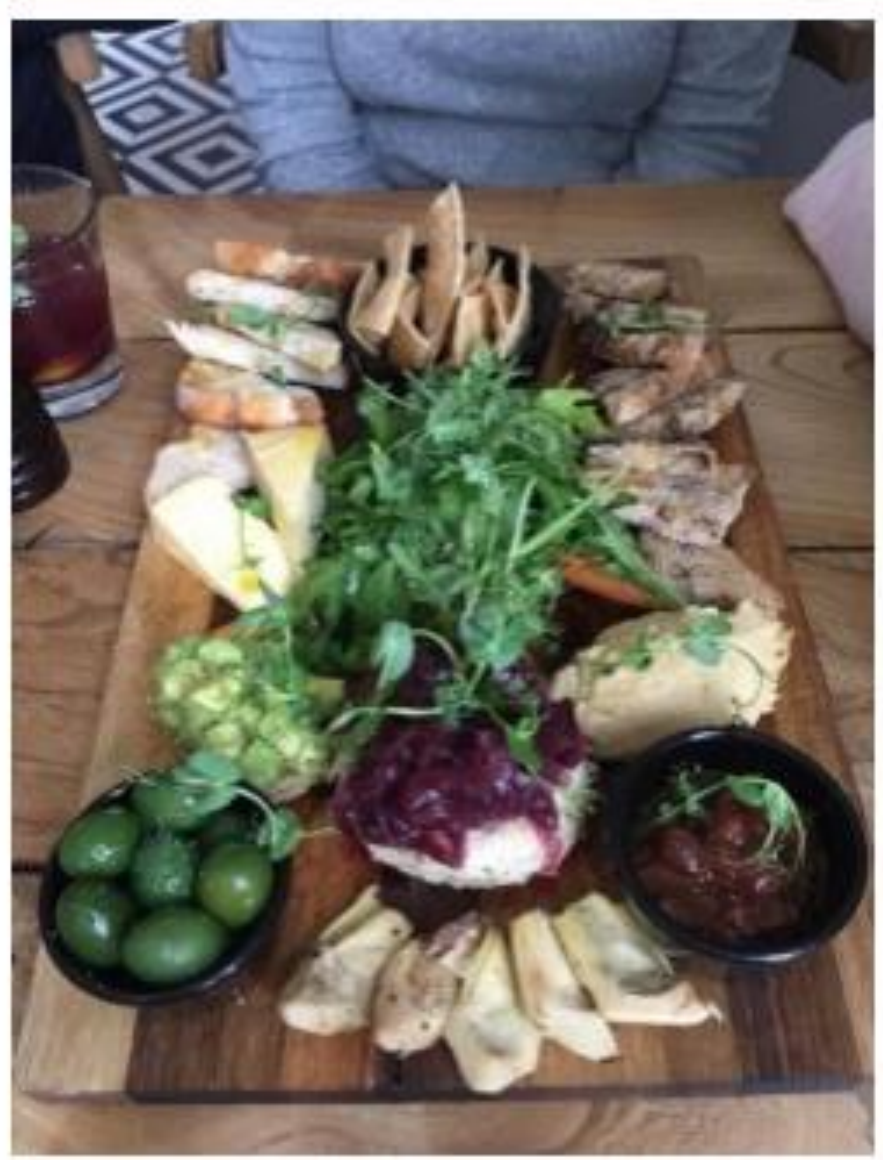

Based on this photo, I would describe the Greater Wellington Region as:

\begin{tabular}{|c|c|c|}
\hline Plessant & 0000000 & Unpieasant \\
\hline Reliaxing & 0000000 & Distressing \\
\hline Exating & 0000000 & Gloarmy \\
\hline Arausing & 0000000 & Sleepy \\
\hline Develaped & 0000000 & Underdevelicped \\
\hline Atbraclive & 0000000 & Unstlractive \\
\hline Unique & 0000000 & Ortinary \\
\hline Vibrant & 0000000 & Dull \\
\hline Friendly & 0000000 & Unfierendily \\
\hline Creative & 0000000 & Unimaginative \\
\hline
\end{tabular}




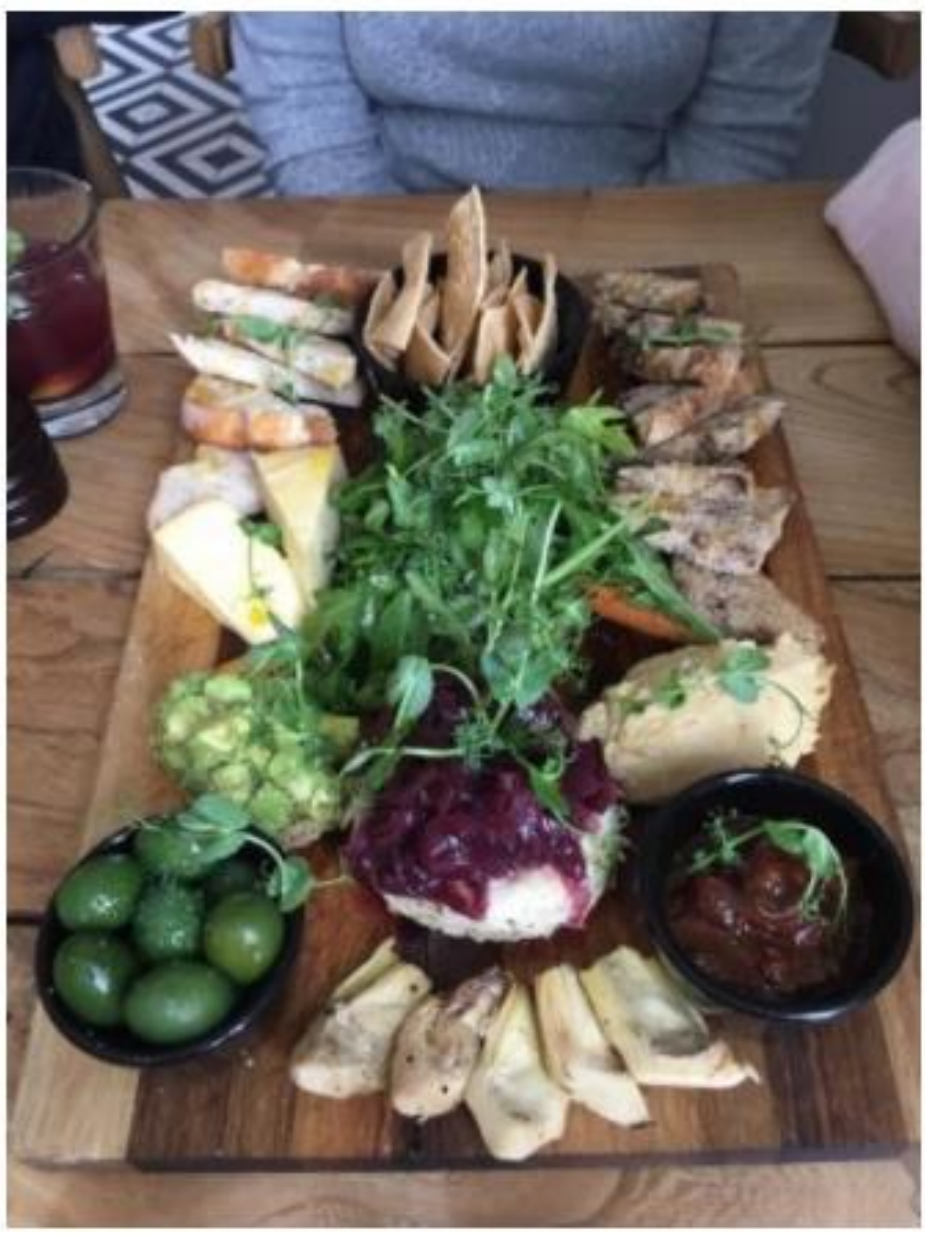

Based on this photo how positive is your impression of the Greater Wellington Region as a travel destination?

$\begin{array}{ccccccc}\begin{array}{c}\text { Not at all } \\ \text { positive }\end{array} & \begin{array}{c}\text { Moderately } \\ \text { negative }\end{array} & \begin{array}{c}\text { Slightly } \\ \text { negative }\end{array} & \begin{array}{c}\text { Neither } \\ \text { positive nor } \\ \text { negative }\end{array} & \begin{array}{c}\text { Slightly } \\ \text { positive }\end{array} & \begin{array}{c}\text { Moderately } \\ \text { positive }\end{array} & \begin{array}{c}\text { Very much } \\ \text { positive }\end{array} \\ 0 & 0 & 0 & 0 & 0 & 0 & 0\end{array}$

$0 \%$ 


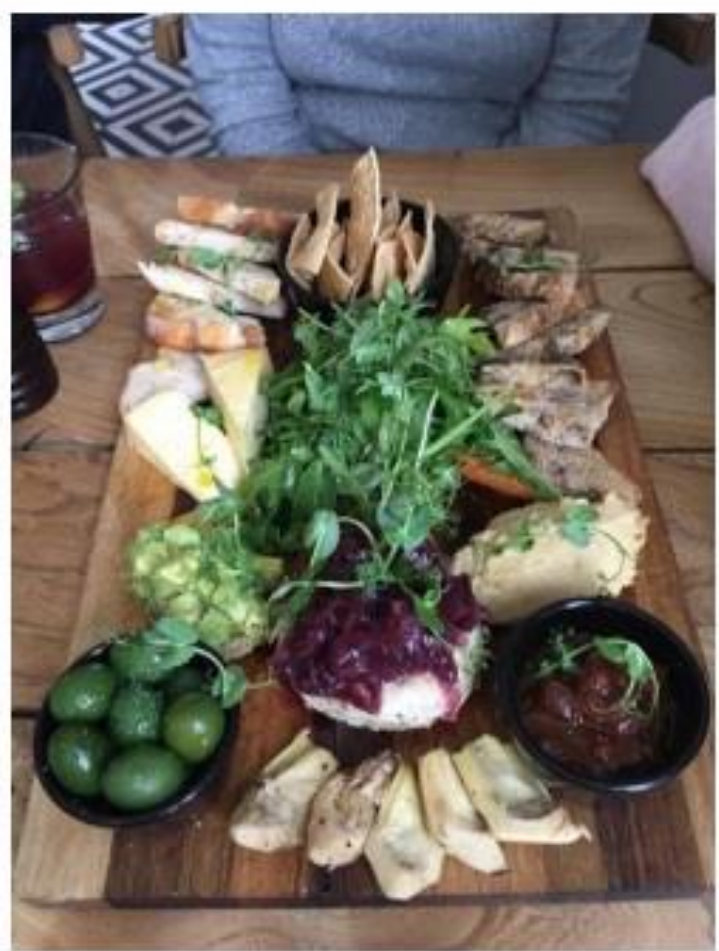

Based on this photo, please provide your opinion on the following questions.

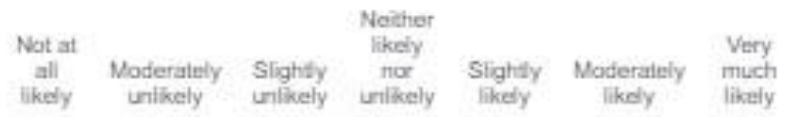

How likely are you to sesk information about the Grester Wellinglon Regan?

How ikely are you to visit the Greater Wellinctan Regian in the future?

$\begin{array}{lllllll}0 & 0 & 0 & 0 & 0 & 0 & 0\end{array}$

How ikely are yau

to seek out this

placelexperience

shiculd you visit the

Greater Welington

Region in the

future?

How ikely are you

is ravel to the

Greater Welington

Region to spend

fime with your

friend frelative in the

o

o

$0 \quad 0$

o

00

futere?

How ikely are you

to stay in a private

accommodation

(e.g holel) if you

were to visit the in the fulure?

$\begin{array}{lllllll}0 & 0 & 0 & 0 & 0 & 0 & 0\end{array}$

$\begin{array}{lllllll}0 & 0 & 0 & 0 & 0 & 0 & 0\end{array}$ 


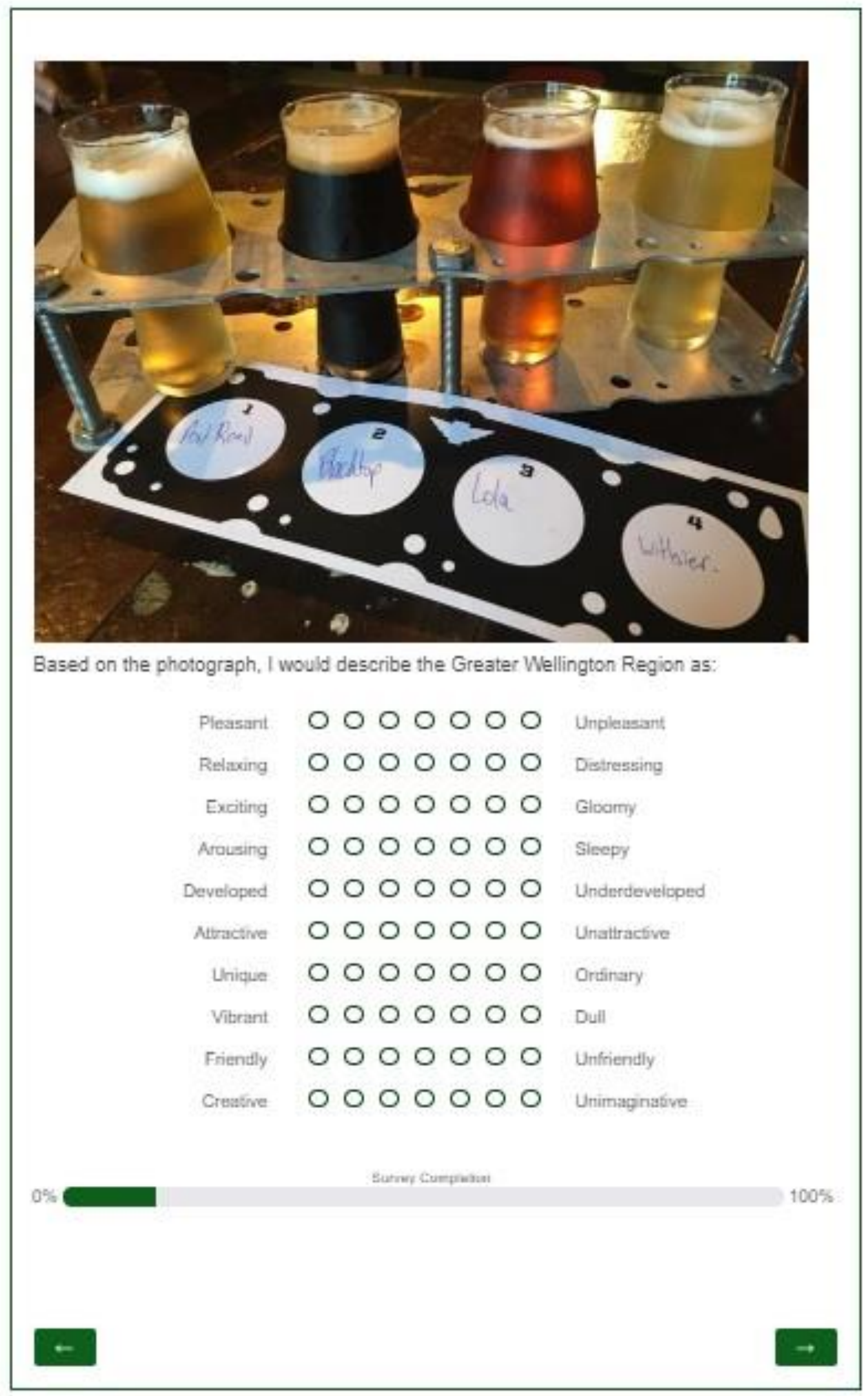




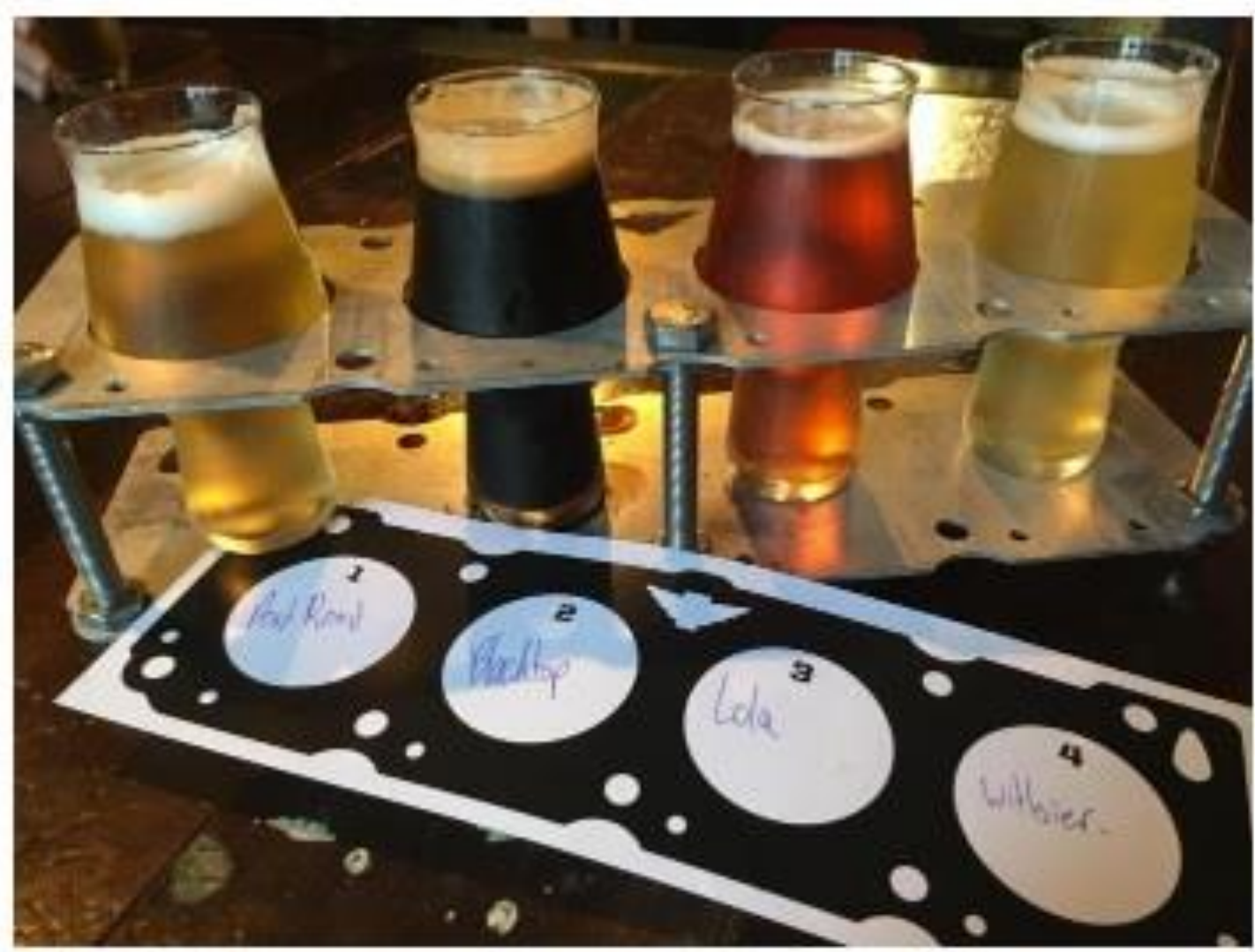

Based on this photo how positive is your impression of the Greater Wellington Region as a travel destination?

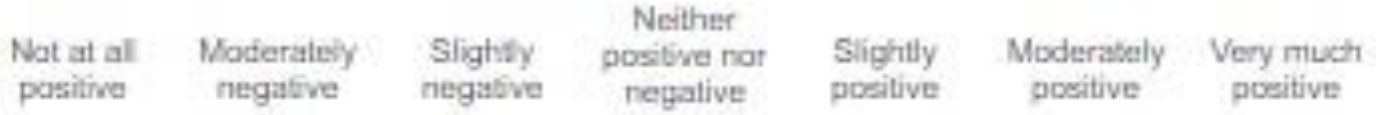
$\mathrm{O}$
$\mathrm{O}$
$\mathrm{O}$
O
O
$\mathrm{O}$
$\mathrm{O}$ 


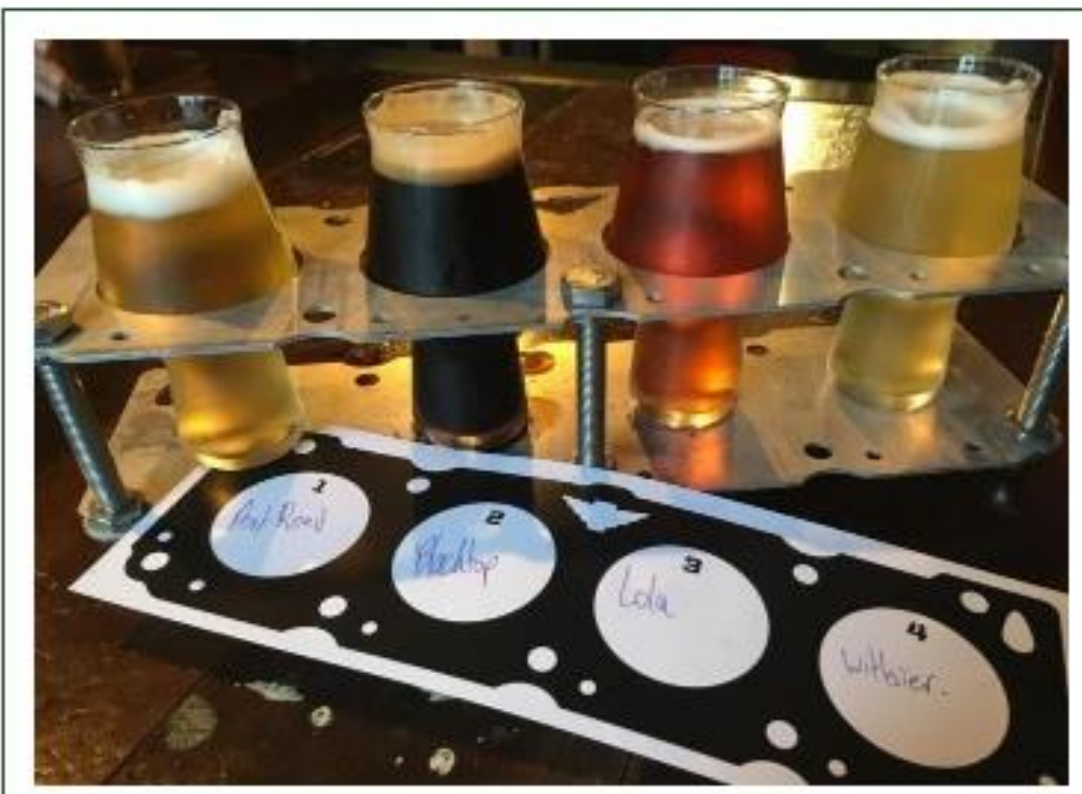

Based on this photo, please provide your opinion on the following questions.

\begin{tabular}{|c|c|c|c|c|c|c|c|}
\hline & $\begin{array}{l}\text { Not at } \\
\text { al } \\
\text { fikety }\end{array}$ & $\begin{array}{l}\text { Moderabely } \\
\text { unlikely }\end{array}$ & $\begin{array}{l}\text { Sligitly } \\
\text { unsikely }\end{array}$ & $\begin{array}{l}\text { Neither } \\
\text { likely } \\
\text { nor } \\
\text { urlikely }\end{array}$ & $\begin{array}{l}\text { Sligntly } \\
\text { likely }\end{array}$ & $\begin{array}{l}\text { Moderately } \\
\text { likely }\end{array}$ & $\begin{array}{l}\text { Very } \\
\text { much } \\
\text { likedy }\end{array}$ \\
\hline $\begin{array}{l}\text { How likely are you } \\
\text { to scek infarmation } \\
\text { about the Greater } \\
\text { Wellington Region? }\end{array}$ & 0 & 0 & 0 & 0 & 0 & 0 & 0 \\
\hline $\begin{array}{l}\text { How likely are you } \\
\text { to vish the Geaster } \\
\text { Welington Region } \\
\text { in the fulure? }\end{array}$ & 0 & 0 & 0 & 0 & 0 & 0 & 0 \\
\hline $\begin{array}{l}\text { Hiow likely are you } \\
\text { to seck out this } \\
\text { placelexperience } \\
\text { shauld you visit thet } \\
\text { Greater Weslirigitsn } \\
\text { Region in the } \\
\text { future? }\end{array}$ & 0 & 0 & 0 & 0 & 0 & 0 & 0 \\
\hline $\begin{array}{l}\text { How likely are you } \\
\text { to travel to the } \\
\text { Grester Wellingiton } \\
\text { Regian to spernd } \\
\text { time with your } \\
\text { friendirelytive in the } \\
\text { future? }\end{array}$ & 0 & 0 & 0 & 0 & 0 & 0 & 0 \\
\hline 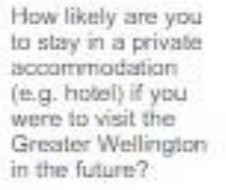 & 0 & 0 & 0 & 0 & 0 & 0 & 0 \\
\hline \multicolumn{8}{|c|}{ Suruer, Curpinacon } \\
\hline$\leftarrow$ & & & & & & & $\rightarrow$ \\
\hline
\end{tabular}




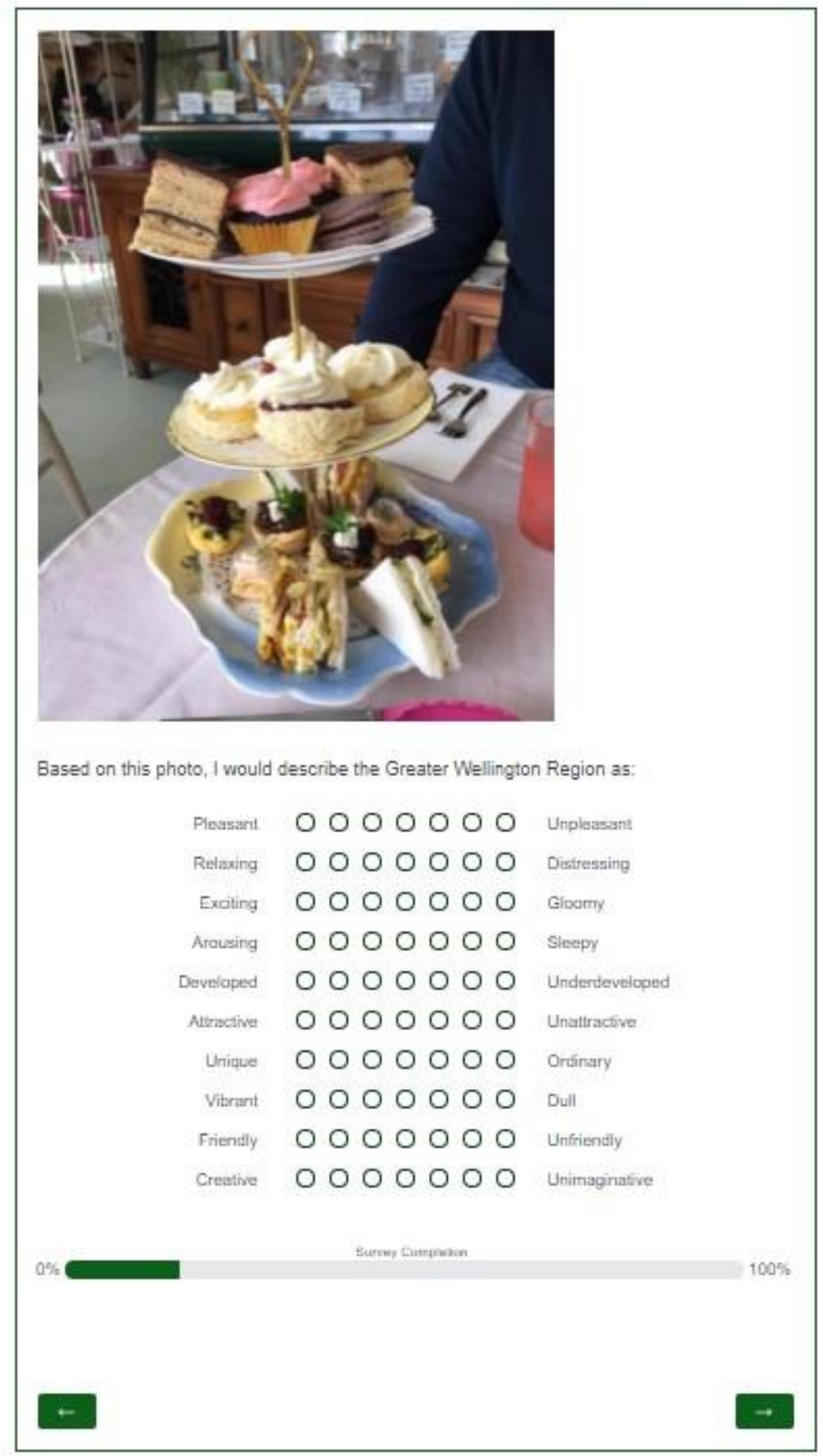




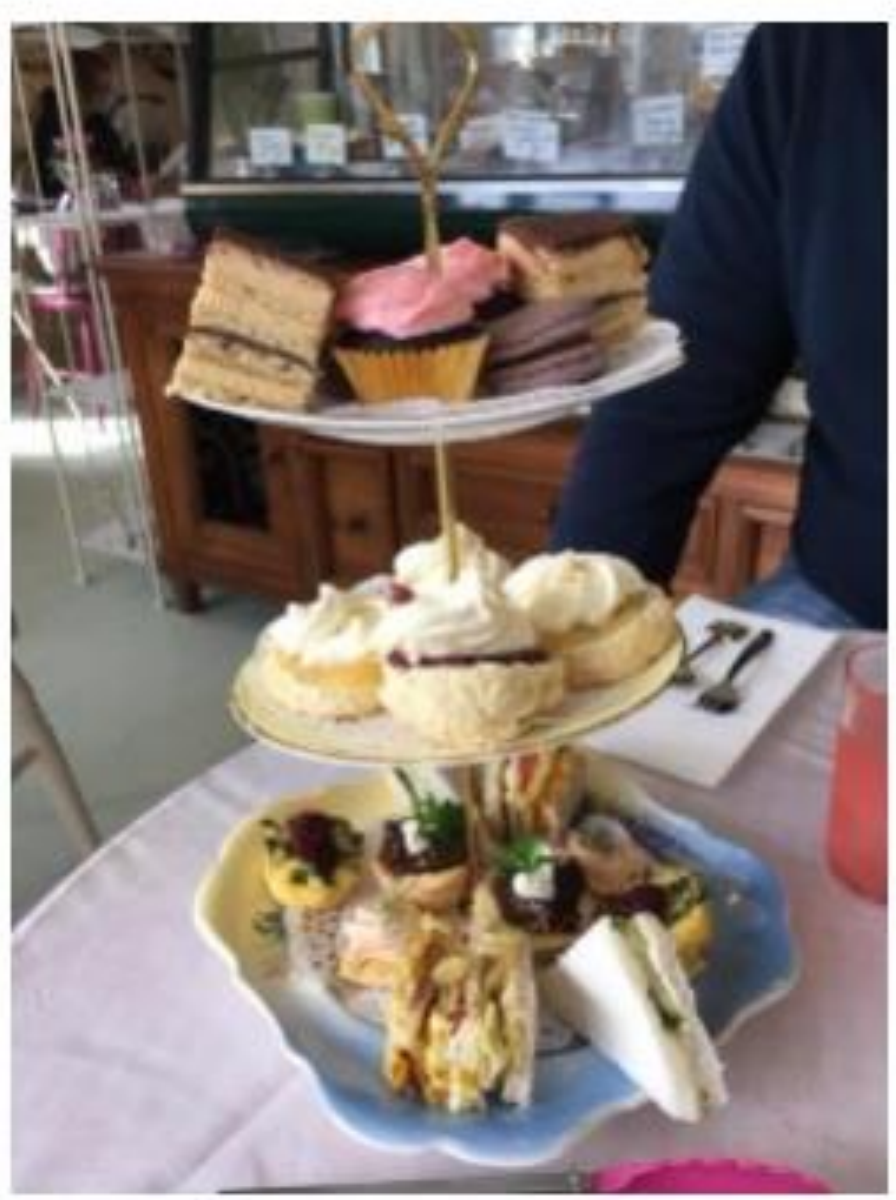

Based on this photo how positive is your impression of the Greater Wellington Region as a travel destination?

\begin{tabular}{|c|c|c|c|c|c|c|}
\hline $\begin{array}{l}\text { Nat at al } \\
\text { pasitive }\end{array}$ & $\begin{array}{l}\text { Moderately } \\
\text { negative }\end{array}$ & $\begin{array}{l}\text { Sightsy } \\
\text { negative }\end{array}$ & $\begin{array}{l}\text { Neither } \\
\text { posibe nor } \\
\text { negative }\end{array}$ & $\begin{array}{l}\text { Slightly } \\
\text { positive }\end{array}$ & $\begin{array}{l}\text { Moderately } \\
\text { positive }\end{array}$ & $\begin{array}{l}\text { Very much } \\
\text { positive }\end{array}$ \\
\hline 0 & 0 & 0 & 0 & 0 & 0 & 0 \\
\hline
\end{tabular}




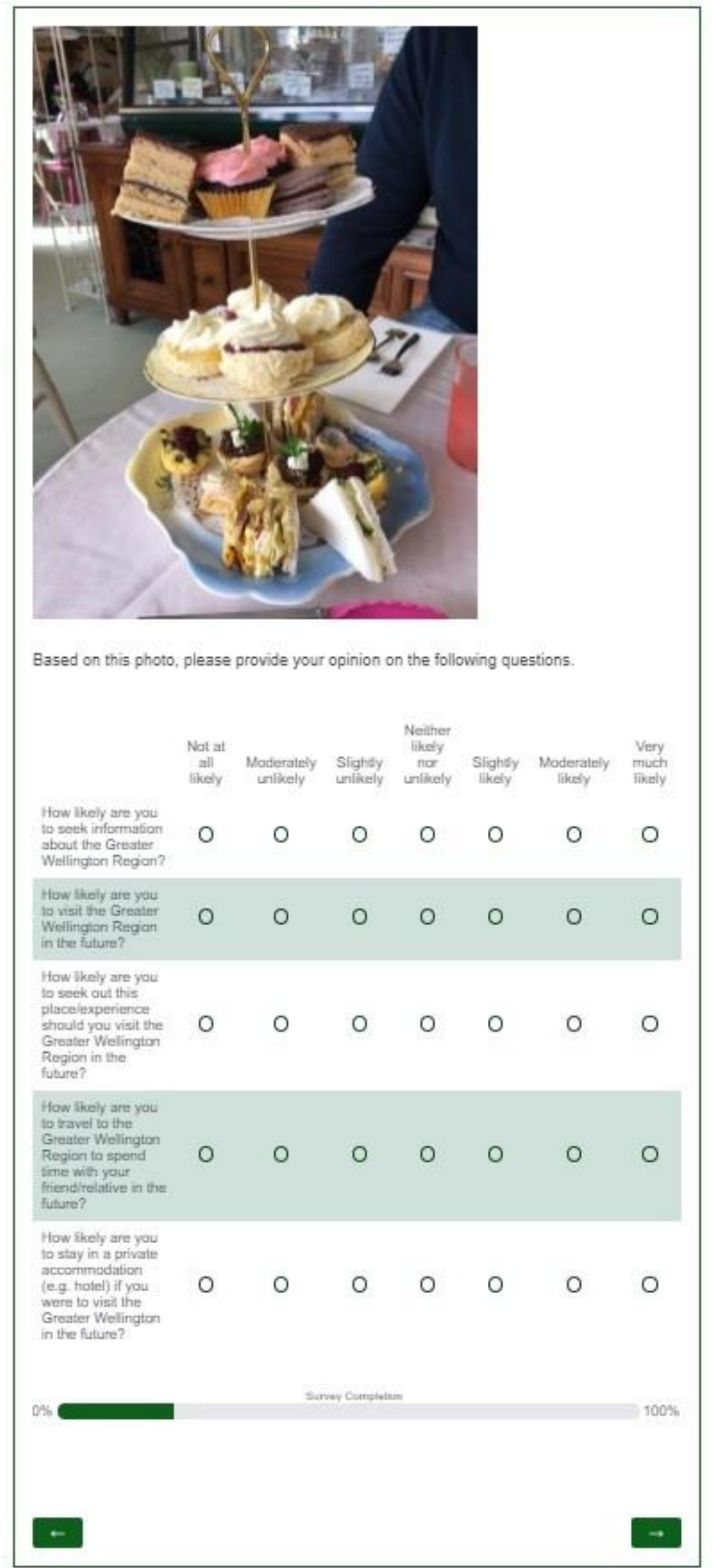




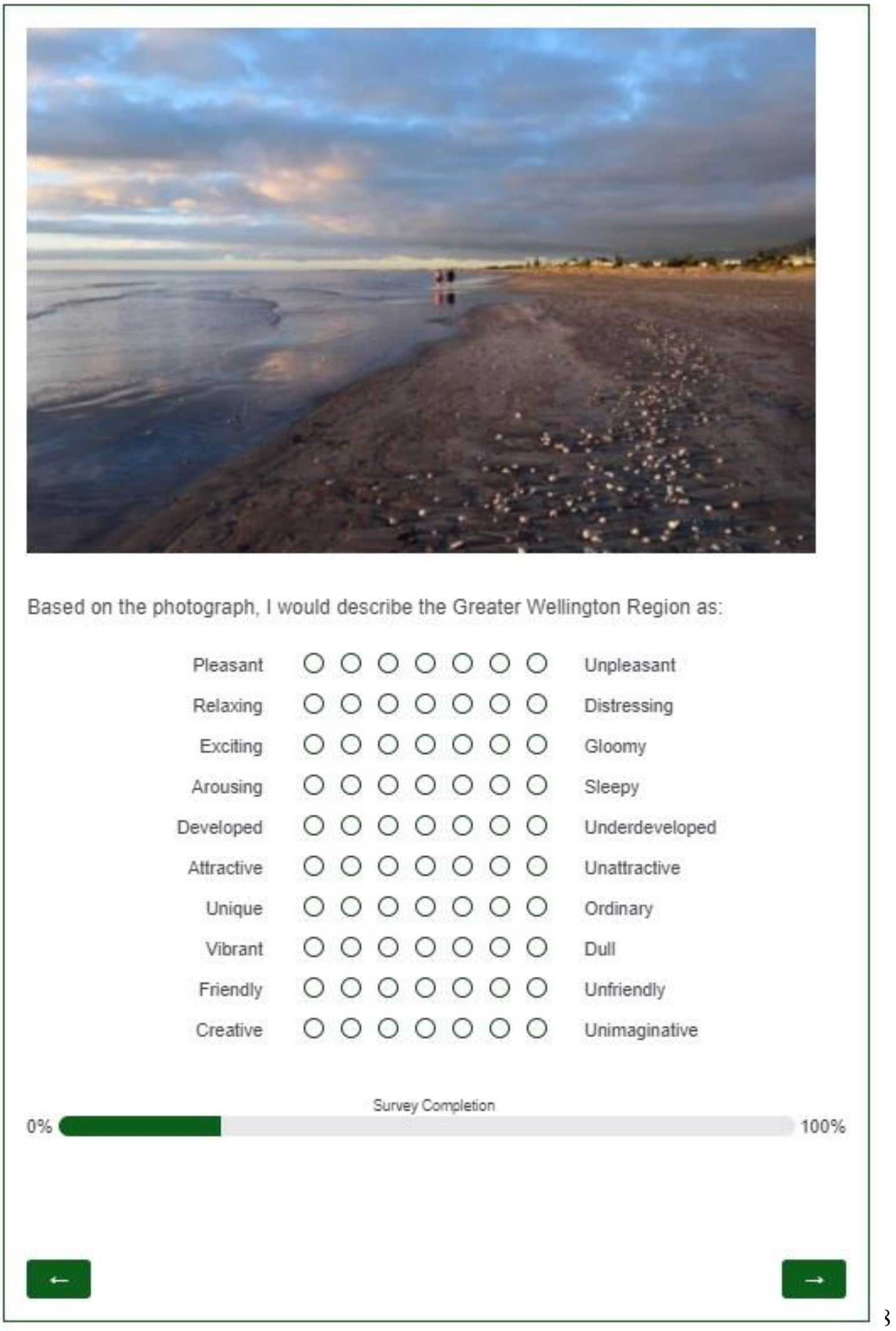




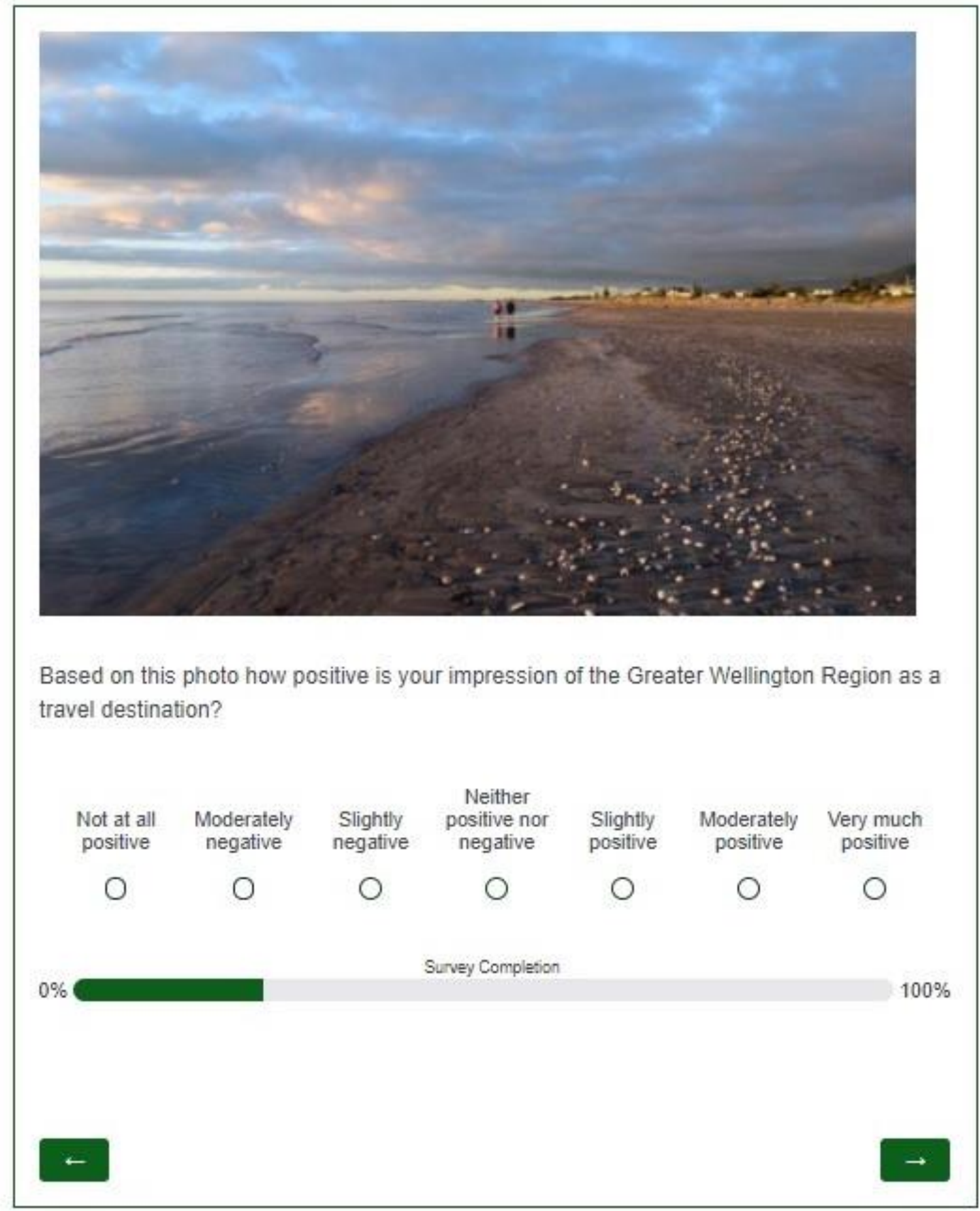




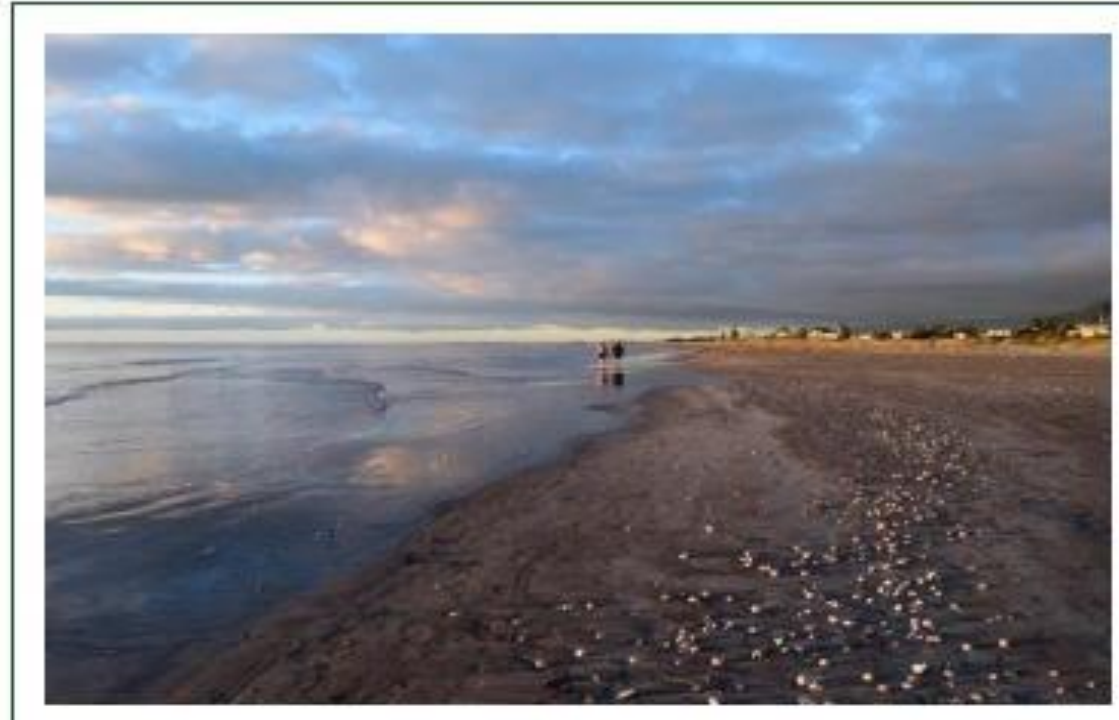

Based on this photo, please provide your opinion on the following questions.

\begin{tabular}{|c|c|c|c|c|c|c|c|}
\hline & $\begin{array}{c}\text { Not at } \\
\text { al } \\
\text { likely }\end{array}$ & $\begin{array}{l}\text { Moderately } \\
\text { unlikely }\end{array}$ & $\begin{array}{l}\text { Slightly } \\
\text { unlikely }\end{array}$ & $\begin{array}{c}\text { Neither } \\
\text { likely } \\
\text { nor } \\
\text { unlikely }\end{array}$ & $\begin{array}{l}\text { Slightly } \\
\text { likely }\end{array}$ & $\begin{array}{l}\text { Moderately } \\
\text { likely }\end{array}$ & $\begin{array}{l}\text { Very } \\
\text { muth } \\
\text { likdy }\end{array}$ \\
\hline $\begin{array}{l}\text { How likely are you } \\
\text { to seek information } \\
\text { abouit the Greater } \\
\text { Wellingtan Region? }\end{array}$ & 0 & 0 & $\mathrm{O}$ & $\mathrm{O}$ & 0 & $\mathrm{O}$ & $\mathrm{O}$ \\
\hline $\begin{array}{l}\text { How likely are you } \\
\text { to visin the Greater } \\
\text { Wellington Region } \\
\text { in the futurn? }\end{array}$ & $\mathrm{O}$ & 0 & 0 & 0 & 0 & $\mathrm{O}$ & $\mathrm{O}$ \\
\hline $\begin{array}{l}\text { How likely are you } \\
\text { to seek out this } \\
\text { placelexperience } \\
\text { hrould you visil the } \\
\text { Grester Wellington } \\
\text { Region in the } \\
\text { future? }\end{array}$ & $\mathrm{O}$ & $\mathrm{O}$ & $\mathrm{O}$ & $\mathrm{O}$ & $\mathrm{O}$ & $\mathrm{O}$ & $\mathrm{O}$ \\
\hline $\begin{array}{l}\text { How likely are you } \\
\text { to travel to the } \\
\text { Grester Wellinglon } \\
\text { Regian to spend } \\
\text { time witty your } \\
\text { friendirelative in the } \\
\text { future? }\end{array}$ & 0 & 0 & 0 & 0 & 0 & 0 & 0 \\
\hline $\begin{array}{l}\text { How likely are ypu } \\
\text { to stay in a private } \\
\text { iscournoudstian } \\
\text { (e.g. hobel) if you } \\
\text { were to visit the } \\
\text { Grester Wellinglon } \\
\text { in the future? }\end{array}$ & $\mathrm{O}$ & 0 & $\mathrm{O}$ & $\mathrm{O}$ & 0 & $\mathrm{O}$ & $\mathrm{O}$ \\
\hline \multicolumn{7}{|c|}{ Surun Chumpuasn } & $100 \%$ \\
\hline$\leftarrow$ & & & & & & & $\Rightarrow$ \\
\hline
\end{tabular}




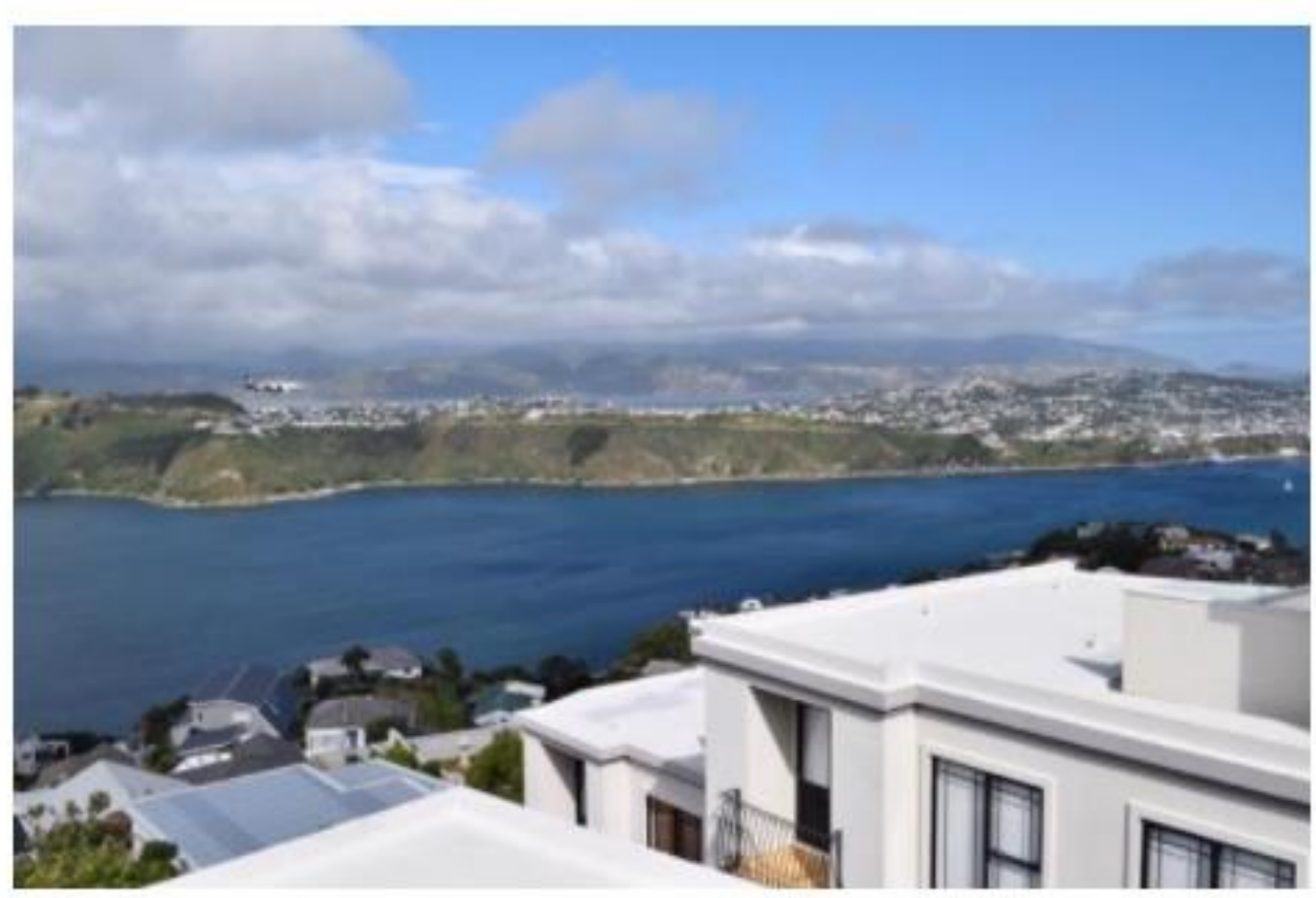

Based on the photograph, I would describe the Greater Wellington Region as:

$\begin{array}{cccccccll}\text { Pleasant } & 0 & 0 & 0 & 0 & 0 & 0 & 0 & \text { Unpleasant } \\ \text { Relaxing } & 0 & 0 & 0 & 0 & 0 & 0 & 0 & \text { Distressing } \\ \text { Exciting } & 0 & 0 & 0 & 0 & 0 & 0 & 0 & \text { Gloomy } \\ \text { Arousing } & 0 & 0 & 0 & 0 & 0 & 0 & 0 & \text { Sleepy } \\ \text { Developed } & 0 & 0 & 0 & 0 & 0 & 0 & 0 & \text { Underdeveloped } \\ \text { Attractive } & 0 & 0 & 0 & 0 & 0 & 0 & 0 & \text { Unattractive } \\ \text { Unique } & 0 & 0 & 0 & 0 & 0 & 0 & 0 & \text { Ordinary } \\ \text { Vibrant } & 0 & 0 & 0 & 0 & 0 & 0 & 0 & \text { Dull } \\ \text { Friendly } & 0 & 0 & 0 & 0 & 0 & 0 & 0 & \text { Unfriendly } \\ \text { Creative } & 0 & 0 & 0 & 0 & 0 & 0 & 0 & \text { Unimaginative }\end{array}$




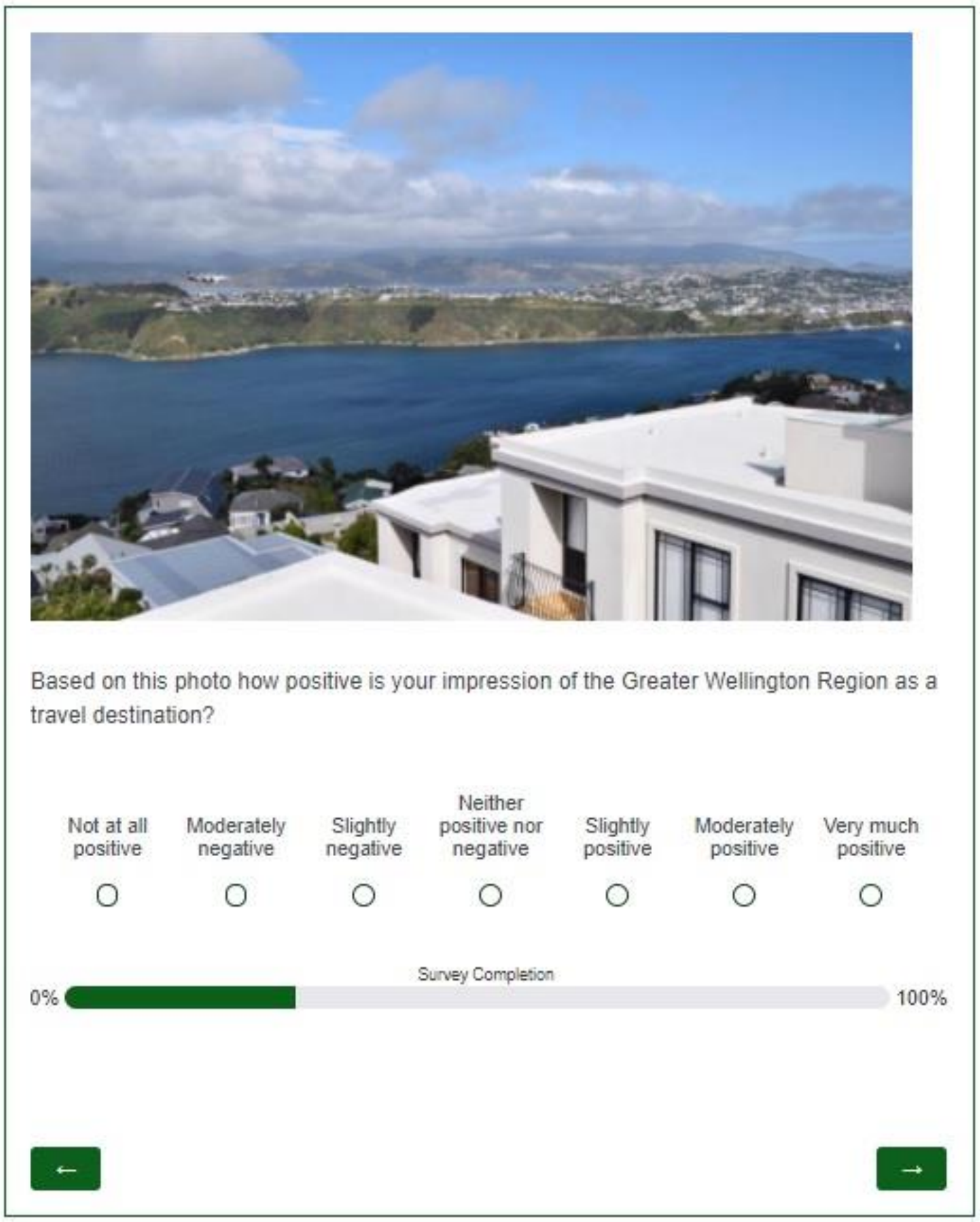




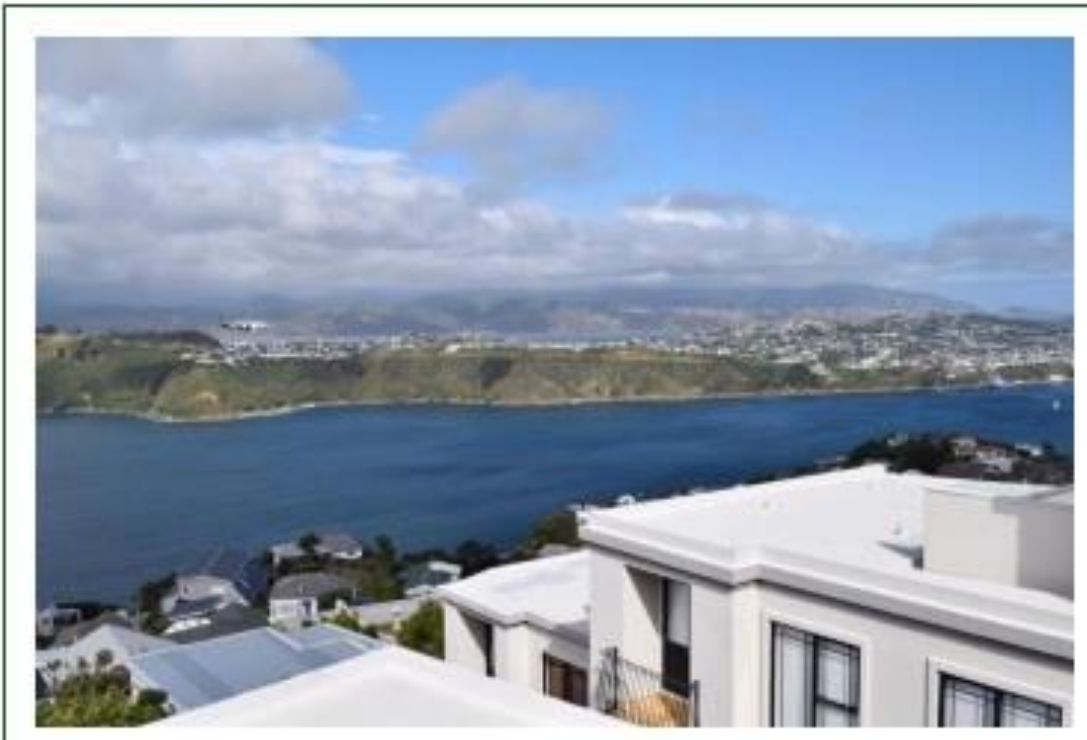

Based on this photo, please provide your opinion on the following questions.

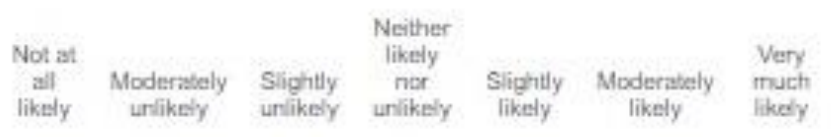

How likely are you

to seek information

about the Greater

Weilingtan Regicr?
$0 \quad 0$
$0 \quad 0$
$0 \quad 0$
0

How liksty are you

ta visil the Greater

Welington Region

$0 \quad 0$

0

0

00

○

in the futurt?

How likely are you

to stek put this

paremexperic

sheuld you visit the

Gresiter Wellingtor

Regian in the

future?

How likely are you

to travel in the

Gresiter Wellington

Regian to spernd

time with your

friendirelative in the

fuliure?

How liksty are you

to stay in a private

sccommodstian

(t.g. hobel) if you

were to visit the

Gresiter Wellingter

$\begin{array}{lllllll}0 & 0 & 0 & 0 & 0 & 0 & 0\end{array}$

$\begin{array}{lllllll}0 & 0 & 0 & 0 & 0 & 0 & 0\end{array}$ 


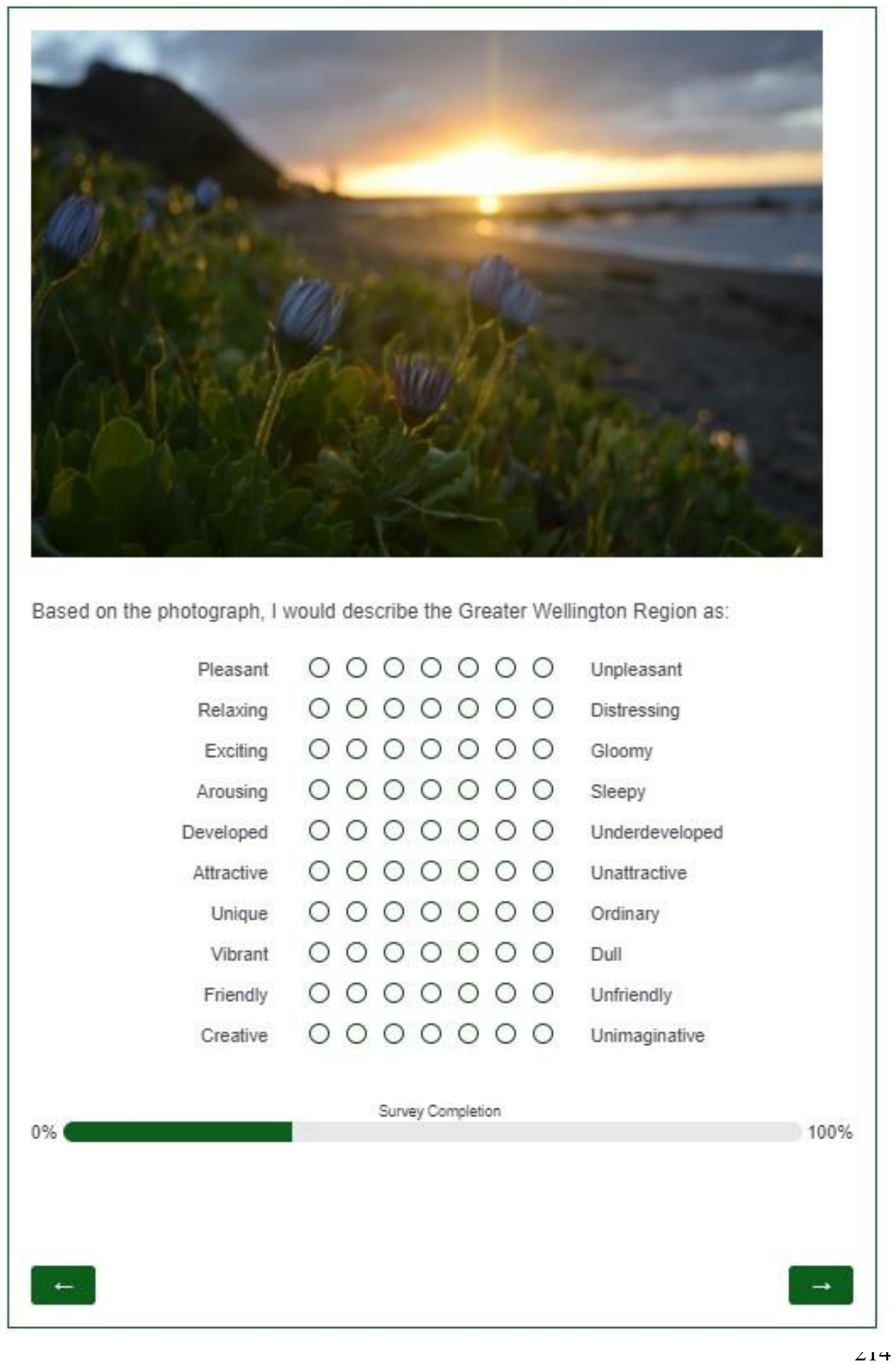




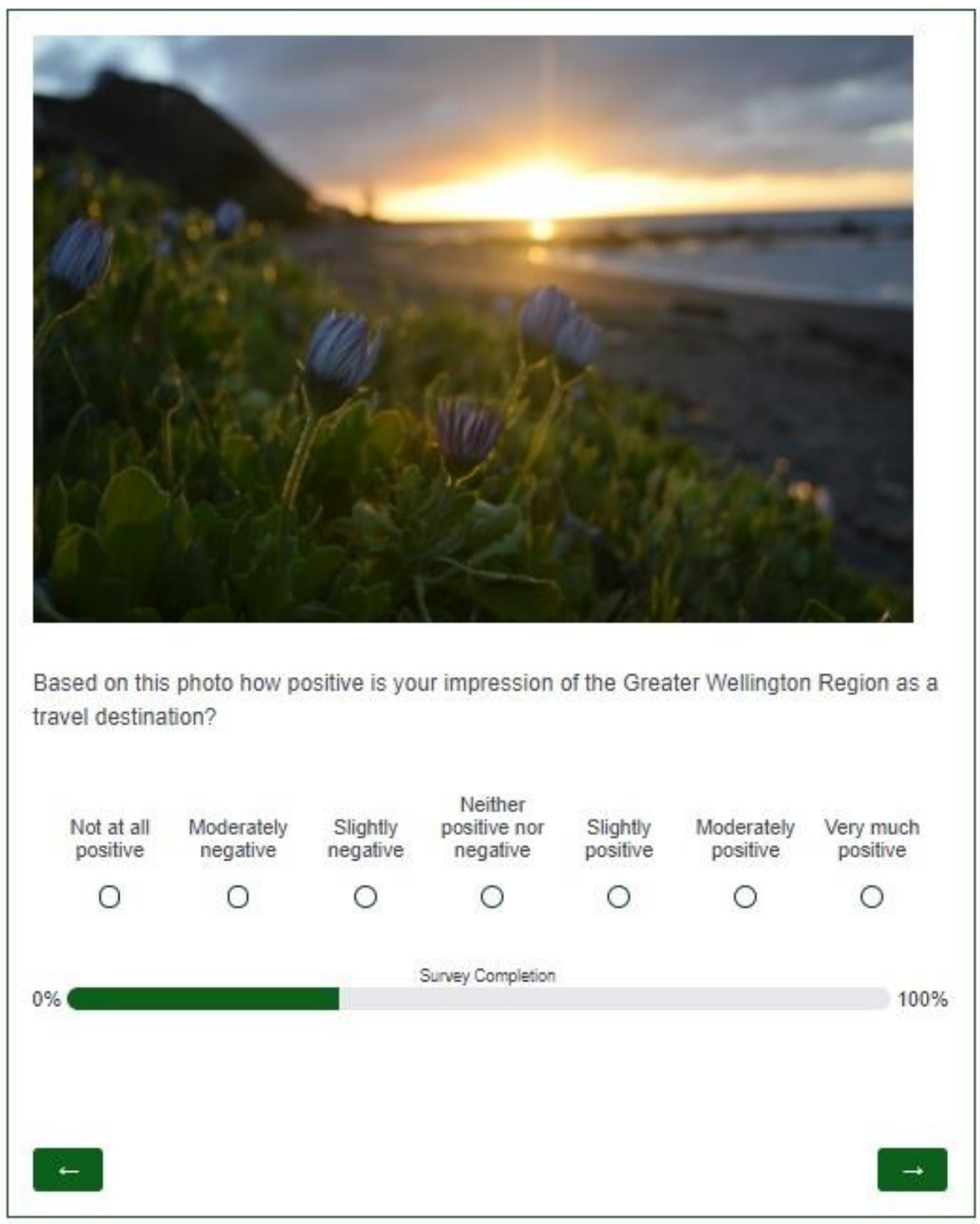




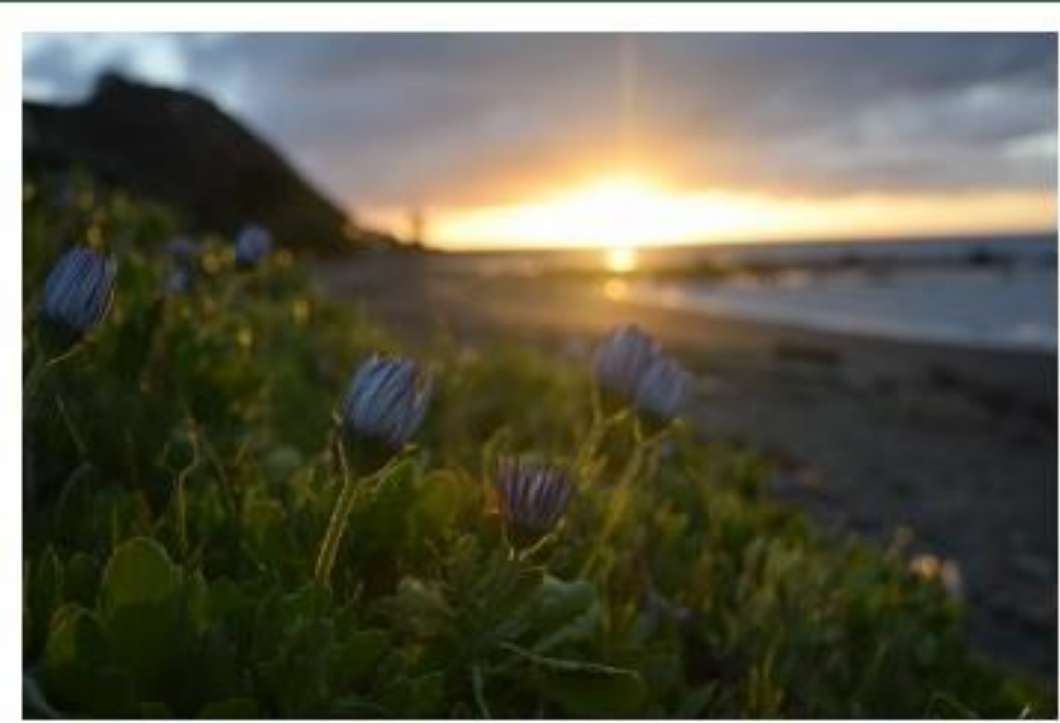

Based on this photo, please provide your opinion on the following questions.

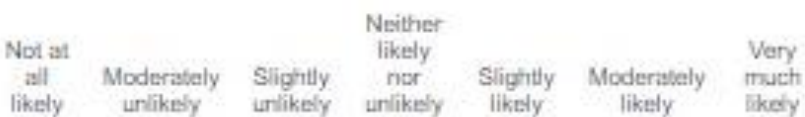

How liksty are you fa seek information about the Greater

Weilingtan Region?

How likely are you

to visit the Greater

Welington Revion

in the flture?
○
O
○
0
0
$0 \quad 0$

How likely are you

to seck out this

placelexperience

shauld you visil the

Grester Wellington

0000

000

Region ir the:

fulure?

How liksty are ypu

to iravel to the

Greater Wellingion

Region to spernet

time with yout

friendirelative in the

future?

Hew likely are you

to stasy in a private:

scoommodatian

e.g. hodely if you

were to visit the

Grester Wellingicon

$\begin{array}{lllll}0 & 0 & 0 & 0 & 0\end{array}$

$0 \quad 0$

O

in the future? 


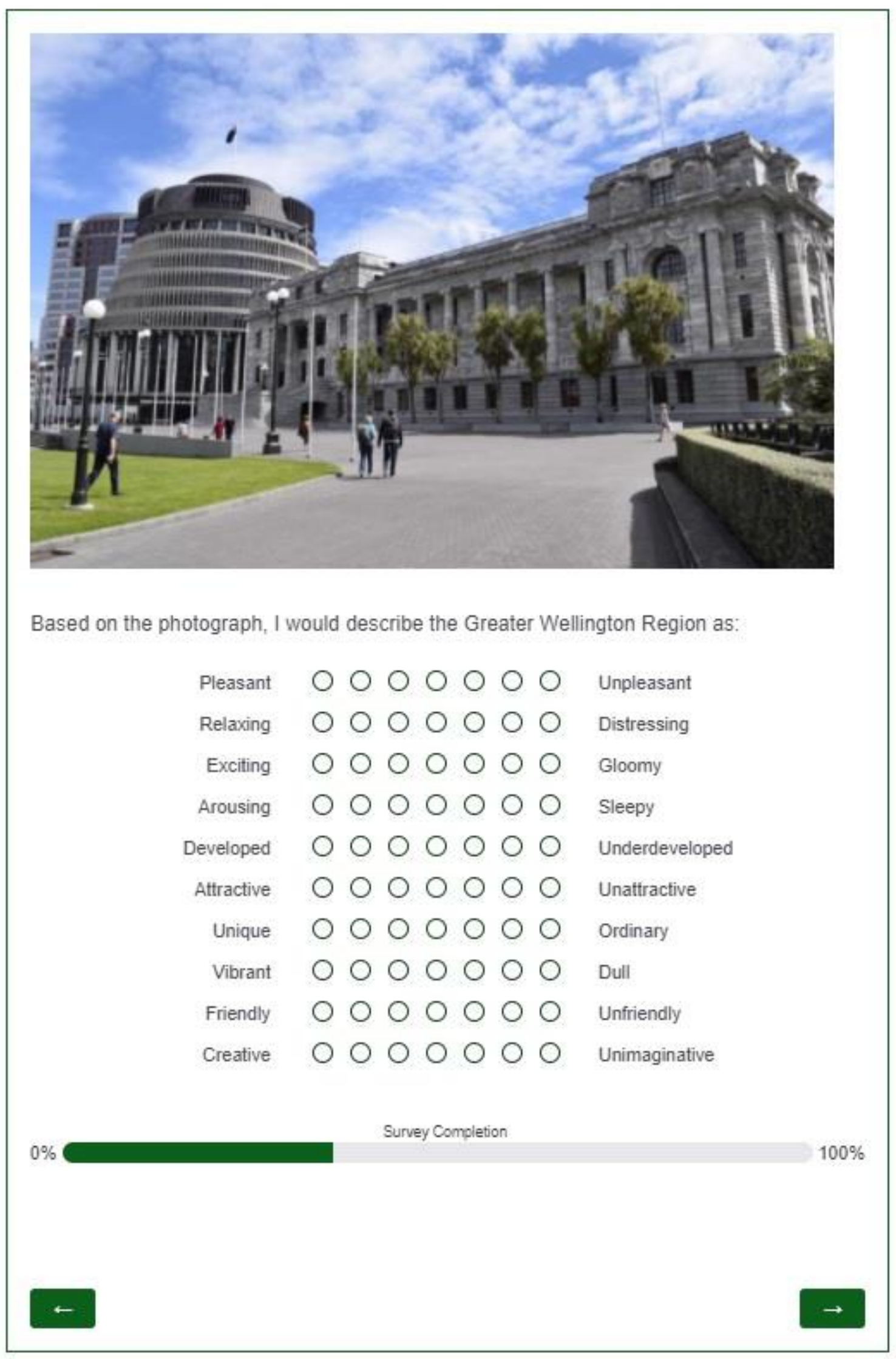




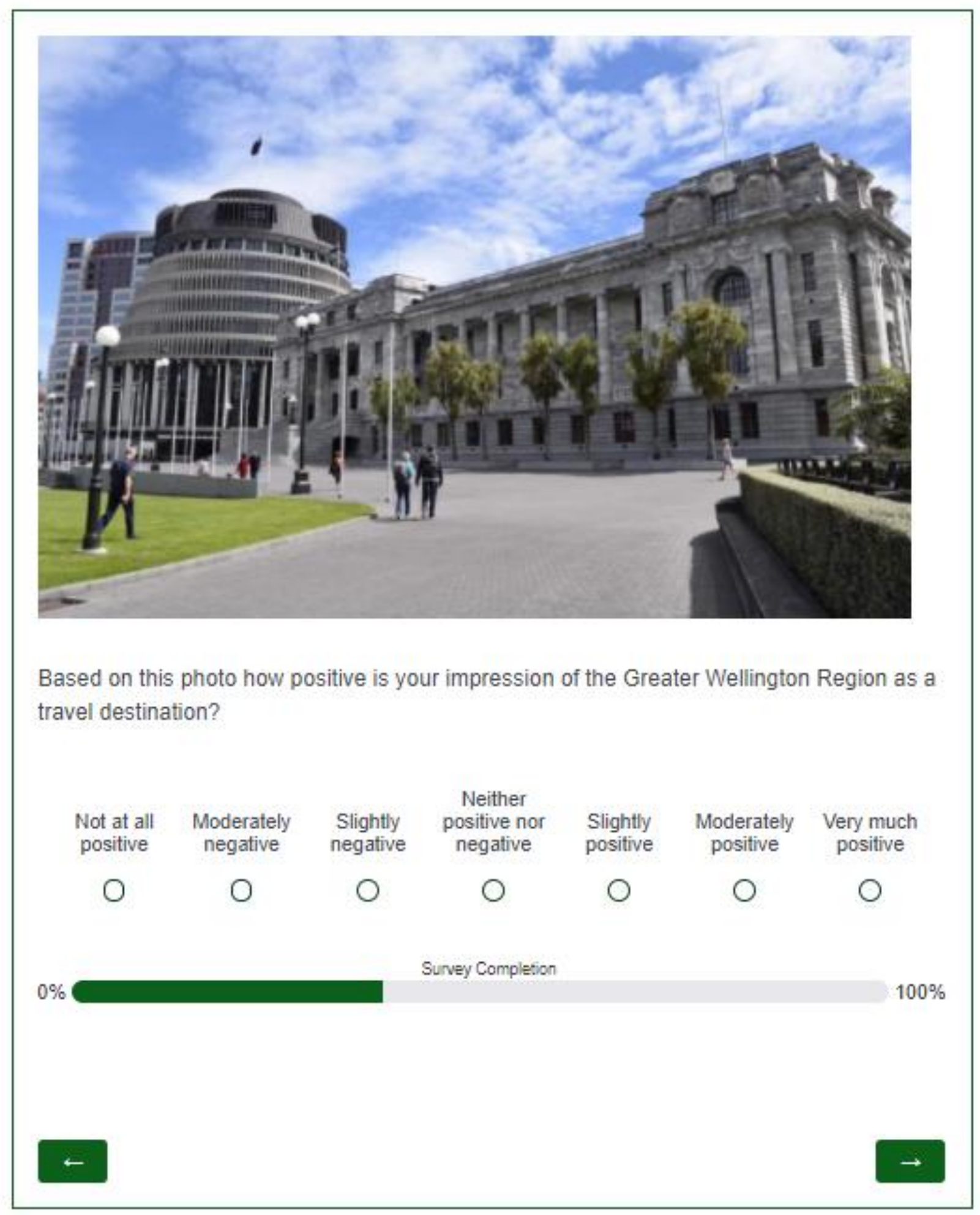




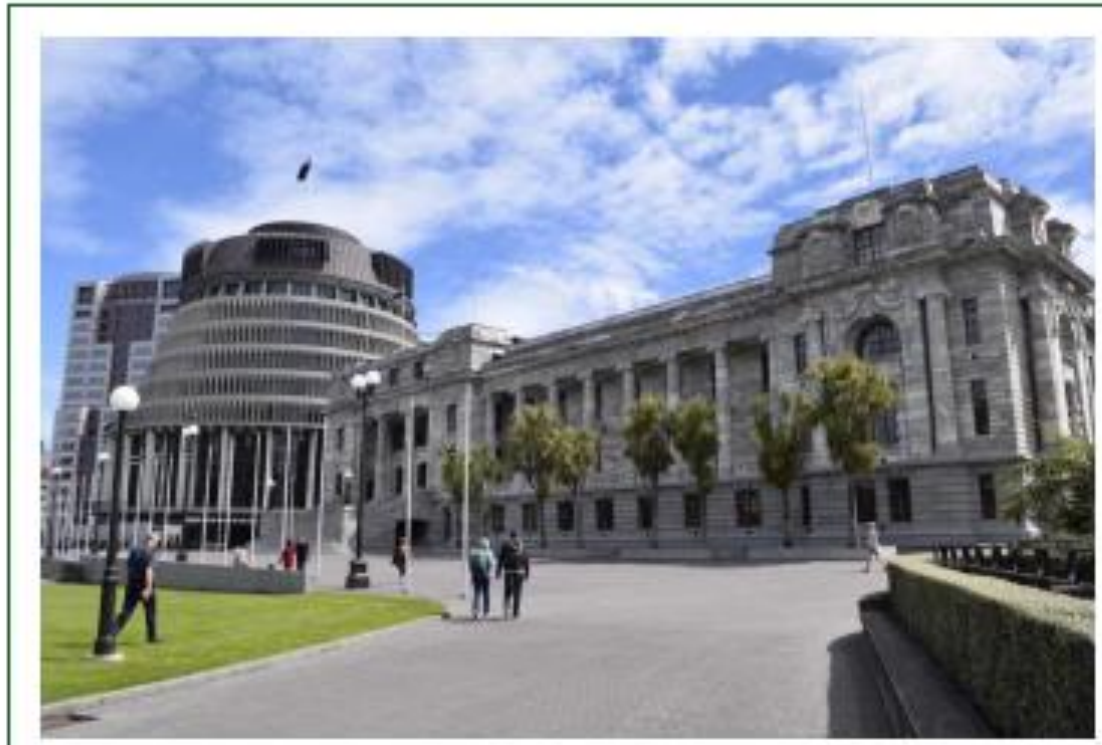

Based on this photo, please provide your opinion on the following questions.

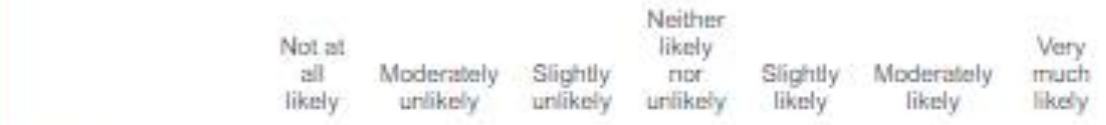

How likely are you

to seek information

about the Greaber

Welington Region?

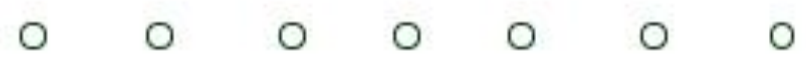

How likely are you

to visit the Greater

Weilingtan Region

in the future?

$\begin{array}{lllllll}0 & 0 & 0 & 0 & 0 & 0 & 0\end{array}$

How likely are you

to seek out this

placelexperience

should you visit the

Grester Wellingtor

$\begin{array}{lllllll}0 & 0 & 0 & 0 & 0 & 0 & 0\end{array}$

Regian in the

future?

How likely are you

to travel to the

Greater Wellington

Regian to sperit

time with your

$\begin{array}{lllllll}0 & 0 & 0 & 0 & 0 & 0 & 0\end{array}$

friendirelalive in the

future?

How fikely are you

to stay in a private

accorrmodation

(e.g. hobel) if you

were to visit the

Greater Wellingicr

$0 \quad 0 \quad 0 \quad 0 \quad 0 \quad 000$

in the future? 


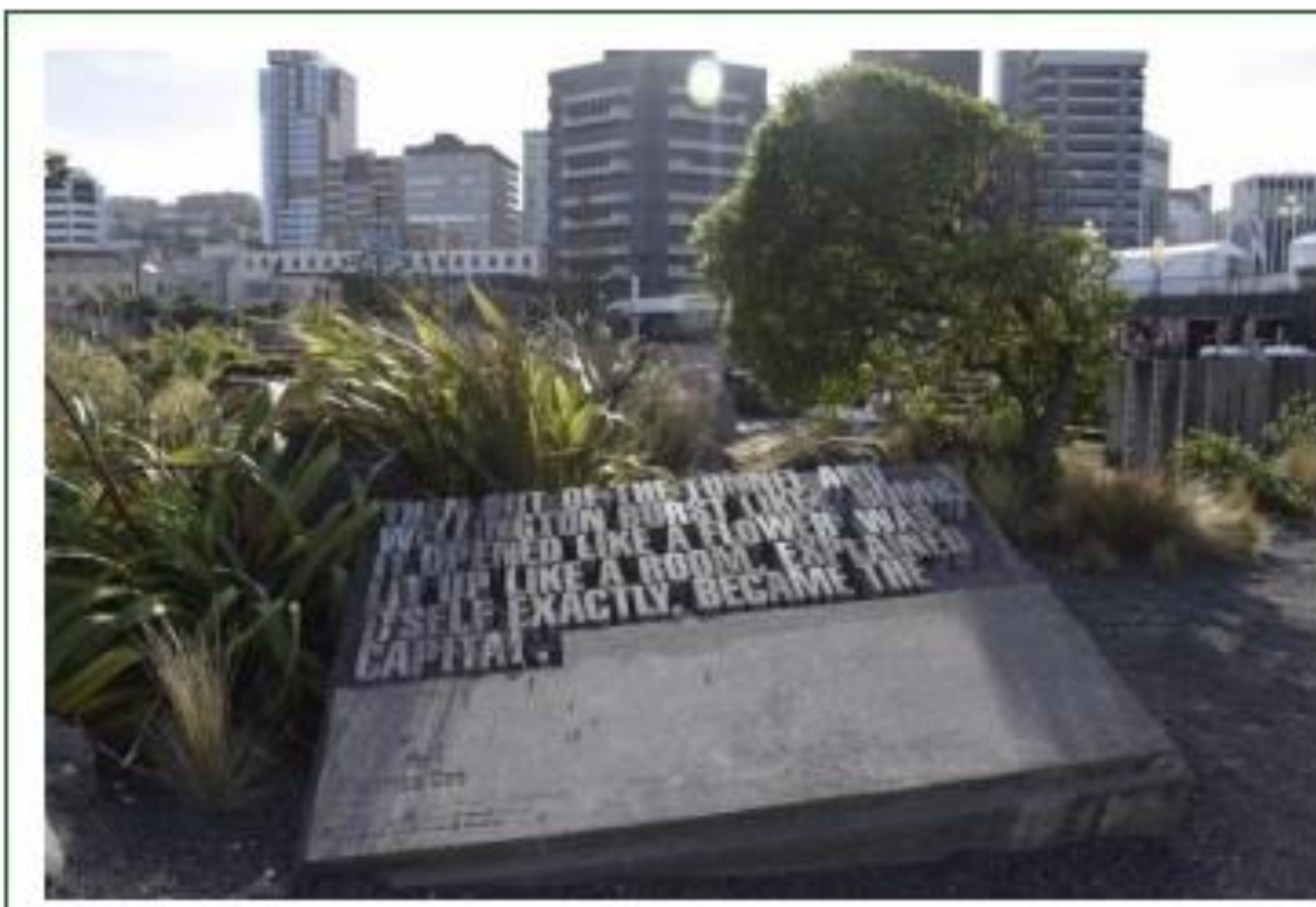

Based on the photograph, I would describe the Greater Wellington Region as:

\begin{tabular}{|c|c|c|}
\hline Pleasant & 0000000 & Unpleasant \\
\hline Reliwaing & 0000000 & Distressing \\
\hline Exciting & 0000000 & Gloarmy: \\
\hline Arausing & 0000000 & Sleepy \\
\hline Develaped & 0000000 & Underdevelspeed \\
\hline Atractive & 0000000 & Unaltractive \\
\hline Unique & 0000000 & Oranaty \\
\hline Vibrant & 0000000 & Dull \\
\hline Frierndly & 000000 & Unfriendly \\
\hline Creative & 0000000 & Unimaginabive \\
\hline
\end{tabular}

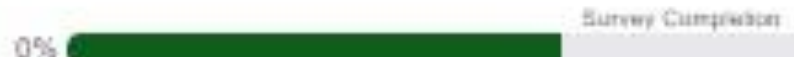




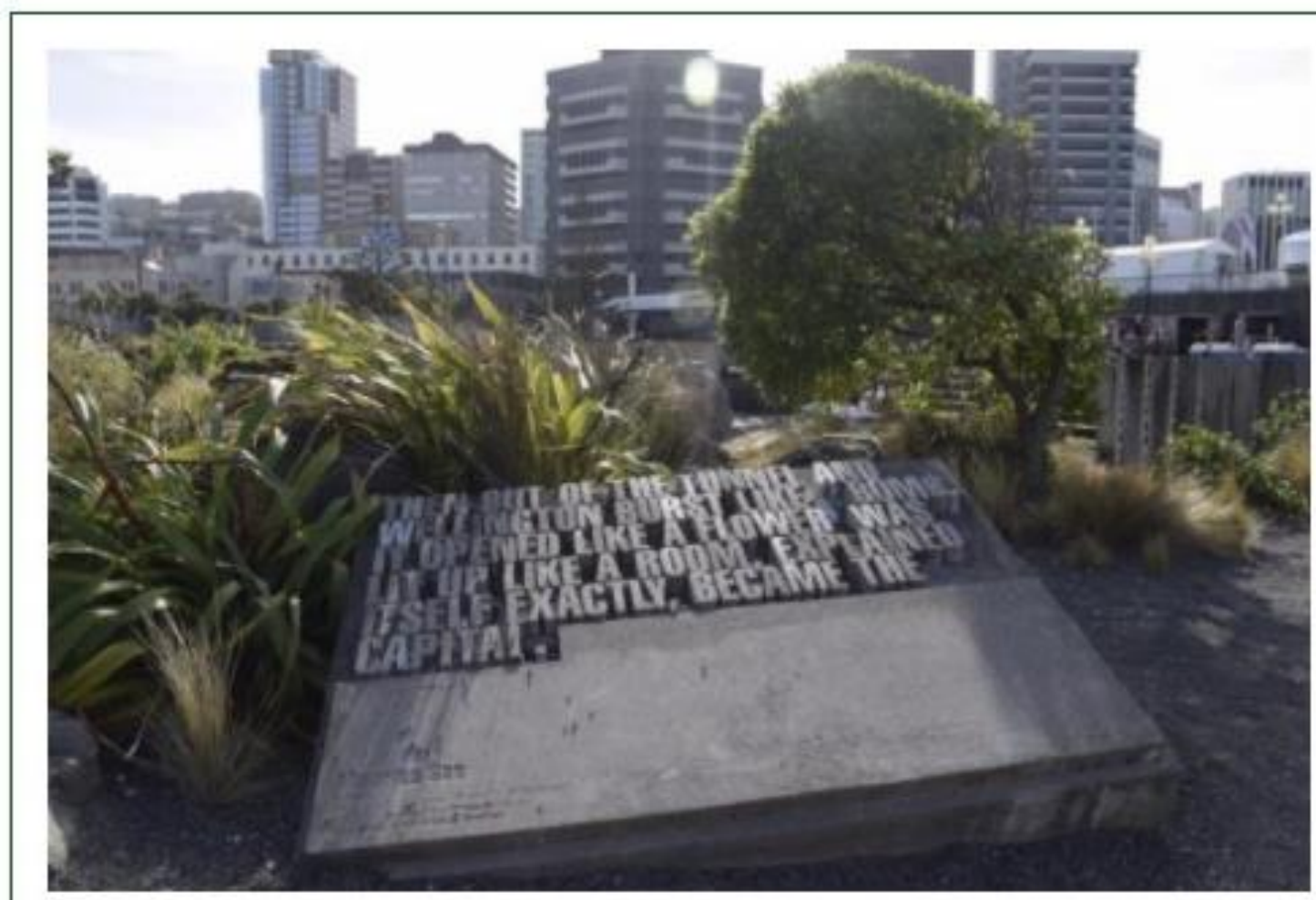

Based on this photo how positive is your impression of the Greater Wellington Region as a travel destination?

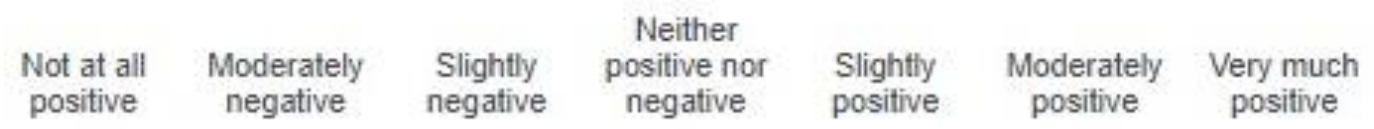

$\begin{array}{lllllll}0 & 0 & 0 & 0 & 0 & 0 & 0\end{array}$

$0 \%$ 


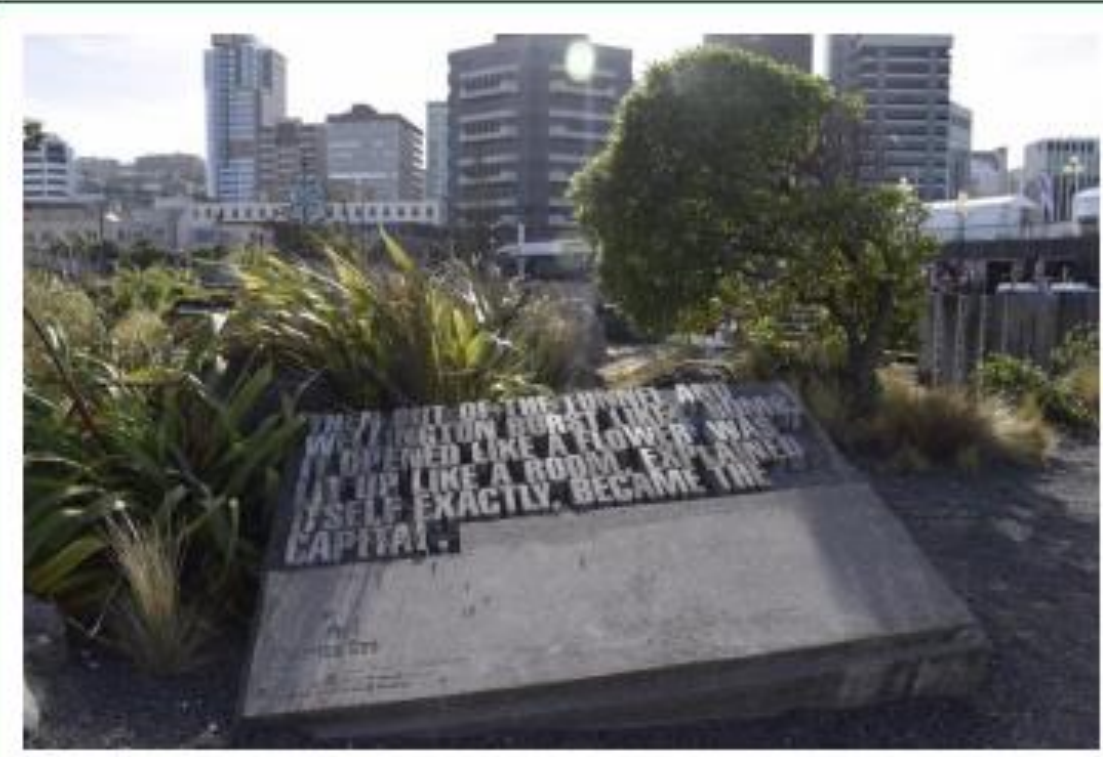

Based on this photo, please provide your opinion on the following questions.

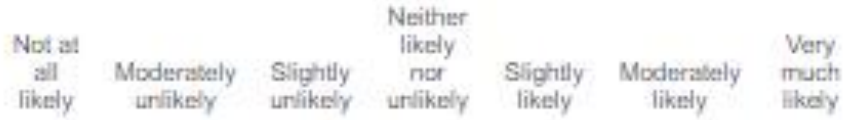

How likely are you

to seek infarmation

aboul the Greater

Welington Region?

How likely are you

to visit the Grester

Welingtan Region

○

○

0

$\circ$

○

00

in the future?

How likely are you

to seak out this

placelexperience

should you visit thet

Grester Wellingten

Regian in the

fultre?

How likely are you
to travel is the
Greater Wellingion
Regian to spend
time with your
friendirelative in the
fulure?

Hew likely are you

to stay in a privates

acooummodation

(e.g. hobel) if you

were to visit the

Grester Wellingtor

in the future?

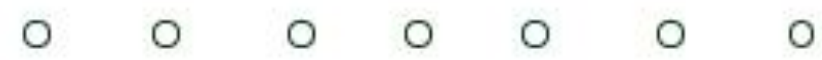

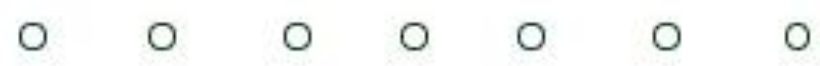

.




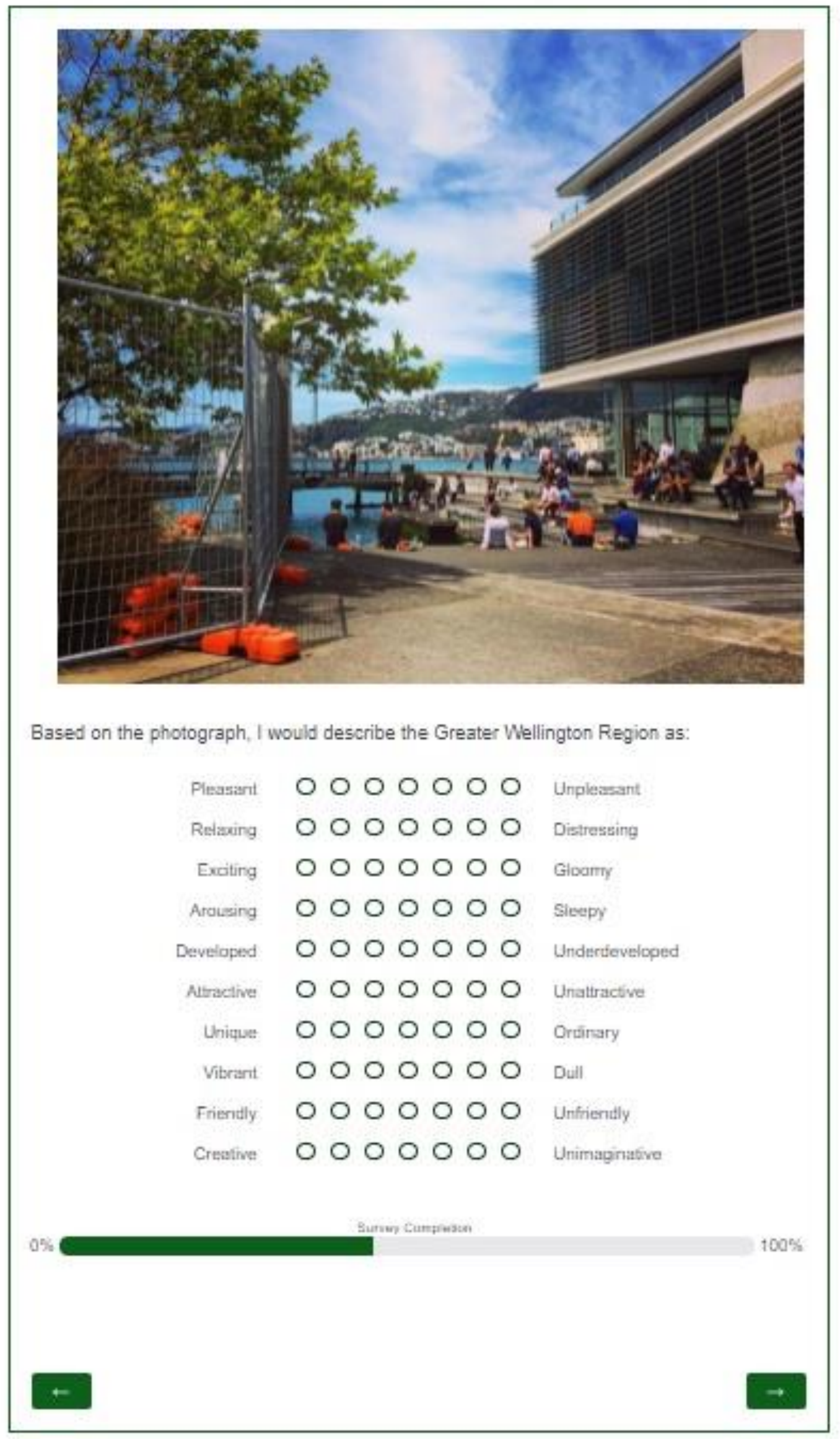




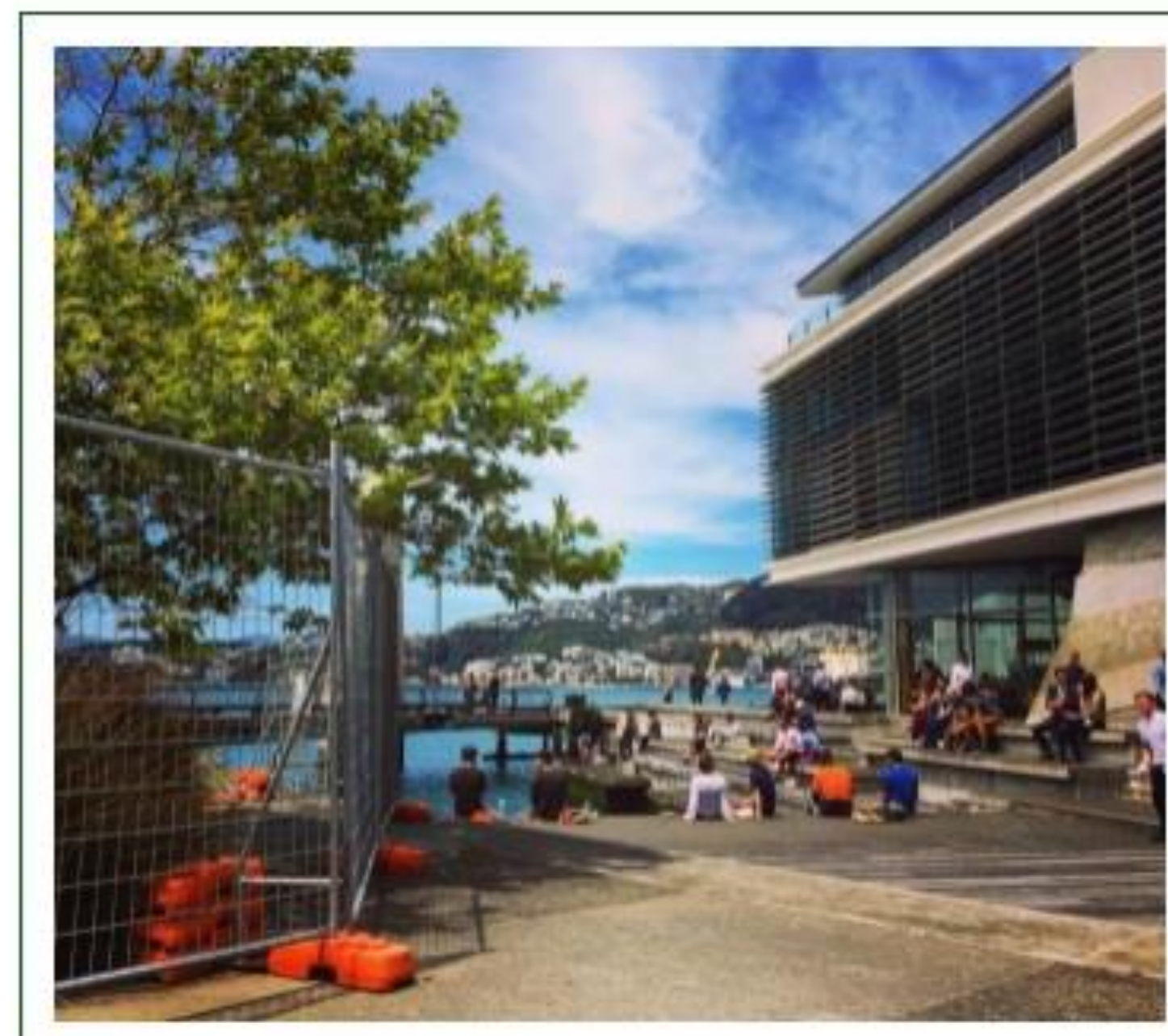

Based on this photo how positive is your impression of the Greater Wellington Region as a travel destination?

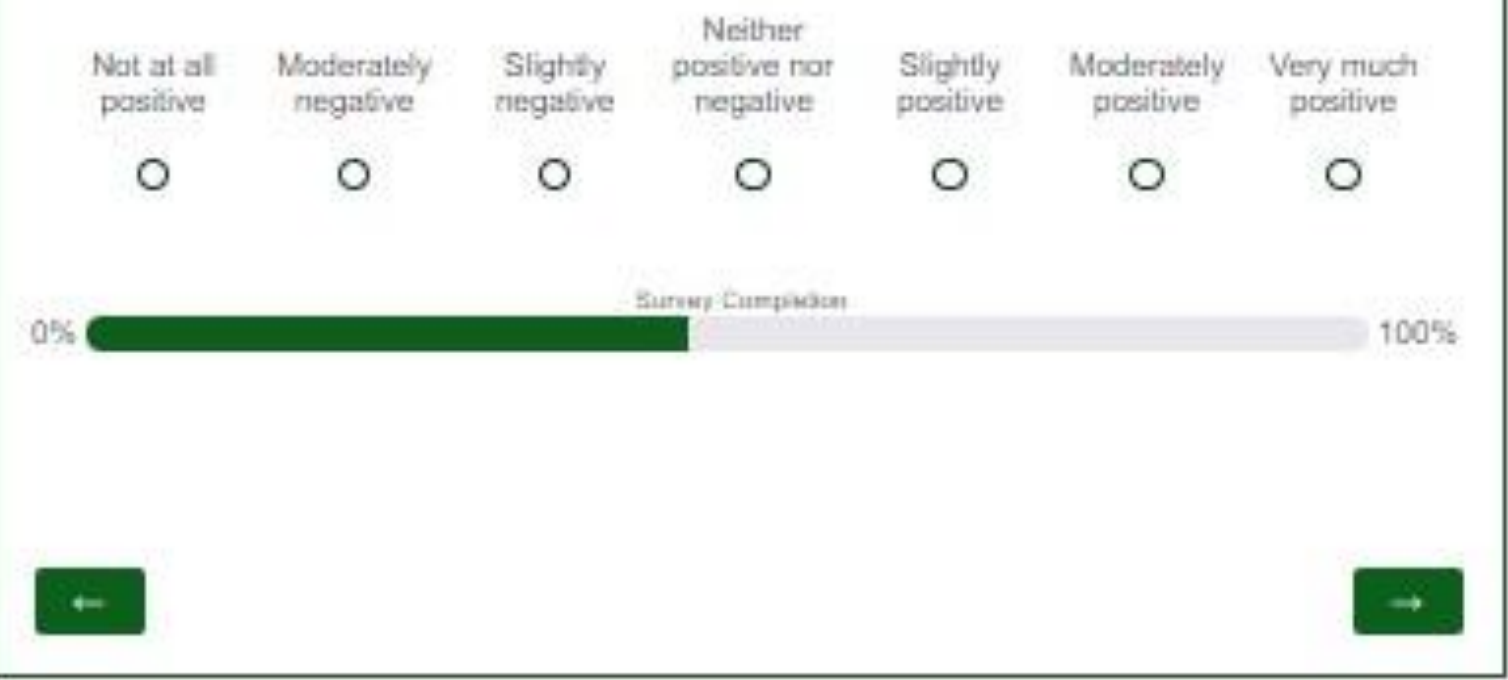




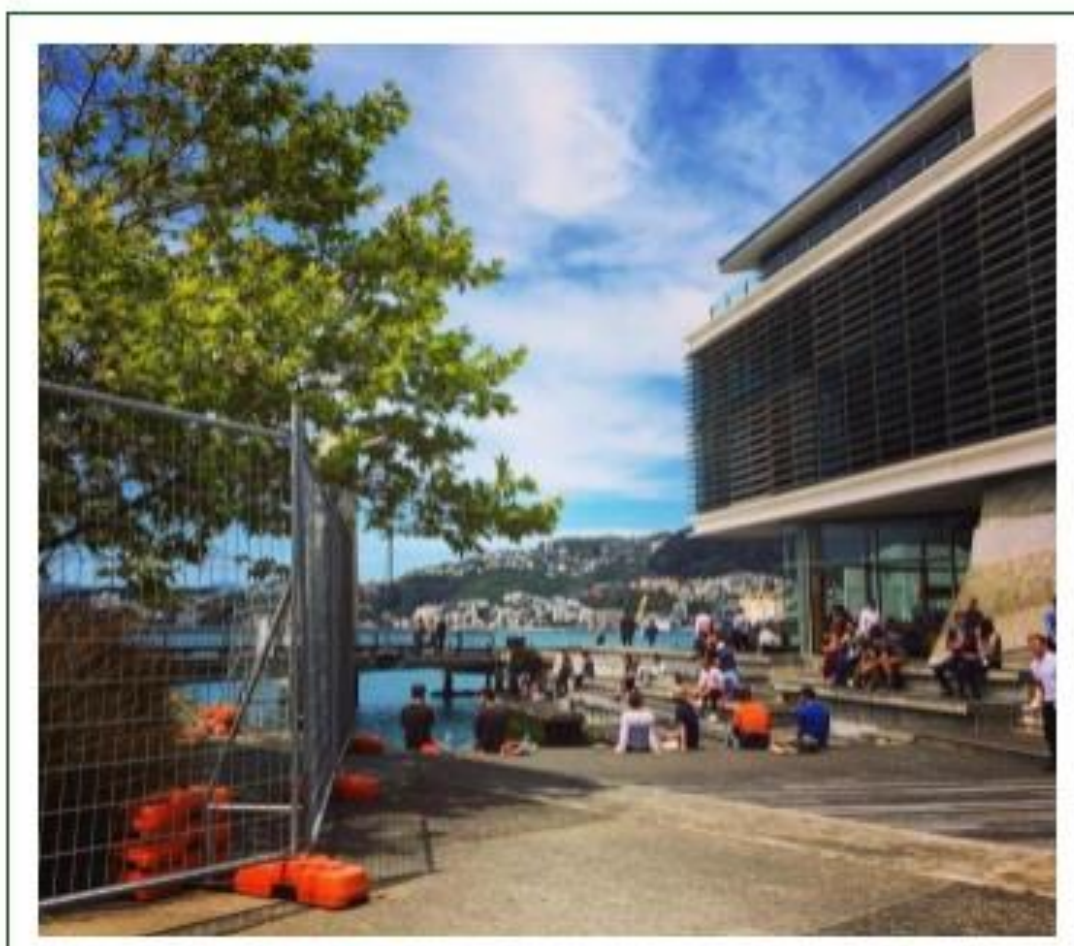

Based on this photo, please provide your opinion on the following questions

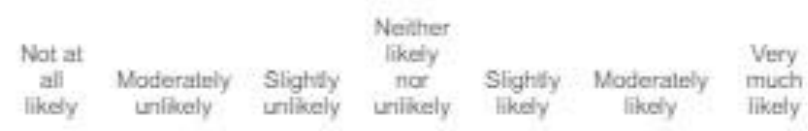

How likely are you to seek irflormation about the Grester

Weilinglen Region?

How Ikely are you

to visit tele Greater Weilington Region in the future?

$\begin{array}{lllllll}0 & 0 & 0 & 0 & 0 & 0 & 0\end{array}$

How ikely are you

to sesk out this

placeiexperience

should you visit the

Greater Wolington

Region in the

future?

Haw ikely are you

to travel to the

Greater Welingter

Region to spend

time with your

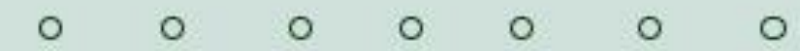

friend rejutive in the

futare?

Haw Skely are you

to stay in a private

accrommodation

(e.q. hatel) if you

were to visit the

Greaber Welington

in the future?

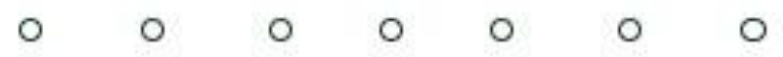

$\bigcirc$

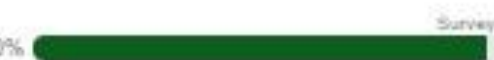




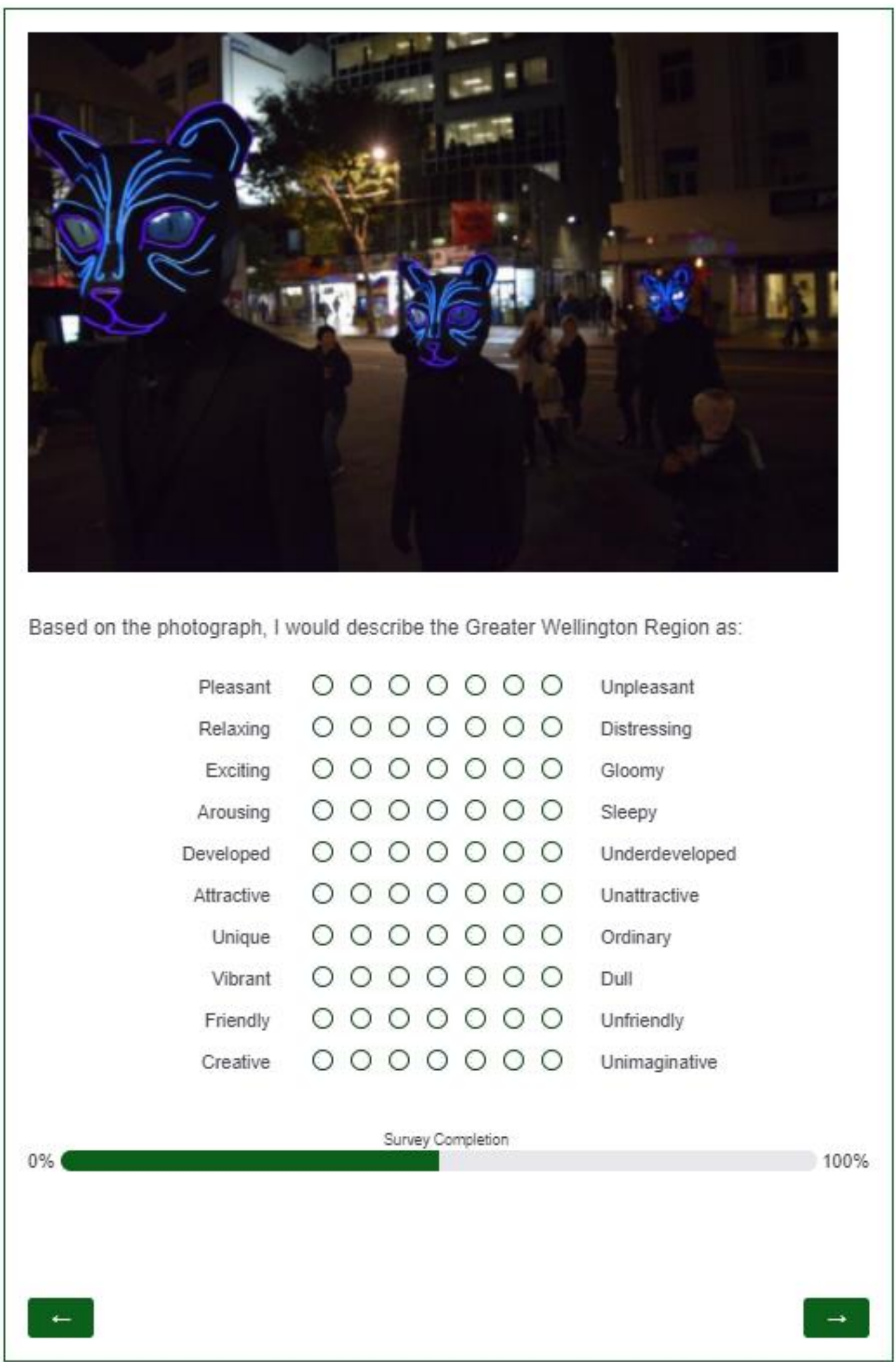




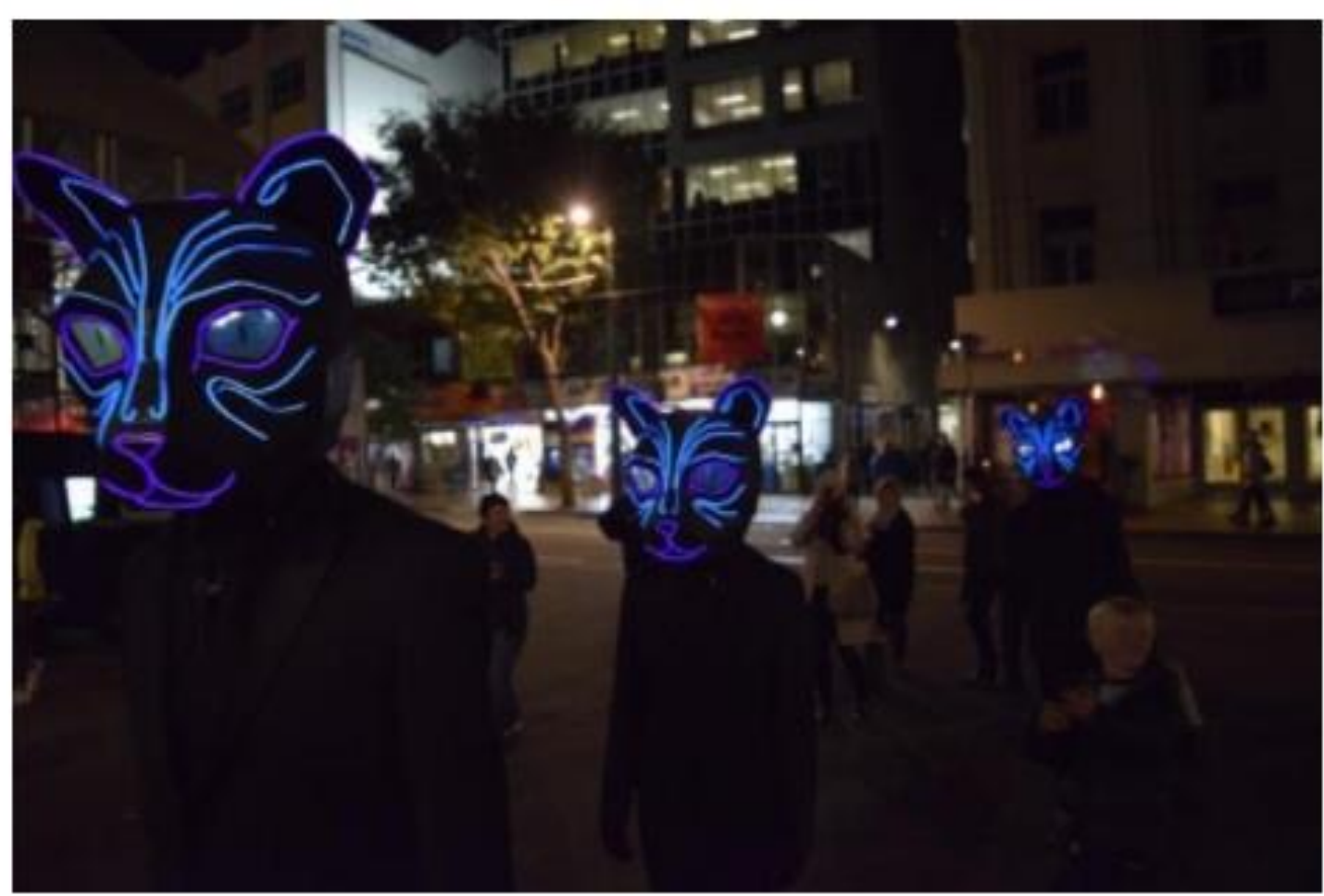

Based on this photo how positive is your impression of the Greater Wellington Region as a travel destination?

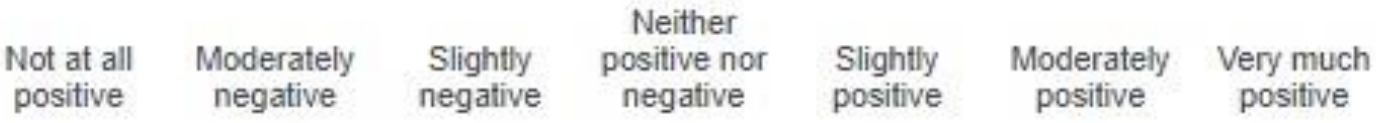
○
O
$\bigcirc$
○
$\bigcirc$
$\bigcirc$
$\bigcirc$ 


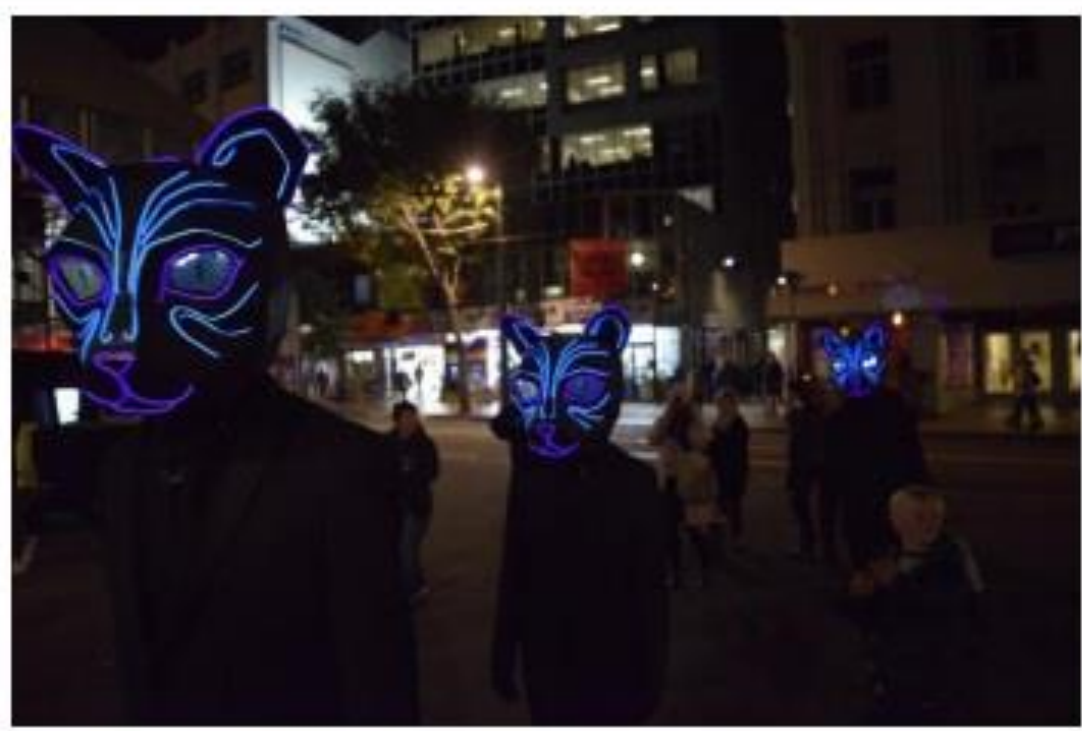

Based on this photo, please provide your opinion on the following questions.

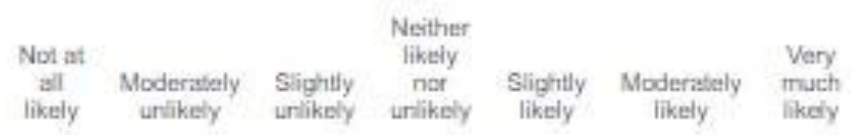

How likely are you

to seak infarm

Welitingtan Region?

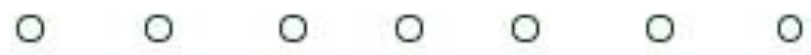

How likely are you to visit the Greater Wellingtan Region

in the future?
O
O
O
0
O 0
0

How liknly are you

to seck out this

platulexperienct

shauld you visit the

Greater Wellingiton

$\begin{array}{lllllll}0 & 0 & 0 & 0 & 0 & 0 & 0\end{array}$

Regian in the

fulure?

How likely are you

to travel in the

Greater Weilingion

Region to spend

time with yout

$\begin{array}{llllll}0 & 0 & 0 & 0 & 0\end{array}$

$0 \quad 0$

friend/relative in the

future?

How fikely are you

to stay in a private

accainting

(e.g. hobel) if you

were to visit the

Grester Wellington

in the future?

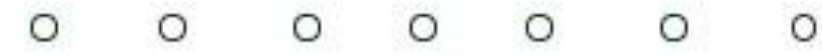




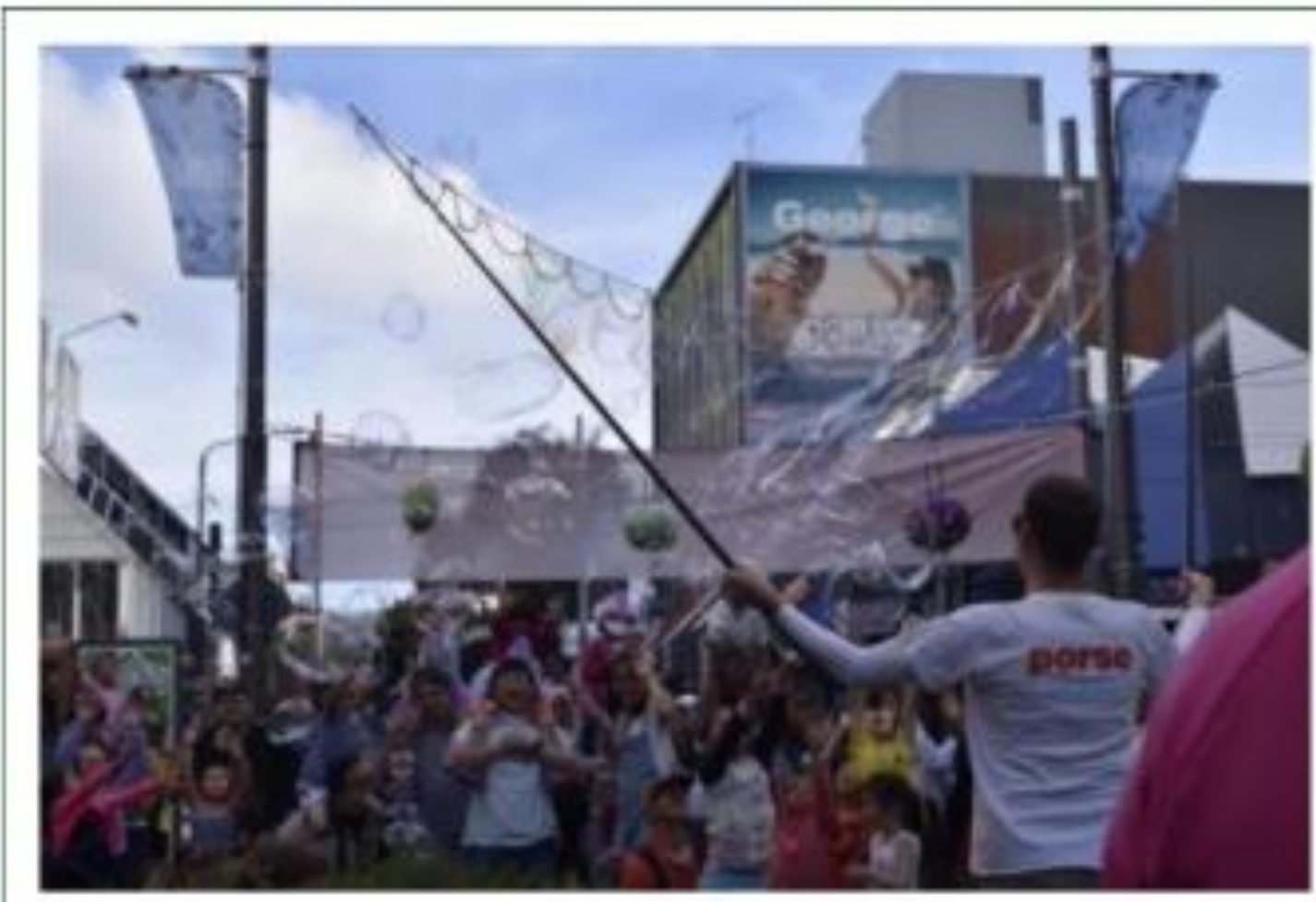

Based on the photograph, I would describe the Greater Welington Region as

\begin{tabular}{|c|c|c|}
\hline Pleasant & 0000000 & Unpleasant \\
\hline Relading & 0000000 & Distressing \\
\hline Exctling & 0000000 & Glocmy \\
\hline Arocusing & 0000000 & Seepy \\
\hline Developed & 0000000 & Underdeveloped \\
\hline Attractive & 0000000 & Unattractive \\
\hline Unique & 0000000 & Ondinary \\
\hline vbrant & 0000000 & Duil \\
\hline Friendly & 0000000 & Unfivendy \\
\hline Creative & 0000000 & Unimaginative \\
\hline
\end{tabular}




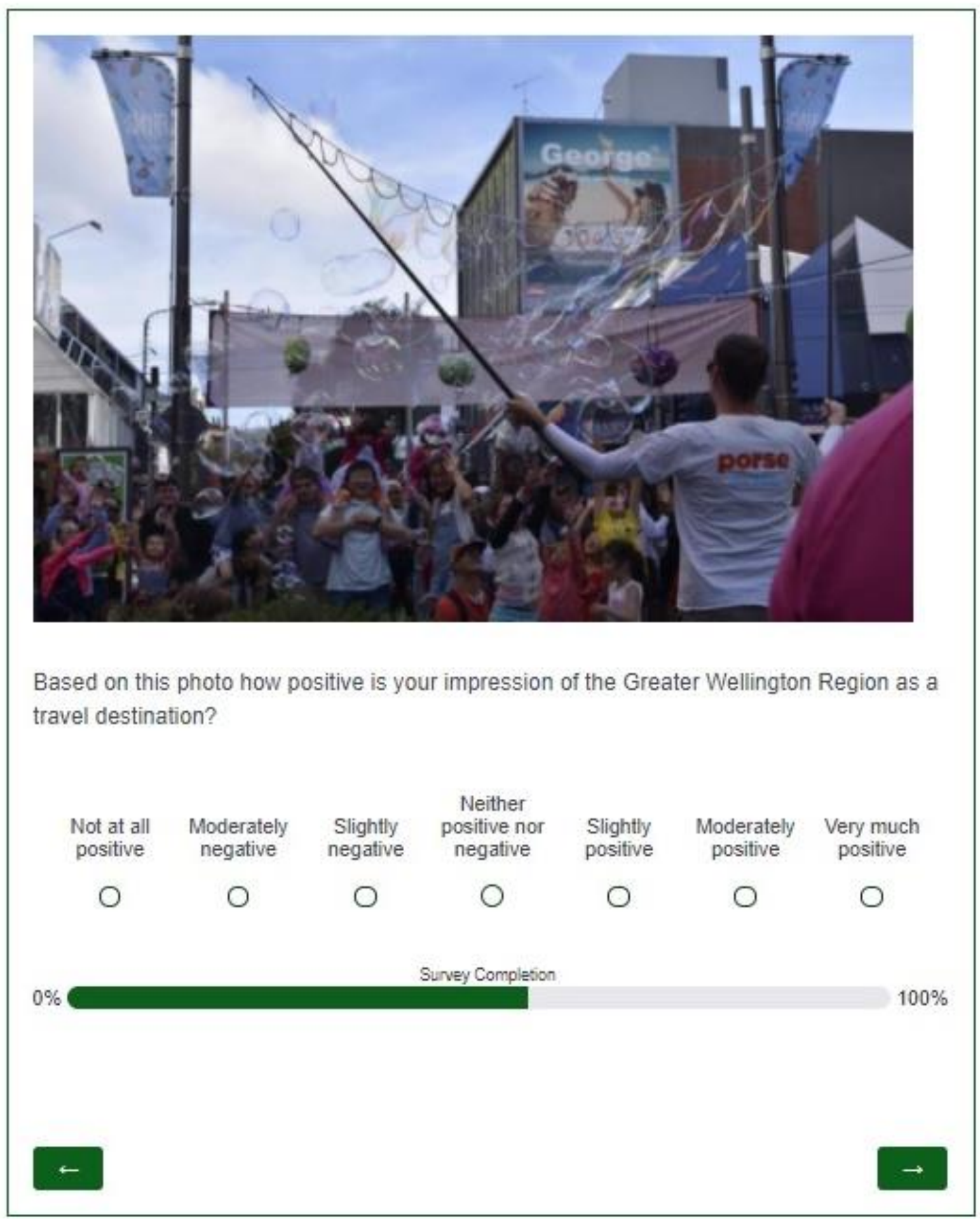




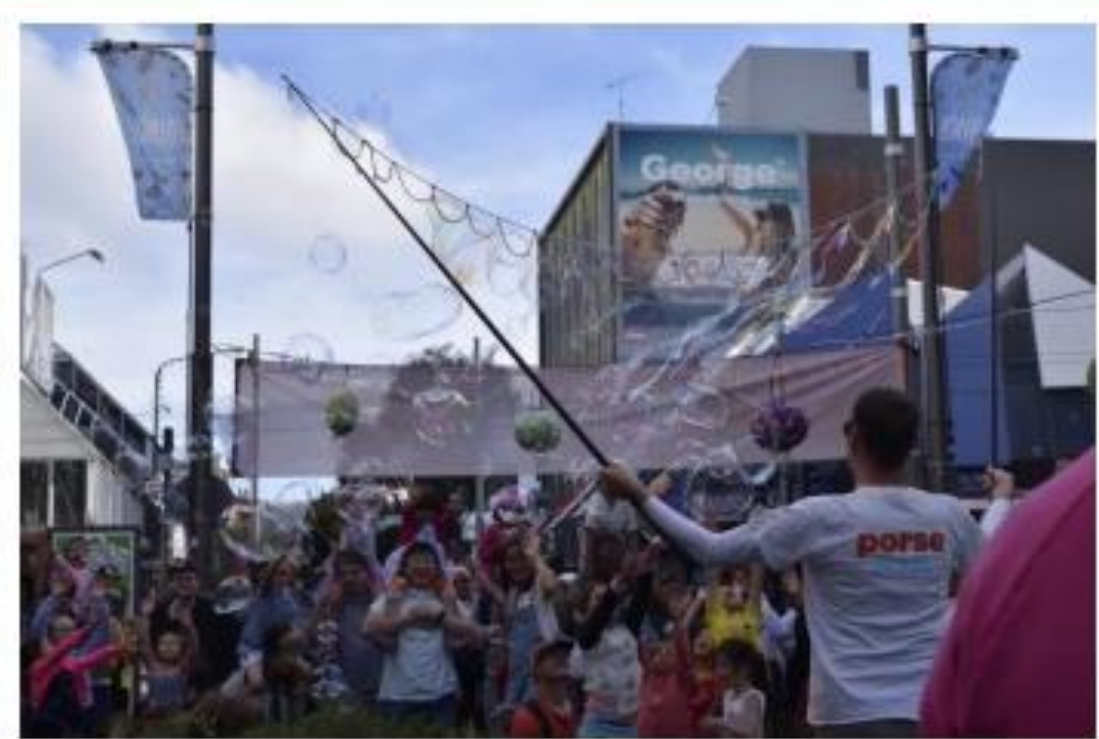

Based on this photo, please provide your opinion on the following questions.

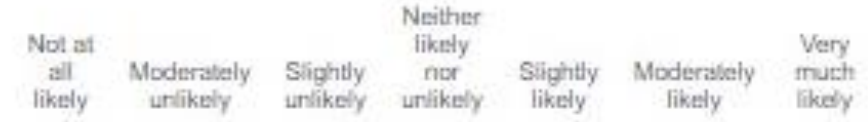

How likely are you

to seek information

about the Greater

Welingtan Region?

How likely are you

to visit the Greater

Welington Region

in the fulure?

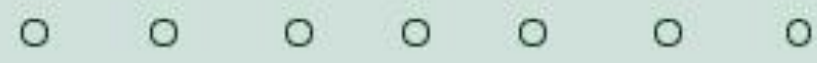

How likely are you

to seek out this

placelexperience

shauld you visit the

Grester Wellinglon

Regian in the

future?

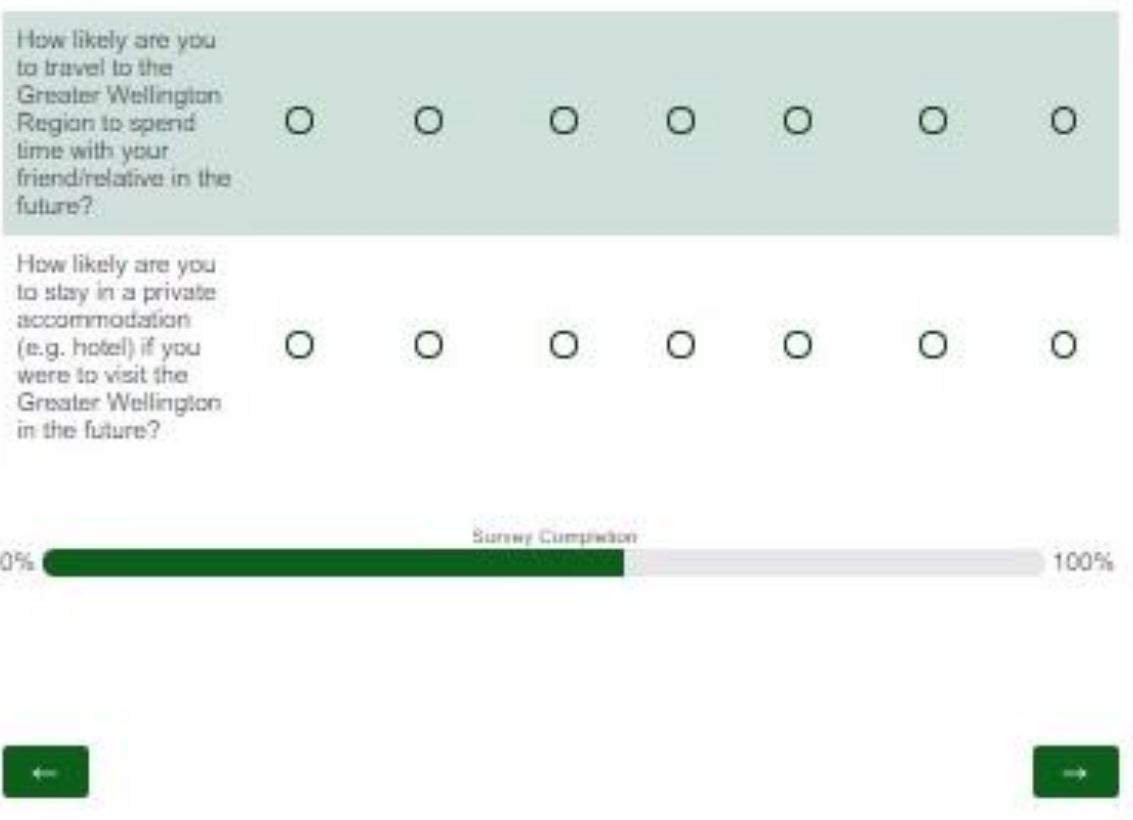




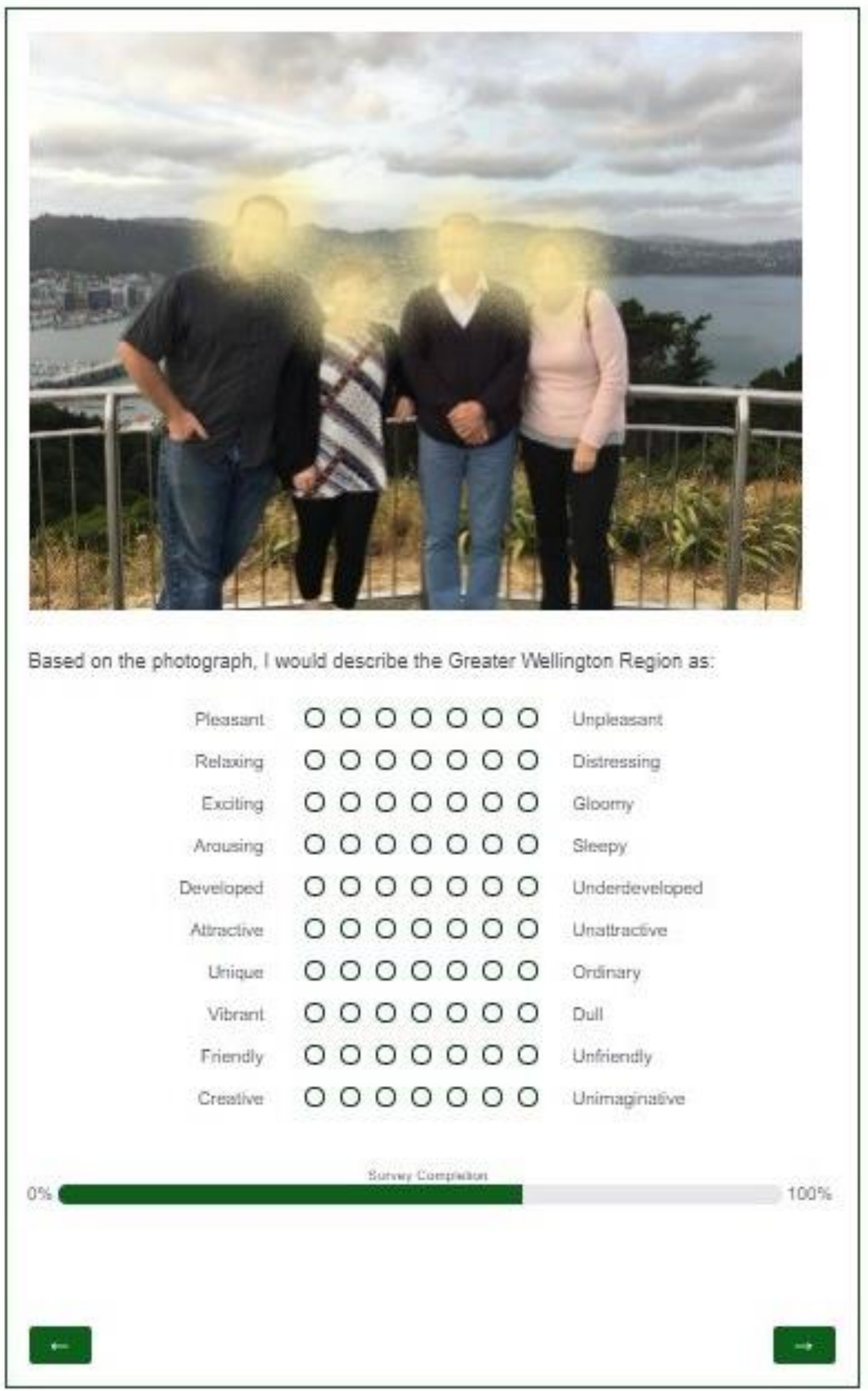




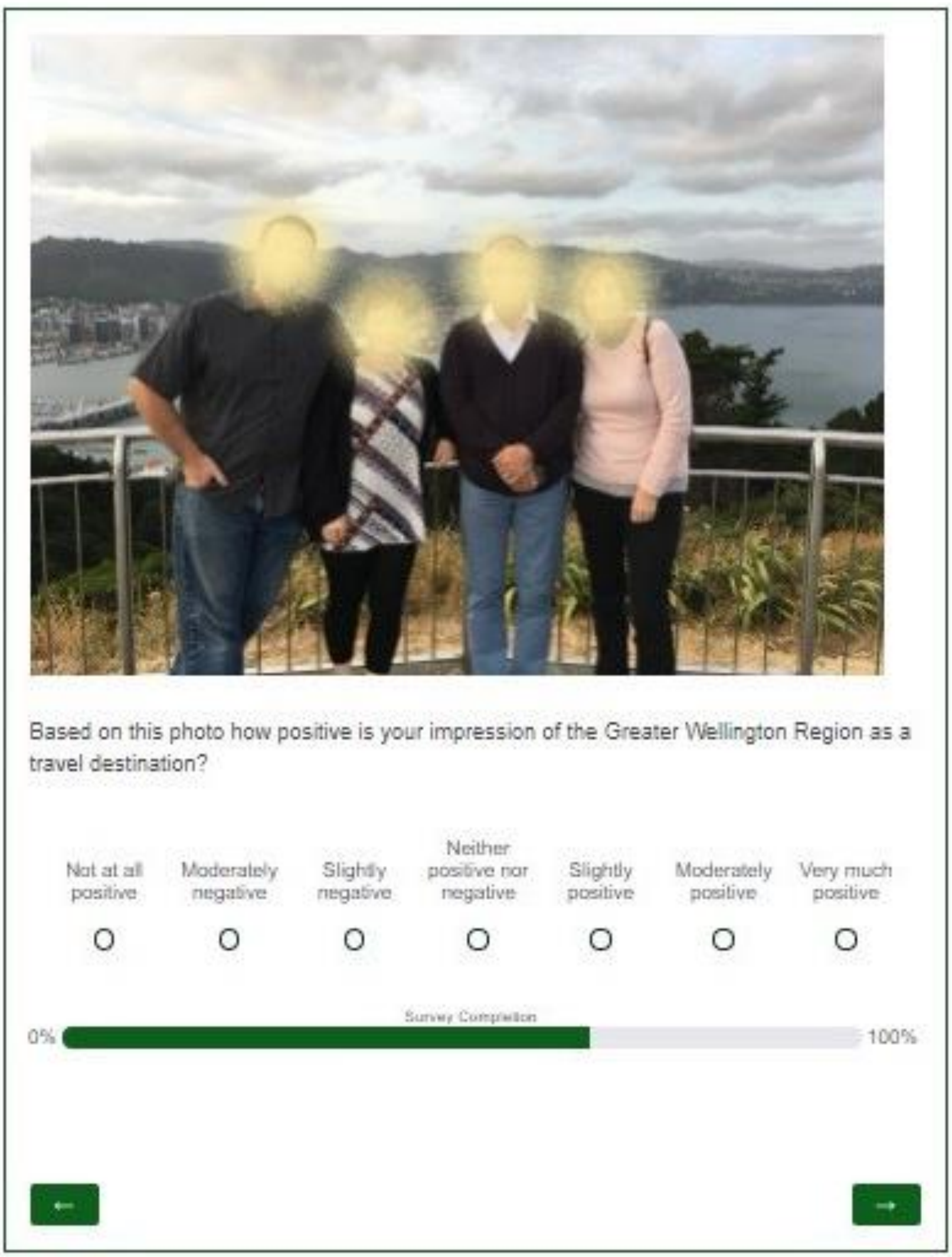




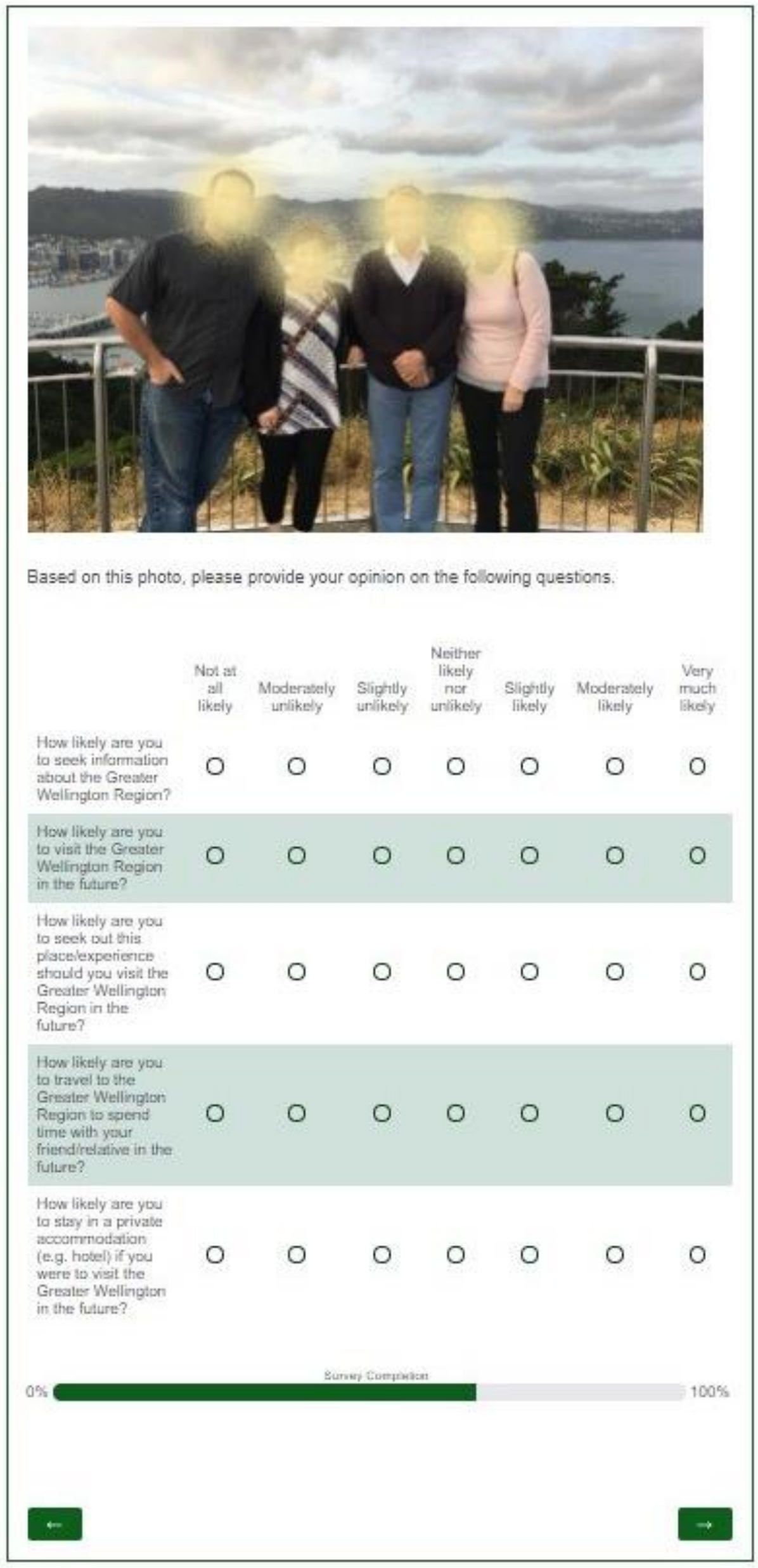




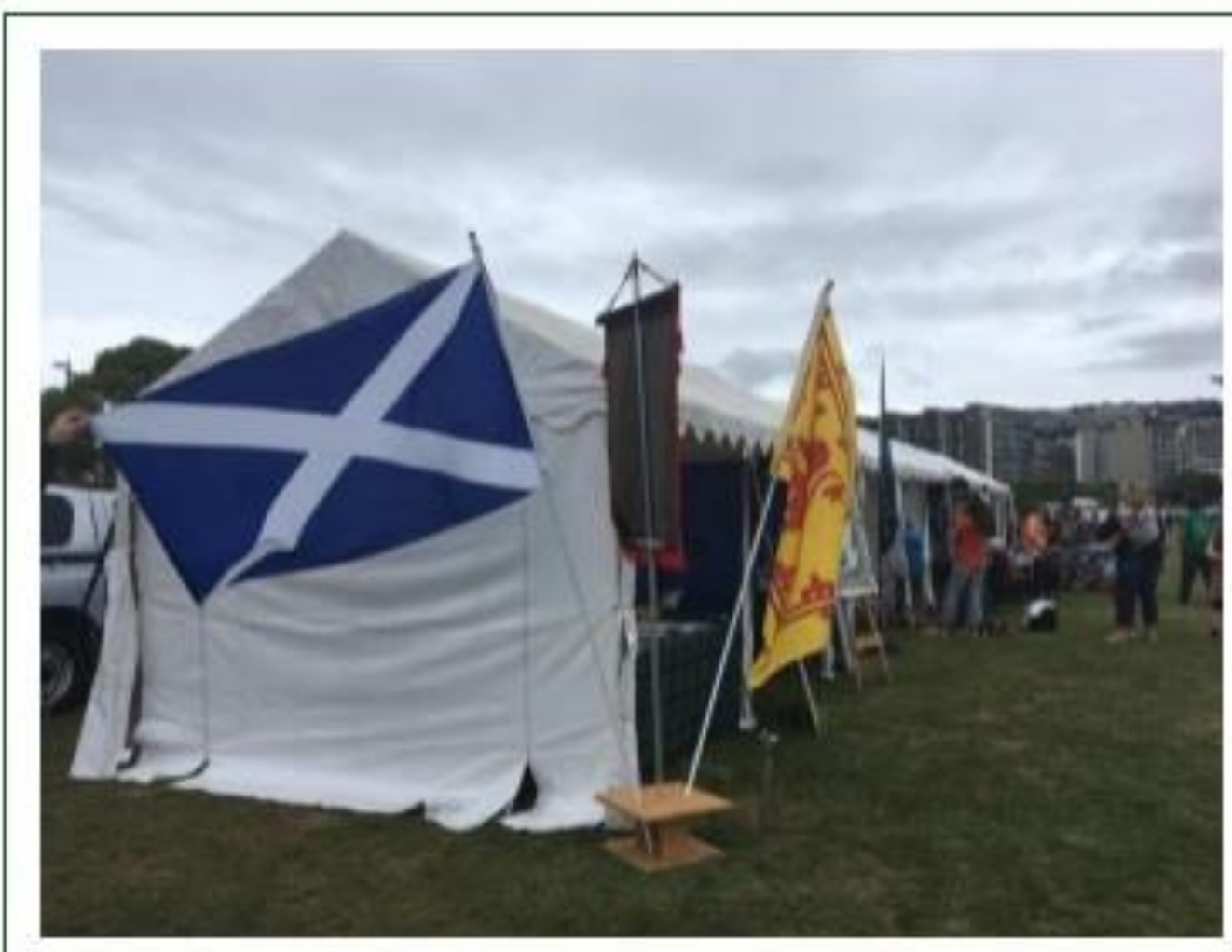

Based on the photograph, I would describe the Greater Wellington Region as:

\begin{tabular}{|c|c|c|}
\hline Plessant & 0000000 & Unpieteant \\
\hline Relasing & 0000000 & Distressing \\
\hline Exciting & 0000000 & Gloarny \\
\hline Arousing & 0000000 & Sleapy \\
\hline Developed & 0000000 & Underdeveloped \\
\hline Altrsetive & 0000000 & Unattractive \\
\hline Unique & 0000000 & Orisinary \\
\hline Vitrant & 0000000 & Dull \\
\hline Frissudly & 0000000 & Unfrierndly \\
\hline Crisative & 0000000 & Unimagrabeve \\
\hline
\end{tabular}




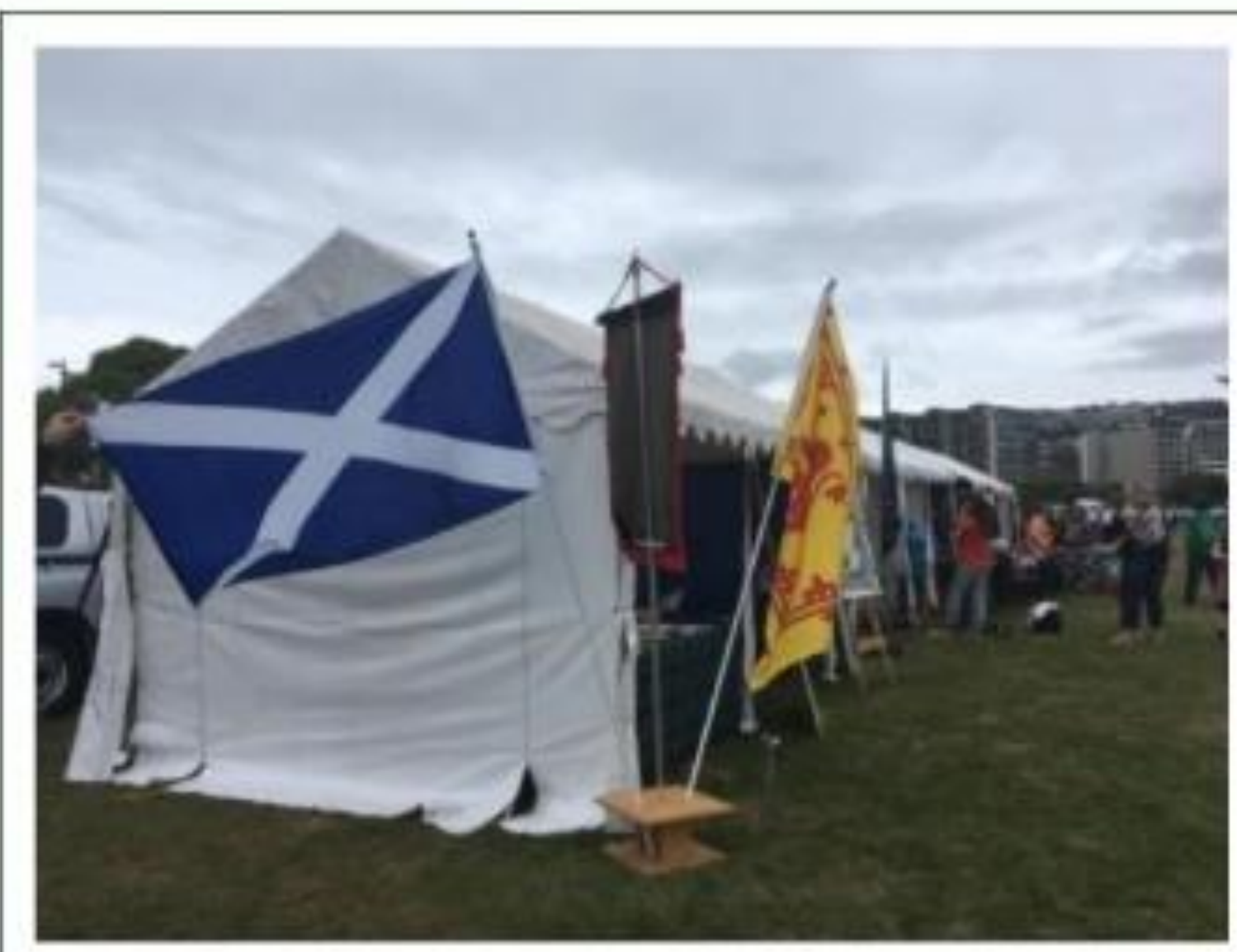

Based on this photo how positive is your impression of the Greater Wellington Regian as a travel destination?

\begin{tabular}{|c|c|c|c|c|c|c|}
\hline $\begin{array}{l}\text { Nat at ail } \\
\text { posithe }\end{array}$ & $\begin{array}{c}\text { Moderately } \\
\text { negative }\end{array}$ & $\begin{array}{l}\text { Slinghty } \\
\text { negative }\end{array}$ & $\begin{array}{l}\text { Nether } \\
\text { posithe nor } \\
\text { Eegdtve }\end{array}$ & $\begin{array}{l}\text { Slightly } \\
\text { postive }\end{array}$ & $\begin{array}{c}\text { Moderately } \\
\text { posinge }\end{array}$ & $\begin{array}{l}\text { Very much } \\
\text { postive }\end{array}$ \\
\hline 0 & 0 & 0 & 0 & 0 & 0 & 0 \\
\hline
\end{tabular}




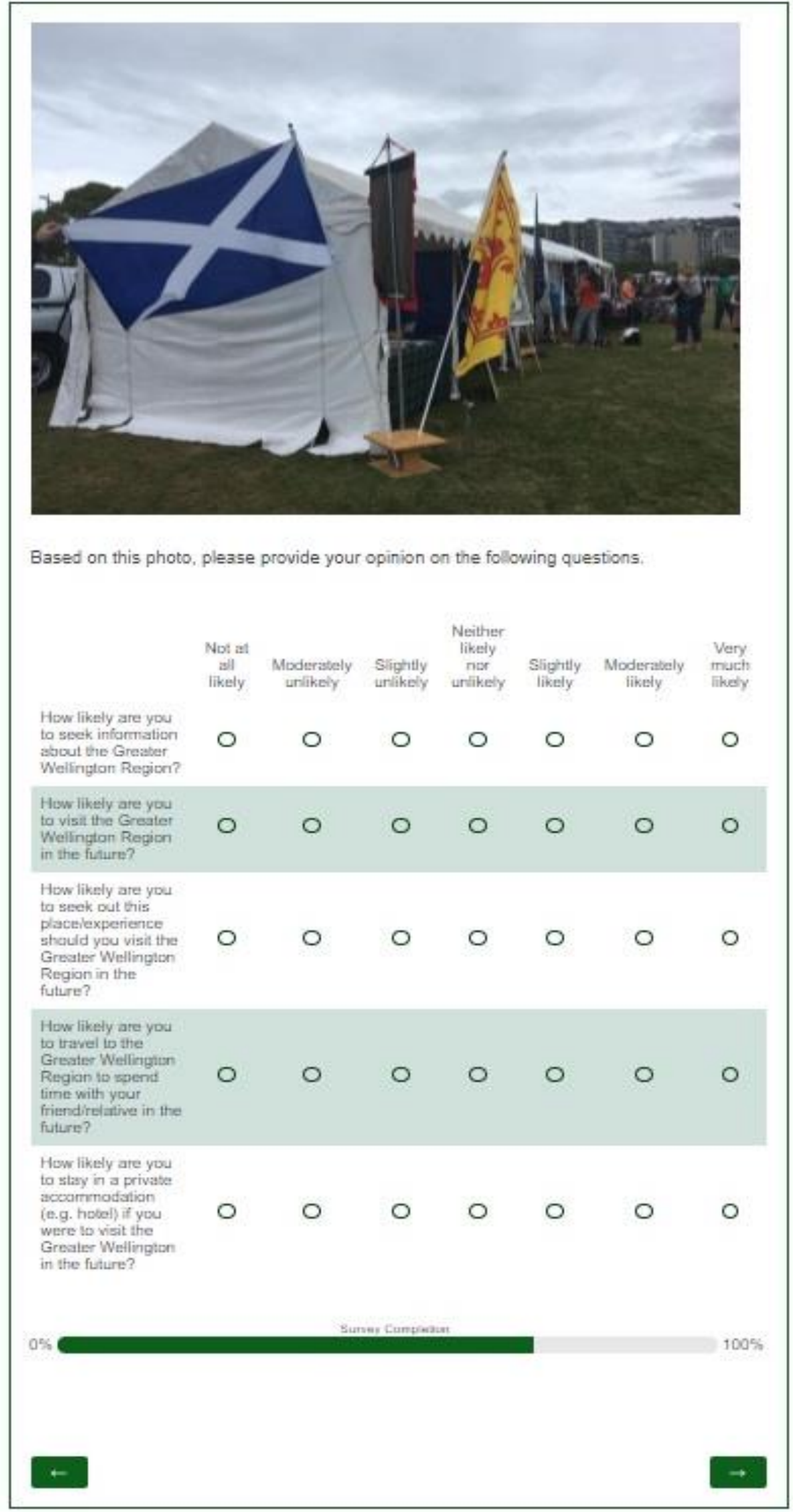


The following questions are about your relationship between you and your friend/relative based in the Greater Wellington Region. Please read the statements carefully and select the response most appropriate to you.

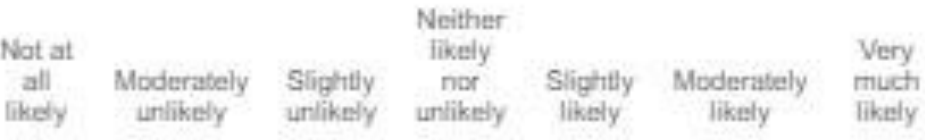

How likely would you be ta share:

persanal

cocrfidences with

$\mathrm{O}$

$0 \quad 0$

O

$\mathrm{O}$

$\mathrm{O}$

himiher?

How likely wouls

you be to perform

a LARGE favdue

$0 \quad 0 \quad 0 \quad 0$

O

$\mathrm{O}$

for himher?

How likely are you

to spend a free

aflernocn with

$\begin{array}{lllllll}0 & 0 & 0 & 0 & 0 & 0 & 0\end{array}$

himiher?

Please rate your closeness to him/her

Not at all close $\quad 0000000$ Very close

What is your relationship with him/her?

O Friend

O Relative iplease specify i.e brother, causin, aunt:

What platforms do you use to communicate with himher? (You can choose more than one option)

$\square$ Persond amai

$\square$ Social mediaimicro blogging sites (e.g Snapchat, Fackbook, Instagram, Twitber)

$\square$ instart messenger (e.g Whatsapp, Viber, Facebook messenger;

$\square$ Other (plesse specify):

05 


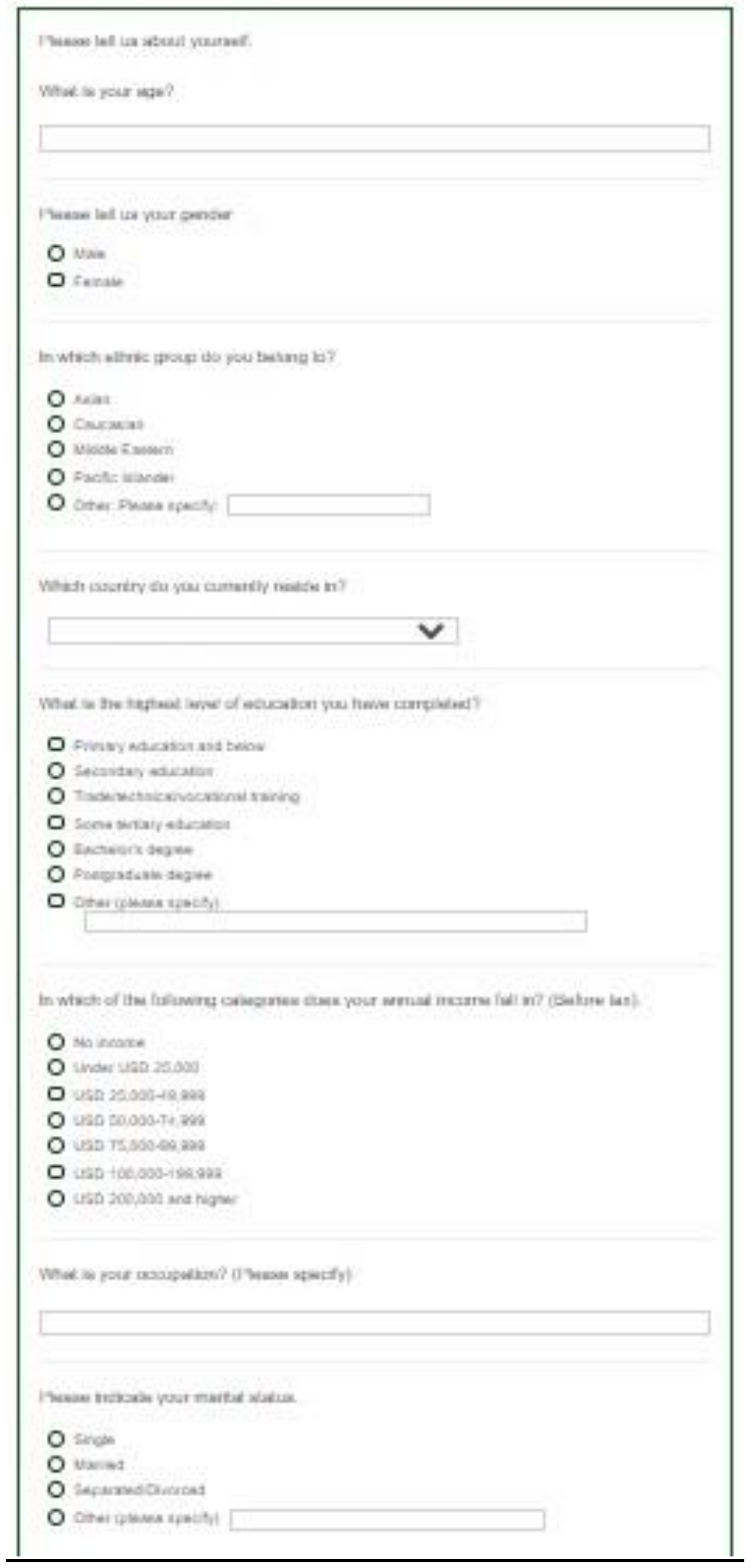


We thank you for your time spent taking this survey.

Your response has been recorded. 


\section{Appendix J: Cover letter (friends \& relatives)}

VICTORIA UNIVERSITY OF WELLINGTON

Te Whare Wānanga o te Ūpoko o te Ika a Māui

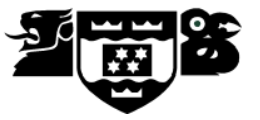

\section{Invitation to participate/information sheet for overseas friend or relative More than Words: Decoding the Influence of User-Generated Images on VFR (Visiting Friends \& Relatives) Tourism}

\section{(VUW Ethics ID 0000026008)}

$\mathrm{Hi}$,

My name is Marlini Bakri and I am a Doctor of Philosophy $(\mathrm{PhD})$ candidate in Marketing at Victoria University of Wellington (VUW). Your friend/relative (sojourner name here) has expressed interest to participate in my study, titled "More than words: Decoding the influence of user-generated images on VFR (visiting friends \& relatives) tourism". She has provided your contact to complete the second half of the study. The study would involve you completing a simple survey, where you would be required to rate images shared by (sojourner name here). The objective of this research is to understand if photographs shared online can communicate information about a destination to overseas friends and relatives.

You can access the survey on desktop computers and mobile devices (e.g. tablets and mobile phones). The survey should not take more than 30 minutes, and can be terminated at any time. The survey platform saves your answers automatically, allowing you to return to the form, using the same device, at different times of the day. All information you provide is completely confidential, and only the research team will have access to the information. The data will be destroyed three years after the completion of the thesis (estimated June 2021).

Click here to start the survey: Qualtrics link here

Your help with this $\mathrm{PhD}$ research is greatly appreciated.

Should you require further information about the study, please contact:

\begin{tabular}{|l|l|l|}
\hline PhD Candidate: & Supervisor: & Supervisor: \\
Marlini Bakri & Dr Jayne Krisjanous & Dr James E. Richard \\
PhD Candidate & Senior Lecturer & Senior Lecturer \\
School of Marketing and & School of Marketing and & School of Marketing and \\
International Business & International Business & International Business \\
Victoria University of & Victoria University of & Victoria University of \\
Wellington & Wellington & Wellington \\
PO Box 600 Wellington & PO Box 600 Wellington & PO Box 600 Wellington \\
6140 New Zealand & 6140 New Zealand & 6140 New Zealand \\
marlini.bakri@ vuw.ac.nz & +6444636023 & +644 463 5415 \\
& jayne.krisjanous@ vuw.ac.nz & james.richard@ vuw.ac.nz \\
\hline
\end{tabular}

Human Ethics Committee information: If you have any concerns about the ethical conduct of the research you may contact the Victoria University HEC Central Convenor: Dr Judith Loveridge. Email hec@vuw.ac.nz or telephone +64-4-4639451 
Appendix K: Sojourner participant profile

\begin{tabular}{|c|c|c|c|c|c|c|c|c|c|c|}
\hline ID & Pseudonym & Age & Occupation & Highest education level & Income & $\begin{array}{l}\text { Marital } \\
\text { status }\end{array}$ & Nationality & Visa type & Gender & $\begin{array}{l}\text { Time in } \\
\text { Wellington }\end{array}$ \\
\hline 1 & Joe & $25-29$ & Project coordinator & Master's degree & $\begin{array}{l}\text { NZ\$50,001- } \\
\text { NZ\$60,000 }\end{array}$ & Single & India & $\begin{array}{l}\text { Permanent } \\
\text { resident }\end{array}$ & Male & $1-2$ years \\
\hline 2 & Ben & $35-39$ & $\mathrm{PhD}$ candidate & Master's degree & $\begin{array}{l}\text { NZ\$5,001- } \\
\mathrm{NZ} \$ 10,000\end{array}$ & Single & China & $\begin{array}{l}\text { Permanent } \\
\text { resident }\end{array}$ & Male & $1-2$ years \\
\hline 3 & Jane & $20-24$ & Student & Bachelor's degree & $\begin{array}{l}\text { NZ\$15,001- } \\
\text { NZ\$20,000 }\end{array}$ & Single & Hungary & Student & Female & $3-5$ years \\
\hline 4 & Felicia & $20-24$ & Recent graduate & Bachelor's degree & $\begin{array}{l}\text { NZ\$1- } \\
\text { NZ\$5,000 }\end{array}$ & Single & Indonesia & Work & Female & $3-5$ years \\
\hline 5 & George & $35-39$ & $\mathrm{PhD}$ candidate & Master's degree & $\begin{array}{l}\text { NZ\$5,001- } \\
\text { NZ\$10,000 }\end{array}$ & Married & Singapore & Student & Male & $\begin{array}{l}\text { Up to } 6 \\
\text { months }\end{array}$ \\
\hline 6 & Helen & $30-34$ & PhD candidate & Master's degree & Zero income & Single & India & Student & Female & $3-5$ years \\
\hline 7 & Hela & $25-29$ & $\begin{array}{l}\text { Research collaborations } \\
\text { executive }\end{array}$ & Bachelor's degree & $\begin{array}{l}\text { NZ\$60,001- } \\
\text { NZ\$70,000 }\end{array}$ & Single & Singapore & $\begin{array}{l}\text { Permanent } \\
\text { resident }\end{array}$ & Female & $\begin{array}{l}\text { More than } 5 \\
\text { years }\end{array}$ \\
\hline 8 & Janice & $30-34$ & Policy advisor & Master's degree & $\begin{array}{l}\text { NZ\$70,001- } \\
\text { NZ\$100,000 }\end{array}$ & $\begin{array}{l}\text { Other } \\
\text { (Partner) }\end{array}$ & UK & $\begin{array}{l}\text { Skilled } \\
\text { migrant }\end{array}$ & Female & $1-2$ years \\
\hline 9 & Cathy & $20-24$ & Student & Bachelor's degree & Zero income & Single & Philippines & Student & Female & $1-2$ years \\
\hline 10 & Leo & $30-34$ & Student & Bachelor's degree & $\begin{array}{l}\text { NZ\$20,001- } \\
\text { NZ\$25,000 }\end{array}$ & Single & Vietnam & Student & Male & $\begin{array}{l}\text { Up to } 6 \\
\text { months }\end{array}$ \\
\hline 11 & Mary & $30-34$ & Post-doctoral researcher & Doctorate & $\begin{array}{l}\text { NZ\$70,001- } \\
\text { NZ\$100,000 }\end{array}$ & $\begin{array}{l}\text { Other } \\
\text { (Partner) }\end{array}$ & Germany & Work & Female & $3-5$ years \\
\hline 12 & Matt & $30-34$ & Programmer & Bachelor's degree & $\begin{array}{l}\text { NZ\$70,001- } \\
\text { NZ\$100,000 }\end{array}$ & Single & Chile & Work & Male & $1-2$ years \\
\hline 13 & Maria & $25-29$ & Student & Master's degree & $\begin{array}{l}\text { NZ\$20,001- } \\
\text { NZ\$25,000 }\end{array}$ & Single & Thailand & Student & Female & $1-2$ years \\
\hline 14 & Mike & $40-44$ & $\mathrm{PhD}$ candidate & Master's degree & $\begin{array}{l}\text { NZ\$70,001- } \\
\text { NZ\$100,000 }\end{array}$ & Married & Serbia & Student & Male & $\begin{array}{l}\text { Up to } 6 \\
\text { months }\end{array}$ \\
\hline 15 & Paul & $25-29$ & PhD candidate & Postgraduate diploma & $\begin{array}{l}\text { NZ\$25,001- } \\
\text { NZ\$30,000 }\end{array}$ & Single & Sri Lanka & Student & Male & 6-12 months \\
\hline 16 & Sophia & $25-29$ & PhD candidate & Master's degree & $\begin{array}{l}\text { NZ\$20,001- } \\
\text { NZ\$25,000 }\end{array}$ & Single & Canada & Student & Female & $\begin{array}{l}\text { Up to } 6 \\
\text { months }\end{array}$ \\
\hline
\end{tabular}




\begin{tabular}{|c|c|c|c|c|c|c|c|c|c|c|}
\hline ID & Pseudonym & Age & Occupation & Highest education level & Income & $\begin{array}{l}\text { Marital } \\
\text { status }\end{array}$ & Nationality & Visa type & Gender & $\begin{array}{l}\text { Time in } \\
\text { Wellington }\end{array}$ \\
\hline 17 & Sarah & $30-34$ & PhD candidate & Master's degree & $\begin{array}{l}\text { NZ\$20,001- } \\
\text { NZ\$25,000 }\end{array}$ & Married & Bangladesh & Student & Female & $1-2$ years \\
\hline 18 & Sam & $30-34$ & Assistant accountant & Master's degree & Zero income & Married & India & $\begin{array}{l}\text { Permanent } \\
\text { resident }\end{array}$ & Female & $3-5$ years \\
\hline 19 & Sonia & $30-34$ & PhD candidate & Master's degree & Zero income & Single & China & Student & Female & $3-5$ years \\
\hline 20 & Stella & $20-24$ & Student & Postgraduate diploma & Zero income & Single & Cambodia & Student & Female & $\begin{array}{l}\text { More than } 5 \\
\text { years }\end{array}$ \\
\hline 21 & Tiffany & $25-29$ & PhD candidate & Master's degree & $\begin{array}{l}\text { NZ\$25,001- } \\
\mathrm{NZ} \$ 30,000\end{array}$ & Married & Nigeria & Student & Female & $1-2$ years \\
\hline 22 & Tara & $30-34$ & $\mathrm{PhD}$ candidate & Master's degree & $\begin{array}{l}\text { NZ\$20,001- } \\
\text { NZ\$25,000 }\end{array}$ & Married & Vietnam & Student & Female & $1-2$ years \\
\hline 23 & Sharon & $30-34$ & $\mathrm{PhD}$ candidate & Master's degree & $\begin{array}{l}\text { NZ\$20,001- } \\
\text { NZ\$25,000 }\end{array}$ & Married & Vietnam & Student & Female & $1-2$ years \\
\hline 24 & Wendy & $30-34$ & Student & Bachelor's degree & Zero income & Married & China & Student & Female & $\begin{array}{l}\text { Up to } 6 \\
\text { months }\end{array}$ \\
\hline 25 & Ken & $25-29$ & Student & Bachelor's degree & Zero income & Single & China & Student & Male & $3-5$ years \\
\hline 26 & Hannah & $30-34$ & PhD candidate & Master's degree & $\begin{array}{l}\text { NZ\$20,001- } \\
\text { NZ\$25,000 }\end{array}$ & Single & Russia & Student & Female & 6-12 months \\
\hline 27 & Tina & $25-29$ & Freelance programmer & $\begin{array}{l}\text { Overseas, NCEA level } 3 \\
\text { equivalent }\end{array}$ & $\begin{array}{l}\text { NZ\$5,001- } \\
\text { NZ\$10,000 }\end{array}$ & $\begin{array}{l}\text { Other } \\
\text { (Partner) }\end{array}$ & USA & $\begin{array}{l}\text { Skilled } \\
\text { migrant }\end{array}$ & Female & $1-2$ years \\
\hline 28 & Mark & $35-39$ & PhD candidate & Master's degree & $\begin{array}{l}\text { NZ\$30,001- } \\
\text { NZ\$35,000 }\end{array}$ & Married & Pakistan & Student & Male & $3-5$ years \\
\hline 29 & Simon & $25-29$ & PhD candidate & Master's degree & $\begin{array}{l}\text { NZ\$60,001- } \\
\text { NZ\$70,000 }\end{array}$ & Single & Ghana & Student & Male & $3-5$ years \\
\hline 30 & Zoe & $30-34$ & Student & Master's degree & Zero income & Married & China & Diplomatic & Female & $1-2$ years \\
\hline 31 & Dave & $30-34$ & $\mathrm{PhD}$ candidate & Master's degree & $\begin{array}{l}\text { NZ\$35,001- } \\
\text { NZ\$40,000 }\end{array}$ & Single & Zimbabwe & Student & Male & $1-2$ years \\
\hline 32 & Mia & $25-29$ & Market research analyst & Bachelor's degree & $\begin{array}{l}\text { NZ\$40,001- } \\
\text { NZ\$50,000 }\end{array}$ & Single & Philippines & $\begin{array}{l}\text { Skilled } \\
\text { migrant }\end{array}$ & Female & 6-12 months \\
\hline 33 & Julia & $25-29$ & Administrator & Postgraduate diploma & Zero income & Single & Ireland & $\begin{array}{l}\text { Working } \\
\text { holiday }\end{array}$ & Female & $\begin{array}{l}\text { Up to } 6 \\
\text { months }\end{array}$ \\
\hline
\end{tabular}


Appendix L: Overall Fleiss kappa results

\begin{tabular}{ccccc}
\hline & Kappa & Std. Error & $z$ & $p$-value \\
\hline Overall & 0.770 & 0.011 & 69.016 & $<.001$ \\
\hline
\end{tabular}

Appendix M: Harman's single-factor test results

\begin{tabular}{|c|c|c|c|}
\hline Factor & Total & \%Variance & Cumulative \% \\
\hline AFF_1 & 9.441 & 47.205 & 47.205 \\
\hline AFF_2 & 3.164 & 15.820 & 63.026 \\
\hline AFF_3 & 1.932 & 9.660 & 72.685 \\
\hline AFF_4 & 0.747 & 3.733 & 76.418 \\
\hline COG_1 & 0.607 & 3.036 & 79.454 \\
\hline COG_2 & 0.532 & 2.658 & 82.112 \\
\hline COG_3 & 0.517 & 2.584 & 84.696 \\
\hline $\mathrm{COG}_{-} 4$ & 0.411 & 2.054 & 86.750 \\
\hline COG_5 & 0.367 & 1.833 & 88.583 \\
\hline COG_6 & 0.340 & 1.698 & 90.280 \\
\hline IMP & 0.306 & 1.529 & 91.809 \\
\hline INT_1 & 0.286 & 1.431 & 93.240 \\
\hline INT_2 & 0.255 & 1.275 & 94.516 \\
\hline INT_3 & 0.226 & 1.132 & 95.648 \\
\hline INT_4 & 0.178 & 0.892 & 96.540 \\
\hline INT_5 & 0.176 & 0.878 & 97.418 \\
\hline TS_1 & 0.168 & 0.838 & 98.256 \\
\hline TS_2 & 0.141 & 0.703 & 98.959 \\
\hline TS_3 & 0.127 & 0.634 & 99.593 \\
\hline TS_4 & 0.081 & 0.407 & 100.000 \\
\hline
\end{tabular}


Appendix N: t-test results for non-response bias

Group Statistics: Tie strength

\begin{tabular}{cccccc}
\hline & Groups & $N$ & Mean & $\begin{array}{c}\text { Std. } \\
\text { Deviation }\end{array}$ & $\begin{array}{c}\text { Std. Error } \\
\text { Mean }\end{array}$ \\
\hline \multirow{2}{*}{ TS } & Early & 40 & 6.2563 & .72166 & .11410 \\
& Late & 33 & 5.8864 & 1.13380 & .19737 \\
\hline
\end{tabular}

t-test for Equality of Means

\begin{tabular}{|c|c|c|c|c|c|c|c|}
\hline & & $t$ & $d f$ & $\begin{array}{l}\text { Sig. } \\
\text { (2-tailed) }\end{array}$ & $\begin{array}{l}\text { Mean } \\
\text { Difference }\end{array}$ & $\begin{array}{l}\text { Std. Error } \\
\text { Difference }\end{array}$ & $\begin{array}{l}95 \% \mathrm{CI} \text { of the } \\
\text { Difference }\end{array}$ \\
\hline \multirow[t]{2}{*}{$\mathrm{TS}$} & $\begin{array}{l}\text { Equal variances } \\
\text { assumed }\end{array}$ & 1.691 & 71 & .095 & .36989 & .21877 & {$[-.06634 ; .80611]$} \\
\hline & $\begin{array}{l}\text { Equal variances } \\
\text { not assumed }\end{array}$ & 1.622 & 52.182 & .111 & .36989 & .22798 & {$[-.08755 ; .82732]$} \\
\hline
\end{tabular}


Group statistics: Events

\begin{tabular}{cccccc}
\hline Construct & Groups & $N$ & Mean & Std. Deviation & Std. Error Mean \\
\hline iWOM & Early & 131 & 5.4305 & 1.22963 & .10743 \\
& Late & 99 & 5.1374 & 1.42217 & .14293 \\
IMP & Early & 131 & 5.32 & 1.223 & .107 \\
& Late & 99 & 5.16 & 1.441 & .145 \\
INT & Early & 131 & 5.1939 & 1.18138 & .10322 \\
& Late & 99 & 5.0101 & 1.22304 & .12292 \\
\hline
\end{tabular}

t-test for Equality of Means

\begin{tabular}{|c|c|c|c|c|c|c|c|}
\hline & & $t$ & $d f$ & $\begin{array}{l}\text { Sig. } \\
\text { (2-tailed) }\end{array}$ & $\begin{array}{l}\text { Mean } \\
\text { Difference }\end{array}$ & $\begin{array}{l}\text { Std. Error } \\
\text { Difference }\end{array}$ & $\begin{array}{l}95 \% \mathrm{CI} \text { of the } \\
\text { Difference }\end{array}$ \\
\hline \multirow[t]{2}{*}{ iWOM } & $\begin{array}{l}\text { Equal variances } \\
\text { assumed }\end{array}$ & 1.673 & 228 & .096 & .29316 & .17523 & {$[-.05212 ; .63844]$} \\
\hline & $\begin{array}{l}\text { Equal variances } \\
\text { not assumed }\end{array}$ & 1.640 & 193.461 & .103 & .29316 & .17881 & {$[-.05950 ; .64582]$} \\
\hline \multirow[t]{2}{*}{ IMP } & $\begin{array}{l}\text { Equal variances } \\
\text { assumed }\end{array}$ & .904 & 228 & .367 & .159 & .176 & {$[-.188 ; .506]$} \\
\hline & $\begin{array}{l}\text { Equal variances } \\
\text { not assumed }\end{array}$ & .883 & 191.112 & .378 & .159 & .180 & {$[-.196 ; .514]$} \\
\hline \multirow[t]{2}{*}{ INT } & $\begin{array}{l}\text { Equal variances } \\
\text { assumed }\end{array}$ & 1.151 & 228 & .251 & .18379 & .15973 & {$[-.13095 ; .49854]$} \\
\hline & $\begin{array}{l}\text { Equal variances } \\
\text { not assumed }\end{array}$ & 1.145 & 207.250 & .254 & .18379 & .16051 & {$[-.13265 ; .50023]$} \\
\hline
\end{tabular}


Group statistics: Food and drinks/dining

\begin{tabular}{cccccc}
\hline Construct & Groups & $N$ & Mean & Std. Deviation & Std. Error Mean \\
\hline iWOM & Early & 112 & 5.2509 & 1.16433 & .11002 \\
& Late & 95 & 5.0021 & 1.17147 & .12019 \\
IMP & Early & 112 & 5.39 & 1.211 & .114 \\
& Late & 95 & 5.25 & 1.360 & .140 \\
INT & Early & 112 & 4.8839 & 1.24355 & .11750 \\
& Late & 95 & 4.9411 & 1.23663 & .12688 \\
\hline
\end{tabular}

t-test for Equality of Means

\begin{tabular}{|c|c|c|c|c|c|c|c|}
\hline & & $t$ & $d f$ & $\begin{array}{l}\text { Sig. } \\
\text { (2-tailed) }\end{array}$ & $\begin{array}{l}\text { Mean } \\
\text { Difference }\end{array}$ & $\begin{array}{l}\text { Std. Error } \\
\text { Difference }\end{array}$ & $\begin{array}{l}95 \% \text { CI of the } \\
\text { Difference }\end{array}$ \\
\hline \multirow[t]{2}{*}{ iWOM } & $\begin{array}{l}\text { Equal variances } \\
\text { assumed }\end{array}$ & 1.528 & 205 & .128 & .24879 & .16286 & {$[-.07231 ; .56988]$} \\
\hline & $\begin{array}{l}\text { Equal variances } \\
\text { not assumed }\end{array}$ & 1.527 & 199.129 & .128 & .24879 & .16294 & {$[-.07252 ; .57010]$} \\
\hline \multirow[t]{2}{*}{ IMP } & $\begin{array}{l}\text { Equal variances } \\
\text { assumed }\end{array}$ & .785 & 205 & .434 & .140 & .179 & {$[-.212 ; .493]$} \\
\hline & $\begin{array}{l}\text { Equal variances } \\
\text { not assumed }\end{array}$ & .777 & 190.087 & .438 & .140 & .180 & {$[-.216 ; .496]$} \\
\hline \multirow[t]{2}{*}{ INT } & $\begin{array}{l}\text { Equal variances } \\
\text { assumed }\end{array}$ & -.330 & 205 & .742 & -.05712 & .17301 & {$[-.39823 ; .28398]$} \\
\hline & $\begin{array}{l}\text { Equal variances } \\
\text { not assumed }\end{array}$ & -.330 & 199.879 & .741 & -.05712 & .17293 & {$[-.39812 ; .28388]$} \\
\hline
\end{tabular}


Group statistics: Nature/scenic landscape

\begin{tabular}{cccccc}
\hline Variable & Groups & $N$ & Mean & Std. Deviation & Std. Error Mean \\
\hline iWOM & Early & 158 & 5.7538 & 1.02047 & .08118 \\
& Late & 115 & 5.4339 & 1.25264 & .11681 \\
IMP & Early & 158 & 6.19 & .945 & .075 \\
& Late & 115 & 5.83 & 1.147 & .107 \\
INT & Early & 158 & 5.7722 & 1.15642 & .09200 \\
& Late & 115 & 5.4887 & 1.09422 & .10204 \\
\hline
\end{tabular}

$t$-test for Equality of Means

\begin{tabular}{|c|c|c|c|c|c|c|c|}
\hline & & $t$ & $d f$ & $\begin{array}{l}\text { Sig. } \\
(2- \\
\text { tailed }) \\
\end{array}$ & $\begin{array}{l}\text { Mean } \\
\text { Difference }\end{array}$ & $\begin{array}{l}\text { Std. Error } \\
\text { Difference }\end{array}$ & $\begin{array}{l}95 \% \mathrm{CI} \text { of the } \\
\text { Difference }\end{array}$ \\
\hline \multirow[t]{2}{*}{ iWOM } & $\begin{array}{l}\text { Equal variances } \\
\text { assumed }\end{array}$ & 2.322 & 271 & .021 & .31988 & .13777 & {$[.04864 ; .59113]$} \\
\hline & $\begin{array}{l}\text { Equal variances } \\
\text { not assumed }\end{array}$ & 2.249 & 214.408 & .026 & .31988 & .14225 & {$[.03950 ; .60027]$} \\
\hline \multirow[t]{2}{*}{ IMP } & $\begin{array}{l}\text { Equal variances } \\
\text { assumed }\end{array}$ & 2.800 & 271 & .005 & .355 & .127 & {$[.105 ; .605]$} \\
\hline & $\begin{array}{l}\text { Equal variances } \\
\text { not assumed }\end{array}$ & 2.716 & 216.276 & .007 & .355 & .131 & {$[.097 ; .613]$} \\
\hline \multirow[t]{2}{*}{ INT } & $\begin{array}{l}\text { Equal variances } \\
\text { assumed }\end{array}$ & 2.045 & 271 & .042 & .28346 & .13859 & {$[.01060 ; .55631]$} \\
\hline & $\begin{array}{l}\text { Equal variances } \\
\text { not assumed }\end{array}$ & 2.063 & 253.191 & .040 & .28346 & .13739 & {$[.01289 ; .55403]$} \\
\hline
\end{tabular}


Group statistics: Urban city

\begin{tabular}{cccccc}
\hline Variable & Groups & $N$ & Mean & Std. Deviation & Std. Error Mean \\
\hline iWOM & Early & 155 & 5.2348 & 1.22679 & .09854 \\
& Late & 114 & 5.0702 & 1.32638 & .12423 \\
IMP & Early & 155 & 5.41 & 1.188 & .095 \\
& Late & 114 & 5.30 & 1.420 & .133 \\
INT & Early & 155 & 5.1781 & 1.24558 & .10005 \\
& Late & 114 & 5.1105 & 1.21585 & .11387 \\
\hline
\end{tabular}

t-test for Equality of Means

\begin{tabular}{|c|c|c|c|c|c|c|c|}
\hline & & $t$ & $d f$ & $\begin{array}{l}\text { Sig. } \\
\text { (2-tailed) }\end{array}$ & $\begin{array}{l}\text { Mean } \\
\text { Difference }\end{array}$ & $\begin{array}{l}\text { Std. Error } \\
\text { Difference }\end{array}$ & $\begin{array}{l}95 \% \text { CI of the } \\
\text { Difference }\end{array}$ \\
\hline \multirow[t]{2}{*}{ iWOM } & $\begin{array}{l}\text { Equal variances } \\
\text { assumed }\end{array}$ & 1.051 & 267 & .294 & .16466 & .15668 & {$[-.14383 ; .47316]$} \\
\hline & $\begin{array}{l}\text { Equal variances } \\
\text { not assumed }\end{array}$ & 1.038 & 232.417 & .300 & .16466 & .15856 & {$[-.14774 ; .47707]$} \\
\hline \multirow[t]{2}{*}{ IMP } & $\begin{array}{l}\text { Equal variances } \\
\text { assumed }\end{array}$ & 679 & 267 & .498 & .108 & .159 & {$[-.206 ; .422]$} \\
\hline & $\begin{array}{l}\text { Equal variances } \\
\text { not assumed }\end{array}$ & .661 & 217.091 & .509 & .108 & .164 & {$[-.214 ; .431]$} \\
\hline \multirow[t]{2}{*}{ INT } & $\begin{array}{l}\text { Equal variances } \\
\text { assumed }\end{array}$ & .444 & 267 & .657 & .06754 & .15214 & {$[-.23201 ; .36709]$} \\
\hline & $\begin{array}{l}\text { Equal variances } \\
\text { not assumed }\end{array}$ & .446 & 246.853 & .656 & .06754 & .15158 & {$[-.23102 ; .36610]$} \\
\hline
\end{tabular}




\section{REFERENCES}

Advancing international education. (2020). Retrieved May 19, 2020, from https://www.universitiesnz.ac.nz/sector-research/advancing-international-education

Advice for a recovering tourism industry. (2020). Retrieved October 3, 2020, from https://www.newsroom.co.nz/ideasroom/advice-for-a-recovering-tourism-industry

Afshardoost, M., \& Eshaghi, M. S. (2020). Destination image and tourist behavioural intentions: a meta-analysis. Tourism Management, 81, Advance online publication. https://doi.org/10.1016/j.tourman.2020.104154

Aguinis, H., Beaty, J. C., Boik, R. J., \& Pierce, C. A. (2005). Effect size and power in assessing moderating effects of categorical variables using multiple regression: A 30year review. Journal of Applied Psychology, 90(1), 94-107. https://doi.org/10.1037/0021-9010.90.1.94

Ajzen, I., \& Fishbein, M. (2000). Attitudes and the attitude-behavior relation: reasoned and automatic processes. European Review of Social Psychology, 11(1), 1-33. https://doi.org/10.1080/14792779943000116

Alexander, J. C. (1983). Theoretical Logic in Sociology. London: Routledge \& Kegan Paul.

Ali Memon, M., Cheah, J.-H., Ramayah Hiram Ting, T., Chuah, F., Huei Cham, T., \& Tunku Abdul Rahman, U. (2019). Moderation analysis: issues and guidelines. Journal of Applied Structural Equation Modeling, 3(1), 2590-4221.

Ali, F., Rasoolimanesh, S. M., Sarstedt, M., Ringle, C. M., \& Ryu, K. (2018). An assessment of the use of partial least squares structural equation modeling (PLS-SEM) in hospitality research. International Journal of Contemporary Hospitality Management, 30(1), 514538. https://doi.org/10.1108/IJCHM-10-2016-0568

Allsop, D. T., Bassett, B. R., \& Hoskins, J. A. (2007). Word-of-mouth research: Principles and applications. Journal of Advertising Research, 47(4). https://doi.org/10.2501/S0021849907070419

Almeida-García, F., Domígunez-Azcue, J., Mercadé-Melé, P., \& Pérez-Tapia, G. (2020). Can a destination really change its image? The roles of information sources, motivations, and 
visits. Tourism Management Perspectives, 34, 100662.

https://doi.org/10.1016/j.tmp.2020.100662

AlSaleh, D., \& Moufakkir, O. (2019). An exploratory study of the experience of VFR tourists: a culture shock perspective. Tourism Geographies, 21(4), 565-585. https://doi.org/10.1080/14616688.2018.1545251

Amblee, N., \& Bui, T. (2011). Harnessing the influence of social proof in online shopping: the effect of electronic word of mouth on sales of digital microproducts. International Journal of Electronic Commerce, 16(2), 91-113. https://doi.org/10.2753/JEC10864415160205

Anderson, M. (2015). Men catch up with women on overall social media use. Retrieved March 2, 2020, from https://www.pewresearch.org/fact-tank/2015/08/28/men-catch-upwith-women-on-overall-social-media-use/

Aral, S., \& Walker, D. (2014). Tie strength, embeddedness, and social influence: a largescale networked experiment. Management Science, 60(6), 1352-1370. https://doi.org/10.1287/mnsc.2014.1936

Aristotle. (350BC/2004). Rhetoric / by Aristotle. (W. R. Roberts, Ed.). Mineola, NY: Dover. Armstrong, J. S., \& Overton, T. S. (1977). Estimating nonresponse bias in mail surveys. Journal of Marketing Research, 14(3), 396. https://doi.org/10.2307/3150783

Arnaboldi, V., Conti, M., La Gala, M., Passarella, A., \& Pezzoni, F. (2016). Ego network structure in online social networks and its impact on information diffusion. Computer Communications, 76, 26-41. https://doi.org/10.1016/j.comcom.2015.09.028

Arndt, J. (1967a). Role of product-related conversations in the diffusion of a new product. Journal of Marketing Research, 4(3), 291-295. https://doi.org/10.2307/3149462

Arndt, J. (1967b). Word of mouth advertising and informal communication. In D. F. Cox (Ed.), Risk taking and information handling in consumer behaviour (pp. 188-239). President and Fellows of Harvard College.

Ashley, C., \& Tuten, T. (2015). Creative stratgies in social media marketing: an exploratory study of branded social content and consumer engagement. Psychology \& Marketing, 
32(1), 15-27. https://doi.org/10.1002/mar.20761

Assaker, G. (2014). Examining a hierarchical model of Australia's destination image. Journal of Vacation Marketing, 20(3), 195-210. https://doi.org/10.1177/1356766714527104

Avraham, E., \& Ketter, E. (2017). Destination image repair while combatting crises: tourism marketing in Africa. Tourism Geographies, 19(5), 780-800.

https://doi.org/10.1080/14616688.2017.1357140

Ayeh, J. K., Au, N., \& Law, R. (2013). “Do we believe in TripAdvisor?” Examining credibility perceptions and online travelers' attitude toward using user-generated content. Journal of Travel Research, 52(4), 437-452. https://doi.org/10.1177/0047287512475217

Azzopardi, E., \& Nash, R. (2014). An examination of philosophical paradigms and a rationale for adopting a mixed methods approach. Tourism Analysis, 19(2), 151-159. https://doi.org/10.3727/108354214X13963557455522

Bacharach, S. B. (1989). Organizational theories: some criteria for evaluation. Academy of Management Review, 14(4), 496-515. https://doi.org/10.5465/amr.1989.4308374

Backer, E. R. (2008). VFR travellers - visiting the destination or visiting the hosts? Asian Journal of Tourism and Hospitality Research, 2(1), 60-70.

Backer, E. R. (2010). Opportunities for commercial accommodation in VFR travel. International Journal of Tourism Research, 12, 334-354. https://doi.org/10.1002/jtr

Backer, E. R. (2011). VFR travel: how long are they staying? Tourism Review International, 14, 61-70. https://doi.org/10.3727/154427211X13044361606252

Backer, E. R. (2012). VFR travel: it is underestimated. Tourism Management, 33, 74-79. https://doi.org/10.1016/j.tourman.2011.01.027

Backer, E. R. (2019). VFR travel: do visits improve or reduce our quality of life? Journal of Hospitality and Tourism Management, 38, 161-167. https://doi.org/10.1016/j.jhtm.2018.04.004

Backer, E. R., \& King, B. (2015). Local impacts, global prospects: the future of VFR travel. 
In E. Backer \& B. King (Eds.), VFR travel research: International perspectives (pp. 207-218). Clevedon: Channel View Publications.

Backer, E. R., \& King, B. (2015). Local impacts, global prospects: the future of VFR travel. In E. Backer \& B. King (Eds.), VFR travel research: International perspectives (pp. 207-218). Clevedon: Channel View Publications.

Backer, E. R., \& King, B. (2017). VFR traveller demographics: the social tourism dimension. Journal of Vacation Marketing, 23(3), 191-204. https://doi.org/10.1177/1356766716665439

Backer, E. R., \& Ritchie, B. W. (2017). VFR Travel: a viable market for tourism crisis and disaster recovery? International Journal of Tourism Research, 19(4), 400-411. https://doi.org/10.1002/jtr.2102

Backer, E. R., Leisch, F., \& Dolnicar, S. (2017). Visiting friends or relatives? Tourism Management, 60, 56-64. https://doi.org/10.1016/j.tourman.2016.11.007

Bagozzi, R. P., Yi, Y., \& Phillips, L. W. (1991). Assessing construct validity in organizational research. Administrative Science Quarterly, 36(3), 421-458. https://doi.org/10.2307/2393203

Baka, V. (2016). The becoming of user-generated reviews: looking at the past to understand the future of managing reputation in the travel sector. Tourism Management, 53, 148162. https://doi.org/10.1016/j.tourman.2015.09.004

Baker, A. M., Donthu, N., \& Kumar, V. (2016). Investigating how word of mouth conversations about brands influence purchase and retransmission intentions. Journal of Marketing Research, 53(2), 225-239. https://doi.org/http://dx.doi.org/10.1509/jmr.14.0099

Bakri, M., Krisjanous, J., \& Richard, J. E. (2020). Decoding service brand image through user-generated images. Journal of Services Marketing, 34(4), 429-442. https://doi.org/10.1108/JSM-11-2018-0341

Baloglu, S. (1997). The relationship between destination images and sociodemographic and trip characteristics of international travellers. Journal of Vacation Marketing, 3(3), 221- 
233.

Baloglu, S., \& Brinberg, D. (1997). Affective images of tourism destinations. Journal of Travel Research, 35, 11-15. https://doi.org/10.1177/004728759703500416

Baloglu, S., \& McCleary, K. W. (1999). A model of destination image. Annals of Tourism Research, 26(4), 868-897. https://doi.org/10.1016/S0160-7383(99)00030-4

Balomenou, N., \& Garrod, B. (2014). Using volunteer-employed photography to inform tourism planning decisions: A study of St David's Peninsula, Wales. Tourism Management, 44, 126-139. https://doi.org/10.1016/j.tourman.2014.02.015

Balomenou, N., \& Garrod, B. (2016). A review of participant-generated image methods in the social sciences. Journal of Mixed Methods Research, 10(4), 335-351. https://doi.org/10.1177/1558689815581561

Balomenou, N., \& Garrod, B. (2019). Photographs in tourism research: prejudice, power, performance and participant-generated images. Tourism Management, 70, 201-217. https://doi.org/10.1016/j.tourman.2018.08.014

Bansal, H. S., \& Voyer, P. A. (2000). Word-of-mouth processes within a services purchase decision context. Journal of Service Research, 3(2), 166-177.

Barclay, D. W., Higgins, C. A., \& Thompson, R. (1995). The partial least squares approach to causal modeling: personal computer adoption and use as illustration. Technology Studies, 2(2), 285-309.

Baron, R., \& Kenny, D. (1986). The moderator-mediator variable distinction in social psychological research. Journal of Personality and Social Psychology, 51(6), 11731182. https://doi.org/10.1037/0022-3514.51.6.1173

Barthes, R. (1977). Image, music, text. (S. Heath, Ed.). New York: Hill and Wang.

Bateman, J. A. (2014). Text and image: a critical introduction to the visual/verbal divide. New York: Routledge.

Becker, J.-M., Ringle, C. M., \& Sarstedt, M. (2018). Estimating moderating effects in PLSSEM and PLSc-SEM: interaction term generation*data treatment. Journal of Applied 
Structural Equation Modeling, 2(2), 1-21.

Beerli, A., \& Martín, J. D. (2004a). Tourists' characteristics and the perceived image of tourist destinations: a quantitative analysis - a case study of Lanzarote, Spain. Tourism Management, 25, 623-636. https://doi.org/10.1016/j.tourman.2003.06.004

Beerli, A., \& Martín, J. D. (2004b). Factors influencing destination image. Annals of Tourism Research, 31(3), 657-681. https://doi.org/10.1016/j.annals.2004.01.010

Belk, R. W. (2013). Extended self in a digital world. Journal of Consumer Research, 40(3), 477-500. https://doi.org/10.1086/671052

Benitez, J., Henseler, J., Castillo, A., \& Schuberth, F. (2020). How to perform and report an impactful analysis using partial least squares: guidelines for confirmatory and explanatory IS research. Information and Management, 57(2), Advance online publication. https://doi.org/10.1016/j.im.2019.05.003

Berezina, K., Bilgihan, A., Cobanoglu, C., \& Okumus, F. (2016). Understanding satisfied and dissatisfied hotel customers: text mining of online hotel reviews. Journal of Hospitality Marketing and Management, 25(1), 1-24. https://doi.org/10.1080/19368623.2015.983631

Berger, J. (2014). Word of mouth and interpersonal communication: a review and directions for future research. Journal of Consumer Psychology, 24(4), 586-607. https://doi.org/10.1016/j.jcps.2014.05.002

Bergkvist, L., \& Rossiter, J. R. (2007). The predictive validity of multiple-item versus singleitem measures of the same constructs. Journal of Marketing Research, 44(2), 175-184. https://doi.org/10.1509/jmkr.44.2.175

Bigné Alcañiz, E., Sánchez García, I., \& Sanz Blas, S. (2009). The functional-psychological continuum in the cognitive image of a destination: a confirmatory analysis. Tourism Management, 30, 715-723. https://doi.org/10.1016/j.tourman.2008.10.020

Birdsell, D. S., \& Groarke, L. (2007). Outlines of a theory of visual argument. Argumentation and Advocacy, 43(Winter \& Spring), 103-113. https://doi.org/10.1080/00028533.2007.11821666 
Birdsell, D. S., \& Groarker, L. (2007). Outlines of a theory of visual argument. Argumentation \& Advocacy, 43(Winter \& Spring), 103-113.

Bischoff, E. E., \& Koenig-Lewis, N. (2007). VFR tourism: the importance of university students as hosts. International Journal of Tourism Research, 9(6), 465-484. https://doi.org/10.1002/jtr.618

Bitner, M. J. (1992). Servicescapes: the impact of physical surroundings on customers and employees. Journal of Marketing, 56(2), 57-71. Retrieved from https://www.jstor.org/stable/pdf/1252042.pdf?refreqid=excelsior\%3A0031dd5af7173c1 dba4ffdd6d7216f09

Blain, C., Levy, S. E., \& Ritchie, J. R. B. (2005). Destination branding: insights and practices from destination management organizations. Journal of Travel Research, 43(4), 328338. https://doi.org/10.1177/0047287505274646

Blair, A. (2004). The rhetoric of visual arguments. (C. A. Hill \& M. Helmers, Eds.), Defining visual rhetorics. London: Lawrence Erlbaum. Retrieved from https://ebookcentral.proquest.com/lib/vuw/detail.action?docID=238919.

Blazevic, V., Hammedi, W., Garnefeld, I., Rust, R. T., Keiningham, T., Andreassen, T. W., ... Carl, W. (2013). Beyond traditional word-of-mouth. Journal of Service Management, 24(3), 294-313. https://doi.org/10.1108/09564231311327003

Boeriis, M., \& Holsanova, J. (2012). Tracking visual segmentation: connecting semiotic and cognitive perspectives. Visual Communication, 11(3), 259-281. https://doi.org/10.1177/1470357212446408

Book, L. A., Tanford, S., Montgomery, R., \& Love, C. (2018). Online traveler reviews as social influence: price is no longer king. Journal of Hospitality and Tourism Research, 42(3), 445-475. https://doi.org/10.1177/1096348015597029

Bosangit, C., Hibbert, S., \& McCabe, S. (2015). "If I was going to die I should at least be having fun": travel blogs, meaning and tourist experience. Annals of Tourism Research, 55, 1-14. https://doi.org/10.1016/j.annals.2015.08.001

Bosnjak, M., Tuten, T. L., \& Wittmann, W. W. (2005). Unit (non)response in Web-based 
access panel surveys: an extended planned-behavior approach. Psychology and Marketing, 22(6), 489-505. https://doi.org/10.1002/mar.20070

Boulding, K. E. (1956). The image. Ann Arbor, Michigan: University of Michigan Press.

Boyacigiller, N. (1990). The role of expatriates in the management of interdependence, complexity and risk in multinational corporations. Journal of International Business Studies, 21(3), 357-381.

Bramwell, B., \& Rawding, L. (1996). Tourism marketing images of industrial cities. Annals of Tourism Research, 23(1), 201-221. https://doi.org/10.1016/0160-7383(95)00061-5

Braunlich, C. G., \& Nadkarni, N. (1995). The importance of the VFR market to the hotel industry. The Journal of Tourism Studies, 6(1), 38-47.

Brown, J. J., \& Reingen, P. H. (1987). Social ties and word-of-mouth referral behavior. Journal of Consumer Research, 14(3), 350. https://doi.org/10.1086/209118

Brown, J., Broderick, A. J., \& Lee, N. (2007). Word of mouth communication within online communities: conceptualizing the online social network. Journal of Interactive Marketing, 21(3), 2-20. https://doi.org/10.1002/dir.20082

Brown, L. (2009). The transformative power of the international sojourn: an ethnographic study of the international student experience. Annals of Tourism Research, 36(3), 502521. https://doi.org/10.1016/j.annals.2009.03.002

Bruwer, J., Pratt, M. A., Saliba, A., \& Hirche, M. (2017). Regional destination image perception of tourists within a winescape context. Current Issues in Tourism, 20(2), 157-177. https://doi.org/10.1080/13683500.2014.904846

Bryant, D. C. (1972). Rhetoric: its function and its scope. In D. Ehinger (Ed.), Contemporary rhetoric - a reader's coursebook (pp. 15-37). Glenview, Illinois: Scott, Foresman and Company.

Bryman, A. (2007). Barriers to Integrating Quantitative and Qualitative Research. Journal of Mixed Methods Research, 1(1), 8-22. https://doi.org/10.1177/2345678906290531

Buhalis, D., \& Law, R. (2008). Progress in information technology and tourism management: 
20 years on and 10 years after the Internet - the state of eTourism research. Tourism Management, 29, 609-623. https://doi.org/10.1016/j.tourman.2008.01.005

Burke, K. E. (1969). A rhetoric of motives. Berkeley and Los Angeles: University of California Press.

Burns, R. B., \& Burns, R. A. (2008). Business research methods and statistics using SPSS. Los Angeles: SAGE Publications.

Buttle, F. A. (1998). Word of mouth: understanding and managing referral marketing. Journal of Strategic Marketing, 6(3), 241-254. https://doi.org/10.1080/096525498346658

Byrne, B. (2010). Structural equation modeling with AMOS: basic concepts, applications, and programming (Second Edi). New York: Routledge. https://doi.org/10.4324/9781410600219

Campbell, D. T. (1955). The informant in quantitative research. American Journal of Sociology, 60, 339-342. https://doi.org/10.2307/3537596

Campbell, D. T., \& Fiske, D. W. (1959). Convergent and discriminant validation by the multitrait-multimethod matrix. Psychological Bulletin, 56(2), 81-105. https://doi.org/10.1037/h0046016

Campelo, A., Aitken, R., \& Gnoth, J. (2011). Visual rhetoric and ethics in marketing of destinations. Journal of Travel Research, 50(1), 3-14. https://doi.org/10.1177/0047287510362777

Camprubí, R., \& Coromina, L. (2016). Content analysis in tourism research. Tourism Management Perspectives, 18, 134-140. https://doi.org/10.1016/j.tmp.2016.03.002

Capistrano, R. C. G., \& Weaver, A. (2018). That's what friends are for: emotional solidarity, friendship and social interactions between first-generation immigrants and their visiting friends. Journal of Hospitality and Tourism Management, 36, 57-66. https://doi.org/10.1016/j.jhtm.2018.07.003

Capistrano, R. C., \& Weaver, A. (2017). Host-guest interactions between first-generation immigrants and their visiting relatives: social exchange, relations of care and travel. 
International Journal of Culture, Tourism, and Hospitality Research, 11(3), 406-420. https://doi.org/10.1108/IJCTHR-11-2016-0115

Carnevale, M., Luna, D., \& Lerman, D. (2017). Brand linguistics: a theory-driven framework for the study of language in branding. International Journal of Research in Marketing, 34(2), 572-591. https://doi.org/10.1016/j.ijresmar.2017.01.003

Carrion, G. C., Nitzl, C., \& Roldan, J. L. (2017). Mediation analyses in partial least squares structural equation modeling: guidelines and empirical examples. In H. Latan \& R. Noonan (Eds.), Partial Least Squares Path Modeling: Basic Concepts, Methodological Issues and Applications (pp. 173-195). Cham, Switzerland: Springer. https://doi.org/10.1007/978-3-319-64069-3

Castillo-Montoya, M. (2016). Preparing for interview research: the interview protocol refinement framework. The Qualitative Report, 21(5), 811-831.

Cavana, R. Y., Delahaye, B. L., \& Sekaran, U. (2001). Applied business research: qualitative and quantitative methods (Australian). Milton, Qld: John Wiley \& Sons Inc.

Cave, J., Ryan, C., \& Panakera, C. (2003). Residents' perceptions, migrant groups and culture as an attraction - The case of a proposed Pacific Island cultural centre in New Zealand. Tourism Management, 24(4), 371-385. https://doi.org/10.1016/S02615177(02)00110-3

Chang, S. J., Van Witteloostuijn, A., \& Eden, L. (2010). From the editors: common method variance in international business research. Journal of International Business Studies, 4l(2), 178-184. https://doi.org/10.1057/jibs.2009.88

Chatzigeorgiou, C. (2017). Modelling the impact of social media influencers on behavioural intentions of millennials: the case of tourism in rural areas in Greece. Journal of Tourism, Heritage \& Services Marketing, 3(2), 25-29.

Cheah, J. H., Ting, H., Cham, T. H., \& Memon, M. A. (2019). The effect of selfie promotion and celebrity endorsed advertisement on decision-making processes: a model comparison. Internet Research, 29(3), 552-577. https://doi.org/10.1108/IntR-12-20170530 
Chen, C. F., \& Tsai, D. C. (2007). How destination image and evaluative factors affect behavioral intentions? Tourism Management, 28, 1115-1122. https://doi.org/10.1016/j.tourman.2006.07.007

Cheung, M., Luo, C., Sia, C., \& Chen, H. (2009). Credibility of electronic word-of-mouth: informational and normative determinants of on-line consumer recommendations. International Journal of Electronic Commerce, 13(4), 9-38. https://doi.org/10.2753/JEC1086-4415130402

Chevalier, J. A., \& Mayzlin, D. (2006). The effect of word of mouth on sales: online book reviews. Journal of Marketing Research, 43(3), 345-354.

Chin, W. W. (2010). How to write up and report PLS analyses. In V. E. Vinzi, W. W. Chin, J. Henseler, \& H. Wang (Eds.), Handbook of Partial Least Squares: Concepts, Methods and Applicationss (pp. 655-690). Heidelberg, Dordrecht, London, New York: Springer. https://doi.org/10.1007/978-3-540-32827-8

Chin, W. W., Marcelin, B. L., \& Newsted, P. R. (2003). A partial least squares latent variable modeling approach for measuring interaction effects: Results from a Monte Carlo simulation study and an electronic-mail emotion/adoption study. Information Systems Research, 14(2).

Chin, W., Peterson, R., \& Brown, S. (2008). Structural equation modeling in marketing: some practical reminders. The Journal of Marketing Theory and Practice, 16(4), 287-298. https://doi.org/10.2753/MTP1069-6679160402

Choi, J. G., Tkachenko, T., \& Sil, S. (2011). On the destination image of Korea by Russian tourists. Tourism Management, 32, 193-194. https://doi.org/10.1016/j.tourman.2009.12.002

Choi, S., \& Fu, X. (2018). Hosting friends and family as a sojourner in a tourism destination. Tourism Management, 67, 47-58. https://doi.org/10.1016/j.tourman.2017.12.023

Choi, S., \& Wu, H. C. (2018). Tourism communicative actions of sojourners and information recipients. Journal of Destination Marketing and Management, 9, 279-287. https://doi.org/10.1016/j.jdmm.2018.02.005 
Christodoulides, G. (2009). Branding in the post-internet era. Marketing Theory, 9(1), 141144. https://doi.org/10.1177/1470593108100071

Chryslee, G. J., Foss, S. K., \& Ranney, A. L. (1996). The construction of claims in visual argumentation. Visual Communication Quarterly, 3(2), 9-13. https://doi.org/10.1080/15551399609363319

Clark, T., \& Pugh, D. S. (2001a). Foreign country priorities in the internationalization process: a measure and an exploratory test on British firms. International Business Review, 10(3), 285-303. https://doi.org/10.1016/S0969-5931(01)00017-8

Clark, T., \& Pugh, D. S. (2001b). Foreign country priorities in the internationalization process: A measure and an exploratory test on British firms. International Business Review, 10(3), 285-303. https://doi.org/10.1016/S0969-5931(01)00017-8

Cohen, J. (1988). Statistical power analysis for the behavioral sciences. Hillsdale, N.J.: L. Erlbaum Associates.

Cohen, J. (1992). A power primer. Psychological Bulletin, 112(1), 155-159. https://doi.org/10.1037/0033-2909.112.1.155

Collier, J. J. (1967). Visual anthropology photography as a research method. (G. Spindler \& L. Spindler, Eds.). New York: Holt Rinehart and Winston.

Confente, I. (2015). Twenty-five years of word-of-mouth studies: a critical review of tourism research. International Journal of Tourism Research, 17, 613-624. https://doi.org/10.1002/jtr.2029

Connell, J. (2012). Film tourism - evolution, progress and prospects. Tourism Management, 33, 1007-1029. https://doi.org/10.1016/j.tourman.2012.02.008

Cook, C., Heath, F., \& Thompson, R. L. (2000). A meta-analysis of response rates in web- or internet-based surveys. Educational and Psychological Measurement, 60(6), 821-836.

Cook, T. D. (1985). Postpositivist critical multiplism. In R. L. Shotland \& M. M. Mark (Eds.), Social science and social policy (pp. 21-62). Beverly Hills, California: Sage Publications. 
Coplan, A. (2006). Catching characters' emotions: emotional contagion responses to narrative fiction film. Film Studies, 2006(8), 26-38. https://doi.org/10.7227/fs.8.5

Creswell, J. (2014). Research design: Qualitative, quantitative, and mixed methods. Thousand Oaks: Sage Publications.

Creswell, J. W., \& Plano Clark, V. L. (2018). Designing and conducting mixed methods research $\left(3^{\text {rd }}\right)$. Thousand Oaks, California: Sage Publications, Inc.

Crompton, J. L. (1979). An assessment of the image of Mexico as a vacation destination and the influence of geographical location upon that image. Journal of Travel Research, 17, 18-23. https://doi.org/10.1177/004728757901700404

Crompton, J. L. (1981). Dimensions of the social group role in pleasure vacations. Annals of Tourism Research, 8(4), 550-568. https://doi.org/10.1016/0160-7383(81)90041-4

Cronbach, L. J. (1951). Coefficient alpha and the internal structure of tests. Psychometrika, 16(3), 297-334. https://doi.org/10.1007/BF02310555

Crotty, M. (1998). The foundations of social research: Meaning and perspective in the research process. St Leanords, NSW: Allen \& Unwin.

Danks, N. P., \& Ray, S. (2018). Predictions from partial least squares models. In Applying Partial Least Squares in Tourism and Hospitality Research (pp. 35-52). Emerald Publishing Limited. https://doi.org/10.1108/978-1-78756-699-620181003

Darwin, C. (1872). The expression of the emotions in man and animals. https://doi.org/10.1037/10001-000

Daugherty, T., \& Hoffman, E. (2014). eWOM and the importance of capturing consumer attention within social media. Journal of Marketing Communications, 20(1-2), 82-102. https://doi.org/10.1080/13527266.2013.797764

Davis, D. F., Golicic, S. L., \& Boerstler, C. N. (2011). Benefits and challenges of conducting multiple methods research in marketing. Journal of the Academy of Marketing Science, 39, 467-479. https://doi.org/10.1007/s11747-010-0204-7

De Bruyn, A., \& Lilien, G. L. (2008). A multi-stage model of word-of-mouth influence 
through viral marketing. International Journal of Research in Marketing, 25(3), 151163. https://doi.org/10.1016/j.ijresmar.2008.03.004

DeCuir-Gunby, J. T., Marshall, P. L., \& McCulloch, A. W. (2011). Developing and using a codebook for the analysis of interview data: an example from a professional development research project. Field Methods, 23(2), 136-155. https://doi.org/10.1177/1525822X10388468

Dellarocas, C. (2003). The digitization of word of mouth: promise and challenges of online feedback mechanisms. Management Science, 49(10), 1407-1424. https://doi.org/10.1287/mnsc.49.10.1407.17308

Deng, N., \& Li, X. (Robert). (2018). Feeling a destination through the "right" photos: a machine learning model for DMOs' photo selection. Tourism Management, 65, 267278. https://doi.org/10.1016/j.tourman.2017.09.010

DeVellis, R. F. (2012). Scale development: theory and application. ( $3^{\text {rd }}$ ed.). Los Angeles: Sage Publications.

Devlin, C. (2018). Economic agency gets $\$ 2.5 \mathrm{~m}$ to attract Chinese tourists to Wellington. Retrieved August 23, 2019, from https://www.stuff.co.nz/dominionpost/news/105501653/economic-agency-gets-25m-to-attract-chinese-tourists-towellington

Di Pietro, L., Di Virgilio, F., \& Pantano, E. (2012). Social network for the choice of tourist destination: attitude and behavioural intention. Journal of Hospitality and Tourism Technology, 3(1), 60-76. https://doi.org/10.1108/17579881211206543

Diamantopoulos, A., Sarstedt, M., Fuchs, C., Wilczynski, P., \& Kaiser, S. (2012). Guidelines for choosing between multi-item and single-item scales for construct measurement: a predictive validity perspective. Journal of the Academy of Marketing Science, 40(3), 434-449. https://doi.org/10.1007/s11747-011-0300-3

Dichter, E. (1985). What's in an image? Journal of Consumer Marketing, 2(1), 75-81. https://doi.org/http://dx.doi.org/10.1108/eb038824

Dillman, D. A. (2000). Mail and internet surveys: the tailored design method. New York: 
John Wiley \& Sons Inc.

Dinçer, M. Z., \& Alrawadieh, Z. (2017). Negative word of mouse in the hotel industry: a content analysis of online reviews on luxury hotels in Jordan. Journal of Hospitality Marketing and Management, 26(8), 785-804. https://doi.org/10.1080/19368623.2017.1320258

Dinhopl, A., \& Gretzel, U. (2016). Selfie-taking as touristic looking. Annals of Tourism Research, 57, 126-139. https://doi.org/10.1016/j.annals.2015.12.015

do Valle, P. O., \& Assaker, G. (2016). Using partial least squares structural equation modeling in tourism research: a review of past research and recommendations for future applications. Journal of Travel Research, 55(6), 695-708.

https://doi.org/10.1177/0047287515569779

Dolnicar, S., \& Grün, B. (2013). Validly measuring destination image in survey studies. Journal of Travel Research, 52(1), 3-14. https://doi.org/10.1177/0047287512457267

Duan, W., Yu, Y., Cao, Q., \& Levy, S. (2016). Exploring the impact of social media on hotel service performance: a sentimental analysis approach. Cornell Hospitality Quarterly, 57(3), 282-296. https://doi.org/10.1177/1938965515620483

Durgee, J. F. (2003). Visual rhetoric in new product design. Advances in Consumer Research, $30,367-372$.

Dutt, C. S., \& Ninov, I. (2017). Expatriates' learning: the role of VFR tourism. Journal of Hospitality and Tourism Management, 31, 253-264. https://doi.org/10.1016/j.jhtm.2017.03.003

Duverger, P. (2013). Curvilinear effects of user-generated content on hotels' market share: a dynamic panel-data analysis. Journal of Travel Research, 52(4), 465-478. https://doi.org/10.1177/0047287513478498

Dwyer, L., Seetaram, N., Forsyth, P., \& King, B. (2014). Is the migration-tourism relationship only about VFR? Annals of Tourism Research, 46, 130-143. https://doi.org/10.1016/j.annals.2014.03.009

Echtner, C. M., \& Ritchie, J. R. B. (1993). The measurement of destination image: an 
empirical assessment. Journal of Travel Research, 31(4), 3-13.

Echtner, C. M., \& Ritchie, J. R. B. (2003). The meaning and measurement of destination image. Journal of Travel Research, 14(1), 37-48. https://doi.org/10.1177/004728759303100402

Ehninger, D. (1972). Contemporary rhetoric: a reader's course book. Glenview, Illinois: Scott, Foresman and Company.

Errmann, A., Seo, Y., Choi, Y. K., \& Yoon, S. (2019). Divergent Effects of Friend Recommendations on Disclosed Social Media Advertising in the United States and Korea. Journal of Advertising, 48(5), 495-511. https://doi.org/10.1080/00913367.2019.1663320

Ertimur, B., \& Gilly, M. C. (2012). So whaddya think? Consumers create ads and other consumers critique them. Journal of Interactive Marketing, 26(3), 115-130. https://doi.org/10.1016/j.intmar.2011.10.002

Fakeye, P. C., \& Crompton, J. L. (1991). Image differences between prospective, first-time, and repeat visitors to the lower Rio Grande Valley. Journal of Travel Research, 30(2), 10-16. https://doi.org/10.1177/004728759103000202

Faul, F., Erdfelder, E., Buchner, A., \& Lang, A.-G. (2009). Statistical power analyses using $\mathrm{G}^{*}$ Power 3.1: Tests for correlation and regression analyses. Behavior Research Methods, 41(4), 1149-1160. https://doi.org/10.3758/BRM.41.4.1149

Fischer, F. (1998). Beyond empiricism: Policy inquiry in postpositivist perspective. Policy Studies Journal, 26(1), 129-146.

Fishbein, M., \& Ajzen, I. (1975). Belief, attitude, intention and behavior: an introduction to theory and research. Reading, Massachusetts: Addison-Weslye Pub. Co.

Fornell, C., \& Larcker, D. F. (1981). Evaluating structural equation models with unobservable variables and measurement error. Journal of Marketing Research, 18(1), $39-50$.

Foss, S. K. (1993). The construction of appeal in visual images: a hypothesis. In D. Zarefsky (Ed.), Rhetorical movement: Essays in honor of Leland M. Griffin (pp. 210-224). 
Evanston, IL: Northwestern University Press. Retrieved from http://www.sonjafoss.com/html/Foss29.pdf

Foss, S. K. (1994). A rhetorical schema for the evaluation of visual imagery. Communication Studies, 45(3-4), 213-224. https://doi.org/10.1080/10510979409368425

Foss, S. K. (2005). Theory of visual rhetoric. In K. Smith, S. E. Moriarty, G. Barbatsis, \& K. Kenney (Eds.), Handbook of Visual Communication: Theory, Methods and Media (pp. 141-152). Mahwah, New Jersey: Lawrence Erlbaum.

Foss, S.K. (1993). The construction of appeal in visual images: a hypothesis. In D. Zarefsky (Ed.), Rhetorical movement: Essays in honor of Leland M. Griffin (pp. 210-224). Evanston, IL: Northwestern University Press. Retrieved from http://www.sonjafoss.com/html/Foss29.pdf

Fowler, F. J. (2014). Survey research methods (Fifth edit). Thousand Oaks, California: Sage Publications.

Fox, A. K., Bacile, T. J., Nakhata, C., \& Weible, A. (2018). Selfie-marketing: exploring narcissism and self-concept in visual user-generated content on social media. Journal of Consumer Marketing, 35(1), 11-21. https://doi.org/10.1108/JCM-03-2016-1752

Franke, G., \& Sarstedt, M. (2019). Heuristics versus statistics in discriminant validity testing: a comparison of four procedures. Internet Research, 29(3), 430-447. https://doi.org/10.1108/IntR-12-2017-0515

Frenzen, J. K., \& Davis, H. L. (1990). Purchasing behavior in embedded markets. Journal of Consumer Research, 17(1), 1-12. https://doi.org/10.1086/208532

Fritz, M. S., Taylor, A. B., \& MacKinnon, D. P. (2012). Explanation of two anomalous results in statistical mediation analysis. Multivariate Behavioral Research, 47(1), 61-87. https://doi.org/10.1080/00273171.2012.640596

Fuchs, C., \& Diamantopoulos, A. (2009). Using single-item measures for construct measurement in management research: conceptual issues and application guidelines. Die Betriebswirtschaft, 69(2), 195-210.

Gafter, L. M., \& Tchetchik, A. (2017). The role of social ties and communication 
technologies in visiting friends tourism - a GMM simultaneous equations approach. Tourism Management, 61, 343-353. https://doi.org/10.1016/j.tourman.2017.02.024

Gallarza, M. G., Saura, I. G., \& García, H. C. (2002). Destination image: towards a conceptual framework. Annals of Tourism Research, 29(1), 56-78. https://doi.org/10.1016/S0160-7383(01)00031-7

Gao, B., Li, X., Liu, S., \& Fang, D. (2018). How power distance affects online hotel ratings: The positive moderating roles of hotel chain and reviewers' travel experience. Tourism Management, 65, 176-186. https://doi.org/10.1016/j.tourman.2017.10.007

Gardner, B. B., \& Levy, S. J. (1955). The product and the brand. Harvard Business Review, 33(2), 33-39. https://doi.org/10.1016/0737-6782(88)90037-9

Garrod, B. (2008). Exploring place perception a photo-based analysis. Annals of Tourism Research, 35(2), 381-401. https://doi.org/10.1016/j.annals.2007.09.004

Gartner, W. C. (1994). Image formation process. Journal of Travel \& Tourism Marketing, 2(2-3), 191-216. https://doi.org/10.1300/J073v02n02_12

Gefen, D., Straub, D. W., \& Boudreau, M.-C. (2000). Structural equation modeling and regression: guidelines for research practice. Communications of the Association for Information Systems, 4(October), 2-77. https://doi.org/10.1.1.25.781

Geisser, S. (1975). The predictive sample reuse method with applications. Journal of the American Statistical Association, 70(350), 320-328. https://doi.org/10.1080/01621459.1975.10479865

Ghose, A., \& Han, S. P. (2009). An empirical analysis of user content generation and usage behavior in mobile digital media. Management Science, 57(9), 1671-1691.

Giddings, L. S., \& Grant, B. M. (2006). Mixed methods research for the novice researcher. Contemporary Nurse : A Journal for the Australian Nursing Profession, 23(1), 3-11. https://doi.org/10.5172/conu.2006.23.1.3

Gitelson, R., \& Kerstetter, D. (1994). The influence of friends and relatives in travel decisionmaking. Journal of Travel \& Tourism Marketing, 3(3), 59-68. https://doi.org/10.1300/J073v03n03 
Gleeson, K. (2011), "Polytextual thematic analysis for visual data - Pinning down the analytic", in Reavey, P. (Ed.), Visual methods in psychology: using and interpreting Images in Qualitative Research, Routledge, pp. 314-329.

Golden, B. R. (1992). The past is the past - or is it? The use of retrospective accounts as indicators of past strategy. The Academy of Management Journal, 35(4), 848-860.

Gombeski, W. R., Fay, G. W., Niedzielski, K. R., \& Weaver, F. J. (1988). Evaluating promotional strategy effectiveness for a health care organization. Journal of Business Research, 17(1), 81-90. https://doi.org/10.1016/0148-2963(88)90025-2

Goransson, K., \& Fagerholm, A. S. (2018). Towards visual strategic communications: an innovative interdisciplinary perspective on visual dimensions within the strategic communications field. Journal of Communication Management, 22(1), 46-66. https://doi.org/10.1108/JCOM-12-2016-0098

Govers, R., \& Go, F. M. (2005). Projected Destination Image Online: Website Content Analysis of Pictures and Text. Information Technology \& Tourism, 7(2002), 73-89. https://doi.org/10.3727/1098305054517327

Granovetter, M. (1983). The strength of weak ties: a network theory revisited. Sociological Theory, 1(1983), 201-233. https://doi.org/10.1207/s15326985ep4001

Granovetter, M. S. (1973). The strength of weak ties. American Journal of Sociology, 78(6), 1360-1380.

Greene, J. C. (2007). Mixed methods in social inquiry. San Francisco, California: John Wiley \& Sons Inc.

Greene, J. C., Carcelli, V. J., \& Graham, W. F. (1989). Toward a conceptual framework for mixed-method evaluation designs. Educationl Evaluation and Policy Analysis, 11(3), $255-274$.

Griffin, T. (2013a). Research note: a content analysis of articles on visiting friends and relatives tourism, 1990-2010. Journal of Hospitality Marketing \& Management, 22(7), 781-802. https://doi.org/10.1080/19368623.2012.708960

Griffin, T. (2013b). Visiting friends and relatives tourism and implications for community 
capital. Journal of Policy Research in Tourism, Leisure and Events, 5(3), 233-251. https://doi.org/10.1080/19407963.2013.776370

Griffin, T. (2015). The experience and implications of immigrant hosts. In E. Backer \& B. King (Eds.), VFR travel research: International perspectives (pp. 73-86). Clevedon: Channel View Publications.

Griffin, T. (2017). Immigrant hosts and intra-regional travel. Tourism Geographies, 19(1), 44-62. https://doi.org/10.1080/14616688.2016.1169314

Griffin, T., \& Dimanche, F. (2017). Urban tourism: the growing role of VFR and immigration. Journal of Tourism Futures, 3(2), 103-113. https://doi.org/10.1108/JTF10-2016-0036

Griffin, T., \& Nunkoo, R. (2016). Paid accommodation use of international VFR multidestination travellers. Tourism Review, 71(2), 90-104. https://doi.org/10.1108/TR-092015-0041

Groves, R. M. (2006). Nonresponse rates and nonresponse bias in household surveys. Public Opinion Quarterly, 70(5), 646-675. https://doi.org/10.1093/poq/nfl033

Gunn, C. A. (1988). Vacationscape: designing tourist regions ( $2^{\text {nd }}$ ed.). New York: Van Nostrand Reinhold Company.

Guo, Y., Barnes, S. J., \& Jia, Q. (2017). Mining meaning from online ratings and reviews: tourist satisfaction analysis using latent dirichlet allocation. Tourism Management, 59, 467-483. https://doi.org/10.1016/j.tourman.2016.09.009

Hadi, N. U. (2016). Making sense of mediating analysis: a marketing perspective. Review of Integrative Business and Economics Research, 5(2), 62-76. https://doi.org/10.1037/a0034592

Hair, J. F., Hult, G. T. M., \& Sarstedt, M. (2017). A primer of partial least squares structural equation modeling (PLS-SEM). Thousand Oaks, California: Sage Publications.

Hair, J. F., Ringle, C. M., \& Sarstedt, M. (2011). PLS-SEM: indeed a silver bullet. Journal of Marketing Theory and Practice, 19(2), 139-151. https://doi.org/10.2753/MTP10696679190202 
Hair, J. F., Risher, J. J., Sarstedt, M., \& Ringle, C. M. (2019). When to use and how to report the results of PLS-SEM. European Business Review, 31(1), 2-24. https://doi.org/10.1108/EBR-11-2018-0203

Hair, J. F., Sarstedt, M., \& Ringle, C. M. (2019). Rethinking some of the rethinking of partial least squares. European Journal of Marketing, 53(4), 566-584. https://doi.org/10.1108/EJM-10-2018-0665

Hair, J. F., Sarstedt, M., Matthews, L. M., \& Ringle, C. M. (2016). Identifying and treating unobserved heterogeneity with FIMIX-PLS: part I - method. European Business Review, 28(1), 63-76. https://doi.org/10.1108/EBR-09-2015-0094

Hair, J. F., Sarstedt, M., Ringle, C. M., \& Gudergan, S. P. (2018). Advanced issues in partial least squares structural equation modeling. Thousand Oaks, California: Sage Publications.

Hair, J. F., William, C., Babin, B. J., \& Anderson, R. E. (2014). Multivariate data analysis ( $7^{\text {th }}$ ed.). London: Pearson Education Limited.

Hamilton, R. (2016). Consumer-based strategy: using multiple methods to generate consumer insights that inform strategy. Journal of the Academy of Marketing Science, 44(3), 281285. https://doi.org/10.1007/s11747-016-0476-7

Hanlan, J., \& Kelly, S. (2005). Image formation, information sources and an iconic Australian tourist destination. Journal of Vacation Marketing, 11(2), 163-177. https://doi.org/10.1177/1356766705052573

Harman, H. H. (1976). Modern factor analysis. ( $3^{\text {rd }}$ Ed.). Chicago: University of Chicago Press.

Harrison, R. L., \& Reilly, T. M. (2011). Mixed methods designs in marketing research. Qualitative Market Research: An International Journal, 14(1), 7-26. https://doi.org/10.1108/13522751111099300

Hasford, J., Hardesty, D. M., \& Kidwell, B. (2015). More than a feeling: emotional contagion effects in persuasive communication. Journal of Marketing Research, 52(6), 836-847. https://doi.org/10.1509/jmr.13.0081 
Hatfield, E., Bensman, L., Thornton, P. D., \& Rapson, R. L. (2014). New perspectives on emotional contagion: a review of classic and recent research on facial mimicry and contagion. Interpersona: An International Journal on Personal Relationships, 8(2), 159-179. https://doi.org/10.5964/ijpr.v8i2.162

Hatfield, E., Cacioppo, J. T., \& Rapson, R. L. (1993). Emotional contagion. Current Directions in Psychological Science, 2(3), 96-100. https://doi.org/10.1111/14678721.ep10770953

Hatfield, E., Carpenter, M., \& Rapson, R. L. (2014). Emotional contagion as a precursor to collective emotions. In Collective Emotions (pp. 108-122). Oxford University Press. https://doi.org/10.1093/acprof:oso/9780199659180.003.0008

Hayes, A. F. (2009). Beyond Baron and Kenny: statistical mediation analysis in the new millennium. Communication Monographs, 76(4), 408-420. https://doi.org/10.1080/03637750903310360

Hayes, A. F. (2018). Partial, conditional, and moderated moderated mediation:

Quantification, inference, and interpretation. Communication Monographs, 85(1), 4-40. https://doi.org/10.1080/03637751.2017.1352100

Hayes, A. F., \& Scharkow, M. (2013). The relative trustworthiness of inferential tests of the indirect effect in statistical mediation analysis: does method really matter? Psychological Science, 24(10), 1918-1927. https://doi.org/10.1177/0956797613480187

Heckathorn, D. D. (1997). Respondent-driven sampling: a new approach to the study of hidden populations. Social Problems, 44(2), 174-199. https://doi.org/10.2307/3096941

Hennig-Thurau, T., Groth, M., Paul, M., \& Gremier, D. D. (2006). Are all smiles created equal? How emotional contagion and emotional labor affect service relationships. Journal of Marketing, 70(3), 58-73. https://doi.org/10.1509/jmkg.70.3.58

Hennig-Thurau, T., Gwinner, K. P., Walsh, G., \& Gremler, D. D. (2004). Electronic word-ofmouth via consumer-opinion platforms: What motivates consumers to articulate themselves on the Internet? Journal of Interactive Marketing, 18(1), 38-52. https://doi.org/10.1002/dir.10073 
Henseler, J., \& Chin, W. W. (2010). A comparison of approaches for the analysis of interaction effects between latent variables using partial least squares path modeling. Structural Equation Modeling, 17(1), 82-109. https://doi.org/10.1080/10705510903439003

Henseler, J., \& Fassott, G. (2010). Testing moderating effects in PLS path models: an illustration of available procedures. In V. E. Vinzi, W. W. Chin, J. Henseler, \& H. Wang (Eds.), Handbook of partial least squares (pp. 713-735). Heidelberg, Dordrecht, London, New York: Springer. https://doi.org/10.1007/978-3-540-32827-8

Henseler, J., Hubona, G., \& Ray, P. A. (2017). Partial least squares path modeling: updated guidelines. In H. Latan \& R. Noonan (Eds.), Partial least squares path modeling: basic concepts, methodological issues and applications (pp. 19-39). Cham, Switzerland: Springer. https://doi.org/10.1007/978-3-319-64069-3

Henseler, J., Müller, T., \& Schuberth, F. (2018), "New guidelines for the use of PLS path modeling in hospitality, travel, and tourism research", in Ali, F., Rasoolimanesh, S.M. and Cobanoglu, C. (Eds.), Applying Partial Least Squares in Tourism and Hospitality Research, Emerald Publishing Limited, pp. 17-33.

Henseler, J., Ringle, C. M., \& Sarstedt, M. (2015). A new criterion for assessing discriminant validity in variance-based structural equation modeling. Journal of the Academy of Marketing Science, 43, 115-135. https://doi.org/10.1007/s11747-014-0403-8

Henseler, J., Ringle, C. M., \& Sarstedt, M. (2016). Testing measurement invariance of composites using partial least squares. International Marketing Review, 33(3), 405-431. https://doi.org/10.1108/IMR-09-2014-0304

Henseler, J., Ringle, C. M., \& Sinkovics, R. R. (2009). The use of partial least squares path modeling in international marketing. Advances in International Marketing, 20(2009), 277-319. https://doi.org/10.1108/S1474-7979(2009)0000020014

Hess, U., \& Fischer, A. (2013). Emotional mimicry as social regulation. Personality and Social Psychology Review, 17(2), 142-157. https://doi.org/10.1177/1088868312472607

Holbrook, M. B., \& Batra, R. (1987). Assessing the role of emotions as mediators of consumer responses to advertising. Journal of Consumer Research, 14(3), 404-420. 
https://doi.org/10.1086/209123

Holmes, R. (2019). In 2020 social media will be less social. Retrieved February 7, 2020, from https://www.fastcompany.com/90444337/in-2020-social-media-will-be-less-social

Hopkins, J. (1998). Signs of the post-rural: marketing myths of a symbolic countryside. Geografiska Annaler, 80(2), 65-81. https://doi.org/10.1111/1468-0467.00030

Horn, J. L., \& Mcardle, J. J. (1992). A practical and theoretical guide to measurement invariance in aging research. Experimental Aging Research, 18(3), 117-144. https://doi.org/10.1080/03610739208253916

Hosany, S., Ekinci, Y., \& Uysal, M. (2006). Destination image and destination personality: an application of branding theories to tourism places. Journal of Business Research, 59, 638-642. https://doi.org/10.1016/j.jbusres.2006.01.001

Howard, D. J., \& Gengler, C. (2001). Emotional contagion effects on product attitudes. Journal of Consumer Research, 28(2), 189-201. https://doi.org/10.1086/322897

Howard, J., \& Sheth, J. (1969). The theory of buyer behavior. New York: John Wiley \& Sons Inc.

Hsieh, H. F., \& Shannon, S. E. (2005). Three approaches to qualitative content analysis. Qualitative Health Research, 15(9), 1277-1288. https://doi.org/10.1177/1049732305276687

Hu, B., Morrison, A. M., \& O’Leary, J. T. (2002). An analysis of the variety-seeking behaviour of the U.S. visiting friends and relatives market. Journal of Tourism Studies, 13(2), 28-40. Retrieved from http://www.jcu.edu.au/business/idc/groups/public/documents/journal_article/

Hu, F., \& Trivedi, R. H. (2020). Mapping hotel brand positioning and competitive landscapes by text-mining user-generated content. International Journal of Hospitality Management, 84, Advance online publication. https://doi.org/10.1016/j.ijhm.2019.102317

Huang, J. (2017). The dining experience of Beijing Roast Duck: A comparative study of the Chinese and English online consumer reviews. International Journal of Hospitality 
Management, 66, 117-129. https://doi.org/10.1016/j.ijhm.2017.07.003

Huang, W. J., King, B., \& Suntikul, W. (2017). VFR tourism and the tourist gaze: overseas migrant perceptions of home. International Journal of Tourism Research, 19(4), 421434. https://doi.org/10.1002/jtr.2104

Hudoyo, M. (2019). Wellington Capital Tastes, New Zealand. Retrieved January 23, 2020, from https://www.ttgasia.com/2019/08/21/wellington-capital-tastes-new-zealand/

Hudson, L. A., \& Ozanne, J. L. (1988). Alternative ways of seeking knowledge in consumer research. Journal of Consumer Research, 14(4), 508-521.

Hudson, S., Wang, Y., \& Gil, S. M. (2011). The influence of a film on destination image and the desire to travel: A cross-cultural comparison. International Journal of Tourism Research, 13(2), 177-190. https://doi.org/10.1002/jtr.808

Hulland, J. (1999). Use of partial least squares (PLS) in strategic managment research: a review of four recent studies. Strategic Management Journal, 21(10), 195-204.

Hulland, J., Baumgartner, H., \& Smith, K. M. (2018). Marketing survey research best practices: evidence and recommendations from a review of JAMS articles. Journal of the Academy of Marketing Science, 46(1), 92-108. https://doi.org/10.1007/s11747-0170532-y

Humbracht, M. (2015). Reimagining transnational relations: the embodied politics of visiting friends and relatives mobilities. Population, Space and Place, 21, 640-653. https://doi.org/10.1002/psp.1918

Hunt, J. D. (1975). Image as a factor in tourism development. Journal of Travel Research, 13(Winter), 1-7.

Hunt, S. (2003). Controversy in marketing theory: for reason, realism, truth, and objectivity. Armonk, N.Y.: M.E. Sharpe.

Hunt, S. D., Sparkman, R. D., \& Wilcox, J. B. (1982). The pretest in survey research: issues and preliminary findings. Journal of Marketing Research, 23(2), 269-273.

Hunt, T. (2018). Dear Wellington visitors: thanks for coming and for the $\$ 2.5$ billion you 
spent. Retrieved from https://www.stuff.co.nz/business/102815446/dear-wellingtonvisitors-thanks-for-coming-and-for-the-25-billion-you-spent

Hunter, W. C. (2012). Projected destination image: a visual analysis of Seoul. Tourism Geographies, 14(3), 419-443. https://doi.org/10.1080/14616688.2011.613407

Hunter, W. C. (2012). Projected destination image: a visual analysis of Seoul. Tourism Geographies, 14(3), 419-443. https://doi.org/10.1080/14616688.2011.613407

ICEF Monitor. (2019). OECD: number of degree-holders worldwide will reach 300 million by 2030. Retrieved April 28, 2020, from https://monitor.icef.com/2019/07/oecd-numberof-degree-holders-worldwide-will-reach-300-million-by-2030/

Ilieva, J., Baron, S., \& Healey, N. M. (2002). Online surveys in marketing research. International Journal of Market Research, 44(3), 1-14. https://doi.org/10.1177/147078530204400303

Immigration New Zealand. (2020). Statistics. Retrieved March 30, 2020, from https://www.immigration.govt.nz/about-us/research-and-statistics/statistics

International Tourism Highlights, 2019 Edition. (2019). World Tourism Organization. https://doi.org/doi:10.18111/9789284421152

Investment boost for New Zealand tourism. (2019). Retrieved from https://www.nzte.govt.nz/about/news/news-and-features/investment-boost-for-nztourism

Iqani, M., \& Schroeder, J. E. (2016). \#selfie: Digital self-portraits as commodity form and consumption practice. Consumption Markets and Culture, 19(5), 405-415. https://doi.org/10.1080/10253866.2015.1116784

Jackson, M. (2001). Cultural influences on tourist destination choices of 21 Pacific Rim nations. In 2001 CAUTHE National Research Conference (pp. 166-176).

Jackson, R. T. (2003). VFR tourism: is it underestimated? [reprint of original article publised in 1 (2), 1990: 10-17]. Journal of Tourism Studies, 14(1), 17-24.

Jacobsen, J. K. S., \& Munar, A. M. (2012). Tourist information search and destination choice 
in a digital age. Tourism Management Perspectives, 1(1), 39-47.

https://doi.org/10.1016/j.tmp.2011.12.005

Jalilvand, M. R. (2017). Word-of-mouth vs. mass media: their contributions to destination image formation. Anatolia, 28(2), 151-162. https://doi.org/10.1080/13032917.2016.1270840

Jalilvand, M. R., \& Heidari, A. (2017). Comparing face-to-face and electronic word-of-mouth in destination image formation: the case of Iran. Information Technology and People, 30(4), 710-735. https://doi.org/10.1108/ITP-09-2016-0204

Jalilvand, M. R., \& Samiei, N. (2012). The effect of electronic word of mouth on brand image and purchase intention: An empirical study in the automobile industry in Iran. Marketing Intelligence and Planning, 30(4), 460-476.

https://doi.org/10.1108/02634501211231946

Jalilvand, M. R., \& Samiei, N. (2012). The effect of word of mouth on inbound tourists' decision for traveling to Islamic destinations (the case of Isfahan as a tourist destination in Iran). Journal of Islamic Marketing, 3(1), 12-21. https://doi.org/10.1108/17590831211206554

Jalilvand, M. R., \& Samiei, N. (2012). The impact of electronic word of mouth on a tourism destination choice: Testing the theory of planned behavior (TPB). Internet Research, 22(5), 591-612. https://doi.org/10.1108/10662241211271563

Jalilvand, M. R., Esfahani, S. S., \& Samiei, N. (2011). Electronic word-of-mouth: challenges and opportunities. Procedia Computer Science, 3, 42-46. https://doi.org/10.1016/j.procs.2010.12.008

Jalilvand, M. R., Samiei, N., Dini, B., \& Yaghoubi Manzari, P. (2012). Examining the structural relationships of electronic word of mouth, destination image, tourist attitude toward destination and travel intention: An integrated approach. Journal of Destination Marketing and Management, 1(1-2), 134-143. https://doi.org/10.1016/j.jdmm.2012.10.001

Jang, S. C., Yu, L., \& Pearson, T. E. (2003). Chinese travellers to the United States: a comparison of business travel and visiting friends and relatives. Tourism Geographies, 
5(1), 87-108. https://doi.org/10.1080/1461668032000034097

Janta, H., \& Christou, A. (2019). Hosting as social practice: gendered insights into contemporary tourism mobilities. Annals of Tourism Research, 74, 167-176. https://doi.org/10.1016/j.annals.2018.11.008

Jarvis, C. B., MacKenzie, S. B., \& Podsakoff, P. M. (2003). A critical review of construct indicators and measurement model misspecification in marketing and consumer research. Journal of Consumer Research, 30(2), 199-218. https://doi.org/10.1086/376806

Jenkins, O. (1999). Understanding and measuring tourist destination images. International Journal of Tourism Research, 1, 1-15.

Jenkins, O. (2003). Photography and travel brochures: the circle of representation. Tourism Geographies, 5(3), 305-328. https://doi.org/10.1080/14616680309715

Johnson, R. B., \& Onwuegbuzie, A. J. (2004). Mixed methods research: a research paradigm whose time has come. Educational Researcher, 33(7), 14-26. https://doi.org/url\{10.3102/0013189X033007014\}

Joo, Y., Seok, H., \& Nam, Y. (2020). The moderating effect of social media use on sustainable rural tourism: A theory of planned behavior model. Sustainability (Switzerland), 12(10). https://doi.org/10.3390/su12104095

Josiam, B. M., Spears, D. L., Pookulangara, S., Dutta, K., Kinley, T. R., \& Duncan, J. L. (2015). Using structural equation modeling to understand the impact of Bollywood movies on destination image, tourist activity, and purchasing behavior of Indians. Journal of Vacation Marketing, 21(3), 251-261. https://doi.org/10.1177/1356766715573650

Kao, T. Y., Yang, M. H., Wu, J. T. Ben, \& Cheng, Y. Y. (2016). Co-creating value with consumers through social media. Journal of Services Marketing, 30(2), 141-151. https://doi.org/10.1108/JSM-03-2014-0112

Katz, E., \& Lazarsfeld, P. F. (2017). Personal influence. New York: Routledge. https://doi.org/10.4324/9781315126234 
Keller, K. L. (1993). Conceptualizing, measuring, and managing customer-based brand equity. Journal of Marketing, 57(1), 1-22. Retrieved from http://www.jstor.org/stable/1252054

Keller, K. L. (2003). Brand synthesis: the multidimensionality of brand knowledge. Journal of Consumer Research, 29(4), 595-600. https://doi.org/10.1086/346254

Kenney, K. (2002). Building visual communication theory by borrowing from rhetoric. Journal of Visual Literacy, 22(1), 53-80. https://doi.org/10.1080/23796529.2002.11674581

Kenny, D. A. (2016). Moderation. Retrieved June 9, 2020, from http://davidakenny.net/cm/moderation.htm

Kenny, L. (2018). Wellington named New Zealand's top destination by Lonely Planet. Retrieved April 4, 2019, from https://www.stuff.co.nz/travel/news/107002347/wellington-named-new-zealands-topdestination-by-lonely-planet

Key tourism statistics. (2020). Retrieved July 15, 2020, from https://www.mbie.govt.nz/assets/key-tourism-statistics.pdf

Khoo-Lattimore, C., Mura, P., \& Yung, R. (2019). The time has come: a systematic literature review of mixed methods research in tourism. Current Issues in Tourism, 22(13), 15311550. https://doi.org/10.1080/13683500.2017.1406900

Kim, H., \& Stepchenkova, S. (2015). Effect of tourist photographs on attitudes towards destination: manifest and latent content. Tourism Management, 49, 29-41. https://doi.org/10.1016/j.tourman.2015.02.004

Kim, J., \& Tussyadiah, I. P. (2013). Social networking and social support in tourism experience: the moderating role of online self-presentation strategies. Journal of Travel and Tourism Marketing, 30(1-2), 78-92. https://doi.org/10.1080/10548408.2013.751220

Kim, J., \& Tussyadiah, I. P. (2013). Social networking and social support in tourism experience: the moderating role of online self-presentation strategies. Journal of Travel 
and Tourism Marketing, 30(1-2), 78-92.

https://doi.org/10.1080/10548408.2013.751220

Kim, S. S., \& Agrusa, J. (2008). Segmenting Japanese tourists to Hawaii according to tour purpose. Journal of Travel \& Tourism Marketing, 24(1), 63-80. https://doi.org/10.1300/J073v24n01

King, B., \& Dwyer, L. (2015). The VFR and migration nexus - the impacts of migration on inbound and outbound Australian VFR Travel. In E. Backer \& B. King (Eds.), VFR travel research: international perspectives (pp. 46-58). Clevedon: Channel View Publications.

King, R. A., Racherla, P., \& Bush, V. D. (2014). What we know and don't know about online word-of-mouth: a review and synthesis of the literature. Journal of Interactive Marketing, 28, 167-183. https://doi.org/10.1016/j.intmar.2014.02.001

Kinsella, E., \& Border, C. (2019). How Insta-farming has led to blooming business at rural farms. Retrieved July 13, 2020, from https://www.abc.net.au/news/2019-05-04/instafarming-has-businesses-booming-at-sunflower-farm/11049998

Kjeldsen, J. E. (2018). Visual rhetorical argumentation. Semiotica, 2018(220), 69-94. https://doi.org/10.1515/sem-2015-0136

Klarmann, M., \& Feurer, S. (2018). Control variables in marketing research. Marketing, Zeitschrift Für Forschung Und Praxis, 40(2), 26-40. https://doi.org/10.15358/03441369-2018-2-26

Kock, N., \& Hadaya, P. (2018). Minimum sample size estimation in PLS-SEM: the inverse square root and gamma-exponential methods. Information Systems Journal, 28(1), 227261. https://doi.org/10.1111/isj.12131

Kogut, B., \& Singh, H. (1988). The effect of national culture on the choice of entry mode. Journal of International Business Studies, 19(3), 411-432.

Kolbe, R. H., \& Burnett, M. S. (1991). Content-analysis research: an examination of applications with directives for improving research reliability and objectivity. Journal of Consumer Research, 18(2), 243-250. https://doi.org/10.1086/209256 
Kozinets, R. V, de Valck, K., Wojnicki, A. C., \& Wilner, S. J. S. (2010). Networked narratives: understanding word-of-mouth marketing in online communities. Journal of Marketing, 74(2), 71-89. https://doi.org/10.1509/jmkg.74.2.71

Kress, G., \& van Leeuwen, T. (2006). Reading images: the grammar of visual design $\left(2^{\text {nd }}\right.$ ed.). New York: Routledge.

Krippendorff, K. (2013). Content analysis: an introduction to its methodology ( $3^{\text {rd }}$ ed.). California: Sage Publications.

Kronrod, A., \& Danziger, S. (2013). “Wii will rock you!” The use and effect of figurative language in consumer reviews of hedonic and utilitarian consumption. Journal of Consumer Research, 40(4), 726-739. https://doi.org/10.1086/671998

Kumar, N., Stern, L. W., \& Anderson, J. C. (1993). Conducting interorganizational research using key informants. The Academy of Management Journal, 36(6), 1633-1651.

Kwok, L., Xie, K. L., \& Richards, T. (2017). Thematic framework of online review research: a systematic analysis of contemporary literature on seven major hospitality and tourism journals. International Journal of Contemporary Hospitality Management, 29(1), 307354. https://doi.org/10.1108/IJCHM-11-2015-0664

Labrecque, L. I., Markos, E., \& Milne, G. R. (2011). Online personal branding: processes, challenges, and implications. Journal of Interactive Marketing, 25(1), 37-50. https://doi.org/10.1016/j.intmar.2010.09.002

Lacy, S., Watson, B. R., Riffe, D., \& Lovejoy, J. (2015). Issues and best practices in content analysis. Journalism and Mass Communication Quarterly, 92(4), 791-811. https://doi.org/10.1177/1077699015607338

Lai, K., \& Li, X. (Robert). (2016). Tourism destination image: conceptual problems and definitional solutions. Journal of Travel Research, 55(8), 1065-1080. https://doi.org/10.1177/0047287515619693

Lamberton, C., \& Stephen, A. T. (2016). A thematic exploration of digital, social media, and mobile marketing: research evolution from 2000 to 2015 and an agenda for future inquiry. Journal of Marketing, 80(6), 146-172. https://doi.org/10.1509/jm.15.0415 
Landis, J. R., \& Koch, G. G. (1977). The measurement of observer agreement for categorical data. Biometrics, 33(1), 159-174. https://doi.org/10.2307/2529310

Larsen, J., Urry, J., \& Axhausen, K. W. (2007). Networks and tourism: mobile social life. Annals of Tourism Research, 34(1), 244-262. https://doi.org/10.1016/j.annals.2006.08.002

Larsen, V., Luna, D., \& Peracchio, L. A. (2004). Points of view and pieces of time: a taxonomy of image attributes. Journal of Consumer Research, 31(1), 102-111. https://doi.org/10.1086/383427

Lee, B. K., Lee, C. K., \& Lee, J. (2014). Dynamic nature of destination image and influence of tourist overall satisfaction on image modification. Journal of Travel Research, 53(2), 239-251. https://doi.org/10.1177/0047287513496466

Lee, C. F., \& King, B. (2016). International students in Asia: Travel behaviors and destination perceptions. Asia Pacific Journal of Tourism Research, 21(4), 457-476. https://doi.org/10.1080/10941665.2015.1062786

Lee, G., Morrison, A. M., You, L. X., Webb, J., \& Reid, J. (2005). VFR: is it really marginal? A financial consideration of French overseas travellers. Journal of Vacation Marketing, 11(4), 340-356. https://doi.org/10.1177/1356766705056630

Lee, J. K., \& Kronrod, A. (2020). The strength of weak-tie consensus language. Journal of Marketing Research, 57(2), 353-374. https://doi.org/10.1177/0022243720904957

Lehto, X. Y., Morrison, A. M., \& O’Leary, J. T. (2001). Does the visiting friends and relatives' typology make a difference? A study of the international VFR market to the United States. Journal of Travel Research, 40(2), 201-212. https://doi.org/10.1177/004728750104000211

Leiper, N. (1995). Tourism management. Australia: RMIT University Press.

Leiper, N. (2004). Tourism management ( $3^{\text {rd }}$ ed.). Frenchs Forest, NSW: Pearson Education.

Leisen, B. (2001). Image segmentation: the case of a tourism destination. Journal of Services Marketing, 15(1), 49-66. https://doi.org/10.1108/08876040110381517 
Leung, D., Law, R., van Hoof, H., \& Buhalis, D. (2013). Social media in tourism and hospitality: a literature review. Journal of Travel and Tourism Marketing, 30(1-2), 322. https://doi.org/10.1080/10548408.2013.750919

Levin, D. Z., \& Cross, R. (2004). The strength of weak ties you can trust: the mediating role of trust in effective knowledge transfer. Management Science, 50(11), 1477-1490. https://doi.org/10.1287/mnsc.1030.0136

Lew, A. A. (1987). A framework of tourist attraction research. Annals of Tourism Research, 14(4), 553-575. https://doi.org/10.1016/0160-7383(87)90071-5

Lewis-Beck, M., Bryman, A., \& Futing Liao, T. (2004). The SAGE Encyclopedia of Social Science Research Methods. Thousand Oaks, California: Sage Publications, Inc. https://doi.org/10.4135/9781412950589

Lieber, E., \& Wesiner, T. S. (2010). Meeting the practical challenges of mixed methods research. In A. Tashakkori \& C. Teddlie (Eds.), SAGE handbook of mixed methods in social \& behavioral research ( $2^{\text {nd }}$ ed., pp. 559-579). Thousand Oaks, California: Sage Publications, Inc.

Lietz, P. (2010). Research into questionnaire design: a summary of the literature. International Journal of Market Research, 52(2), 249-272. https://doi.org/10.2501/S147078530920120X

Lim, W. M. (2016). Understanding the selfie phenomenon: current insights and future research directions. European Journal of Marketing, 50(9/10), 1773-1788. https://doi.org/10.1108/EJM-07-2015-0484

Litvin, S. W., Goldsmith, R. E., \& Pan, B. (2008). Electronic word-of-mouth in hospitality and tourism management. Tourism Management. https://doi.org/10.1016/j.tourman.2007.05.011

Litvin, S. W., Goldsmith, R. E., \& Pan, B. (2018). A retrospective view of electronic wordof-mouth in hospitality and tourism management. International Journal of Contemporary Hospitality Management, 30(1), 313-325. https://doi.org/10.1108/IJCHM-08-2016-0461 
Liu, G., \& Ryan, C. (2011). The role of Chinese students as tourists and hosts for overseas travel. Asia Pacific Journal of Tourism Research, 16(4), 445-464.

https://doi.org/10.1080/10941665.2011.588877

Liu, X., Schuckert, M., \& Law, R. (2016). Online incentive hierarchies, review extremity, and review quality: empirical evidence from the hotel sector. Journal of Travel and Tourism Marketing, 33(3), 279-292. https://doi.org/10.1080/10548408.2015.1008669

Lo, A. S., \& Yao, S. S. (2019). What makes hotel online reviews credible?: An investigation of the roles of reviewer expertise, review rating consistency and review valence. International Journal of Contemporary Hospitality Management, 31(1), 41-60. https://doi.org/10.1108/IJCHM-10-2017-0671

Lo, I. S., \& McKercher, B. (2015). Ideal image in process: online tourist photography and impression management. Annals of Tourism Research, 52, 104-116. https://doi.org/10.1016/j.annals.2015.02.019

Lockyer, T., \& Ryan, C. (2007). Visiting friends and relatives distinguishing between the two groups: the case of Hamilton, New Zealand. Tourism Recreation Research, 32(1), 5968. https://doi.org/10.1080/02508281.2007.11081524

Lofgren, O. (1999). Looking for sights. In On holiday: A history of vacationing (pp. 13-40). University of California Press. https://doi.org/10.1111/j.1835-9310.1982.tb01239.x

Lu, W., \& Stepchenkova, S. (2012). Ecotourism experiences reported online: classification of satisfaction attributes. Tourism Management, 33, 702-712. https://doi.org/10.1016/j.tourman.2011.08.003

Lu, W., \& Stepchenkova, S. (2015). User-generated content as a research mode in tourism and hospitality applications: Topics, methods, and software. Journal of Hospitality Marketing and Management, 24(2), 119-154. https://doi.org/10.1080/19368623.2014.907758

Lu, Y. (Tracy), Chen, Z. (Wade), \& Law, R. (2018). Mapping the progress of social media research in hospitality and tourism management from 2004 to 2014. Journal of Travel and Tourism Marketing, 35(2), 102-118. https://doi.org/10.1080/10548408.2017.1350249 
Ludwig, S., de Ruyter, K., Friedman, M., Brüggen, E. C., Wetzels, M., \& Pfann, G. (2013). More than words: the influence of affective content and linguistic style matches in online reviews on conversion rates. Journal of Marketing, 77(1), 87-103. https://doi.org/10.1509/jm.11.0560

Lutz, C., \& Collins, J. (1991). The photograph as an intersection of gazes: the example of national geographic. Visual Anthropology Review, 7(1), 134-149. https://doi.org/10.1525/var.1991.7.1.134

MacHado, L. P. (2010). Does destination image influence the length of stay in a tourism destination? Tourism Economics, 16(2), 443-456. https://doi.org/10.5367/000000010791305554

MacInnis, D. J., \& Price, L. L. (1987). The role of imagery in information processing: review and extensions. Journal of Consumer Research, 13(4), 473-491. https://doi.org/10.1086/209082

MacKay, K. J., \& Fesenmaier, D. R. (1997). Pictorial element of destination in image formation. Annals of Tourism Research, 24(3), 537-565. https://doi.org/10.1016/s01607383(97)00011-x

MacKenzie, S. B., Lutz, R. J., \& Belch, G. E. (1986). The role of attitude toward the ad as a mediator of advertising effectiveness: a test of competing explanations. Journal of Marketing Research, 23(2), 130-143. https://doi.org/10.2307/3151660

MacKinnon, D. P., Coxe, S., \& Baraldi, A. N. (2012). Guidelines for the investigation of mediating variables in business research. Journal of Business and Psychology, 27(1), 114. https://doi.org/10.1007/s10869-011-9248-z

Mackinnon, D. P., Lockwood, C. M., \& Williams, J. (2004). Confidence limits for the indirect effect: distribution of the product and resampling methods. Multivariate Behavioral Research, 39(1), 99-128. https://doi.org/10.1207/s15327906mbr3901

MacKinnon, D. P., Lockwood, C. M., Hoffman, J. M., West, S. G., \& Sheets, V. (2002). A comparison of methods to test mediation and other intervening variable effects. Psychological Methods, 7(1), 83-104. https://doi.org/10.1037/1082-989X.7.1.83 
Mak, A. H. N. (2017). Online destination image: comparing national tourism organisation's and tourists' perspectives. Tourism Management, 60, 280-297. https://doi.org/10.1016/j.tourman.2016.12.012

Manfreda, K. L., Bosnjak, M., Berzelak, J., Haas, I., \& Vehovar, V. (2008). Web surveys versus other survey modes: a meta-analysis comparing response rates. International Journal of Market Research, 50(1), 79-104. https://doi.org/10.1177/147078530805000107

Mangold, W. G. (1987). Use of commercial sources of information in the purchase of professional services: what the literature tells us. Services Marketing Quarterly, 3(1/2), 5-17. https://doi.org/10.1080/15332969.1987.9984863

Mangold, W. G., \& Faulds, D. J. (2009). Social media: the new hybrid element of the promotion mix. Business Horizons, 52, 357-365. https://doi.org/10.1016/j.bushor.2009.03.002

Manosuthi, N., Lee, J. S., \& Han, H. (2020). Impact of distance on the arrivals, behaviours and attitudes of international tourists in Hong Kong: a longitudinal approach. Tourism Management, 78, Advance online publication. https://doi.org/10.1016/j.tourman.2019.103963

Manzo, A. N., \& Burke, J. (2012). Increasing response rate in Web-based/Internet surveys. In L. Gideon (Ed.), Handbook of Survey Methodology for the Social Sciences (pp. 327344). New York: Springer. https://doi.org/10.1007/978-1-4614-3876-2

Mariani, M. M., Di Felice, M., \& Mura, M. (2016). Facebook as a destination marketing tool: evidence from Italian regional destination management organizations. Tourism Management, 54, 321-343. https://doi.org/10.1016/j.tourman.2015.12.008

Marine-Roig, E., \& Anton Clavé, S. (2015). Tourism analytics with massive user-generated content: A case study of Barcelona. Journal of Destination Marketing \& Management, 4(3), 162-172. https://doi.org/10.1016/j.jdmm.2015.06.004

Marine-Roig, E., \& Ferrer-Rosell, B. (2018). Measuring the gap between projected and perceived destination images of Catalonia using compositional analysis. Tourism Management, 68, 236-249. https://doi.org/10.1016/j.tourman.2018.03.020 
Markwick, M. (2001). Postcards from Malta. Annals of Tourism Research, 28(2), 417-438. https://doi.org/10.1016/S0160-7383(00)00049-9

Marschall, S. (2017). Transnational migrant home visits as identity practice: the case of African migrants in South Africa. Annals of Tourism Research, 63, 140-150. https://doi.org/10.1016/j.annals.2017.01.011

Marsden, P. V., \& Campbell, K. E. (1984). Measuring tie strength. Social Forces, 63(2), $482-501$.

Martínez, S. C., \& Alvarez, M. D. (2010). Country versus destination image in a developing country. Journal of Travel and Tourism Marketing, 27(7), 748-764. https://doi.org/10.1080/10548408.2010.519680

Marwick, A. E. (2015). Instafame: luxury selfies in the attention economy. Public Culture, 27(1), 137-160. https://doi.org/10.1215/08992363-2798379

Mason, C., \& Perreault, W. (1991). Collinearity, power, and interpretation of multiple regression analysis. Journal of Marketing Research, 28(3), 268-280. https://doi.org/10.1177/002224379102800302

Massidda, I. E., \& Romano, P. (2015). Migration and inbound tourism: an Italian perspective. Current Issues in Tourism, 18(12), 1152-1171. https://doi.org/10.1080/13683500.2014.912206

Matthews, L. M. (2017). Applying multi-group analysis in PLS-SEM: A step-by-step proces. In H. Latan \& R. Noonan (Eds.), Partial Least Squares Path Modeling: Basic Concepts, Methodological Issues and Applications (pp. 219-243). Berlin: Springer International Publishing.

Matthews, L., Hair, J., \& Matthews, R. (2018). PLS-SEM: the holy grail for advanced analysis. Marketing Management Journal, 28(1), 1-13.

Mayr, S., Erdfelder, E., Buchner, A., \& Faul, F. (2007). A short tutorial in GPower. Tutorials in Quantitative Methods for Psychology, 3(2), 51-59.

McKercher, B. (1996). Host involvement in VFR travel. Annals of Tourism Research, 23(3), 701-703. https://doi.org/10.1016/0160-7383(95)00100-X 
McKercher, B., \& Chow So-Ming, B. (2001). Cultural distance and participation in cultural tourism. Pacific Tourism Review, 5, 23-32.

Mcpherson, M., Smith-lovin, L., \& Cook, J. M. (2001). Birds of a feather: homophily in social networks. Annual Review of Sociology, 27(1), 415-444.

McQuarrie, E. F., Miller, J., \& Phillips, B. J. (2013). The megaphone effect: taste and audience in fashion blogging. Journal of Consumer Research, 40, 136-158. https://doi.org/10.1086/669042

Melo, A. J. D. V. T., Hernández-Maestro, R. M., \& Muñoz-Gallego, P. A. (2017). Service quality perceptions, online visibility, and business performance in rural lodging establishments. Journal of Travel Research, 56(2), 250-262. https://doi.org/10.1177/0047287516635822

Memon, M. A., Hwa, C. J., Ramayah, T., \& Ting, H. (2018). Mediation analysis: issues and recommendations. Journal of Applied Structural Equation Modeling, 2(1), i-ix.

Memon, M. A., Ting, H., Cheah, J.-H., Thurasamy, R., Chuah, F., \& Cham, T. H. (2020). Sample size for survey research: review and recommendations. Journal of Applied Structural Equation Modeling, 4(2), i-Xx. https://doi.org/10.47263/JASEM.4(2)01

Meuter, M. L., McCabe, D. B., \& Curran, J. M. (2013). Electronic word-of-mouth versus interpersonal word-of-mouth: are all forms of word-of-mouth equally influential? Services Marketing Quarterly, 34(3), 240-256. https://doi.org/10.1080/15332969.2013.798201

Michèle Langlois, S., Theodore, J., \& Ineson, Elizabeth, M. (1999). Poland: in-bound tourism from the UK. Tourism Management, 20(4), 461-469. https://doi.org/10.1016/S02615177(99)00017-5

Mick, D. G. (1986). Consumer research and semiotics: exploring the morphology of signs, symbols, and significance. Journal of Consumer Research, 13(2), 196-213. https://doi.org/10.1086/209060

Mick, D. G. (1986). Consumer research and semiotics: exploring the morphology of signs, symbols, and significance. Journal of Consumer Research, 13(2), 196-213. 
https://doi.org/10.1086/209060

Miles, M. B., \& Huberman, M. A. (1984). Qualitative data analysis. New Delhi: Sage Publications.

Miles, M. B., \& Huberman, M. A. (1994). Qualitative data analysis (Second Edi). Thousand Oaks, California: SAGE Publications.

Ministry of Business Innovation and Employment. (2018). Migration trends 2016/2017. Retrieved March 2, 2020, from https://www.mbie.govt.nz/assets/Uploads/c22ab0c547/migration-trends-2016-17.pdf

Mitchell, A. A. (1986). The effect of verbal and visual components of advertisements on brand attitudes and attitude toward the advertisement. Journal of Consumer Research, 13, 12-24. https://doi.org/10.1086/209044

Molina-Azorín, J. F., \& Font, X. (2015). Mixed methods in sustainable tourism research: an analysis of prevalence, designs and application in JOST (2005-2014). Journal of Sustainable Tourism, 9582(September), 1-25. https://doi.org/10.1080/09669582.2015.1073739

Molinillo, S., Liébana-Cabanillas, F., Anaya-Sánchez, R., \& Buhalis, D. (2018). DMO online platforms: image and intention to visit. Tourism Management, 65, 116-130. https://doi.org/10.1016/j.tourman.2017.09.021

Mooi, E., \& Sarstedt, M. (2011). A concise guide to market research - the process, data, and methods using IBM SPSS statistics. Berlin, Heidelberg: Springer Berlin Heidelberg. https://doi.org/10.1007/978-3-642-12541-6

Moore, G. C., \& Benbasat, I. (1991). Development of an instrument to measure the perceptions of adopting an information technology innovation. Information Systems Research, 2(3), 192-222. https://doi.org/10.1287/isre.2.3.192

Morgan, N., Pritchard, A., \& Pride, R. (2003). Marketing to the Welsh diaspora: the appeal to hiraeth and homecoming. Journal of Vacation Marketing, 9(1), 69-80. https://doi.org/10.1177/135676670200900105

Morrison, A. M., Hsieh, S., \& O’Leary, J. T. (1995). Segmenting the visiting friends and 
relatives market by holiday activity participation. Journal of Tourism Studies, 6(1), 4863.

Morrison, A., Woods, B., Pearce, P., Moscardo, G., \& Sung, H. H. (2000). Marketing to the visiting friends and relatives segment: an international analysis. Journal of Vacation Marketing, 6(2), 102-118. https://doi.org/10.1177/135676670000600202

Moscardo, G., Pearce, P., Morrison, A., Green, D., \& O’Leary, J. T. (2000). Developing a typology for understanding visiting friends and relatives markets. Journal of Travel Research, 38(3), 251-259. https://doi.org/10.1177/004728750003800307

Munar, A. M., \& Jacobsen, J. K. S. (2013). Trust and involvement in tourism social media and Web-based travel information sources. Scandinavian Journal of Hospitality and Tourism, 13(1), 1-19. https://doi.org/10.1080/15022250.2013.764511

Munar, A. M., \& Jacobsen, J. K. S. (2014). Motivations for sharing tourism experiences through social media. Tourism Management, 43, 46-54. https://doi.org/10.1016/j.tourman.2014.01.012

Munoz, J. R., Griffin, T., \& Humbracht, M. (2017). Towards a new definition for "visiting friends and relatives.” International Journal of Tourism Research, 19(5), 477-485. https://doi.org/10.1002/jtr.2110

Murray, K. B. (1991). A test of services marketing theory: consumer information acquisition activities. Journal of Marketing, 55(1), 10-25. https://doi.org/10.2307/1252200

Murtell, J. (2020). How the meaning derived from signs and symbols can help unlock a more resonant communication strategy. Retrieved May 19, 2020, from https://www.ama.org/marketing-news/making-semioticswork/?utm_content=buffer9d398\&utm_medium=social\&utm_source=AMAlinkedin\&ut m_campaign=buffer

Naaman, M., Boase, J., \& Lai, C.-H. (2010). Is it really about me? Message content in social awareness streams. In CSCW 2010. https://doi.org/10.1371/journal.pcbi.1003109

Nam, H., \& Kannan, P. K. (2014). The informational value of social tagging networks. Journal of Marketing, 78(4), 21-40. https://doi.org/10.1509/jm.12.0151 
Narangajavana Kaosiri, Y., Callarisa Fiol, L. J., Moliner Tena, M. Á., Rodríguez Artola, R. M., \& Sánchez García, J. (2019). User-generated content sources in social media: a new approach to explore tourist satisfaction. Journal of Travel Research, 58(2), 253-265. https://doi.org/10.1177/0047287517746014

Nemeroff, C., \& Rozin, P. (1994). The contagion concept in adult thinking in the United States: transmission of germs and of interpersonal influence. Ethos, 22(2), 158-186.

Ng, S. I., Lee, J. A., \& Soutar, G. N. (2007). Tourists' intention to visit a country: the impact of cultural distance. Tourism Management, 28, 1497-1506. https://doi.org/10.1016/j.tourman.2006.11.005

Ng, S. I., Lim, Q. H., Cheah, J., Ho, J. A., \& Tee, K. K. (2020). A moderated-mediation model of career adaptability and life satisfaction among working adults in Malaysia. Current Psychology. https://doi.org/10.1007/s12144-020-00837-7

Nikjoo, A., \& Bakhshi, H. (2019). The presence of tourists and residents in shared travel photos. Tourism Management, 70, 89-98. https://doi.org/10.1016/j.tourman.2018.08.005

Nitzl, C., Roldan, J. L., \& Cepeda, G. (2016). Mediation analysis in partial least squares path modelling: helping researchers discuss more sophisticated models. Industrial Management and Data Systems, 116(9), 1849-1864. https://doi.org/10.1108/IMDS-072015-0302

Noone, B. M., \& McGuire, K. A. (2014). Effects of price and user-generated content on consumers' prepurchase evaluations of variably priced services. Journal of Hospitality and Tourism Research, 38(4), 562-581. https://doi.org/10.1177/1096348012461551

Noth, W. (1988). The language of commodities groundwork for semiotics. International Journal of Research in Marketing, 4(3), 173-186.

NVivo. (2020). Retrieved from https://www.qsrinternational.com/nvivo-qualitative-dataanalysis-software/home

O'Leary, Z. (2004). The essential guide to doing research. London: Sage Publications.

Oliveira, E., \& Panyik, E. (2015). Content, context and co-creation: digital challenges in destination branding with references to Portugal as a tourist destination. Journal of 
Vacation Marketing, 21(1), 53-74. https://doi.org/10.1177/1356766714544235

Oliver, G., Liehr-gobbers, K., \& Krafft, M. (2010). Evaluation of structural equation models using the partial least squares (PLS) approach. In V. E. Vinzi, W. W. Chin, J. Henseler, \& H. Wang (Eds.), Handbook of Partial Least Squares (pp. 691-711). Heidelberg, Dordrecht, London, New York: Springer. https://doi.org/10.1007/978-3-540-32827-8

Olson, L. C. (2007). Intellectual and conceptual resources for visual rhetoric: a reexamination of scholarship since 1950. Review of Communication, 7(1), 1-20. https://doi.org/10.1080/15358590701211035

Ordenes, F. V., Ludwig, S., De Ruyter, K., Grewal, D., \& Wetzels, M. (2017). Unveiling what is written in the stars: analyzing explicit, implicit, and discourse patterns of sentiment in social media. Journal of Consumer Research, 43(6), 875-894. https://doi.org/10.1093/jcr/ucw070

Ostrom, A. L., Bitner, M. J., Brown, S. W., Burkhard, K. A., Goul, M., Smith-Daniels, V., ... Rabinovich, E. (2010). Moving forward and making a difference: Research priorities for the science of service. Journal of Service Research, 13(1), 4-36. https://doi.org/10.1177/1094670509357611

Padgett, D., \& Allen, D. (1997). Communication experiences: a narrative approach to creating service brand image. Journal of Advertising, 26(4), 49-62.

Pallant, J. (2013). A step by step guide to data analysis using IBM SPSS (5th ed.). Crows Nest, N.S.W: Allen \& Unwin.

Palovic, Z., Kam, S., Janta, H., Cohen, S., \& Williams, A. (2014). Surrey think tank Reconceptualising Visiting Friends and Relatives (VFR) travel. Journal of Destination Marketing and Management, 2(4), 266-268. https://doi.org/10.1016/j.jdmm.2013.11.004

Panhwar, A. H., Ansari, S., \& Shah, A. A. (2017). Post-positivism: an effective paradigm for social and educational research. International Research Journal of Arts \& Humanities, 45(45), 253-259. Retrieved from http://search.proquest.com/docview/2044301228

Pantano, E., Priporas, C. V., \& Stylos, N. (2017). 'You will like it!' using open data to predict tourists' response to a tourist attraction. Tourism Management, 60, 430-438. 
https://doi.org/10.1016/j.tourman.2016.12.020

Papadimitriou, D., Kaplanidou, K. (Kiki), \& Apostolopoulou, A. (2018). Destination image components and word-of-mouth intentions in urban tourism: a multigroup approach. Journal of Hospitality and Tourism Research, 42(4), 503-527. https://doi.org/10.1177/1096348015584443

Paré, G., Trudel, M. C., Jaana, M., \& Kitsiou, S. (2015). Synthesizing information systems knowledge: a typology of literature reviews. Information \& Management, 52, 183-199. https://doi.org/10.1016/j.im.2014.08.008

Park, E., \& Kim, S. (2018). Are we doing enough for visual research in tourism? The past, present, and future of tourism studies using photographic images. International Journal of Tourism Research, 20(4), 433-441. https://doi.org/10.1002/jtr.2194

Patton, M. Q. (2002). Qualitative research and evaluation methods ( $3^{\text {rd }}$ ed.). Thousand Oaks, California: Sage Publications.

Paül i Agustí, D. (2018). Characterizing the location of tourist images in cities. Differences in user-generated images (Instagram), official tourist brochures and travel guides. Annals of Tourism Research, 73, 103-115. https://doi.org/10.1016/j.annals.2018.09.001

Pearce, D., Tan, R., \& Schott, C. (2004). Tourism distribution channels in Wellington, New Zealand. International Journal of Tourism Research, 6(6), 397-410. https://doi.org/10.1002/jtr.503

Peirce, S., \& Ritchie, B. W. (2007). National capital branding: a comparative case study of Canberra, Australia and Wellington, New Zealand. Journal of Travel \& Tourism Marketing, 22(3-4), 67-78. https://doi.org/10.1300/J073v22n03

Pellemans, P. A. (1971). The consumer decision-making process. European Journal of Marketing, 5(2), 8-21.

Pennington-Gray, L. (2003). Understanding the domestic VFR drive market in Florida. Journal of Vacation Marketing, 9(4), 354-367. https://doi.org/10.1177/135676670300900405

Perez-Vega, R., Taheri, B., Farrington, T., \& O’Gorman, K. (2018). On being attractive, 
social and visually appealing in social media: the effects of anthropomorphic tourism brands on Facebook fan pages. Tourism Management, 66, 339-347. https://doi.org/10.1016/j.tourman.2017.11.013

Peterson, M. O. (2019). Aspects of visual metaphor: an operational typology of visual rhetoric for research in advertising. International Journal of Advertising, 38(1), 67-96. https://doi.org/10.1080/02650487.2018.1447760

Peterson, R. (2000). Constructing effective questionnaires. Thousand Oaks, California: SAGE Publications, Inc. https://doi.org/10.4135/9781483349022

Petrescu, M. (2013). Marketing research using single-item indicators in structural equation models. Journal of Marketing Analytics, 1(2), 99-117. https://doi.org/10.1057/jma.2013.7

Phau, I., Shanka, T., \& Dhayan, N. (2010). Destination image and choice intention of university student travellers to Mauritius. International Journal of Contemporary Hospitality Management, 22(5), 758-764. https://doi.org/10.1108/09596111011053846

Philander, K., \& Zhong, Y. Y. (2016). Twitter sentiment analysis: capturing sentiment from integrated resort tweets. International Journal of Hospitality Management, 55, 16-24. https://doi.org/10.1016/j.ijhm.2016.02.001

Phillips, B. J., \& McQuarrie, E. F. (2004). Beyond visual metaphor: a new typology of visual rhetoric in advertising. Marketing Theory, 4(1/2), 113-136. https://doi.org/10.1177/1470593104044089

Phillips, B. J., Miller, J., \& McQuarrie, E. F. (2014). Dreaming out loud on Pinterest: new forms of indirect persuasion. International Journal of Advertising, 33(4), 633-655. https://doi.org/10.2501/IJA-33-4-633-655

Phillips, D., Olson, J., \& Baumgartner, H. (1995). Consumption visions in consumer decision making. Advances in Consumer Research, 22, 280-284.

Pike, S., \& Page, S. J. (2014). Destination marketing organizations and destination marketing: A narrative analysis of the literature. Tourism Management, 41, 202-227. https://doi.org/10.1016/j.tourman.2013.09.009 
Pike, S., \& Ryan, C. (2004). Destination positioning analysis through a comparison of cognitive, affective, and conative perceptions. Journal of Travel Research, 42(4), 333342. https://doi.org/10.1177/0047287504263029

Podoshen, J. S. (2013). Dark tourism motivations: simulation, emotional contagion and topographic comparison. Tourism Management, 35, 263-271. https://doi.org/10.1016/j.tourman.2012.08.002

Podsakoff, P. M., MacKenzie, S. B., \& Podsakoff, N. P. (2012). Sources of method bias in social science research and recommendations on how to control it. Annual Review of Psychology, 63(1), 539-569. https://doi.org/10.1146/annurev-psych-120710-100452

Podsakoff, P. M., MacKenzie, S. B., Lee, J.-Y., \& Podsakoff, N. P. (2003). Common method biases in behavioral research: a critical review of the literature and recommended remedies. The Journal of Applied Psychology, 88(5), 879-903. https://doi.org/10.1037/0021-9010.88.5.879

Prayag, G., Hall, C. M., \& Wood, H. (2018). I Feel Good! Perceptions and Emotional Responses of Bed \& Breakfast Providers in New Zealand Toward Trip Advisor. Journal of Hospitality Marketing and Management, 27(1), 1-20. https://doi.org/10.1080/19368623.2017.1318731

Preacher, K. J., Rucker, D. D., \& Hayes, A. F. (2007). Addressing moderated mediation hypotheses: Theory, methods, and prescriptions. Multivariate Behavioral Research, 42(1), 185-227. https://doi.org/10.1080/00273170701341316

Preston, C. C., \& Colman, A. M. (2000). Optimal number of response categories in rating scales: reliability, validity, discriminating power, and respondent preferences. Acta Psychologica, 104(1), 1-15. https://doi.org/10.1016/S0001-6918(99)00050-5

Prosser, J. (2005). The moral maze of image ethics. In K. Nind, M., Rix, J., Sheehy, K., \& Simmons (Ed.), Ethics and research in inclusive education: Values into practice (pp. 133-149). Routledge. https://doi.org/10.4324/9781315018171

Provenzano, D., \& Baggio, R. (2017). The contribution of human migration to tourism: the VFR travel between the EU28 member states. International Journal of Tourism Research, 19(4), 412-420. https://doi.org/10.1002/jtr.2127 
Rakić, T. (2012). Philosophies of the visual [method] in tourism research. In T. Rakić \& D. Chambers (Eds.), Contemporary geographies of leisure, tourism and mobility - An introduction to visual research methods in tourism (pp. 17-32). Abingdon: Routledge.

Ramayah, T., Cheah, J. H., Chuah, F., Ting, H., \& Memon, M. A. (2018). Partial least squares structural equation modeling (PLS-SEM) using SmartPLS 3.0: an updated and practical guide to statistical analysis (2nd ed.). Kuala Lumpur, Malaysia: Pearson.

Reichel, D., \& Morales, L. (2017). Surveying immigrants without sampling frames evaluating the success of alternative field methods. Comparative Migration Studies, 5(1), 1-22. https://doi.org/10.1186/s40878-016-0044-9

Reinartz, W., Haenlein, M., \& Henseler, J. (2009). An empirical comparison of the efficacy of covariance-based and variance-based SEM. International Journal of Research in Marketing, 26(4), 332-344. https://doi.org/10.1016/j.ijresmar.2009.08.001

Richter, N. F., Cepeda, G., Roldán, J. L., \& Ringle, C. M. (2016). European management research using partial least squares structural equation modeling (PLS-SEM). European Management Journal, 34(6), 589-597. https://doi.org/10.1016/j.emj.2016.08.001

Richter, N. F., Sinkovics, R. R., Ringle, C. M., \& Schlägel, C. (2016). A critical look at the use of SEM in international business research. International Marketing Review, 33(3), 376-404. https://doi.org/10.1108/IMR-04-2014-0148

Riefler, P., Diamantopoulos, A., \& Siguaw, J. A. (2012). Cosmopolitan consumers as a target group for segmentation. Journal of International Business Studies, 43(3), 285-305. https://doi.org/10.1057/jibs.2011.51

Riffe, D., Lacy, S., \& Fico, F. G. (2005). Analyzing media messages: using quantitative content analysis in research. Mediating the message ( $2^{\text {nd }}$ ed.). Mahwah, New Jersey: Lawrence Erlbaum.

Rindfleisch, A., Malter, A. J., Ganesan, S., \& Moorman, C. (2008). Cross-sectional versus longitudinal survey research: Concepts, findings, and guidelines. Journal of Marketing Research, 45(3), 261-279. https://doi.org/10.1509/jmkr.45.3.261

Ring, A., Tkaczynski, A., \& Dolnicar, S. (2016). Word-of-mouth segments: online, offline, 
visual or verbal. Journal of Travel Research, 55(4), 481-492.

https://doi.org/10.1177/0047287514563165

Ringle, C. M., Sarstedt, M., Mitchell, R., \& Gudergan, S. P. (2018). Partial least squares structural equation modeling in HRM research. International Journal of Human Resource Management, 5192, 1-27. https://doi.org/10.1080/09585192.2017.1416655

Ringle, C. M., Wende, S., \& Becker, J. M. (2015). Smartpls 3. Bönningstedt: SmartPLS. Retrieved from http://www.smartpls.com

Risselada, H., Verhoef, P. C., \& Bijmolt, T. H. A. (2014). Dynamic effects of social influence and direct marketing on the adoption of high-technology products. Journal of Marketing, 78(2), 52-68. https://doi.org/10.1509/jm.11.0592

Ritzer, G., \& Jurgenson, N. (2010). Production, consumption, prosumption: the nature of capitalism in the age of the digital "prosumer." Journal of Consumer Culture, 10(1), 1336. https://doi.org/10.1177/1469540509354673

Robinson, P. (2014). Emediating the tourist gaze: memory, emotion and choreography of the digital photograph. Inf Technol Tourism, 14(3), 177-196. https://doi.org/10.1007/s40558-014-0008-6

Rodrigues, H., Brochado, A., \& Troilo, M. (2020). Listening to the murmur of water: essential satisfaction and dissatisfaction attributes of thermal and mineral spas. Journal of Travel and Tourism Marketing, 37(5), 649-661. https://doi.org/10.1080/10548408.2019.1633986

Roggeveen, A. L., Grewal, D., Townsend, C., \& Krishnan, R. (2015). The impact of dynamic presentation format on consumer preferences for hedonic products and services. Journal of Marketing, 79(6), 34-49. https://doi.org/10.1509/jm.13.0521

Rokka, J., \& Canniford, R. (2016). Heterotopian selfies: how social media destabilizes brand assemblages. European Journal of Marketing, 50(9-10), 1789-1813. https://doi.org/10.1108/EJM-08-2015-0517

Rönkkö, M., \& Evermann, J. (2013). A critical examination of common beliefs about partial least squares path modeling. Organizational Research Methods, 16(3), 425-448. 
https://doi.org/10.1177/1094428112474693

Rose, G. (2016). Visual methodologies: an introduction to researching with visual materials. (Robert Rojek, Ed.) (4 ${ }^{\text {th }}$ ed.). Sage Publications.

Rossolatos, G. (2017). A sociosemiotic approach to consumer engagement in user-generated advertising. Social Semiotics, 28(4), 1-35. https://doi.org/10.1080/10350330.2017.1381452

Rungtusanatham, M., Miller, J. W., \& Boyer, K. K. (2014). Theorizing, testing, and concluding for mediation in SCM research: tutorial and procedural recommendations. Journal of Operations Management, 32(3), 99-113. https://doi.org/10.1016/j.jom.2014.01.002

Ryan, C. (2010). Ways of conceptualizing the tourist experience: a review of literature. Tourism Recreation Research, 35(1), 37-46. https://doi.org/10.1080/02508281.2010.11081617

Ryan, C. (2020). Refereeing articles including SEM - what should referees look for? Tourism Critiques: Practice and Theory, 1(1), 47-61. https://doi.org/10.1108/trc-03-2020-0002

San Martín, H., \& Rodriguez del Bosque, I. A. (2008). Exploring the cognitive-affective nature of destination image and the role of psychological factors in its formation. Tourism Management, 29, 263-277. https://doi.org/10.1016/j.tourman.2007.03.012

Sardeshmukh, S. R., \& Vandenberg, R. J. (2017). Integrating moderation and mediation: a structural equation modeling approach. Organizational Research Methods, 20(4), 721745. https://doi.org/10.1177/1094428115621609

Sarstedt, M., \& Cheah, J. H. (2019). Partial least squares structural equation modeling using SmartPLS: a software review. Journal of Marketing Analytics, 7(3), 196-202. https://doi.org/10.1057/s41270-019-00058-3

Sarstedt, M., Nitzl, C., \& Howard, M. C. (2020). Beyond a tandem analysis of SEM and PROCESS: use of PLS-SEM for mediation analyses! International Journal of Market Research,O0(0), 1-12. https://doi.org/10.1177/1470785320915686

Sarstedt, M., Ringle, C. M., \& Hair, J. F. (2017a). Partial least squares structural equation 
modeling. In C. Homburg, M. Klarmann, \& A. Vomberg (Eds.), Handbook of market research (pp. 1-34). Heidelberg: Springer. https://doi.org/10.1108/ebr-10-2013-0128

Sarstedt, M., Ringle, C. M., \& Hair, J. F. (2017b). PLS path modeling: basic concepts, methodological issues and applications. (Hengky Latan \& R. Noonan, Eds.). Cham, Switzerland: Springer. https://doi.org/10.1007/978-3-319-64069-3

Schau, H. J., \& Gilly, M. C. (2003). We are what we post? Self- presentation in personal web space. Journal of Consumer Research, 30(3), 385-404. https://doi.org/10.1086/378616

Schmallegger, D., Carson, D., \& Jacobsen, D. (2010). The use of photographs on consumer generated content websites: practical implications for destination image analysis. In N. Sharda (Ed.), Tourism Informatics:visual travel recommender systems, social communities, and user interface design (pp. 243-260). Hershey, PA: Information Science Reference.

Schroeder, J. (2013). Snapshot aesthetics and strategic imagination. Invisible Culture, 18. Retrieved from https://search.proquest.com/docview/1771538681?accountid=14782

Schroeder, J. E. (2006). Critical visual analysis. In R. W. Belk (Ed.), Handbook of qualitative research methods in marketing (pp. 303-321). Cheltenham, Gloucestershire: Edward Elgar Publishing Limited.

Scott, L. M. (1994). Images in advertising: the need for a theory of visual rhetoric. Journal of Consumer Research, 21(2), 252-272.

Scott, L. M., \& Vargas, P. (2007). Writing with pictures: toward a unifying theory of consumer response to images. Journal of Consumer Research, 34(3), 341-356. https://doi.org/10.1086/519145

Seaton, A. V, \& Palmer, C. (1997). Understanding VFR tourism behaviour: the first five years of the United Kingdom tourism survey. Tourism Management, 18(6), 345-355. https://doi.org/10.1016/S0261-5177(97)00033-2

Seaton, A. V. (1997). The status of the visiting friends and relatives category in recent tourism analysis. The Tourist Review, 52(4), 52-62. https://doi.org/10.1108/eb058262

Seaton, A. V., \& Tagg, S. (1995). Disaggregating friends and relatives in VFR tourism 
research: the Northern Ireland evidence 1991-1993. The Journal of Tourism Studies, 6(1), 6-18.

Seaton, T. (2017). Qualitative approaches to the phenomenology of VFR travel: the use of literary and cultural texts as resources. International Journal of Tourism Research, 19(4), 455-465. https://doi.org/10.1002/jtr.2100

Seaton, T., \& Tie, C. (2015). Are relatives friends? Disaggregating VFR travel 1994-2014. In E. Backer \& B. King (Eds.), VFR travel research: international perspectives (pp. 28 45). Bristol, Blue Ridge Summit: Multilingual Matters. https://doi.org/10.21832/9781845415198-004

Seo, Y., Kim, J., Choi, Y. K., \& Li, X. (2019). In "likes" we trust: likes, disclosures and firmserving motives on social media. European Journal of Marketing, 53(10), 2173-2192. https://doi.org/10.1108/EJM-11-2017-0883

Shani, A. (2013). The VFR experience: "home" away from home? Current Issues in Tourism, 16(1), 1-15. https://doi.org/10.1080/13683500.2011.643859

Shani, A., \& Uriely, N. (2012). VFR tourism - the host experience. Annals of Tourism Research, 39(1), 421-440. https://doi.org/10.1016/j.annals.2011.07.003

Shani, A., Chen, P. J., Wang, Y., \& Hua, N. (2010). Testing the impact of a promotional video on destination image change: application of China as a tourism destination. International Journal of Tourism Research, 12(2), 116-133. https://doi.org/10.1002/jtr.738

Shanka, T., \& Taylor, R. (2003). International student graduation ceremonies: an oppurtunity for local tourism services providers. Asia Pacific Journal of Tourism Research, 8(2), 13-22. https://doi.org/10.1080/10941660308725464

Shmueli, G., Ray, S., Velasquez Estrada, J. M., \& Chatla, S. B. (2016). The elephant in the room: predictive performance of PLS models. Journal of Business Research, 69(10), 4552-4564. https://doi.org/10.1016/j.jbusres.2016.03.049

Shmueli, G., Sarstedt, M., Hair, J. F., Cheah, J. H., Ting, H., Vaithilingam, S., \& Ringle, C. M. (2019). Predictive model assessment in PLS-SEM: guidelines for using PLSpredict. 
European Journal of Marketing, 53(11), 2322-2347. https://doi.org/10.1108/EJM-022019-0189

SmartPLS release notes. (2020). Retrieved June 9, 2020, from https://www.smartpls.com/release_notes

Sobel, M. E. (1982). Asymptotic confidence intervals for indirect effects in structural equation models. Sociological Methodology, 13(1982), 290. https://doi.org/10.2307/270723

Solonchak, T., \& Pesina, S. (2015). Cognitive properties of images and metaphors. Procedia - Social and Behavioral Sciences, 192(C), 650-655. https://doi.org/10.1016/j.sbspro.2015.06.113

Spoor, J. R., \& Kelly, J. R. (2004). The evolutionary significance of affect in groups: Communication and group bonding. Group Processes and Intergroup Relations, 7(4), 398-412. https://doi.org/10.1177/1368430204046145

Statement of intent 2019-2022. (2019). Retrieved from https://www.wellingtonnz.com/assets/Uploads/resources/92e666579f/WREDA0-SOI2019-22.pdf

Statista. (2019). Average number of social media accounts per internet user as of July 2019, by age group. Retrieved March 30, 2020, from https://www.statista.com/statistics/381964/number-of-social-media-accounts/

Stats NZ. (2020). 3 out of 5 migrants arrive on temporary visas. Retrieved March 3, 2020, from https://www.stats.govt.nz/news/3-out-of-5-migrants-arrive-on-temporary-visas

Stats NZ. (2020). International migration: December 2019. Retrieved February 17, 2020, from https://www.stats.govt.nz/information-releases/international-migration-december2019

Staudenmaier, R. (2019). Freudenberg: a small German town but a big Instagram star. Retrieved July 13, 2020, from https://www.dw.com/en/freudenberg-a-small-germantown-but-a-big-instagram-star/a-47338206

Stedman, R., Beckley, T., \& Ambard, M. (2004). A picture and 1000 words: using resident- 
employed photography to understand attachment to high amenity places. Journal of Leisure Research, 36(4), 580-606.

Steenkamp, J. E. M., \& Baumgartner, H. (1998). Assessing measurement invariance in crossnational consumer research. Journal of Consumer Research, 25(1), 78-107. https://doi.org/10.1086/209528

Stepchenkova, S., \& Mills, J. E. (2010). Destination image: a meta-analysis of 2000-2007 research. Journal of Hospitality Marketing and Management, 19(6), 575-609. https://doi.org/10.1080/19368623.2010.493071

Stepchenkova, S., Shichkova, E., Kim, H., Pennington-Gray, L., \& Rykhtik, M. (2015). Segmenting the "visiting friends and relatives" travel market to a large urban destination: the case of Nizhni Novgorod, Russia. Journal of Destination Marketing and Management, 4(4), 235-247. https://doi.org/10.1016/j.jdmm.2015.09.001

Stokowski, P. A. (2002). Languages of place and discourses of power: constructing new senses of place. Journal of Leisure Research, 34(4), 368-382. https://doi.org/10.1080/00222216.2002.11949977

Stone, M. (1974). Cross-validatory choice and assessment of statistical predictions. Journal of the Royal Statistical Society, 36(2), 111-147.

Stopher, P. (2012). Collecting, managing, and assessing data using sample surveys. Cambridge, UK: Cambridge University Press.

Streukens, S., \& Leroi-Werelds, S. (2016). Bootstrapping and PLS-SEM: a step-by-step guide to get more out of your bootstrap results. European Management Journal, 34(6), 618-632. https://doi.org/10.1016/j.emj.2016.06.003

Stringam, B. B., \& Gerdes, J. (2010). An analysis of word-of-mouse ratings and guest comments of online hotel distribution sites. Journal of Hospitality Marketing and Management, 19(7), 773-796. https://doi.org/10.1080/19368623.2010.508009

Stylidis, D., Belhassen, Y., \& Shani, A. (2017). Destination image, on-site experience and behavioural intentions: path analytic validation of a marketing model on domestic tourists. Current Issues in Tourism, 20(15), 1653-1670. 
https://doi.org/10.1080/13683500.2015.1051011

Stylidis, D., Shani, A., \& Belhassen, Y. (2017). Testing an integrated destination image model across residents and tourists. Tourism Management, 58, 184-195. https://doi.org/10.1016/j.tourman.2016.10.014

Sun, M., Ryan, C., \& Pan, S. (2014). Assessing tourists' perceptions and behaviour through photographic and blog analysis: The case of Chinese bloggers and New Zealand holidays. Tourism Management Perspectives, 12, 125-133. https://doi.org/10.1016/j.tmp.2014.09.007

Sun, M., Zhang, X., \& Ryan, C. (2014). Perceiving tourist destination landscapes through Chinese eyes: the case of South Island, New Zealand. Tourism Management, 46, 582595. https://doi.org/10.1016/j.tourman.2014.08.010

Sung, Y., Kim, E., \& Choi, S. M. (2018). \#Me and brands: understanding brand-selfie posters on social media. International Journal of Advertising, 37(1), 14-28. https://doi.org/10.1080/02650487.2017.1368859

Taheri, B., Jafari, A., \& O’Gorman, K. (2014). Keeping your audience: presenting a visitor engagement scale. Tourism Management, 42, 321-329. https://doi.org/10.1016/j.tourman.2013.12.011

Tanlaka, E. F., Ewashen, C., \& King-Shier, K. (2019). Postpositivist critical multiplism: its value for nursing research. Nursing Open, 6(3), 740-744. https://doi.org/10.1002/nop2.306

Tarde, G. (2018). L'opinion et la foule. Retrieved from https://ebookcentral-proquestcom.helicon.vuw.ac.nz.

Tasci, A. D., \& Kozak, M. (2006). Destination brands vs destination images: do we know what we mean? Journal of Vacation Marketing, 12(4), 299-317. https://doi.org/10.1177/1356766706067603

Tashakkori, A., \& Creswell, J. W. (2007). Editorial: the new era of mixed methods. Journal of Mixed Methods Research, 1(1), 3-7. https://doi.org/10.1177/2345678906293042

Tchetchik, A. (2015). Do communication technologies and migration induced travel 
complement or compete with each other? Letters in Spatial and Resource Sciences, 8(3), 335-356. https://doi.org/DOI 10.1007/s12076-015-0136-4

Teddlie, C., \& Tashakkori, A. (2009). Foundations of mixed methods research: integrating quantitative and qualitative approaches in social and behavioural sciences. Los Angeles: Sage Publications.

Tessitore, T., Pandelaere, M., \& Van Kerckhove, A. (2014). The Amazing Race to India: prominence in reality television affects destination image and travel intentions. Tourism Management, 42, 3-12. https://doi.org/10.1016/j.tourman.2013.10.001

Tham, A. M.-E. (2006). Travel stimulated by international students in Australia. International Journal of Tourism Research, 8(6), 451-468. https://doi.org/10.1002/jtr.588

Tham, A., Croy, G., \& Mair, J. (2013). Social media in destination choice: distinctive electronic word-of-mouth dimensions. Journal of Travel \& Tourism Marketing, 30(1-2), 144-155. https://doi.org/10.1080/10548408.2013.751272

The Wellington Region - current population estimate. (2019). Retrieved November 1, 2019, from https://profile.idnz.co.nz/greater-wellington/population-estimate

Ting, H., Fam, K. S., Jun Hwa, J. C., Richard, J. E., \& Xing, N. (2019). Ethnic food consumption intention at the touring destination: the national and regional perspectives using multi-group analysis. Tourism Management, 71, 518-529. https://doi.org/10.1016/j.tourman.2018.11.001

Torres, E. N., Singh, D., \& Robertson-Ring, A. (2015). Consumer reviews and the creation of booking transaction value: lessons from the hotel industry. International Journal of Hospitality Management, 50, 77-83. https://doi.org/10.1016/j.ijhm.2015.07.012

Townsend, C., \& Kahn, B. E. (2013). The "visual preference heuristic": the influence of visual versus verbal depiction on assortment processing, perceived variety, and choice overload. Journal of Consumer Research, 40(5), 993-1015. https://doi.org/10.1086/673521

Trauer, B., \& Ryan, C. (2005). Destination image, romance and place experience - An 
application of intimacy theory in tourism. Tourism Management, 26(4), 481-491. https://doi.org/10.1016/j.tourman.2004.02.014

Tseng, C., Wu, B., Morrison, A. M., Zhang, J., \& Chen, Y. (2015). Travel blogs on China as a destination image formation agent: a qualitative analysis using Leximancer. Tourism Management, 46, 347-358. https://doi.org/10.1016/j.tourman.2014.07.012

Tussyadiah, I. P. (2010). Visitor-generated images - do they represent similar stories ? In P. Burns, J. Lester, \& L. Bibbings (Eds.), Tourism and visual culture: methods and cases (Vol. 2, pp. 156-168). Oxfordshire: CABI Publishing.

Uchinaka, S., Yoganathan, V., \& Osburg, V. (2019). Classifying residents' roles as online place-ambassadors. Tourism Management, 71, 137-150. https://doi.org/10.1016/j.tourman.2018.10.008

Underwood, R. L., \& Klein, N. M. (2002). Packaging as brand communication: effects of product pictures on consumer responses to the package and brand. Journal of Marketing Theory and Practice, 10(4), 58-68. https://doi.org/10.1080/10696679.2002.11501926

Urry, J. (1992). The tourist gaze " revisited ". The American Behavioral Scientist, 36(2), 172186.

Urry, J., \& Larsen, J. (2011). The tourist gaze 3.0 ( $2^{\text {nd }}$ ed.). London: Sage Publications.

Van Kleef, G. A., Van Doorn, E. A., Heerdink, M. W., \& Koning, L. F. (2011). Emotion is for influence. European Review of Social Psychology, 22(1), 114-163. https://doi.org/10.1080/10463283.2011.627192

Vandenberg, R. J., \& Lance, C. E. (2000). A review and synthesis of the measurement invariance literature: suggestions, practices, and recommendations for organizational research. Organizational Research Methods, 3(1), 4-69. https://doi.org/10.1177/109442810031002

VanMeter, R. A., Grisaffe, D. B., \& Chonko, L. B. (2015). Of "Likes" and "Pins": the effects of consumers' attachment to social media. Journal of Interactive Marketing, 32, 70-88. https://doi.org/10.1016/j.intmar.2015.09.001

Venkatesh, V., Brown, S. A., \& Bala, H. (2013). Bridging the qualitative-quantitative divide: 
guidelines for conducting mixed methods research in information systems. MIS Quarterly, 37(1), 21-54.

Vilnai-Yavetz, I., \& Tifferet, S. (2009). Images in academic web pages as marketing tools: Meeting the challenge of service intangibility. Journal of Relationship Marketing, 8(2), 148-164. https://doi.org/10.1080/15332660902876893

Vinzi, V. E., Trinchera, L., \& Amato, S. (2011). PLS path modeling: from foundations to recent developments and open issues for model assessment and improvement. In V. E. Vinzi, W. W. Chin, J. Henseler, \& H. Wang (Eds.), Handbook of partial least squares concepts, methods and applications (pp. 47-82). Heidelberg, Dordrecht, London, New York: Springer. https://doi.org/10.1007/978-3-642-16345-6

Volo, S. (2010). Bloggers' reported tourist experiences: Their utility as a tourism data source and their effect on prospective tourists. Journal of Vacation Marketing, 16(4), 297-311. https://doi.org/10.1177/1356766710380884

Voorhees, C. M., Brady, M. K., Calantone, R., \& Ramirez, E. (2016). Discriminant validity testing in marketing: an analysis, causes for concern, and proposed remedies. Journal of the Academy of Marketing Science, 44(1), 119-134. https://doi.org/10.1007/s11747-0150455-4

Walmsley, D. J., \& Young, M. (1998). Evaluative images and tourism: the use of personal constructs to describe the structure of destination images. Journal of Travel Research, 36(3), 65-69. https://doi.org/10.1177/004728759803600307

Wang, C. Y., \& Hsu, M. K. (2010). The relationships of destination image, satisfaction, and behavioral intentions: An integrated model. Journal of Travel and Tourism Marketing, 27(8), 829-843. https://doi.org/10.1080/10548408.2010.527249

Wang, H. Y. (2011). Exploring the factors of gastronomy blogs influencing readers' intention to taste. International Journal of Hospitality Management, 30(3), 503-514. https://doi.org/10.1016/j.ijhm.2010.07.009

Wang, J. J., Wang, L. Y., \& Wang, M. M. (2018). Understanding the effects of eWOM social ties on purchase intentions: a moderated mediation investigation. Electronic Commerce Research and Applications, 28, 54-62. https://doi.org/10.1016/j.elerap.2018.01.011 
Wang, S., Kirillova, K., \& Lehto, X. (2017). Travelers' food experience sharing on social network sites. Journal of Travel and Tourism Marketing, 34(5), 680-693. https://doi.org/10.1080/10548408.2016.1224751

Wang, W. (2011). A Content Analysis of Reliability in Advertising Content Analysis Studies. Electronic Theses and Dissertations.

We are social. (2020). Digital 2020: global digital overview. Retrieved March 30, 2020, from https://wearesocial.com/digital-2020

Weaver, A. (2009). Tourism and aesthetic design: enchantment, style, and commerce. Journal of Tourism and Cultural Change, 7(3), 179-189. https://doi.org/10.1080/14766820903259493

Wellington Regional Economic Development Agency: annual report 2015. (2015). Wellington, New Zealand.

Wellington Regional Strategy Committee. (2012), Wellington Regional Strategy 2012 Growing a Sustainable Economy, available at: https://mstn.govt.nz/wpcontent/uploads/2020/07/Wellington-Regional-Strategy-2012.pdf (accessed 24 January 2020).

West, J., \& Graham, J. (2004). A linguistic-based measure of cultural distance and its relationship to managerial values. Management International Review, 44(3), 239-260.

Whang, H., Yong, S., \& Ko, E. (2016). Pop culture, destination images, and visit intentions: theory and research on travel motivations of Chinese and Russian tourists. Journal of Business Research, 69(2), 631-641. https://doi.org/10.1016/j.jbusres.2015.06.020

Wheeler, L., Reis, H. T., \& Bond, M. H. (1989). Collectivism-individualism in everyday social life: the middle kingdom and the melting pot. Journal of Personality and Social Psychology, 57(1), 79-86. https://doi.org/10.1037/0022-3514.57.1.79

White, N. R., \& White, P. B. (2007). Home and away: tourists in a connected world. Annals of Tourism Research, 34(1), 88-104. https://doi.org/10.1016/j.annals.2006.07.001

Williams, A. M. (2013). Mobilities and sustainable tourism: path-creating or path-dependent relationships? Journal of Sustainable Tourism, 21(4), 511-531. 
https://doi.org/10.1080/09669582.2013.768252

Williams, A. M., \& Hall, C. M. (2000). Tourism and migration: new relationships between production and consumption. Tourism Geographies, 2(1), 5-27. https://doi.org/10.1080/146166800363420

Wiseman, J. P. (1986). Friendship: bonds and binds in a voluntary relationship. Journal of Social and Personal Relationships, 3, 191-211.

Wold, H. (1982). Soft modeling: the basic design and some extensions. In K. G. Joreskog \& H. Wold (Eds.), Systems under indirect observation: cuasality, structure, prediction (pp. 1-54). Amsterdam: North-Holland Publishing Company.

Woosnam, K. M., Stylidis, D., \& Ivkov, M. (2020). Explaining conative destination image through cognitive and affective destination image and emotional solidarity with residents. Journal of Sustainable Tourism, 28(6), 917-935. https://doi.org/10.1080/09669582.2019.1708920

Wu, M. Y., Pearce, P., \& Dong, W. (2017). How satisfying are Shanghai's superior hotels? The views of international tourists. International Journal of Contemporary Hospitality Management, 29(4), 1096-1115. https://doi.org/10.1108/IJCHM-01-2015-0014

Wyatt, J. C. (2000). When to Use Web-based surveys. Journal of the American Medical Informatics Association, 7(4), 426-430.

Xiang, Z., \& Gretzel, U. (2010). Role of social media in online travel information search. Tourism Management, 31, 179-188. https://doi.org/10.1016/j.tourman.2009.02.016

Yang, S., Kim, S. K., \& Ro, Y. M. (2007). Semantic home photo categorization. IEEE Transactions on Circuits and Systems for Video Technology, 17(3), 324-335. https://doi.org/10.1109/TCSVT.2007.890829

Yang, S., Kim, S. K., \& Ro, Y. M. (2007). Semantic home photo categorization. IEEE Transactions on Circuits and Systems for Video Technology, 17(3), 324-335. https://doi.org/10.1109/TCSVT.2007.890829

Yang, Y., Mao, Z., \& Tang, J. (2018). Understanding guest satisfaction with urban hotel location. Journal of Travel Research, 57(2), 243-259. 
https://doi.org/10.1177/0047287517691153

Ye, H., \& Tussyadiah, I. P. (2011). Destination visual image and expectation of experiences. Journal of Travel \& Tourism Marketing, 28(2), 129-144. https://doi.org/10.1080/10548408.2011.545743

Ye, Q., Law, R., \& Gu, B. (2009). The impact of online user reviews on hotel room sales. International Journal of Hospitality Management, 28(1), 180-182. https://doi.org/10.1016/j.ijhm.2008.06.011

Yoo, K. H., \& Gretzel, U. (2011). Influence of personality on travel-related consumergenerated media creation. Computers in Human Behavior, 27(2), 609-621. https://doi.org/10.1016/j.chb.2010.05.002

Young, C. A., Corsun, D. L., \& Baloglu, S. (2007). A taxonomy of hosts visiting friends and relatives. Annals of Tourism Research, 34(2), 497-516. https://doi.org/10.1016/j.annals.2006.12.003

Young, M. (1995). Evaluative constructions of domestic tourist places. Australian Geographical Studies, 33(2), 272-286. https://doi.org/10.1111/j.14678470.1995.tb00699.x

Yousuf, M. S., \& Backer, E. (2017). Hosting friends versus hosting relatives: is blood thicker than water? International Journal of Tourism Research, 19(4), 435-446. https://doi.org/10.1002/jtr.2098

Yousuf, M., \& Backer, E. (2015). A content analysis of visiting friends and relatives (VFR) travel research. Journal of Hospitality and Tourism Management, 25, 1-10. https://doi.org/10.1016/j.jhtm.2015.07.003

Zajonc, R., \& Markus, H. (1982). Affective and cognitive factors in preferences. Journal of Consumer Research, 9(2), 123-131. https://doi.org/10.1086/208905

Zátori, A., Michalkó, G., Nagy, J. T., Kulcsár, N., \& Balizs, D. (2019). The tourist experience of domestic VFR travellers: the case of Hungary. Current Issues in Tourism, 22(12), 1437-1459. https://doi.org/10.1080/13683500.2017.1371117

Zeithaml, V. A., Parasuraman, A., \& Berry, L. L. (1985). Problems and strategies in services 
marketing. Journal of Marketing, 49(2), 33-46. https://doi.org/10.2307/1251563

Zhang, Honghong, Fam, K. S., Goh, T. T., \& Dai, X. (2018). When are influentials equally influenceable? The strength of strong ties in new product adoption. Journal of Business Research, 82, 160-170. https://doi.org/10.1016/j.jbusres.2017.09.013

Zhang, Hongmei, Fu, X., Cai, L. A., \& Lu, L. (2014). Destination image and tourist loyalty: a meta-analysis. Tourism Management, 40, 213-223. https://doi.org/10.1016/j.tourman.2013.06.006

Zhao, X., \& Belk, R. W. (2008). Advertising consumer culture in 1930s Shanghai: globalization and localization in Yuefenpai. Journal of Advertising, 37(2), 45-56. https://doi.org/10.2753/JOA0091-3367370204

Zhao, X., Lynch, J. G., \& Chen, Q. (2010). Reconsidering Baron and Kenny: myths and truths about mediation analysis. Journal of Consumer Research, 37(2), 197-206. https://doi.org/10.1086/651257

Zhou, L., Ye, S., Pearce, P. L., \& Wu, M. Y. (2014). Refreshing hotel satisfaction studies by reconfiguring customer review data. International Journal of Hospitality Management, 38, 1-10. https://doi.org/10.1016/j.ijhm.2013.12.004 